
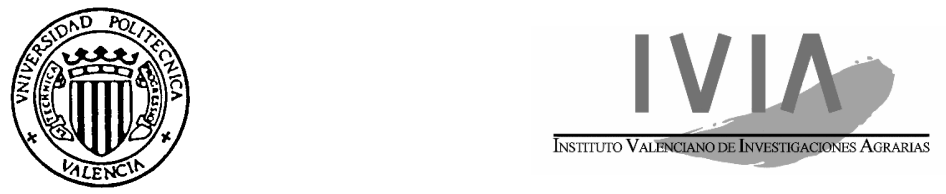

\title{
MECANIZACIÓN DE MÉTODOS DE CONTROL DE Ceratitis capitata (WIEDEMANN) EN CÍTRICOS
}

\author{
TESIS DOCTORAL: \\ Patricia Chueca Adell \\ Director: \\ Dr. Enrique Moltó García \\ Instituto Valenciano de Investigaciones Agrarias \\ Tutor: \\ Dr. Luis Val Manterola \\ Universidad Politécnica de Valencia
}

Valencia, 2007 
(C) Patricia Chueca Adell

Valencia, 2007 




\section{AGRADECIMIENTOS}

Quiero expresar mi agradecimiento al Instituto Nacional de Investigación y Tecnología Agraria y Alimentaria (INIA) por la concesión de la beca predoctoral y por financiar el trabajo que se presenta en esta tesis a través del proyecto de investigación con referencia RTA03-103.

También al Centro de Agroingeniería del Instituto Valenciano de Investigaciones Agrarias (IVIA) donde se ha desarrollado esta tesis y que ha puesto a mi servicio las instalaciones, el personal y los equipos necesarios para su consecución. Asimismo, al Centro de Postcosecha y al Departamento de Entomología del IVIA.

A las empresas Pulverizadores FEDE, S.L., Enguix, S.L. Sanz Hermanos, S.L. y Argilés, S.A. por prestarnos equipos para la realización de los ensayos de la tesis.

A la empresa Martí Navarro S.A., y la cooperativa CoPuzol por permitirnos hacer uso de sus parcelas de cítricos en la realización de ensayos de campo.

Al Departamento de Mecanización y Tecnología Agraria de la Universidad Politécnica de Valencia (UPV) por prestarnos la instrumentación necesaria para algunos de los ensayos de esta tesis.

Al Dr. Luis Val Manterola, tutor de esta tesis, por sus comentarios y sugerencias para mejorar este trabajo.

Al Dr. Enrique Moltó García por su gran trabajo de dirección en esta tesis. También por su apoyo y confianza depositada en mi a lo largo de estos años, y como no, por su infinita paciencia. ¡Muchas gracias Enrique! Esta tesis es tan tuya como mía. 
Gracias también a todos los compañeros que están o han pasado por el Centro de Agroingeniería. En especial, a los que han seguido de cerca mis pasos y me han apoyando en todo momento, y a los que han trabajado directamente en la realización de este trabajo mediante su colaboración en ensayos de campo y en el desarrollo electrónico de sistemas de control, su aportación de conocimientos y sus sugerencias. Sin vosotros no hubiera podido realizar esta tesis.

A los compañeros del Departamento de Entomología por introducirme en el maravilloso mundo de la mosca con sus conocimientos, por su colaboración en ensayos de laboratorio y por sus consejos y sugerencias.

$\mathrm{Y}$ por supuesto a Jorge por apoyarme siempre en las decisiones, ayudarme, y sobretodo, hacerme feliz, a mi familia por creer y confiar siempre en mi y a mis amigos por animarme y apoyarme siempre. 


\section{RESUMEN}

La mosca mediterránea de la fruta (Ceratitis capitata Wiedemann) es una de las plagas más importantes que afectan a la citricultura en España y actualmente solo se puede controlar eficazmente con productos organofosforados, principalmente malatión. Por este motivo, recientemente se están buscando alternativas a la lucha química clásica que minimicen el impacto ambiental y los riegos para la salud humana. Entre ellas se encuentran la aplicación de tratamientos cebo a bajo volumen con productos insecticidas alternativos, menos perjudiciales desde el punto de vista ecotoxicológico, y métodos culturales, como la eliminación de los frutos tras la cosecha, ya que éstos son un reservorio para esta mosca.

Para que estos dos métodos puedan emplearse racionalmente en la citricultura española es imprescindible su mecanización. El objetivo de esta tesis es aportar soluciones en este sentido.

La mecanización de los tratamientos cebo a bajo volumen se aborda mediante el diseño y construcción de un equipo de pulverización automático que cumple con los requerimientos de estas aplicaciones.

En primer lugar se describe cómo se seleccionó, de entre los sistemas comerciales que se disponen hoy en día, el dispositivo de pulverización más adecuado (que produce tamaños de gota suficientemente grandes), y cómo se integra éste en un sistema electrónico de control, con el fin de construir un prototipo de máquina. Posteriormente, se comprueba el correcto funcionamiento del prototipo y su adecuación al trabajo para el que fue diseñado. Por último, se proponen diferentes tratamientos cebo a bajo volumen contra $C$. capitata con insecticidas alternativos al malation, los cuales se evalúan en varias plantaciones comerciales durante dos campañas. Los resultados de los ensayos demuestran que los tratamientos realizados con la máquina diseñada, aplicando cebos a bajo 
volumen con nuevos insecticidas, son tan eficaces como los tratamientos convencionales con malation.

En cuanto a la mecanización de la eliminación de los frutos que quedan tras la cosecha, en esta tesis se propone el uso de trituradoras de leña convencionales, ya que son máquinas que se encuentran fácilmente en las explotaciones modernas y a las que se les podría dar este uso complementario.

Con este fin, primeramente se determina, en condiciones de laboratorio, la eficacia del aplastamiento y la trituración como métodos de control de larvas de $C$. Capitata. Tras observar que con ellos se consiguen mortalidades del $29 \%$ y del $81 \%$ respectivamente, se establecen las condiciones de trabajo para que una trituradora produzca la destrucción adecuada de la fruta con un consumo mínimo de energía. Por último, se ensaya este método en condiciones de campo y se observa un efecto de control sobre la población de C. capitata, con una reducción de la primera generación de adultos de la primavera siguiente al tratamiento entre un $27 \%$ y un $46 \%$. 


\begin{abstract}
Mediterranean fruit fly (Ceratitis capitata Wiedemann) is one of the most harmful pests in Spanish citrus growing regions and nowadays it is only effectively controlled by organophosphate insecticides, being malathion the most widely employed. For this reason, alternatives to the classical chemical methods are currently under study, aimed at minimising the environmental impact as well as the risks for human health. Among these, the application of low volume bait treatments with alternative, less eco-toxicologically harmful insecticides, and physical methods, such as the elimination of fruits remaining on the ground after harvest, have been considered. However, these alternatives must be mechanized to be efficient and economically viable, and that is the major objective of this thesis.
\end{abstract}

The mechanization of low volume bait treatments have been addressed by means of the design and development of an automatic sprayer.

First, the selection of a suitable spray device to obtain droplets of convenient size and its integration into an electronic control system is described, together with the integration of both systems on a prototype. Then, the machine is tested to determine its suitability for the purpose it was designed for. Finally, different bait treatments using alternative pesticides against $C$. capitata are proposed. These treatments have been evaluated in different commercial plots during two seasons. Results show that the application of these pesticides with the proposed sprayer generates the same efficacy control levels than current conventional treatments with malathion.

Regarding to the mechanization of the elimination of the fruits remaining on the ground after harvest, this thesis proposes the use of conventional citrus wood grinders or shredders to grind or crush the fruits, because theses machines are common in many modern farms and could be assigned to this complementary use. 
With this purpose, test aimed at assessing the efficacy of these methods to control C. capitata larvae under laboratory conditions have been conducted. In such experiments, $29 \%$ mortality rate was obtained when crushing the fruits and $81 \%$ when grinding them. Then, the conditions of a particular type of machines to crush properly the fruits with the minimal energy consumption have been set. Finally, the efficacy of the method has been tested in field conditions. Results demonstrated that significant control over $C$. capitata population can be achieved by this method. $27 \%-46 \%$ reduction of the first adult generation was attained in the spring following the treatment. 


\section{RESUM}

La mosca mediterrània de la fruita (Ceratitis capitata Wiedemann) és una de les plagues més importants que afecten la citricultura a Espanya i actualment només es pot controlar eficaçment amb productes organofosforats, principalment malation. Per este motiu, recentment s'estan buscant alternatives a la lluita química clàssica que minimitzen l'impacte ambiental i els regs per a la salut humana. Entre elles es troben l'aplicació de tractaments esquer a baix volum amb productes insecticides alternatius, menys perjudicials des del punt de vista ecotoxicológic, i mètodes culturals, com l'eliminació dels fruits que queden després de la collita, ja que estos són un reservori per a esta mosca.

Perquè estos dos mètodes puguen emprar-se racionalment en la citricultura espanyola és imprescindible la seua mecanització. L'objectiu d'esta tesi és aportar solucions en este sentit.

La mecanització dels tractaments esquer a baix volum s'aborda per mitjà del disseny i construcció d'un equip de polvorització automàtic que complix amb els requeriments d'estes aplicacions.

En primer lloc es descriu com es va seleccionar, d'entre els sistemes comercials que es disposen hui en dia, el dispositiu de polvorització més adequat (que produïx grandàries de gota prou grans), i com s'integra este en un sistema electrònic de control, a fi de construir un prototip de màquina. Posteriorment, es comprova el funcionament correcte del prototip i la seua adequació al treball per al que va ser dissenyat. Finalment, es proposen diferents tractaments esquer a baix volum contra $C$. capitata amb insecticides alternatius al malation, els quals s'avaluen en unes quantes plantacions comercials durant dos campanyes. Els resultats dels assajos demostren que els tractaments realitzats amb la màquina dissenyada, aplicant esquers a baix volum amb nous insecticides, són tan eficaços com els tractaments convencionals amb malation. 
Respecte a la mecanització de l'eliminació dels fruits que queden després de la collita, en esta tesi es proposa l'ús de trituradores de llenya convencionals, ja que són màquines que es troben fàcilment en les explotacions modernes i a les que se'ls podria donar este ús complementari.

Amb este fi, primerament es determina, en condicions de laboratori, l'eficàcia de la xafada i la trituració com a mètodes de control de larves de $C$. Capitata. Després d'observar que amb ells s'aconseguixen mortalitats del $29 \%$ i del $81 \%$ respectivament, s'establixen les condicions de treball perquè una trituradora produïsca la destrucció adequada de la fruita amb un consum mínim d'energia. Finalment, s'assaja este mètode en condicions de camp i s'observa un efecte de control sobre la població de C. capitata, amb una reducció de la primera generació d'adults de la primavera següent al tractament entre un $27 \%$ i un $46 \%$. 


\section{ÍNDICE}

CAPÍTULO I. INTRODUCCIÓN GENERAL 1

1 LA IMPORTANCIA DE C. CAPITATA (WIEDEMANN) EN LA CITRICULTURA ACTUAL 2

1.1 CLASIFICACIÓN TAXONÓMICA 2

1.2 DISTRIBUCIÓN GEOGRÁFICA Y HOSPEDANTES___ 3

1.3 BIOLOGÍA Y CICLO BIOLÓGICO __ 4

1.4 DAÑOS E IMPORTANCIA ECONÓMICA _ 9

2 MÉTODOS DE CONTROL DE C. CAPITATA___ 11

2.1 LUCHA AUTOCIDA. TÉCNICA DEL INSECTO ESTÉRIL _ 12

2.2 CONTROL BIOLÓGICO__ 13

2.3. TRAMPEO MASIVO__ 15

2.4. CONTROL QUÍMICO. TENDENCIAS___ 16

2.5 LA ELIMINACIÓN DE LA FRUTA __ 21

CAPÍTULO II. MOTIVACIÓN Y OBJETIVOS GENERALES DE LA TESIS _ 23

1 MOTIVACIÓN__ 23

2 OBJETIVOS GENERALES DE LA TESIS _ 24

CAPÍTULO III. MECANIZACIÓN DE LOS TRATAMIENTOS CEBO A BAJO VOLUMEN__ 27

1 INTRODUCCIÓN: PARTICULARIDADES DE LOS TRATAMIENTOS CEBO FRENTE A LOS CONVENCIONALES __ 27

2 JUSTIFICACIÓN Y OBJETIVOS__ 29

3 ORgANIZACIÓN DEL CAPÍTULO__ 31

4 ANTECEDENTES _ 32

4.1 LA FORMACIÓN DE LAS GOTAS EN LAS MÁQUINAS DE TRATAMIENTOS FITOSANITARIOS _ 32

4.2 CARACTERIZACIÓN DE UNA PULVERIZACIÓN___ 34 
Índice

4.2.1 La distribución de las poblaciones de impactos: Medidas de tamaño___ 34

4.2.2 Métodos para caracterizar la pulverización __ 38

4.3 APLICACIÓN DE AUTOMATISMOS PARA CONTROLAR LA DISTRIBUCIÓN DEL PRODUCTO FITOSANITARIO EN LOS EQUIPOS ACTUALES 40

4.3.1 Aplicaciones homogéneas por unidad de superficie __ 40

4.3.2 Aplicación localizada: Detección de la planta___ 41

4.3.3 Adaptación de la aplicación al volumen de la vegetación detectado___ 42

4.4 EVALUACIÓN DE LA CALIDAD DE UN TRATAMIENTO__ 43

4.4.1 Métodos que estudian la distribución del caldo sobre la cubierta vegetal 44

4.4.2 Métodos que miden el nivel de control sobre el organismo a combatir__ 48

4.4.3 Combinación de ambos métodos _ 49

5 SELECCIÓN DEL DISPOSITIVO DE PULVERIZACIÓN___ 50

5.1 MATERIALES Y MÉTODOS _

5.1.1 Ensayo de caracterización de los dispositivos hidráulicos ___ 51

5.1.2 Ensayo de caracterización de los dispositivos centrífugos ___ 58

5.1.3 Descripción del caldo pulverizado___ 63

5.1.4 Estimación del volumen depositado por unidad de superficie ___ 63

5.1.5 Descripción de los impactos___ 64

5.1.6 Análisis de los datos___ 66

5.2 RESULTADOS Y DISCUSIÓN _ 68

6 SISTEMA AUTOMÁTICO PARA LA APLICACIÓN A BAJO VOLUMEN _77

6.1 DESCRIPCIÓN FUNCIONAL _ _ 77

6.2 DESCRIPCIÓN DEL PROTOTIPO__ 79

6.2.1 Circuito hidráulico___ 79

6.2.2 Sistema electrónico___ 80

6.3 ALGORITMO DE CONTROL _ 82

6.4 INTERFAZ CON EL USUARIO _ _ 83

7 ENSAYOS PARA LA EVALUACIÓN DEL EQUIPO EN CONDICIONES DE CAMPO 83

7.1 MATERIALES Y MÉTODOS ii 
7.1.1 Comprobación de la correcta distribución del caldo sobre la copa de los árboles 84

7.1.2 Validación del funcionamiento del equipo 86

7.2 RESULTADOS Y DISCUSIÓN 87

7.2.1 Comprobación de la correcta distribución del caldo sobre la copa de los árboles 87

7.2.2 Validación del funcionamiento del equipo 88

8 ENSAYOS DE EFICACIA DE CONTROL DE C. CAPITATA 89

8.1 AJUSTE DE LA CONCENTRACIÓN DE $\quad$ SPINTOR $480 \quad$ SC $^{\circledR} \quad$ EN

LABORATORIO__ 90

8.1.1 Materiales y métodos _ 91

8.1.2 Resultados__ 94

8.1.3 Discusión — 98

8.2 EXPERIMENTOS PARA AJUSTAR LOS PROCEDIMIENTOS DE CAMPO 98

8.2.1 Materiales y métodos _ 99

8.2.2 Resultados y discusión 101

8.3 EFICACIA DE LOS TRATAMIENTOS REALIZADOS EN EL CONTROL DE

C. CAPITATA 107

8.3.1 Ensayo de comparación entre los tratamientos convencionales y dos tratamientos cebo a bajo volumen 107

8.3.2 Ensayo de comparación entre tratamientos cebo a bajo volumen _ 109

8.3.3 Metodología para evaluar de la eficacia de los tratamientos__ 110

8.3.4 Análisis de residuos de los insecticidas __ 112

8.3.5 Valoración de la presencia de negrilla y manchas___ 112

8.3.6 Tratamiento de los datos__ 113

8.3.7 Resultados_ 115

8.3.8 Discusión _ 123

9 CONCLUSIONES

CAPÍTULO IV. MECANIZACIÓN DE LOS MÉTODOS CULTURALES _ 127

1 INTRODUCCIÓN — 127

1.1 LAS TRITURADORAS QUE SE EMPLEAN EN CITRICULTURA __ 128 
3 EFICACIA DE LA TRITURACIÓN DE LA FRUTA EN EL CONTROL DE LARVAS DE C. CAPITATA EN CONDICIONES DE LABORATORIO 132

3.1 MATERIALES Y MÉTODOS 133

3.2 RESULTADOS 136

3.3 DISCUSIÓN

4 DETERMINACIÓN DE LAS CONDICIONES DE TRABAJO DE UNA TRITURADORA DE EJE HORIZONTAL PARA DESTRUIR CÍTRICOS 138

4.1 MATERIALES Y MÉTODOS 138

4.1.1 Tractor y trituradoras. Establecimiento de las velocidades de avance y de giro la toma de fuerza para el ensayo

4.1.2 Metodología 141

4.1.3 Calidad de la fruta triturada 142

4.1.4 Medida de la potencia requerida. Coste energético 143

4.1.5 Análisis de los datos 145

4.2 RESULTADOS 145

4.2.1 Calidad de la fruta triturada 145

4.2.2 Potencia requerida por la trituradora y coste energético 148

4.2.3 Selección de las condiciones de trabajo a raíz de los resultados 151

5 EFECTO DEL TRITURADO SOBRE LA POBLACIÓN DE C. CAPITATA EN CONDICIONES DE CAMPO 152

5.1 MATERIALES Y MÉTODOS 152

5.2 RESULTADOS 153

6 CONCLUSIONES 155

CAPÍTULO V. CONCLUSIONES GENERALES 157

CAPÍTULO VI. BIBLIOGRÁFIA 159

ANEJO 1. SELECCIÓN PREVIA DE BOQUILLAS CENTRÍFUGAS 183

ANEJO 2. SELECCIÓN PREVIA DE CABEZALES CENTRÍFUGOS 185

ANEJO 3. CARACTERÍSTICAS DE LOS EQUIPOS EMPLEADOS 191 
ANEJO 4. VALORES DE SSE Y R2 EN EL ENSAYO DE DISPOSITIVOS HIDRAÚLICOS 193

ANEJO 5. RESULTADOS DEL EFECTO DE LOS FACTORES SOBRE LAS VARIABLES EN EL ENSAYO DE DISPOSITIVOS HIDRAÚLICOS 201

ANEJO 6. VALORES DE SSE Y $\mathbf{R}^{2}$ EN EL ENSAYO DE DISPOSITIVOS CENTRÍFUGOS 215

ANEJO 7. RESULTADOS DEL EFECTO DE LOS FACTORES SOBRE LAS VARIABLES EN EL ENSAYO DE DISPOSITIVOS CENTRÍFUGOS 223

ANEJO 8. DESCRIPCIÓN DE LAS PARCELAS 241

ANEJO 9. RESULTADOS DE LOS ANOVAS EN EL ENSAYO DE AJUSTE DE LA CONCENTRACIÓN DE SPINTOR 480 SC ${ }^{\circledR}$ 243

ANEJO 10. RESULTADOS DE LOS ANOVAS EN EL ENSAYO DE TRITURACIÓN: EFECTO DE LOS FACTORES SOBRE LA POTENCIA REQUERIDA POR EL TRACTOR 245 



\section{ÍNDICE DE FIGURAS}

Figura 1. Mapa de distribución mundial de C. capitata. Fuente: Eppo (2007). 3

Figura 2. Macho de Ceratitis capitata. Fuente: San Andrés, V; Urbaneja, A. (2007). _ 5

Figura 3. Hembra de Ceratitis capitata. Fuente: San Andrés, V; Urbaneja, A. (2007). _ 5

Figura 4. Daño producido por la puesta de la mosca mediterránea de la fruta en una naranja. 9

Figura 5. Trampa tipo Nade.l__ 15

Figura 6. Trampa tipo Tephri-trap. __ 15

Figura 7. Equipo de emulación. __ 52

Figura 8. Boquillas AI-11003VS (1), AI-11004VS (2), TT-1004VP (3) y FL-5VS (4)._ 53

Figura 9. Disposición de colectores en la pared __ 55

Figura 10. Esquema de la disposición de los colectores __ 55

Figura 11. Esquema de los elementos empleados para la pulverización centrífuga.__ 59

Figura 12. Discos, d1 (derecha) y d2 (izquierda). _ 60

Figura 13. Disposición de los colectores en el suelo. __ 62

Figura 14. Esquema de la disposición de los colectores.___ 62

Figura 15. Secuencia del proceso de análisis de imagen: 1. Foto original; 2. Foto recortada; 3. Foto en escala de grises; 4. Foto segmentada. Cada impacto está etiquetado con un número diferente. 66

Figura 16. Distribuciones acumuladas para las cuatro boquillas a 1 y 2 bar. 70

Figura 17. Distribuciones acumuladas según cabezal y velocidad de giro para un caudal de $0,42 \mathrm{l} / \mathrm{min}$. 73

Figura 18. Distribuciones acumuladas según disco y velocidad de giro para un caudal de $0,83 \mathrm{l} / \mathrm{min}$. 74

Figura 19. Distribuciones acumuladas para las boquillas de inducción de aire a 1 bar y para varios casos de caudal y velocidad de giro de los cabezales centrífugos. 76 Figura 20. Montaje del sistema hidráulico y electrónico sobre un pulverizador hidráulico suspendido. 79

Figura 21. Unidad de control del prototipo. 80

Figura 22. Diagrama de bloques del sistema electrónico. 81 
Figura 23. Distribución de los papeles hidrosensibles en el árbol. Vista en alzado (Izquierda). Vista en planta (Derecha).

Figura 24. Porcentaje de recubrimiento obtenido en cada posición al promediar las alturas. Valores de la media seguidos de diferente letra muestran diferencias significativas (Prueba LSD a un nivel de confanza del $95 \%$ ).

Figura 25. Hoja de clementino con las 5 gotas de $5 \mu$ l aplicadas mediante micropipeta, unidas por el peciolo a una disolución de Triton ${ }^{\circledR}(3 \%)$.

Figura 26. Unidades de ensayo. A) Eppendorf con miel y agua, B) Eppendorf con agua,

C) Hoja con tratamiento insertada en tubo Eppendorf con solución nutritiva. 93

Figura 27. Mortalidad corregida de adultos de C. capitata para cada tratamiento. Experimentos con A) Residuo fresco, B) residuo de 3 días y C) residuo de 6 días. 97

Figura 28. Plano de situación de las trampas en la parcela A (izquierda) y en la parcela $B$ (derecha). 101

Figura 29. Evolución de las capturas de moscas entre la parcela control, la parcela aislada y la trampa indicadora. 102

Figura 30. Comparación de las capturas de moscas totales en las parcelas A y B con sistemas de trampeo Nadel (abajo) y con Tephri (arriba).

Figura 31. Comparación de las capturas entre sistemas de trampeo Tephri y Nadel en la parcela $A$ (arriba) y en la parcela B (abajo). 104

Figura 32. Distribución de C. capitata mediante curvas isomoscas en la parcela A con trampas Tephri la semana del27de agosto de 2003. El plano XY representa el plano de la parcela. 105

Figura 33. Distribución de machos de C. capitata mediante curvas isomoscas en la parcela B con trampas Tephri y Nadel las semanas del 10 (arriba) y del 17 (abajo) de septiembre de 2003. El plano XY representa el plano de la parcela. 106

Figura 34. Plano de situación de las trampas en una unidad experimental 111

Figura 35. Comparación de las capturas de C. capitata entre el tratamiento convencional y el cebo a bajo volumen durante las aplicaciones de 2004 (arriba) y 2005 (abajo). 116

Figura 36. Evolución de capturas de C. capitata durante los tratamientos cebo a bajo volumen en la parcela de Clemenules (arriba) y de Navel (abajo). 119 
Figura 37. Interacción del factor tratamiento por el factor cara del árbol para la variable porcentaje de infestación de negrilla. Intervalos LSD a un nivel de confianza del $95 \%$. 122

Figura 38. Interacción del factor tratamiento por el factor cara del árbol para la variable porcentaje de presencia de manchas. Intervalos LSD a un nivel de confianza del $95 \%$.

Figura 39. Trituradora de eje horizontal. Vista inferior. 129

Figura 40. Diferentes diseños 129

Figura 41. Diferentes diseños 129

Figura 42. Proceso del tratamiento de trituración en condiciones de laboratorio. 134

Figura 43. Proceso del tratamiento de aplastado en condiciones de laboratorio. 134

Figura 44. Colocación de la fruta en recipientes de plástico sobre rejilla y tapados con muselina, para su almacenamiento en cámaras climáticas. 135

Figura 45 Interacción entre el factor tratamiento y el factor semana para la variable supervivencia de larvas. Intervalos LSD con un nivel de confianza del 95\%. 136

Figura 46. Detalle de las cuchillas. 141

Figura 47. Detalle de los martillos. 141

Figura 48. Proceso de la trituración de los frutos en campo. Colocación de los frutos en el centro de la calle y su trituración. 142

Figura 49. Sensores para medir el par y la velocidad de giro de la toma de fuerza del tractor. 144

Figura 50. Interacción entre el tipo de herramienta y la velocidad de giro para la potencia requerida. Intervalos LSD con un nivel de confianza del $95 \%$. 148

Figura 51. Interacción entre el tipo de herramienta y la velocidad de giro para la potencia requerida. Intervalos LSD con un nivel de confianza del 95\%. 149 Figura 52. Interacción entre la velocidad de avance del tractor y la velocidad de giro de la toma de fuerza. Intervalos LSD con un nivel de confianza del 95\%. 149

Figura 53. Interacción entre la velocidad de avance del tractor y la velocidad de giro de la toma de fuerza. Intervalos LSD con un nivel de confianza del $95 \%$. 150

Figura 54. Comparación de las moscas totales acumuladas entre la parcela triturada y la parcela control. Arriba: primavera de 2005. Abajo: primavera 2006. 154 


\section{ANEJOS}

Figura A. 1. Boquillas de Sanz Hermanos. 183

Figura A. 2. Cabezales 1, 2, 3, 4, 5._ 185

Figura A. 3. Cabezal 1 a $6 \mathrm{~V}$ __ 186

Figura A. 4. Cabezal 1 a $4 \mathrm{~V}$._ 186

Figura A. 5. Cabezal 2 a $10 \mathrm{~V}$ __ 187

Figura A. 6. Cabezal 2 a $7 \mathrm{~V}$. 187

Figura A. 7. Cabezal 2 a $5 \mathrm{~V}$ __ 187

Figura A. 8. Cabezal 2 a $4 \mathrm{~V}$ __ 187

Figura A. 9. Cabezal 3 a $8 \mathrm{~V}$.__ 188

Figura A. 10. Cabezal 3 a $6 \mathrm{~V}$.__ 188

Figura A. 11. Cabezal 3 a $5 \mathrm{~V}$.__ 188

Figura A. 12. Cabezal 4 a 7 V._ 189

Figura A. 13. Interacción del factor presión por el factor boquilla para la variable mediana del diámetro. Intervalos LSD a un nivel de confianza del $95 \%$. 201

Figura A. 14. Interacción del factor presión por el factor boquilla para la variable D25 del diámetro. Intervalos LSD a un nivel de confianza del $95 \%$. 203

Figura A. 15. Interacción del factor boquilla por el factor altura relativa del colector para la variable D25 del diámetro. Intervalos LSD a un nivel de confianza del $95 \%$. 204 Figura A. 16. Interacción del factor presión por el factor boquilla para la variable D75 del diámetro. Intervalos LSD a un nivel de confianza del $95 \%$. 205

Figura A. 17. Interacción del factor presión por el factor boquilla para la variable número de impactos por $\mathrm{cm}^{2} \wedge$ 0,5. Intervalos LSD a un nivel de confianza del $95 \%$ __208 Figura A. 18. Interacción del factor boquilla por el factor altura relativa para la variable número de impactos por $\mathrm{cm}^{2} \wedge$, 5. Intervalos LSD a un nivel de confianza del $95 \%$ __209 Figura A. 19. Interacción del factor presión por el factor altura relativa para la variable número de impactos por $\mathrm{cm}^{2} \wedge$ 0,5. Intervalos LSD a un nivel de confianza del $95 \%$ _ _209 Figura A. 20. Interacción del factor boquilla por el factor altura relativa para la variable recubrimiento. Intervalos LSD a un nivel de confianza del $95 \%$. 211

Figura A. 21. Interacción del factor presión por el factor boquilla para la variable volumen depositado por unidad de superficie. Intervalos LSD a un nivel de confianza del $95 \%$. 212 
Figura A. 22. Interacción del factor boquilla por el factor altura relativa para la variable volumen depositado por unidad de superficie. Intervalos LSD a un nivel de confianza del $95 \%$. 213

Figura A. 23. Interacción del factor presión por el factor altura relativa para la variable volumen depositado por unidad de superficie. Intervalos LSD a un nivel de confianza del $95 \%$. 214

Figura A. 24. Interacción del factor cabezal por el factor caudal para la variable mediana del diámetro. Intervalos LSD a un nivel de confianza del $95 \%$. 223

Figura A. 25. Interacción del factor cabezal por el factor velocidad de giro para la variable mediana del diámetro. Intervalos LSD a un nivel de confianza del $95 \%$. 224

Figura A. 26. Interacción del factor posición relativa por el factor velocidad de giro para la variable mediana del diámetro. Intervalos LSD a un nivel de confianza del $95 \%$ __ 224 Figura A. 27. Interacción del factor cabezal por el factor caudal para la variable D25 del diámetro. Intervalos LSD a un nivel de confianza del $95 \%$. 226

Figura A. 28. Interacción del factor cabezal por el factor velocidad de giro para la variable D25 del diámetro. Intervalos LSD a un nivel de confianza del $95 \%$. 226 Figura A. 29. Interacción del factor posición relativa por el factor velocidad de giro para la variable D25 del diámetro. Intervalos LSD a un nivel de confianza del $95 \% .227$ Figura A. 30. Interacción del factor cabezal por el factor caudal para la variable D75 del diámetro. Intervalos LSD a un nivel de confianza del $95 \%$. 229 Figura A. 31. Interacción del factor cabezal por el factor velocidad de giro para la variable D75 del diámetro. Intervalos LSD a un nivel de confianza del $95 \%$. 229 Figura A. 32. Interacción del factor posición relativa por el factor velocidad de giro para la variable D75 del diámetro. Intervalos LSD a un nivel de confianza del $95 \% .230$ Figura A. 33. Interacción del factor cabezal por el factor caudal para la variable intervalo intercuartílico del diámetro. Intervalos LSD a un nivel de confianza del $95 \%$.

Figura A. 34. Interacción del factor cabezal por el factor velocidad de giro para la variable intervalo intercuartílico del diámetro. Intervalos LSD a un nivel de confianza del $95 \%$.

Figura A. 35. Interacción del factor posición relativa por el factor velocidad de giro para la variable intervalo intercuartílico del diámetro. Intervalos LSD a un nivel de confianza del $95 \%$. 232 
Figura A. 36. Interacción del factor cabezal por el factor caudal para la variable recubrimiento. Intervalos LSD a un nivel de confianza del $95 \%$.

Figura A. 37. Interacción del factor velocidad de giro por el factor caudal para la variable recubrimiento. Intervalos LSD a un nivel de confianza del $95 \%$. 234

Figura A. 38. Interacción del factor cabezal por el factor posición relativa para la variable recubrimiento. Intervalos LSD a un nivel de confianza del $95 \%$. 235

Figura A. 39. Interacción del factor velocidad de giro por el factor cabezal para la variable número de impactos por $\mathrm{cm}^{2}$. Intervalos LSD a un nivel de confianza del $95 \%$.

Figura A. 40. Interacción del factor velocidad de giro por el factor caudal para la variable número de impactos por $\mathrm{cm}^{2}$. Intervalos LSD a un nivel de confianza del $95 \%$.

Figura A. 41. Interacción del factor cabezal por el factor posición relativa para la variable número de impactos por $\mathrm{cm}^{2}$. Intervalos LSD a un nivel de confianza del $95 \%$.

Figura A. 42. Interacción del factor caudal por el factor posición relativa para la variable número de impactos por $\mathrm{cm}^{2}$. Intervalos LSD a un nivel de confianza del $95 \%$.

Figura A. 43. Interacción del factor velocidad de giro por el factor posición relativa para la variable número de impactos por $\mathrm{cm}^{2}$. Intervalos $L S D$ a un nivel de confianza del $95 \%$.

Figura A. 44. Plano de las parcelas A y B. 241 


\section{ÍNDICE DE TABLAS}

Tabla 1. Caudales (media \pm ES) de las boquillas a 1 y 2 bar. 54

Tabla 2. Ancho de pulverización y distancia entre colectores según tipo de boquilla y presión de trabajo. 55

Tabla 3. Velocidad de desplazamiento para pulverizar un volumen de caldo de 40l/ha. 57 Tabla 4. Velocidad de giro (r/min) escogidas para cada cabezal y caudal. Entre paréntesis se indica el voltaje con que se alimentaba el motor para conseguir dicha velocidad. 61

Tabla 5. Ancho de pulverización y distancia entre colectores según tipo de disco y velocidad de giro. 62

Tabla 6. Valores medios de mediana, $D_{25}$ y $D_{75}$ de los impactos producidos por cada boquilla y a 1 y 2 bar de presión. 69

Tabla 7. Valores medios de mediana, $D_{25}$ y $D_{75}$ de los impactos producidos por cada cabezal y velocidad de giro a 0,42 l/min y $0,83 \mathrm{l} / \mathrm{min}$. 71

Tabla 8. Configuraciones de pulverización ensayadas en cada parcela 86

Tabla 9. Porcentaje de mortalidad (media \pm ES) de adultos de C. capitata para cada tratamiento. Efectos residuales medidos a 0 (residuo fresco), 3 y 6 días después de la aplicación. Dentro de cada residuo y cada día de evaluación, valores de la media seguidos de diferente letra muestran diferencias significativas (Prueba LSD a un nivel de confanza del $95 \%$ ). 96

Tabla 10. Características de los tratamientos realizados en el ensayo de comparación entre tratamientos convencionalesl y dos tratamientos cebo a bajo volumen. 108

Tabla 11. Características de los tratamientos realizados en el ensayo de comparación entre tratamientos cebo a bajo volumen. 110

Tabla 12. Niveles establecidos de presencia de negrilla o de manchas según el porcentaje de superficie ocupada en la mitad de cada fruto. 113

Tabla 13. Coeficientes de regresión lineal entre los resultados estandarizados de cada tratamiento en 2004 y 2005.

Tabla 14. Coeficientes de regresión lineal entre cada tratamiento en la parcela de Clemenules y Navel. 120

Tabla 15. Porcentaje de frutos picados por C. capitata. 121 
Índice de tablas

Tabla 16. Ratio de supervivencia de larvas de C. capitata (Media \pm ES) en función de factor tratamiento. Valores de la media seguidos de diferente letra muestran diferencias significativas (Prueba LSD a un nivel de confanza del $95 \%$ ).

Tabla 17. Características del tractor empleado. 139

Tabla 18. Velocidades de avance del tractor a $540 \mathrm{r} / \mathrm{min}$ en función de diferentes combinaciones de la caja de cambio.

Tabla 19. Velocidades de avance y de la toma de fuerza establecidas para el ensayo._140

Tabla 20. Características de las trituradoras de leña de eje horizontal empleadas en los ensayos.

Tabla 21. Distribución de los restos observados tras la trituración en los ensayos con mandarinas. 146

Tabla 22. Distribución de los restos observados tras la trituración en los ensayos con naranjas. 146

Tabla 23. Porcentaje de fruta triturada (Media \pm ES) en función de factor tipo de herramienta, velocidad de avance y velocidad de giro de la toma de fuerza en el ensayo de mandarinas. Dentro de cada factor, valores de la media seguidos de diferente letra muestran diferencias significativas (Prueba LSD a un nivel de confanza del $95 \%$ ). _147 Tabla 24. Porcentaje de fruta triturada (Media \pm ES) en función de factor tipo de herramienta, velocidad de avance y velocidad de giro de la toma de fuerza en el ensayo de naranjas. Dentro de cada factor, valores de la media seguidos de diferente letra muestran diferencias significativas (Prueba LSD a un nivel de confanza del $95 \%$ )._147 Tabla 25. Coste energético de la trituración de mandarinas en función del tipo de herramienta, velocidad de avance y velocidad de giro de la toma de fuerza. 150 Tabla 26. Coste energético de la trituración de naranjas en función del tipo de herramienta, velocidad de avance y velocidad de giro de la toma de fuerza. 151

\section{ANEJOS}

Tabla A. 1. Caudales de las boquillas Sanz Hermanos y volúmenes de caldo por unidad de superficie en función del marco de plantación y la velocidad del tractor al realizar el tratamiento. 184

Tabla A. 2. Velocidades de giro ( $\mathrm{r} / \mathrm{min})$ en función del voltaje. 189

Tabla A. 3. Valores de SSE y R2 para los colectores del ensayo de pulverización hidráulica. 195

xiv 
Tabla A. 4. Mediana del diámetro de impacto (Media \pm ES) en cada posición de colector. Valores de la media seguidos de diferente letra muestran diferencias significativas (Prueba LSD a un nivel de confanza del $95 \%$ ). 202

Tabla A. 5. Resultado del ANOVA para la variable mediana a un nivel de confianza del $95 \%$. 202

Tabla A. 6. Resultado del ANOVA para la variable D25a un nivel de confianza del $95 \%$. 204

Tabla A. 7. D75 del diámetro de impacto (Media \pm ES) en cada posición de colector. Valores de la media seguidos de diferente letra muestran diferencias significativas (Prueba LSD con un intervalo de confanza del $95 \%$ ). 205

Tabla A. 8. Resultado del ANOVA para la variable D75 a un nivel de confianza del $95 \%$. 206

Tabla A. 9. Intervalo intercuartílico del diámetro de impacto (Media \pm ES) para los factores: boquilla, presión y posición de colector. Dentro de cada factor, valores de la media seguidos de diferente letra muestran diferencias significativas (Prueba LSD a un nivel de confanza del $95 \%$ ). 207

Tabla A. 10. Resultado del ANOVA para la variable intervalo intercuartílico a un nivel de confianza del $95 \%$ 207

Tabla A. 11. Resultado del ANOVA para la variable número de impactos por $\mathrm{cm}^{2}$ a un nivel de confianza del $95 \%$. 210

Tabla A. 12. Resultado del ANOVA para la variable recubrimiento a un nivel de confianza del $95 \%$. 211

Tabla A. 13. Resultado del ANOVA para la variable volumen depositado por unidad de superficie a un nivel de confianza del $95 \%$ 214

Tabla A. 14. Valores de SSE y R2 para los colectores del ensayo de pulverización centrífuga. 217

Tabla A. 15. Resultado del ANOVA para la variable mediana del diámetro a un nivel de confianza del $95 \%$. 225

Tabla A. 16. Resultado del ANOVA para la variable D25 del diámetro a un nivel de confianza del $95 \%$. 228

Tabla A. 17. Resultado del ANOVA para la variable D75 del diámetro a un nivel de confianza del $95 \%$. 230 
Índice de tablas

Tabla A. 18. Resultado del ANOVA para la variable intervalo intercuartílico del diámetro a un nivel de confianza del $95 \%$.

Tabla A. 19. Resultado del ANOVA para la variable recubrimiento a un nivel de confianza del $95 \%$.

Tabla A. 20. Volumen depositado por unidad de superficie (Media \pm ES) en posición de colector. Valores de la media seguidos de diferente letra muestran diferencias significativas (Prueba LSD a un nivel de confanza del $95 \%$ ).

Tabla A. 21. Resultado del ANOVA para la variable volumen depositado por unidad de superficie a un nivel de confianza del $95 \%$.

Tabla A. 22. Resultado del ANOVA para la variable número de impactos por $\mathrm{cm}^{2}$ a un nivel de confianza del $95 \%$. 240

Tabla A. 23.Resultado del ANOVA para la variable potencia requerida por el tractor en el ensayo de trituración de naranjas a un nivel de confianza del $95 \%$. 245

Tabla A. 24. Resultado del ANOVA para la variable potencia requerida por el tractoren el ensayo de trituración de mandarinas a un nivle de confianza del $95 \%$. 246 


\section{Capítulo I. INTRODUCCIÓN GENERAL}

La mosca mediterránea de la fruta, Ceratitis capitata (Wiedemann) (Diptera: Tephritidae), es una de las plagas más importantes que afectan a la fruticultura de muchos países. En España, concretamente en cítricos, es, junto con el piojo rojo de California, Aonidiella aurantii (Maskell) (Homoptera: Diaspididae), una de las plagas más graves por su repercusión económica.

Hasta el momento, el método de control de $C$. capitata más utilizado y eficiente consiste en la aplicación de tratamientos fitosanitarios con insecticidas organofosforados. No obstante, es creciente la preocupación mundial alrededor de los efectos negativos de estas aplicaciones. Fruto de ello, en la Unión Europea ya existen normas y recomendaciones sobre el uso sostenible de los plaguicidas, en las que se determinan concretamente los productos cuyo uso está autorizado y se indican las formas en las que se deben realizar los tratamientos (Directiva 91/414/CEE; COM 372 y 373, 2006).

Al mismo tiempo, los tratamientos para el control de plagas representan uno de los costes de cultivo más elevados en la producción de cítricos en España (Juste et al., 1998), en un momento de crisis para el sector productivo, que debe reducir costes en un mercado global, ya que éstos son mucho mayores que los de la competencia exterior (países mediterráneos).

Dentro de este contexto, por lo tanto, es necesario buscar métodos alternativos al uso de organofosforados para el control de la plaga, que sean menos perjudiciales para el medioambiente y representen un menor riesgo para el aplicador. Al mismo tiempo, es imprescindible que estas alternativas tengan un coste reducido, para no incrementar los costes de producción actuales. Por ello, el Instituto Nacional de Investigación y Tecnología Agraria y Alimentaria (INIA), durante 2003-2005, financió un proyecto nacional titulado "Control integrado de la mosca mediterránea de la fruta, Ceratitis capitata (Wiedemann) (Diptera: Tephritidae) en cítricos" (ref. RTA03-103). Uno de los objetivos de este proyecto 
era proponer un sistema de control integrado para reducir las poblaciones de $C$. capitata por debajo de los umbrales de tolerancia de una manera eficiente. Entre los métodos de control que se estudiaron destacan la aplicación de nuevos productos de síntesis, alternativos a los organofosforados, en forma de cebo, y la eliminación de los frutos que quedan tras la cosecha, que son el reservorio natural para las generaciones siguientes de este insecto. Para que estos métodos puedan emplearse racionalmente en la citricultura española actual es imprescindible su mecanización.

La presente tesis forma parte de las aportaciones del mencionado proyecto referidas, por un lado, a la aplicación de nuevos productos en forma de cebo y, por otro, a la eliminación de la fruta en el campo. Por ese motivo, la tesis se ha dividido en dos apartados, cada uno de ellos atendiendo a uno de los temas.

Antes de abordarlos, a continuación se describe con mayor detalle la importancia de esta plaga, sus aspectos biológicos y ecológicos más relevantes, los daños que produce sobre los frutos y la importancia económica que tiene en nuestra citricultura. Además, se exponen los diferentes métodos de control que se proponen a nivel internacional, y las ventajas e inconvenientes de cada uno de ellos. Por último, se explican los problemas más importantes relacionados con la mecanización de la aplicación de los tratamientos cebo y la eliminación de la fruta en el campo.

\section{LA IMPORTANCIA DE C. capitata (WIEDEMANN) EN LA CITRICULTURA ACTUAL \\ 1.1 CLASIFICACIÓN TAXONÓMICA}

La mosca mediterránea de la fruta se clasifica, según Chinery (1980) del siguiente modo:

- CLASE: Insecta

- ORDEN: Diptera

2 
- SUBORDEN: Cyclorrhapha

- SUPERFAMILIA: Schizophora

- SERIE: Acaliptrata

- FAMILIA: Tephritidae (= Trypetidae)

- $\quad$ SUBFAMILIA: Tephritinae (= Trypetinae)

- $\quad$ TRIBU: Tephritini (= Trypetini)

- GÉNERO: Ceratitis

- ESPECIE: capitata

\subsection{DISTRIBUCIÓN GEOGRÁFICA Y HOSPEDANTES}

El origen de $C$ capitata se establece en África (Silvestre, 1911; Maddison y Bartlett, 1989), desde donde se extendió a otras zonas templadas, subtropicales y tropicales de los dos hemisferios.

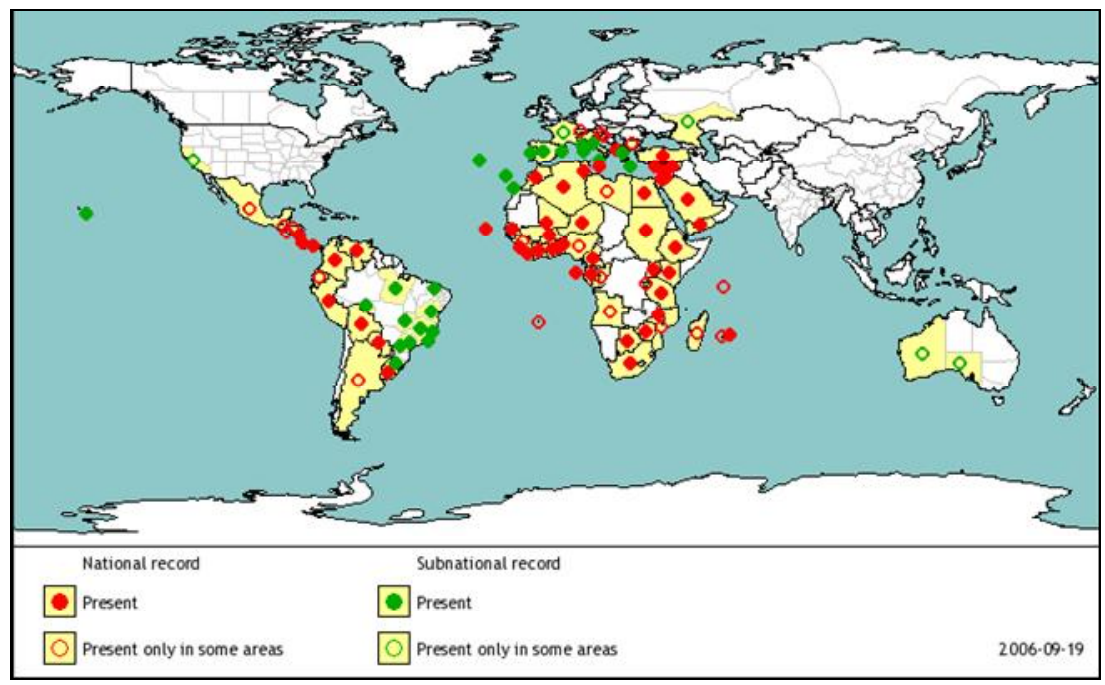

Figura 1. Mapa de distribución mundial de C. capitata. Fuente: Eppo (2007).

Actualmente, se encuentra distribuida en todos los países de la cuenca mediterránea, donde su incidencia económica ha hecho que se le conozca con el nombre común de mosca mediterránea de la fruta. También se encuentra en 
América; en Nueva Zelanda y Australia; en Asia, al este de la India y en prácticamente todo el continente africano (Figura 1) (Maddison y Bartlett, 1989).

En España se detectó por primera vez en Málaga en 1842 por De Brême y en Sevilla en 1894 (Fimiani, 1989). Hoy en día se encuentra distribuida por toda la costa Este y el Sur, donde las condiciones climáticas y el cultivo de frutos hospedantes favorecen su desarrollo, y que coincide con las zonas donde se encuentra la mayoría de la producción citrícola nacional. En las zonas del interior y norte de la península, más frías, en ocasiones se producen ataques que se deben a la reinvasión anual del insecto desde las áreas más cálidas (Del Pino, 2000).

Además de su amplia distribución, este insecto destaca principalmente por ser polífago, atacando a más de 300 especies de plantas (Liquido et al., 1991), y por su alta adaptabilidad. Los cultivos a los que afecta varían según las distintas regiones, e incluyen a la mayoría de los frutos tropicales y subtropicales, como la papaya, el plátano, el mango, los frutales de hueso y pepita, y los cítricos. En España evoluciona sobre distintas especies de frutos de forma escalonada, según su época de maduración: desde naranjas tardías "Valencia late" a albaricoques, melocotones, peras, manzanas, higos, caquis y naranjas y mandarinas tempranas (Gómez-Clemente, 1948). En la actualidad, la gama varietal de cítricos y de otras especies frutales ha aumentado, lo que incrementa el número de hospedantes que son sensibles a su ataque (Alonso y García-Marí, 2003).

\subsection{BIOLOGÍA Y CICLO BIOLÓGICO}

La mosca de la fruta es un insecto que presenta una metamorfosis completa u holometábola, que se divide en los siguientes estados de desarrollo: huevo, larva, pupa y adulto. 
El adulto es de menor tamaño que la mosca doméstica y está vivamente coloreado. Las alas son irisadas, con varias manchas grisáceas, amarillas y negras. La cabeza es oscura y el tórax negro y amarillo, mientras que el abdomen es amarillo anaranjado. Los machos (Figura 2) se distinguen de las hembras por ser más pequeños y por presentar en la frente dos largas sedas que terminan en una paleta romboide de color negro, carácter que no se encuentra en el resto de las especies de tefrítidos de importancia agrícola. Las hembras (Figura 3) se reconocen fácilmente por poseer un abdomen en forma cónica, que termina en el oviscapto, cuya longitud media es de $0,9 \mathrm{~mm}$ y su anchura es de $0,15 \mathrm{~mm}$ (Marchini y Wood, 1983).

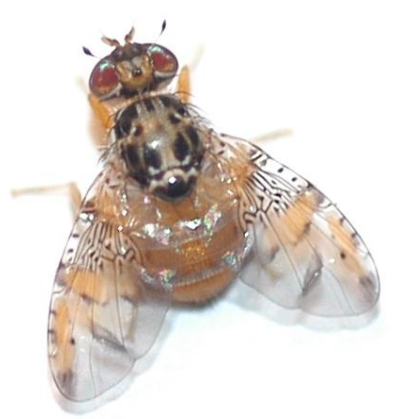

Figura 2. Macho de Ceratitis capitata. Fuente: San Andrés, V; Urbaneja, A. (2007).

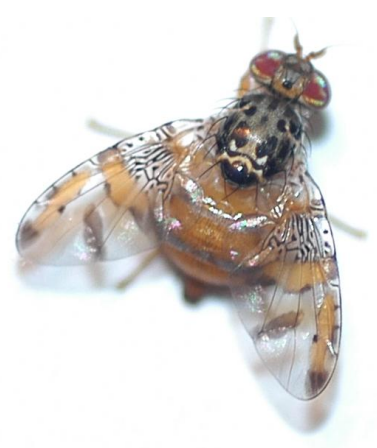

Figura 3. Hembra de Ceratitis capitata. Fuente: San Andrés, V; Urbaneja, A. (2007).

Tras la cópula, la hembra fecundada realiza la puesta de los huevos dentro de los frutos, atraídas por el olor y el color, generalmente sobre frutos que están próximos a la maduración (60-70 \% de madurez). Pero si no los encuentra, también hace la puesta sobre frutos verdes. Una sola cópula en la vida de la hembra es suficiente para la fertilización continua de los huevos, pues la hembra posee una espermateca, donde almacena los espermatozoides del macho. En cada puesta, las moscas depositan entre 5 y 20 huevos, llegando a ovipositar más de 1000 a lo largo de toda su vida (Aluja, 1993). 
Los huevos son blancos, alargados y ligeramente curvados, con un tamaño medio de $1 \mathrm{~mm}$ por 0,2 $\mathrm{mm}$ (Robles-Chillida, 1975). Poseen un corion compuesto por varias capas diferentes, atravesadas por una estructura de poros, que permiten la oxigenación del embrión, pero que también, son la causa de la sensibilidad del huevo a la desecación (Prokopy y Hendrichs, 1979).

Las larvas, al eclosionar de los huevos, penetran inmediatamente hacia el interior del fruto para alimentarse de la pulpa. Son de color blanco-amarillento, ápodas y con la parte anterior situada en el extremo agudo del cuerpo, mientras que la parte posterior es más ancha y truncada. A medida que se alimentan de la pulpa crecen, pasando por tres estadios larvarios $\left(\mathrm{L}_{1}, \mathrm{~L}_{2}\right.$ y $\left.\mathrm{L}_{3}\right)$ y alcanzando un tamaño aproximado de $1 \mathrm{~cm}$ al final de su desarrollo (Aluja, 1993).

Al completar el tercer estadio larvario, las larvas abandonan el hospedante y se desplazan reptando y mediante saltos (Maitland, 1992) hasta encontrar un lugar adecuado para enterrarse y realizar la pupación. Las pupas tienen forma de barrilete, con la superficie lisa y miden aproximadamente 3,5-4,8 mm de largo y 2-2,4 mm de ancho. Su coloración varía desde pardo amarillenta a marrón oscura, dependiendo de la alimentación que recibió el insecto en el estado de larva, su edad y el medio ambiente en que se encuentra.

Por último, el adulto emerge del pupario. Recién emergido es blando y está húmedo, por lo que busca un refugio (hojas secas, troncos) donde permanecer estático secándose. Sus alas aún no adquieren la coloración típica y su vuelo es corto. Una vez seco, se activa y vuela a la parte superior de los árboles, donde busca alimento. Éste lo encuentra en frutas maduras que presentan alguna herida, incluso cuando están sobre el suelo, en secreciones de troncos u hojas, en excrementos de pájaros silvestres y en las secreciones melosas de áfidos y otros insectos chupadores. Tras alimentarse de materias azucaradas y ciertos aminoácidos esenciales y necesarios para su supervivencia y madurez sexual (Christenson y Foote, 1960; Bateman, 1972), se aparea, completando su ciclo biológico (White y Elson-Harris, 1992). 
La duración del ciclo de vida depende de factores como la temperatura, la humedad, la vegetación, el sustrato de pupación, el sustrato donde ponen los huevos y la disponibilidad de alimento y, por tanto, de las condiciones ecológicas de cada región (Aluja, 1993).

Los adultos de $C$. capitata viven entre 30 y 45 días, pero a veces pueden mantenerse vivos más de 8 meses (Del Pino, 2000). En climas templados son más longevos que en climas tropicales (Aluja, 1993). Para alcanzar la madurez sexual requieren entre 5 y 20 días. Back y Pemberton (1918) demostraron que a temperaturas entre 23 y $30^{\circ} \mathrm{C}$, la hembra está dispuesta para el acoplamiento a los 4 ó 5 días de su nacimiento y el macho a los 3 días. A temperaturas menores de $20^{\circ} \mathrm{C}$, este periodo se prolonga a 8 ó 10 días y por debajo de $13{ }^{\circ} \mathrm{C}$ no tiene lugar la fecundación.

Los huevos tienen un periodo de incubación entre 1 y 7 días, pudiendo ser viables después de 16-18 días en condiciones frías de temperaturas (Prokopy y Hendrichs, 1979).

El periodo de desarrollo de la larva se ve afectado por el tipo de hospedante y, especialmente, por las condiciones climáticas. Se ha observado que con temperaturas entre $15-16,5{ }^{\circ} \mathrm{C}$ completan su desarrollo en 24-50 días, mientras que con $19-28,5^{\circ} \mathrm{C}$ lo hacen en 6-11 días (Aluja, 1993).

El estado de pupa puede durar de 7 a 15 días si las condiciones de temperatura y humedad son adecuadas, o prolongarse varios meses si las temperaturas son bajas o la humedad mínima (Aluja, 1993; Putruele, 1996).

La dependencia del ciclo de vida de los factores abióticos y de la presencia de alimento y sustrato donde desarrollarse influye directamente sobre la dinámica poblacional de la plaga. España se caracteriza por un clima templado con variabilidad estacional, de ahí que la evolución de la población de mosca varíe a lo largo del año. En abril y mayo se inician las capturas de adultos, incrementándose con rapidez hasta junio y julio, cuando alcanzan el máximo 
nivel de población. Después se produce un descenso rápido en agosto a niveles bajos y, posteriormente, una recuperación en septiembre-noviembre, pero siempre con poblaciones más reducidas. Poco después, con la llegada del frío las capturas disminuyen hasta valores cercanos a cero, que se mantienen aproximadamente hasta la siguiente primavera (Gómez-Clemente y PlanesGarcía, 1951-1952; Alonso y García-Marí, 2003; Martínez-Ferrer et al., 2007).

Existen numerosos estudios sobre cómo $C$. capitata pasa el invierno. En las condiciones de la Comunidad Valenciana, experimentos realizados por Del Pino (2000) mostraron que tanto los adultos como los estados inmaduros son capaces de sobrevivir durante el invierno, ya que las temperaturas no son lo suficientemente bajas para detener el ciclo del insecto. Según este trabajo, los adultos pueden sobrevivir a temperaturas inferiores de $0{ }^{\circ} \mathrm{C}$, su periodo de prepuesta puede alargarse considerablemente a bajas temperaturas y pueden madurar sexualmente durante el invierno. Si la puesta de huevos se realiza al principio del invierno, éstos evolucionan a larvas que se desarrollan lentamente, alcanzando el estado de pupa en el mes de marzo. Sin embargo, si la puesta se realiza más tarde, los huevos y primeros estadios larvarios no evolucionan debido a su mayor sensibilidad a las bajas temperaturas. De Andrés y García-Marí (2007) concluyen que las poblaciones de invierno se inician con los huevos puestos durante el mes de octubre, que evolucionan pasando por los estadios de larva y pupa durante noviembre y diciembre, apareciendo los adultos de estas puestas en enero. Estas poblaciones, aunque en niveles muy bajos, se mantienen durante febrero y marzo y son los adultos que sobreviven los que dan lugar a la primera generación anual.

En estudios realizados en zonas límites del área de distribución de este insecto hay evidencias de que la larva y la pupa son los estados presentes en invierno (Cirio et al., 1972; Zervas et al., 1995; Papadopoulos et al., 1996; Katsoyannos et al., 1998; Papadopoulos et al., 1998). También se ha indicado que, en las montañas centrales de Israel, a altitudes de $400 \mathrm{~m}$, la mosca se 
encuentra en estado de larva y pupa durante el invierno (Israely et al. 2004; Israely y Oman, 2005), mientras que a altitudes superiores a $700 \mathrm{~m}$ es incapaz de sobrevivir. El hecho de que la plaga esté presente en primavera y verano es debido a reinvasiones del insecto desde altitudes inferiores.

\subsection{DAÑOS E IMPORTANCIA ECONÓMICA}

C. capitata produce daños directos, debidos a la puesta de la hembra en los frutos y posterior desarrollo larvario en su interior, que favorece los procesos de oxidación y maduración prematura y, que da lugar a la caída de los frutos. El daño se caracteriza por un pequeño orificio, producido por la hembra al insertar el oviscapto y, por una aureola alrededor de color castaño (Figura 4). También produce daños indirectos, derivados de la descomposición de los tejidos vegetales debido a la intervención de organismos secundarios como bacterias y hongos.

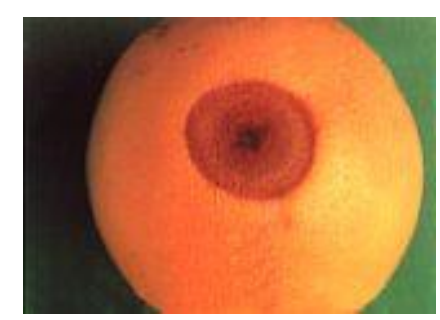

Figura 4. Daño producido por la puesta de la mosca mediterránea de la fruta en una naranja.

Además de los daños sobre la fruta, la mosca mediterránea de la fruta ocasiona otras importantes pérdidas económicas. C. capitata está incluida en las denominadas plagas de cuarentena, por lo que las especies de frutos hospedantes y los países en los que se encuentra, están sujetos a severos protocolos, impuestos por los países importadores para evitar la propagación de la plaga a nuevas áreas. Estos protocolos generan gastos debidos a la aplicación obligatoria de tratamientos insecticidas, a la vigilancia y seguimiento de las parcelas en campo y a los tratamientos post-recolección de desinfección y de cuarentena. También 
hay gastos de inspección en origen y destino, y los debidos al retraso en la comercialización.

El incumplimiento de los protocolos o la presencia de la plaga en los frutos exportados pueden dar lugar al cierre de las fronteras por parte de los países importadores. Particularmente graves fueron las pérdidas debidas al bloqueo de Estados Unidos a la exportación de clementinas españolas en la campaña 2001-2002, por la presencia de una larva viva de C. capitata en un envío. Supuso unas pérdidas de 54 millones de euros según datos de Intercitrus (2002, informe interno), sin contar las debidas a la potencial caída de la exportación a otros mercados. En la campaña siguiente, Estados Unidos permitió la exportación, pero a costa de incrementar los controles sobre la producción, para garantizar la ausencia de la plaga en la fruta exportada, con el consiguiente incremento de los gastos.

La Consellería de Agricultura, Pesca y Alimentación de la Comunidad Valenciana, donde se produce alrededor del 70\% de los cítricos de España, ha invertido en los últimos 5 años alrededor de 9 millones de euros anuales para combatir la mosca mediterránea de la fruta (Tragsa, 2007). Esto ha permitido establecer una red de vigilancia y seguimiento de la plaga en toda la Comunidad, mediante su monitoreo con el uso de trampas, realizar tratamientos fitosanitarios aéreos y terrestres, importar machos estériles y efectuar las sueltas y llevar un control de las parcelas cuyos frutos iban a ser destinados a la exportación. Además, en el periodo 2006-2007 ha invertido cerca de 7,5 millones de euros en la construcción y equipamiento de un centro para la producción de machos estériles, cuyo presupuesto para el funcionamiento está en torno a 12 millones de euros anuales, 6 millones para la producción de machos estériles, y los otros 6 , para la evolución, liberación y seguimiento de los mismos (Tragsa, 2007).

Por otra parte, también hay que tener en cuenta los gastos en que incurren los agricultores al realizar los tratamientos. Actualmente se realizan entre $6 \mathrm{y}$ 8 tratamientos terrestres cuando la fruta es susceptible de ser picada, lo que 
supone un gasto de entre 50 y 90 euros por hectárea y tratamiento, cuyo valor varía en función del equipo y del producto empleado.

\section{MÉTODOS DE CONTROL DE $C$. capitata}

En la actualidad, el método de control más utilizado y eficaz para la mosca mediterránea de la fruta es la aplicación de tratamientos fitosanitarios con plaguicidas de síntesis contra el adulto.

A finales del siglo XIX y principios del siglo XX se recomendaba el uso de insecticidas inorgánicos, como el arseniato de plomo o el fluorsilicato de sodio (Back y Pemberton, 1918; Bondenheimer, 1951; Woglum, 1929). Tras la segunda guerra mundial fueron reemplazados por insecticidas organoclorados, como el diclorodifeniltricloroetano (DDT) y el metoxicloro (Ebeling, 1959; Rivnai, 1954; Talhouk, 1969). Posteriormente, desde los años 60 hasta la actualidad, los insecticidas organofosforados se han utilizado ampliamente, sustituyendo a los organoclorados. Entre las materias activas más empleadas estuvieron clortión, paratión, fentión, malatión y triclorfón. El malatión se introdujo para el control de la mosca mediterránea de la fruta en 1956 y actualmente es la materia activa que más se utiliza en todo el mundo, debido a su alta eficacia y bajo coste (Roessler, 1989; Viñuela et al., 1998; Raga y Sato, 2005). En España se empezó a utilizar contra C. capitata en 1995, siendo el fentión el más utilizado hasta entonces.

El uso de estos insecticidas y el modo en que se aplican generan una serie de inconvenientes, como la aparición de fenómenos de resistencia (Ortego et al., 2005), efectos dañinos sobre los enemigos naturales (Ehler y Endicot, 1984; Daane et al., 1990; Hoelmer y Dahlsten 1993; Urbaneja et al., 2004; Urbaneja et al., 2007) y sobre la salud humana (Flessel et al. 1993; Marty et al. 1994), la presencia de residuos en los frutos, la contaminación ambiental, etc. Por ejemplo, en Florida, en 1997, las aplicaciones de malatión aéreas y terrestres provocaron la 
decoloración de la pintura de vehículos y la aparición de peces muertos, lo que dio lugar a numerosas quejas por parte de los ciudadanos (Burns et al., 2001).

Recientemente, tanto fentión, triclorfón y malatión han sido excluidos del anejo 1 de la directiva 91/414/CEE, relativa a la comercialización y homologación de materias activas plaguicidas en la Unión Europea (De Liñán, 2007).

A partir de estos condicionantes se deriva la necesidad de buscar métodos alternativos a las aplicaciones de malation que garanticen la salud pública, que reduzcan el impacto ambiental y que sean igual de eficaces. A continuación se describen los métodos más importantes en los que se ha trabajado en los últimos años para el control de $C$. capitata, algunos de ellos todavía están en fase experimental.

\subsection{LUCHA AUTOCIDA. TÉCNICA DEL INSECTO ESTÉRIL}

La lucha autocida o la técnica del insecto estéril (TIE) se basa en la liberación masiva de machos estériles. Las hembras salvajes, al copular con estos machos, producen huevos infértiles, lo que ocasiona la reducción de la población (Knipling, 1955).

Este es uno de los sistemas de control más respetuosos con el medio ambiente y con la salud humana, pero requiere una gran inversión de medios y personas para realizar tanto la producción como la liberación de los machos. Por otra parte, los procedimientos de cría, esterilización y manipulación de los mismos disminuyen la competitividad de cópula de los machos estériles frente a los salvajes, lo que reduce la eficacia de este método (Robinson et al., 1986; Shelly et al., 1994; Cayol et al., 1999; Lance et al., 2000; Barry et al., 2002).

Steiner et al. (1962) fueron los primeros en estudiar la posibilidad de emplear esta técnica contra $C$. capitata en Hawaii. Observaron que, tras liberar 
durante un año machos estériles, se produjo durante 6 meses una reducción del $90 \%$ de la población de mosca respecto a años anteriores. Sin embargo, continuas reinfestaciones de las áreas no tratadas devolvieron el nivel de plaga al nivel inicial. En la actualidad, en México, Guatemala y Chile se emplean programas TIE con buenos resultados en la prevención, supresión o erradicación de C. capitata (Lindquist, 2000; Hendrichs et al., 2002).

En España, este método se utilizó por primera vez en Tenerife, Murcia y Granada (Mellado, 1971; Mellado et al., 1974). En 2002, la Generalitat Valenciana puso en marcha un programa de liberación de machos estériles. En un principio se importaron pupas esterilizadas desde Argentina, que se hacían evolucionar en Moncada (Valencia), y se realizaron estudios a pequeña y mediana escala, en los que se obtuvieron resultados satisfactorios. Desde entonces se realizan sueltas periódicas en determinadas zonas de la Comunidad Valenciana. En 2007, la Consellería de Agricultura, Pesca y Alimentación inauguró en Caudete de las Fuentes (Valencia) una biofábrica para producir machos estériles y realizar liberaciones periódicas a gran escala. No obstante, dado que la eficacia de esta técnica mejora cuando las poblaciones de mosca silvestres son bajas será necesario complementarla con otros métodos de control (Argilés y Tejedo, 2007).

\subsection{CONTROL BIOLÓGICO}

Los métodos de control biológico de una plaga consisten en utilizar organismos vivos para mantener su población en niveles aceptables. Durante el siglo XX se han realizado varios intentos de control biológico de la mosca mediterránea, basados principalmente en la suelta de parasitoides exógenos (Wharton, 1989). A la hora de aplicar estos métodos biológicos con éxito surgen problemas relacionados con la necesidad de aclimatación de las especies introducidas al nuevo hábitat, su polifagia y el elevado potencial biótico de la 
plaga, así como el tamaño de los frutos afectados y el grosor de su epicarpio (Sivinski, 1996).

En los años 30 se importaron en España dos especies de bracónidos (Hymenoptera, Braconidae), Opius humilis (Silvestri) y Opius trioni (Cameron) pero se fracasó en la cría de los parasitoides en el laboratorio (Gómez-Clemente, 1932; 1934). En 1960 se introdujo el himenóptero eulófido Tetrastichus giffardianus (Silvestri) en Tenerife. Hoy todavía se pueden recuperar ejemplares en campo parasitando a la mosca, aunque no se ha analizado su efecto sobre la plaga (Moner et al., 1988). Actualmente se han importado dos especies de parasitoides desde Hawai, Fopius arisanus (Sonan) (Hymenoptera: Braconidae), parasitoide de huevos, y Diachasmimorpha tryoni (Cameron) (Hymenoptera: Braconidae), parasitoide de larvas, y se está evaluando su potencial parasitario en España en condiciones de laboratorio y de semicampo (Beitia et al., 2006a; Pérez-Hinarejos et al., 2006; Santiago et al., 2006), aunque su capacidad de adaptación a nuestras condiciones todavía no se ha determinado.

También se están buscando parasitoides autóctonos de C. capitata y se estudian sus principales parámetros biológicos, con el fin de conocer su potencial como agente de control de esta plaga. Hasta ahora se han encontrado dos himenópteros parasitoides de pupas de la familia Pteromalidae: Spalangia cameroni (Perkins) y Pachycrepoideus vindemmiae (Rondani) (Beitia et al., 2006b; Falcó et al., 2006). Paralelamente, se está trabajando en la identificación y conservación de depredadores polífagos de C. capitata. Se han citado como depredadores de larvas y pupas a hormigas, carábidos, estafilínidos y arañas, y se ha demostrado el papel importante que desempeñan para el control de C. capitata en campos de cítricos (Urbaneja et al., 2006).

El control biológico contra la mosca mediterránea, por sí solo o en combinación con otras técnicas de manejo integrado, se utiliza satisfactoriamente en Sudamérica, Centroamérica, Australia y en Hawai (USA) (Wong et al., 1991; Headrick y Goeden, 1996; Sivinski, 1996; Bautista et al., 1999). Se prevé que en 
un futuro se pueda desarrollar a escala comercial en la Comunidad Valenciana pero, en la actualidad, solamente se realiza a nivel experimental.

\subsection{TRAMPEO MASIVO}

Este método consiste en la colocación de trampas que contienen sustancias atrayentes para el adulto. Existen diversos atrayentes (sexuales, alimenticios, cromáticos y de forma) y tipos de trampas (Economopoulos, 1989; Llorens, 2002). Actualmente en España la trampa más empleada es la denominada Nadel (Figura 5) con el atrayente sexual trimedlure que atrae únicamente a los machos y que es el más utilizado desde los años 60. En los últimos años se está extendiendo el uso de la trampa Tephri-trap (Figura 6) en combinación con el atrayente alimenticio Tri-pack, que es una mezcla de tres componentes: putrescina, trimetil amina y acetato amónico (Heath et al., 1997). Atrae tanto a machos como a hembras. Las trampas se colocan normalmente en la cara más soleada del árbol y a una altura de 1,5-2 m, donde la presencia de C. capitata es mayor (Fibla et al., 2007).

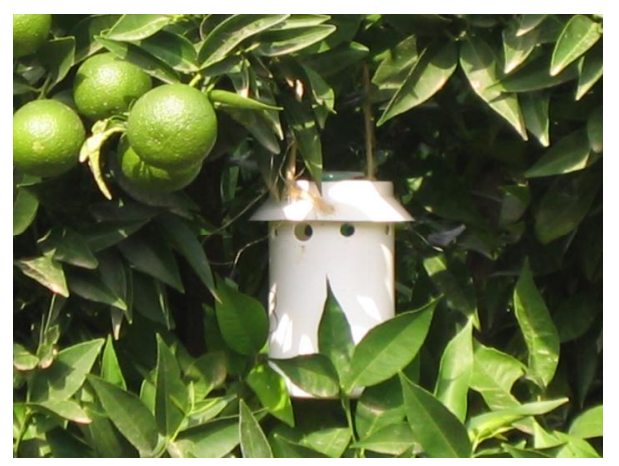

Figura 5. Trampa tipo Nade.l

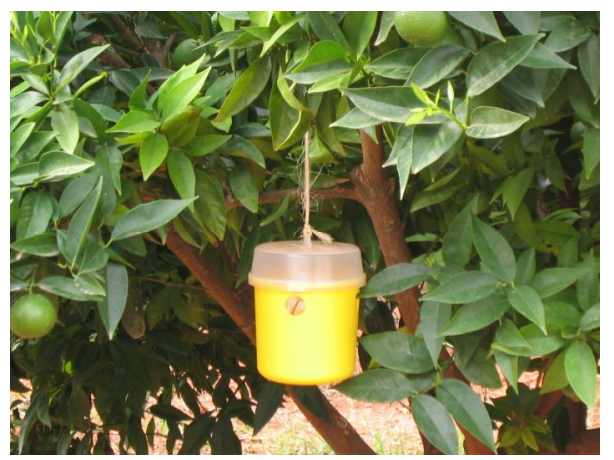

Figura 6. Trampa tipo Tephri-trap.

Dentro de las trampas también se incorporan agentes nocivos para el fitófago. El más utilizado es el insecticida diclorvos en forma de vapona. También se emplean, aunque todavía en fase de experimentación, otros agentes, como esterilizantes (lufenuron), compuestos de acción hormonal o antihormonal, 
y microorganismos entomopatógenos. Estas sustancias se mezclan con el cebo y actúan al ser ingeridos o por contacto.

Las trampas se emplean habitualmente para hacer muestreos y estimar las poblaciones de mosca. También se pueden utilizar masivamente, como un método de control de la plaga. Según Cunningham (1989), el trampeo masivo no consigue reducir con éxito la población de C. capitata. Sin embargo, Fibla et al. (2007) han demostrado que para poblaciones bajas de $C$. capitata $(0,5$ hembras por trampa y día) esta técnica es un buen método de control, mientras que para poblaciones elevadas ( $<2$ hembras por trampa y día) se debe apoyar de tratamientos químicos que disminuyan la población de adultos. Por otra parte, ensayos de trampeo masivo con lufenuron (quimioesterilizante) han demostrado una reducción significativa de la población de $C$. capitata (Casaña-Giner et al., 1999; Navarro-Llopis et al., 2004, 2007).

En la actualidad el trampeo masivo solamente se emplea a pequeña escala, debido fundamentalmente a la alta densidad de trampas que requiere, lo que produce unos costes muy elevados para el productor, no solamente en trampas, insecticidas y atrayentes, sino también en mano de obra.

\subsection{CONTROL QUÍMICO. TENDENCIAS}

La aplicación de productos fitosanitarios contra $C$. capitata se realiza mediante tratamientos aéreos y terrestres. Los tratamientos van dirigidos contra el adulto, ya que es el único estado que queda fácilmente expuesto a las aplicaciones. Los huevos y larvas viven protegidos en el interior del fruto y las pupas enterradas en el suelo.

Los tratamientos contra esta plaga se pueden realizar convencionalmente (mediante cobertura total) o en forma de cebo. En el primer caso, nos referimos a los tratamientos que se basan en pulverizar el producto fitosanitario sobre toda la masa vegetal, intentando alcanzar al objetivo para eliminarlo. El propósito de los tratamientos cebo es diferente. En este caso, se distribuye el insecticida junto con 
un atrayente lo que hace que sea el insecto el que se acerque y entre en contacto con el producto fitosanitario.

La Consellería de Agricultura, Pesca y Alimentación recomienda que las aplicaciones terrestres se realicen como tratamiento cebo cuando los frutos están verdes, y como tratamiento convencional o de cobertura total cuando comienza el viraje de color en los frutos (CAPA, 2001). Se especifica que el tratamiento cebo se realice con proteína hidrolizada y malatión, mientras que el de cobertura total, se realice con unicamente con malatión y a mayor volumen de aplicación.

La combinación de aplicar un cebo y un insecticida conjuntamente para el control de las moscas de la fruta se realiza desde principios del siglo XX. Fue recomendado por primera vez en Sudáfrica por Mally hacia 1908-1909, para el control de la mosca mediterránea, y por Berlese en Italia para el control de la mosca del olivo (Dacus oleae Rossi) (Diptera: Tephritidae). El método fue desarrollado posteriormente por Lounsboury en Sudáfrica en 1912 para el control de C. capitata y por Newman en Australia durante 1913-4 para el control de la mosca de la fruta de Queensland (Bactrocera tryoni (Froggatt) (Diptera: Tephritidae)) (Back y Peberton, 1918).

Por su forma de actuación, en este tipo de tratamientos los volúmenes de caldo que se aplican son bajos. Jones y Skepper (1965) pulverizaron 301 de caldo con malatión y proteína hidrolizada sobre caminos y calles con una mochila para la supresión de la mosca de la fruta de Queensland. Bateman (1978) consiguió un buen control de la misma al aplicar $100 \mathrm{ml}$ de caldo (agua, malatión y proteína hidrolizada) por árbol sobre 50 árboles por hectárea. Para C. capitata empleó $60 \mathrm{ml}$ de caldo por árbol sobre 100-200 árboles por hectárea con buenos resultados.

En España también existen campañas autonómicas de tratamientos aéreos contra $C$. capitata, que consisten en distribuir productos cebo junto con malatión 
desde avionetas. Estos deben complementarse con aplicaciones terrestres realizadas por los agricultores (Primo et al., 2003).

Las formas de tratamiento, sin embargo, van a tener que adaptarse a las nuevas normativas europeas sobre el uso sostenible de los plaguicidas. En la actualidad ya existe una propuesta de la directiva que prohíbe los tratamientos aéreos para limitar el impacto negativo que suponen para la salud humana y el medio ambiente (COM 372 y 373, 2006).

Además, como se ha comentado tres productos organofosforados empleados contra la mosca mediterránea de la fruta (fentión, triclorfón y malatión) se han excluido recientemente del anejo 1 de la directiva 91/414/CEE, relativa a la comercialización y homologación de materias activas plaguicidas en la Unión Europea (De Liñán, 2007). De modo que, los únicos productos que están actualmente autorizados para el control de $C$. capitata en cítricos son: fosmet, lambda-cihalotrin, azadiractina y spinosad. Los dos primeros se han sido aprobados en los últimos años pero presentan limitaciones. Fosmet (organofosforado) tiene un plazo de seguridad de 30 días, lo que es incompatible con las prácticas comerciales actuales. Lambda-cihalotrin es un piretroide que puede dar lugar a desequilibrios biológicos (Urbaneja et al., 2007), por lo que se recomienda únicamente aplicar en pulverización cebo. La azadiractina y el spinosad son insecticidas de origen natural que se encuentra en el registro de manera provisional. Se han desarrollado dando respuesta a la necesidad de buscar alternativas que posean una eficacia similar a la del malatión, pero que sean menos agresivas contra el medio ambiente y la salud humana.

El spinosad es un producto natural resultante de la fermentación de la bacteria actinomicetal, Saccharopolyspora spinosa. En esta fermentación aparecen diversos metabolitos denominados spinosines, siendo los denominados A y D los más activos biológicamente, lo que ha dado lugar al nombre del compuesto (Thompson et al., 1999). Su modo de acción afecta al sistema nervioso, tiene un espectro de actividad variable en los distintos órdenes de 
insectos, y actúa tanto por contacto como por digestión. En condiciones de laboratorio presenta una elevada eficacia en el control de C. capitata (Adán et al., 1996; Stark et al., 2004; Raga y Sato, 2005), y una menor toxicidad y un menor impacto sobre los organismos beneficiosos (Schoonover y Larson, 1995; Williams et al., 2003; Urbaneja et al., 2004; 2007) y el medio ambiente. En condiciones de campo, Burns et al. (2001) evaluaron en parcelas comerciales de cítricos en Florida (USA) tratamientos cebo de spinosad frente a malatión obteniendo el mismo nivel de control de $C$. capitata. Como consecuencia, en los programas de tratamientos cebo en dicho estado, spinosad ha reemplazado al malatión. Este producto también se ha autorizado para combatir $C$. capitata en otros lugares del mundo como México, Brasil, California o Australia (Dow Agrosciences, 2007).

En España este producto se empezó a probar en la campaña 2003-2004 cuando la materia activa formulada junto a un cebo (Spintor Cebo ${ }^{\circledR}$ ) fue aceptada en el registro. Las primeras aplicaciones en cítricos basadas en pulverización cebo a bajo volumen mostraron resultados prometedores en el control de C. capitata (Vergoulas y Torné 2003). Sin embargo, en la Comunidad Valenciana a veces su uso ha dado lugar a la aparición de negrilla sobre la superficie donde se depositan las gotas del producto. En general, este problema se ha producido en parcelas donde la negrilla se encontraba presente antes del tratamiento, asociada a la melaza que producen otras plagas de cítricos como las cochinillas, las moscas blancas, los pulgones, etc. También en ocasiones se han detectado manchas en los frutos en el momento del cambio de color. Dado que estos problemas no han aparecido en Estados Unidos ni en otros países donde se ha ensayado su materia activa spinosad, se puede suponer que se trata de un problema asociado al cebo.

La azadiractina es un componente derivado del árbol del Nim (Azadirachta indica (A. Juss) (Sapindales: Meliaceae)) que se usa para el control de muchos insectos. Actúa como un regulador del crecimiento, interfiriendo en el 
sistema hormonal del insecto y tiene un amplio espectro de actividad. Presenta baja toxicidad para mamíferos y es relativamente seguro para los insectos beneficiosos (Gandhi et al, 1988; Schmutterer, 1990). Estudios sobre los efectos de la azadiractina en la fecundidad y longevidad de $C$. capitata han mostrado una elevada capacidad esterilizante del producto (Di Ilio et al, 1999). No obstante, presenta el inconveniente de que se degrada rápidamente con la radiación UV (Barnby et al., 1989). Según Roessler (1989) y Prokopy y Vargas (1996) su uso sería posible formulado como insecticida cebo mezclado con atrayentes.

En la búsqueda de nuevos insecticidas bioracionales para el control de C. capitata Casaña-Giner et al. (1999) estudiaron la posibilidad del empleo de insecticidas reguladores del desarrollo (IGR's). Compararon en condiciones de laboratorio la eficacia de 10 IGR's como quimioesterilizantes para la mosca mediterránea de la fruta. Los resultados demostraron que el lufenuron presentó mayor actividad esterilizante que los demás. Ensayos posteriores de este IGR en condiciones de campo mostraron una reducción de la población de C. capitata de un 80,4 \% cuando se aplicó mediante pulverización junto a proteínas hidrolizadas, y de un 77,6\% cuando se aplicó mediante trampeo masivo en forma de gel junto a proteínas hidrolizadas (Navarro-Llopis et al., 2004). Además, determinaron la duración de la actividad del lufenuron: 2 semanas cuando fue pulverizado y 3 meses en forma de gel en el interior de trampas. Actualmente el lufenuron también está aceptado para el control de $C$. capitata, pero su uso está limitado al trampeo.

También se han desarrollado insecticidas fototóxicos. Particularmente para el control de $C$. capitata se ha estado investigando el ingrediente activo Phloxine B, que es un colorante fotoactivo derivado del Xanteno. La acción insecticida se produce cuando el insecto ingiere el colorante y se expone a la luz, ya que el colorante se oxida dentro de los tejidos del insecto y le causa la muerte. Por tanto, para ser eficaz el producto debe ser ingerido, de ahí que se formule como cebo. En laboratorio ha demostrado ser tóxico para ciertas especies de 
insectos incluyendo la mosca doméstica, Musca domestica (Linnaeus) (Diptera: Muscidae), C. capitata, y otras especies de la familia Tephritidae (Fondren y Heitz, 1978; Heitz, 1995; Liquido et al., 1995; Schroder et al. 1998). Ensayos en condiciones de campo, realizados para estudiar la eficacia de este producto contra la mosca mediterránea de la fruta, han obtenido resultados satisfactorios (Peck y Mcquate, 2000; Moreno et al., 2001; Vargas et al., 2001).

Asimismo se ha demostrado el efecto insecticida de algunos componentes químicos extraídos de Cestrum parqui (L'Herit) (Solanales: Solanaceae) sobre C. capitata (Zapata et al., 2006).

Además se han evaluado sustancias derivadas de microorganismos. Metabolitos secundarios secretados por el hongo Mucor hiemalis (Wehmer) (Mucorales: Mucoraceae) resultaron tóxicos para adultos de la mosca del olivo y para la mosca mediterránea de la fruta (Konstantopoulou y Mazomenos, 2005; Konstantopoulou et al., 2006).

\subsection{LA ELIMINACIÓN DE LA FRUTA}

La destrucción de frutos atacados y la eliminación de árboles reservorio son prácticas culturales tradicionales en la lucha contra la mosca mediterránea de la fruta. Se ha observado en los últimos años en el área citrícola española que, tras el abandono de muchos huertos, debido a la caída de los precios, se han producido fuertes aumentos de la población de la mosca con el consecuente incremento de frutos picados.

La recolección y posterior enterrado de la fruta caída y madura del árbol que no se vaya a comercializar es una práctica recomendable para disminuir la población de moscas (CAPA, 2001). Por un lado, se eliminan frutos larvados, y por otro, se evita que las hembras grávidas encuentren un lugar donde poner los huevos. 



\section{Capítulo II. MOTIVACIÓN Y OBJETIVOS GENERALES DE LA TESIS}

\section{MOTIVACIÓN}

La presencia de $C$. capitata en la citricultura española tienen una gran repercusión económica ya que, además de los daños que produce sobre los frutos, los costes destinados a su control son muy elevados. Actualmente el método de control más eficaz para combatir este insecto se basa en la aplicación de productos organofosforados, básicamente malation. Sin embargo, su uso está cuestionado por la creciente preocupación por el medio ambiente y la salud humana a nivel mundial. De hecho, como se ha indicado, en la Unión Europea se ha restringido el uso de los organofosforados más eficaces y se ha limitado a unos pocos el número de productos autorizados contra $C$. capitata.

La restricción de productos y la necesidad de realizar las aplicaciones siguiendo una estrategia que sea compatible con el medio ambiente, aumenta la necesidad de evitar los tratamientos de cobertura total y apostar por los tratamientos cebo de bajo volumen y el empleo de nuevos productos insecticidas.

La mosca mediterránea de la fruta es una plaga en la que los tratamientos cebo son especialmente interesantes. En los estados con poca movilidad (huevo, larva y pupa) el insecto está protegido por el fruto o por el suelo, por lo que es difícil acceder a él con sustancias insecticidas. Sin embargo, en el estado adulto, la plaga es muy móvil y puede desplazarse con facilidad hacia el atrayente. No hay, por lo tanto que alcanzar las zonas a las se llega con dificultad en un tratamiento convencional.

Sin embargo, las máquinas para la distribución de productos fitosanitarios que se emplean hoy en día no están adaptadas para las aplicaciones de tratamientos cebo debido a que están diseñadas para realizar tratamientos de cobertura total. Los primeros requieren gotas de gran tamaño (varios $\mathrm{mm}$ ) y se 
aplican bajos volúmenes de caldo (decenas de 1/ha), mientras que en los segundos se distribuyen altos volúmenes (miles de 1/ha), con gotas de pequeño tamaño (200-500 $\mu \mathrm{m})$. Por estos motivos, actualmente los tratamientos cebo a bajo volumen solo se aplican con pulverizadores hidráulicos manuales, principalmente mochilas individuales, lo que supone un elevado coste y el aumento del tiempo necesario para realizar las aplicaciones y de los riesgos para la salud de los operarios.

En la estrategia de lucha contra C. capitata la eliminación de los frutos que quedan tras la cosecha y que pueden ser reservorio de mosca ha sido recomendada como una buena práctica para reducir las poblaciones. El inconveniente principal del proceso de eliminación de fruta es que no existen máquinas específicas para realizar la operación. Aunque tradicionalmente ésta se realizaba de manera manual, recogiendo y enterrando la fruta, es evidente que el método es inviable en la citricultura moderna, pues genera unos costes muy elevados.

\section{OBJETIVOS GENERALES DE LA TESIS}

Como consecuencia de lo anteriormente expuesto, tanto los tratamientos cebo a bajo volumen, como la eliminación de la fruta que queda tras la cosecha son métodos convenientes de lucha contra la mosca mediterránea de la fruta, que resultan muy adecuados desde el punto de vista medioambiental y de la disminución de los riesgos sobre la salud humana.

Pese a ello, se trata de métodos que no son viables económicamente tal y como se realizan en la actualidad. Esta tesis pretende aportar conocimientos y soluciones con el objetivo de que estas dos tareas puedan ser mecanizadas y, como consecuencia de ello, se puedan realizar de una manera adecuada y eficiente en la citricultura española. 
Capítulo II. Motivación y objetivos generales de la tesis

Debido a que ambos estudios son muy diferentes, la tesis se ha estructurado en dos partes, y se describe en cada una de ellas los objetivos particulares del trabajo de una manera más detallada. 



\section{Capítulo III. MECANIZACIÓN DE LOS TRATAMIENTOS CEBO A BAJO VOLUMEN}

\section{INTRODUCCIÓN: PARTICULARIDADES DE LOS TRATAMIENTOS CEBO FRENTE A LOS CONVENCIONALES}

Como hemos comentado anteriormente, los tratamientos contra C. capitata se pueden realizar mediante cobertura convencional o en forma de cebo. El propósito de los tratamientos cebo es distribuir el insecticida junto con un atrayente, para que el insecto entre en contacto con el producto fitosanitario. En el caso de $C$. capitata se utilizan atrayentes alimenticios (proteínas hidrolizadas, azúcares...), que contienen nutrientes esenciales para el desarrollo sexual, tanto de los machos como de hembras. Al ingerir el atrayente, el individuo también ingiere el insecticida, lo que acaba por ocasionarle la muerte.

En los tratamientos convencionales de cobertura, la probabilidad de alcanzar al fitófago aumenta conforme lo hace la superficie mojada del árbol, por lo que requieren un buen recubrimiento foliar para que sean efectivos. Para ello, es necesario utilizar grandes volúmenes de caldo, con la finalidad de mojar todas las partes del árbol, incluso las zonas internas, lo cual es muy difícil de conseguir en árboles de forma globosa y follaje denso como son los cítricos. Sobre el recubrimiento que se consigue sobre la planta influye, entre otros factores, el tamaño de las gotas pulverizadas: éste no debe ser excesivamente pequeño, para evitar la generación de deriva, ni demasiado grande, de modo que las gotas no alcancen las zonas más altas de los árboles o tiendan a escurrir (Reichard et al., 1978). Normalmente se recomienda que el diámetro volumétrico mediano de las gotas producidas esté entre 200 y $500 \mu \mathrm{m}$ (DOGV, 2001). 
La aplicación de productos fitosanitarios es una de las operaciones de mayor coste en un cultivo y, en general, los tratamientos convencionales de cobertura son operaciones con un bajo nivel de eficiencia, ya que se suelen producir importantes pérdidas por deriva atmosférica o por deposición fuera del objetivo. En cultivos arbóreos son habituales niveles de pérdidas superiores al 60-70\%, lo que da lugar a importantes costes económicos, medio ambientales y sanitarios (Planas, 2001). Por otra parte, este tipo de tratamientos no son selectivos, de modo que afectan a organismos para los que no están dirigidos, por lo que pueden producir desequilibrios en el ecosistema.

Como en los tratamientos cebo el objetivo es atraer a la mosca hacia el insecticida, su eficacia no depende tanto del recubrimiento foliar. En este caso, se trata de pulverizar el producto creando pequeños depósitos sobre la vegetación, que actúen como trampas. Por ello, no es necesario aplicarlo sobre toda la copa de los árboles, ni penetrar en el interior de la copa. Es suficiente con depositar una cierta cantidad de gotas en las zonas de la cubierta vegetal a las que C. capitata acceda fácilmente, como es el exterior de la copa y la cara más soleada de los árboles. Además, el producto se puede aplicar en forma de parcheo, es decir, de manera intermitente sobre los diferentes árboles de una parcela. En general, estos tratamientos cebo necesitan tamaños de gotas más grandes (1-6 mm) que los tratamientos convencionales, con el fin de aumentar la permanencia del producto sobre el árbol.

La forma en que se aplican los tratamientos cebo permite una importante reducción de los volúmenes de caldo y, por tanto, una disminución de las pérdidas por deriva. Además, presenta la ventaja de ser una aplicación más selectiva que las de cobertura total, reduciendo el impacto sobre los organismos beneficiosos y aquellos que no son el objetivo del tratamiento. Otra ventaja es que la cantidad de insecticida que se aplica sobre los frutos es menor, lo que disminuye el nivel de residuos. 
Para dar una idea de las diferencias de volumen entre los tratamientos cebo y los convencionales, indicar que la Generalitat Valenciana recomienda que en las aplicaciones terrestres de los tratamientos en forma de cebo se emplee un volumen de caldo de 60-120 1/ha, con una dosis de 0,6 \% de malatión $50 \%$ como insecticida y de $0,6 \%$ de proteína hidrolizada como cebo. Para el tratamiento de cobertura total, se recomienda emplear caldos con el $0,2 \%$ de malatión a razón de 5-7 1 por árbol (aproximadamente 2.000-2.800 1/ha).

Sin embargo, en la práctica, los volúmenes de caldo aplicados por los agricultores no coinciden con los recomendados. En los tratamientos cebo se llegan a emplear volúmenes de caldo de hasta 500 1/ha. Esto se debe a que los agricultores no están acostumbrados a aplicar volúmenes tan bajos para tratamientos foliares y desconfían de su eficacia. Además, los agricultores evitan realizar los tratamientos con pulverizadores manuales, que son los únicos dispositivos en el mercado que actualmente permiten aplicar estos bajos volúmenes. De este modo los agricultores realizan la aplicación cebo como si fuera un tratamiento convencional, pero sólo pulverizando en una cara del árbol y con la adición del cebo al caldo. Por el contrario, en los tratamientos de cobertura total, aplican volúmenes de alrededor de 1.000 1/ha, que son inferiores a los recomendados.

\section{JUSTIFICACIÓN Y OBJETIVOS}

El propósito de los tratamientos cebo es crear pequeños depósitos del producto sobre la masa vegetal que actúen como trampas atrayendo al insecto. Los volúmenes de caldo son bajos (20-100 1/ha) y los depósitos deben de caracterizarse por tener un tamaño de varios mm para que aumente la remanencia del producto y su poder de atracción. Una solución para mecanizar esta operación se basa en el diseño de un equipo de aplicación automático que cumpla con dichos requerimientos. 
Actualmente los dispositivos de pulverización que existen en el mercado no producen gotas del tamaño indicado. No obstante, es posible que se puedan alcanzar dichos tamaños modificando sus condiciones de trabajo.

Asimismo, hoy en día se dispone de tecnología cuya aplicación sobre equipos acoplados a tractor permite limitar las necesidades de mano de obra y mejorar la eficiencia de las operaciones, lo que proporcionaría una solución para mecanizar la aplicación de tratamientos cebo a bajo volumen.

Por otro lado, el diseño de una máquina sin la valoración de su eficacia haría incompleta esta tesis. No obstante, para evaluar de la eficacia de control de tratamientos contra $C$. capitata en campo no existe un método estandarizado para realizar los ensayos y analizar sus resultados, por lo que es necesario hacer propuestas en este sentido.

La eficacia de un tratamiento fitosanitario depende, además de la forma de aplicación y de otros factores externos, del producto que se emplee. Entre los productos alternativos al malation y autorizados en cítricos contra $C$. capitata destaca Spintor Cebo ${ }^{\circledR}$, por sus características ecotoxicológicas y su eficacia contra esta plaga. Dado que en la Comunidad Valenciana tras su uso se han detectado a veces problemas de negrilla y de manchas sobre los frutos, y que estos problemas parecen estar relacionados con el cebo, parece interesante ensayar formulados que tengan la misma sustancia activa pero otros atrayentes.

Como consecuencia a lo anteriormente expuesto, este capítulo de la tesis tiene por objetivos:

1) Encontrar un dispositivo de pulverización y las condiciones de trabajo que proporcionen el tamaño de impacto deseado (1-6 mm).

2) Diseñar un sistema automático de control que permita:

- Mecanizar la aplicación de tratamientos cebo a bajo volumen. 
- Adaptar el equipo a las diferentes situaciones que se encuentran en la vegetación de las plantaciones de cítricos, es decir, continuidad y discontinuidad entre las copas de los árboles.

3) Evaluar el funcionamiento del prototipo en condiciones de campo desde el punto de vista mecánico y electrónico.

4) Elaborar una metodología de ensayo para estudiar la eficacia de control de la mosca mediterránea de la fruta de tratamientos en condiciones de campo.

5) Evaluar la eficacia de diferentes tratamientos cebo a bajo volumen realizados con el prototipo.

\section{ORGANIZACIÓN DEL CAPÍTULO}

Como ya se ha indicado, se hace necesaria la investigación en la mecanización de los tratamientos cebo. Sin embargo, no existen antecedentes sobre la existencia de equipos automáticos adecuados para la aplicación de los tratamientos cebo a bajo volumen.

Antes de diseñar un equipo es recomendable tener conocimiento del estado de la técnica para conocer las posibles alternativas de las que se dispone, lo que ayuda a tomar decisiones sobre qué técnicas, tecnologías o métodos son más adecuados para conseguir el objetivo planteado. Por ese motivo, en el apartado 4 de este capítulo se describen:

- Los diferentes mecanismos que existen para la producción de gotas en los equipos de pulverización y sus posibles aplicaciones

- Los métodos que se encuentran en la literatura científica para caracterizar la pulverización.

- Los antecedentes referentes a la aplicación de automatismos en las máquinas de distribución de productos fitosanitarios. 
- Los métodos que existen para evaluar la calidad de un tratamiento.

Posteriormente, en el apartado 5 comienza la descripción del trabajo directamente relacionado con el objeto del capítulo, empezando con la selección del dispositivo con el que se realizará la pulverización. Seguidamente, en el apartado 6, se hace una descripción de la parte electrónica de control de la máquina que se propone y de sus funcionalidades.

Una vez diseñada la máquina, el siguiente paso es evaluar la calidad de su tratamiento. Los ensayos realizados se describen en el apartado 7. Por último, en el apartado 8 se describen los diferentes ensayos que se han realizado para comprobar la eficacia de la máquina en condiciones reales.

\section{ANTECEDENTES}

\subsection{LA FORMACIÓN DE LAS GOTAS EN LAS MÁQUINAS DE TRATAMIENTOS FITOSANITARIOS}

En los tratamientos cebo se requiere que el producto se distribuya en forma de depósitos grandes (del orden de varios milímetros), para favorecer la persistencia sobre la planta y conseguir un mayor poder de atracción del producto. No olvidemos que se trata de atraer al insecto hacia el insecticida y no de acercar el producto a una plaga poco móvil, por lo que no se necesita un gran recubrimiento ni penetrar mucho dentro de la copa de los árboles, sino localizar el atrayente en lugares adecuados.

El conocimiento de los mecanismos de formación de las gotas es la base para determinar como se puede conseguir este propósito. A continuación, se describen los tres mecanismos de pulverización para la formación de gotas: corriente de aire, presión del líquido y fuerza centrífuga, lo que da lugar, respectivamente, a la pulverización neumática, la hidráulica y la centrífuga.

En la pulverización neumática la formación de gotas se produce por el choque de una corriente de aire con la vena líquida que por gravedad o a baja 
presión sale por unos orificios. Esta corriente de aire es además la encargada de transportar las gotas hasta el objetivo. El tamaño de las gotas depende del caudal de aire, de su velocidad, del caudal de líquido, así como de las propiedades del propio líquido. Se caracteriza por producir poblaciones de gotas bastante homogéneas, con un tamaño expresado en diámetro volumétrico medio (concepto definido más adelante) que oscila entre 50 y $150 \mu \mathrm{m}$ en las aplicaciones agrícolas (Ortiz-Cañavate y Hernanz, 1989). Una disminución del caudal y de la velocidad del aire puede aumentar los tamaños de gota pero influirá en el alcance de éstas ya que la corriente de aire es también la encargada de transportarlas.

En la pulverización hidráulica la formación de las gotas se consigue cuando el líquido, impulsado a una determinada presión, atraviesa una pequeña sección de una tobera en contacto con el ambiente. La resistencia que opone la tobera a la penetración de la vena líquida genera su fragmentación en gotas, a la vez que estas adquieren la energía necesaria para su transporte. El dispositivo encargado de la fragmentación es la boquilla de pulverización. El tamaño de las gotas depende del tipo de boquilla, de su sección de salida y de la presión, además, de las características intrínsecas del líquido a pulverizar. Se consiguen valores de tamaño de gota mayores que con la pulverización neumática. Los diámetros volumétricos medios que se aplican en la distribución convencional de productos fitosanitarios varían entre 100 y $1000 \mu \mathrm{m}$, pero podrían aumentarse utilizando presiones más bajas, lo que conlleva igualmente una reducción del alcance.

En la pulverización centrífuga la formación de gotas se logra gracias a la fuerza centrífuga a la que es sometida una capa de líquido en la periferia de un disco que gira. El tamaño de las gotas depende de la velocidad del disco, de su diámetro, del caudal, además, de la densidad y tensión superficial del líquido a pulverizar. En el sector agrícola los discos suelen trabajan a altas velocidades de giro, lo que produce gotas muy pequeñas $(50-300 \mu \mathrm{m})$. No obstante, se puede 
aumentar el tamaño de las mismas si se disminuye el régimen de giro del disco y se aumenta del caudal de líquido.

\subsection{CARACTERIZACIÓN DE UNA PULVERIZACIÓN}

La pulverización de un líquido genera una población de gotas de distintos tamaños. Cuando éstas se depositan sobre una superficie producen a su vez una población de impactos con tamaños diferentes. Cuando se desea caracterizar la deposición generada por una pulverización carece de interés el estudio de las gotas en el aire y se estudia la distribución de los tamaños los impactos producidos.

\subsubsection{La distribución de las poblaciones de impactos: Medidas de tamaño}

En general, las gotas que se producen por cualquiera de los métodos antes descritos, al encontrarse en el aire presentan formas más o menos esféricas, por lo que su tamaño puede expresarse a través del diámetro de la esfera que se forma. Sin embargo, cuando las gotas chocan contra una superficie crean impactos que pueden ser bastante irregulares y cuya forma y tamaño depende tanto de las características del líquido como de la superficie sobre la que se forman. Brittain (2001) hace referencia a las diferentes aproximaciones utilizadas en la literatura para describir el tamaño de los impactos producidos:

- Diámetro de perímetro: Al impacto se le asigna el diámetro de una circunferencia con el mismo perímetro que el borde proyectado del impacto.

- Diámetro del área proyectado: Al impacto se le asigna el diámetro de un círculo cuya superficie coincide con el área del impacto.

- Diámetro de volumen: Al impacto se le asigna el diámetro de una esfera que tiene el mismo volumen que el que se estima al impacto. 
- Diámetro de Feret: Es la longitud del segmento que une dos puntos del perímetro pasando por el centroide del impacto. Normalmente se emplea la distancia media como diámetro asignado al impacto.

- Diámetro de Martín: Es la longitud del segmento que divide el área proyectada de un impacto en dos áreas proyectadas iguales.

Al igual que en los estudios de las distribuciones de los tamaños de las gotas en el aire, en los estudios para caracterizar los impactos se suele recurrir a expresiones matemáticas que dependen de, al menos, dos parámetros: uno relacionado con la medida del tamaño más representativo y otro que se refiere a la amplitud del intervalo de los tamaños más frecuentes.

El tamaño representativo que más se utiliza en la literatura es el diámetro volumétrico $\left(D_{\mathrm{x}}\right)$. Este parámetro expresa el tamaño de la gota o del impacto en relación con el volumen del líquido pulverizado. Se define como el diámetro a partir del cual el " $\mathrm{x}$ " \% del volumen total pulverizado se presenta en gotas $\mathrm{o}$ impactos de menor diámetro. Por ejemplo, el diámetro volumétrico mediano $\left(\mathrm{D}_{50}\right)$ es el diámetro de gota o impacto de una población donde el $50 \%$ del volumen total presenta gotas o impactos con un diámetro menor.

Para caracterizar la población de los tamaños de las gotas o de los impactos producidos por una pulverización, se suele recurrir a funciones de distribución de frecuencias, en las que la ordenada es el número de gotas o impactos o el porcentaje frente al total y la abscisa es el tamaño (Lefebvre, 1989). También hay otras maneras de representar la población como, por ejemplo, mediante curvas en las que las ordenadas pueden ser el área de los impactos, el volumen o la masa y las abscisas pueden ser el diámetro, el área o el volumen estimados (Verheijen, 2001).

Las representaciones gráficas de las distribuciones de tamaños son laboriosas y según Lefebvre (1993) no se relacionan fácilmente con los resultados de los experimentos, lo que ha llevado a muchos matemáticos a 
reemplazarlas por expresiones matemáticas. Según el mismo autor estas expresiones matemáticas deberían tener los siguientes atributos:

- Suministrar un ajuste satisfactorio a los datos experimentales.

- Facilitar el cálculo de tamaños medios y tamaños representativos de los impactos y otros parámetros de interés.

- Proporcionar una forma sencilla de consolidar grandes cantidades de datos.

- Idealmente, suministrar alguna idea sobre los mecanismos involucrados en la pulverización.

Actualmente exiten un amplio abanico de funciones basadas en la probabilidad o en consideraciones empíricas, tales como las distribuciones: Normal, Log Normal, Nukiyama-Tanasawa, Rosin-Rammler, Valores extremos, etc. Puesto que ninguna función de distribución puede representar todos los tamaños de gotas o impactos, normalmente es necesario probar varias de estas funciones hasta encontrar la que mejor se ajusta al conjunto de datos experimentales.

Debido a las pruebas de ajuste de las diferentes funciones de distribución realizadas en el presente trabajo y dada las aplicaciones de las distribuciones en trabajos similares, en esta revisión se incluyen la distribución Log Normal y la distribución Rosin-Rammler.

A continuación se expresa la ecuación que describe la función Log Normal de densidad (Ecuación 1) y acumulada (Ecuación 2). 
$f(D)=\frac{1}{D \sqrt{2 \pi} \ln \sigma_{g}} \exp \left[-\left(\frac{\ln \left(\frac{D}{\overline{D_{g}}}\right)}{\sqrt{2} \ln \sigma_{g}}\right)^{2}\right]$

Ecuación 1

$F(D)=\frac{1}{2}\left[1+\operatorname{erf}\left(\frac{\ln \left(\frac{D}{\overline{D_{g}}}\right)}{\sqrt{2} \ln \sigma_{g}}\right)\right]$

Ecuación 2

Donde:

- $\quad \sigma_{\mathrm{g}}$ es la desviación geométrica estándar.

- $\quad D_{g}$ es el parámetro de escala de la función. Se llama media geométrica, y coincide con el valor de la mediana.

- $\quad$ erf (z) es una función de error (Ecuación 3). Dado que esta función no es fácil de evaluar, se usó una aproximación numérica (Ecuación 4) en la que $\mathrm{b}=1 /(1+0,33 \mathrm{z})$ (Abramowitz y Stegun, 1964).

$\operatorname{erf}(z)=\frac{2}{\sqrt{\pi}} \int_{0}^{z} e^{-s^{2}} d s$

Ecuación 3

$\operatorname{erf}(z)=1-\left(0,25 b-0,28 b^{2}+1,42 b^{3}-1,45 b^{4}+1,06 b^{5}\right) e^{-z^{2}}$

Ecuación 4

La función Rosin-Rammler de densidad y acumulada se expresa según la Ecuación 5 y la Ecuación 6 respectivamente.

$f(D)=\frac{Q}{X}\left(\frac{D}{X}\right)^{Q-1} \exp \left(-\left(\frac{D}{X}\right)^{Q}\right)$

Ecuación 5 


$$
F(D)=1-\exp \left(-\left(\frac{D}{X}\right)^{Q}\right)
$$

Donde:

- X es el parámetro de escala de la función, o el diámetro volumétrico $63,2 \%\left(\mathrm{D}_{63,2}\right)$.

- Q es el parámetro de forma de la función. Q es una medida de la dispersión de los tamaños, así, cuanto más grande es el valor de Q, más uniforme es el tamaño de los impactos (Lefebvre, 1989). Normalmente Q varía entre 1,5 y 4 aunque puede llegar a 7 con pulverizadores centrífugos.

Estas funciones se han utilizado en diferentes trabajos para representar las distribuciones de tamaños de gotas o impactos de una pulverización. Castillo (2005) las empleó para describir las poblaciones de impactos producidas por aceites minerales en condiciones de laboratorio. La función de Rosin-Rammler se ha usado como modelo para las bases de datos de programas recomendados para estimar la deriva en diversos tipos de aplicaciones de agroquímicos (Teske y Thisle, 2000). También para modelizar las distribuciones de tamaños de gota en flujos de emulsiones aceite-agua (Angeli y Hewitt, 2000). Además, Beck y Watkins (2003) afirman que la distribución volumétrica de Rosin-Rammler es comúnmente aplicada en pulverizadores, particularmente de combustible diesel con boquillas de cono sólido.

\subsubsection{Métodos para caracterizar la pulverización}

Para caracterizar las gotas producidas por una pulverización mientras viajan por el aire, se han empleado técnicas tan dispares como las basadas en fotografías a alta velocidad, las técnicas holográficas o las técnicas basadas en la atenuación de luz o en su difracción, empleando diferentes tipos de láser, así como técnicas basadas en espectrómetros ópticos. 
Estos métodos se han empleado principalmente para la caracterización de las poblaciones de gotas producidas por las boquillas y para la estimación de la posible deriva que podrían tener dichas gotas (Lake, 1979; Young, 1991; Lund, 1994; Lund y Matzen, 1996).

Sin embargo, como los impactos se estudian sobre una superficie, las técnicas utilizadas más comúnmente en la literatura para caracterizar sus poblaciones se basan en el análisis de imágenes. Algunos de los trabajos en los que se emplean estas técnicas son los de Salyani y Fox, (1999) Jiang y Derksen (1995), Ade y Fabbri (2000), Degré et al. (2001), Cerruto (2001) y Holownicki et al. (2002).

No hemos de olvidar que las características morfológicas de los impactos dependen de la superficie que los recibe, además de otros factores como la viscosidad del fluido, la tensión superficial, la temperatura, etc. (Bateman, 1993). El estudio de los impactos directamente sobre las hojas presenta dificultades adicionales a la hora de manipularlas (se doblan, se arrugan, si se trabaja en laboratorio hay que defoliar el árbol, etc.) Además, el hecho de que la superficie de la hoja no sea plana puede dar lugar a medidas incorrectas. Por lo tanto, en muchos estudios se utilizan colectores artificiales, más fáciles de manejar, como pueden ser diferentes películas con recubrimientos especiales (óxido de magnesio), papeles brillantes, papeles sensibles (sobre todo al agua y al aceite), medios líquidos (normalmente aceites viscosos), etc.

Así pues, es importante elegir el colector adecuado para que los impactos producidos se asemejen lo más posible a los que se producen sobre las hojas reales. Palacios (1993) realizó un estudio en el que comparó las deposiciones producidas sobre diferentes colectores artificiales (láminas de policloruro de vinilo recubiertas con una fina capa de silicona, papeles hidrosensibles y placas Petri con dos capas de silicona de diferentes densidades superpuestas) con las deposiciones sobre el haz y el envés de las hojas de los cítricos. Concluyó que los impactos formados sobre láminas de PVC recubiertas con una fina capa de 
silicona son los que más se asemejan a los que se forman sobre las hojas de los cítricos.

\subsection{APLICACIÓN DE AUTOMATISMOS PARA CONTROLAR LA DISTRIBUCIÓN DEL PRODUCTO FITOSANITARIO EN LOS EQUIPOS ACTUALES}

Como se ha comentado anteriormente, los tratamientos cebo se realizan sobre zonas concretas de los árboles, a menudo en forma de parcheo. Para hacer una aplicación localizada con una máquina, en la actualidad se recurre al empleo de automatismos controlados electrónicamente. En este apartado se hace una revisión de los sistemas que se han desarrollado en los últimos años con este propósito.

La incorporación de automatismos en los equipos para la distribución de productos fitosanitarios comenzó en los años 80. Los objetivos que se persiguen normalmente son disminuir el impacto medioambiental de los tratamientos, mejorar la eficacia y aumentar la uniformidad de la distribución de las aplicaciones. Para ello se diseñan, entre otros, sistemas para adaptar el caudal aplicado en función de la velocidad de avance de la máquina, sensores que detectan la vegetación para aplicar el tratamiento localizadamente o sensores que permiten conocer la cantidad de vegetación que hay que tratar en cada instante. En este apartado se presentan algunos ejemplos, clasificados en función de los objetivos que se pretenden conseguir.

\subsubsection{Aplicaciones homogéneas por unidad de superficie}

Las primeras incorporaciones de la electrónica a las máquinas de distribución de productos fitosanitarios tuvieron como finalidad aumentar la uniformidad de los tratamientos en toda la superficie de la parcela y se aplicaron en cultivos herbáceos extensivos. 
Rudolph (1983) diseñó un equipo que regulaba electrónicamente el caudal por unidad de superficie tratada. Para el control de la velocidad utilizó un sensor de velocidad de radar, y un microprocesador, el cual accionaba una válvula de mariposa que controlaba la dosis. Reichard et al. (1982) construyeron un prototipo que presentaba la ventaja de mezclar el producto fitosanitario con el agua en el momento de la aplicación y que ajustaba la concentración del producto en función de la variación de la velocidad de avance. Un tacómetro acoplado a la rueda medía la velocidad de avance y una bomba dosificadora mezclaba el producto y el agua que estaban almacenadaos en dos depósitos independientes. Ghate y Perry (1994) desarrollaron un equipo para cultivos hortícolas que regulaba la cantidad de materia activa en función de la velocidad de avance medida con un sensor de radar de efecto Doppler. Mediante un dosificador se inyectaba directamente el producto fitosanitario en la tubería de distribución del mismo.

\subsubsection{Aplicación localizada: Detección de la planta}

En estos trabajos, el objetivo es detectar la planta para evitar pulverizar en ausencia de las mismas, con el ahorro de producto y la minimización del impacto ambiental que esto supone. Inicialmente, se utilizaron dispositivos mecánicos, como el descrito por Ladd et al. (1978) que se basaba en un alambre de acero para detectar el árbol. Con este equipo se consiguió un control de la plaga similar al de los tratamientos tradicionales y un ahorro de volumen aplicado de un $31 \%$. Posteriormente, los dispositivos mecánicos se sustituyeron por sensores de infrarrojos que actuaban sobre válvulas de solenoide. Ladd y Reichard (1980) utilizaron un sistema electrónico basado en sensor de infrarrojos en cultivos hortícolas, reduciendo, en función del marco de plantación, entre un $24 \%$ y un $51 \%$ la cantidad de producto empleado. En cultivos arbóreos, Porras et al. (1986) desarrollaron un equipo que utilizaba un emisor de luz infrarroja y producía un haz continuo. Cuando la luz se reflejaba en el follaje y era captada por un receptor, éste actuaba sobre una electroválvula que enviaba el producto a 
las boquillas. Ensayos en olivos permitieron un ahorro de entre un $39 \%$ y un $62 \%$ del caldo.

Una alternativa robusta y eficiente se basa en los sensores de ultrasonidos. Balsari y Tamagnone $(1997,1998)$ desarrollaron un prototipo que distribuye el producto solo en presencia del árbol y en función de la altura del mismo. Para ello, emplearon 6 sensores de ultrasonidos, tres a cada lado del equipo, de modo que, cada sensor actuaba sobre la apertura o cierre de una electroválvula que controlaba un sector en altura. Moltó et al. (2000) desarrollaron un equipo que detectaba la presencia del árbol y la distancia a la que se encontraba con un sensor de ultrasonidos, de modo que, una barra de pulverización se acercaba o alejaba del árbol, consiguiendo pulverizar siempre a la misma distancia de la copa.

También se han empleado sistemas de visión artificial para detectar la planta (Giles y Slaughter, 1997) y sistemas ópticos basados en sensores que emiten luz a diferentes longitudes de onda (Doruchowski et al., 1998).

\subsubsection{Adaptación de la aplicación al volumen de la vegetación detectado}

El objetivo de los sistemas que se describen en este apartado no es solo detectar la presencia o ausencia de vegetación, sino estimar el volumen de la misma, con el fin de adaptar instantáneamente el volumen pulverizado a la masa foliar con que se enfrenta la máquina.

McConell et al. (1983) utilizaron un equipo que está formado por una barra vertical con sensores de ultrasonidos a varias alturas para medir el tamaño del árbol y ajustar el volumen que se aplicaba. Giles et al. (1988) usaron sensores de ultrasonidos para obtener información sobre la geometría del árbol. Tres sensores a cada lado del equipo, a distintas alturas, enviaban la información, que se procesaba mediante un algoritmo de control que determinaba la actuación o no sobre electroválvulas que controlaban diferentes boquillas. 
Rosell et al. (1996) relacionan la distancia medida por el sensor de ultrasonidos con el volumen que se aplica. Moltó et al. (2001) detectaban el volumen del árbol en función de la distancia medida por el sensor de ultrasonidos y ajustaban el caldo pulverizado según hubiera mayor o menor follaje en el árbol. Solanelles et al. (2002) desarrollaron un prototipo compuesto por sensores de ultrasonidos y electroválvulas, en el que el volumen pulverizado se ajustaba al tamaño del árbol, según la relación entre la anchura del árbol medido por el sensor de ultrasonidos respecto al árbol de mayor anchura del cultivo.

El LIDAR (Laser Imaging Detection and Ranking) es otro sensor que se ha empleado para proporcionar información volumétrica sobre el cultivo. Walklate et al. (2002) utilizaron mapas tridimensionales del cultivo proporcionados por el LIDAR con el objetivo de modelizar la deposición de diferentes volúmenes de aplicación en manzanos. Sanz et al. (2005) utilizaron el LIDAR en plantaciones de manzano, de peral, de vid y de cítricos con el fin de utilizarlo en tiempo real para optimizar la aplicación de productos fitosanitarios. En la actualidad, el inconveniente de esta tecnología es su elevado precio.

\subsection{EVALUACIÓN DE LA CALIDAD DE UN TRATAMIENTO}

En general, una vez diseñado un prototipo, se realizan ensayos de campo o de laboratorio para evaluar la calidad del tratamiento que se puede realizar con la nueva máquina.

Se considera que la eficacia de un tratamiento sobre un cultivo está influida por:

- Factores físicos propios de la pulverización, como el volumen de caldo por unidad de superficie, y las características del caldo pulverizado (tensión superficial, viscosidad, etc.) lo que produce un recubrimiento y una población de impactos. 
- Factores biológicos, como el desarrollo de la plaga o de la mala hierba, el tipo de cultivo a proteger y su estado vegetativo, la eficacia biocida de la materia activa empleada, etc.

- Factores medioambientales, como la temperatura, la velocidad y dirección del viento, la humedad relativa, etc., que influyen sobre los fenómenos de deriva, evaporación y deposición del producto y que afectan también a la biología de la plaga.

La calidad de un tratamiento se suele evaluar a través de métodos que estudian la distribución del volumen de caldo pulverizado sobre la cubierta vegetal, o bien a través de métodos que miden la eficacia de control de la pulverización sobre el organismo a combatir. Los primeros evalúan cómo se ha realizado el tratamiento desde el punto de vista únicamente de su distribución, esto es, si se han alcanzado las partes de la planta que eran objetivo, si la deposición ha sido homogénea, etc. No obstante, no indican el efecto sobre el organismo a combatir. Los segundos, que a priori parecen más prácticos, a menudo solamente tienen en cuenta efectos biológicos y medioambientales, pero no consideran la distribución del producto sobre la planta. En los siguientes apartados se describen ambos métodos. Por último, se detallan trabajos en los que ambos métodos se han utilizado simultáneamente y que aportan mucha más información.

\subsubsection{Métodos que estudian la distribución del caldo sobre la cubierta vegetal}

Existen métodos cuantitativos en los que se estima la cantidad de volumen de caldo que se deposita sobre la cubierta vegetal y métodos cualitativos en los que se estudia cómo se ha distribuido ese volumen de caldo.

\section{Métodos cuantitativos}

Los métodos cuantitativos se basan en la utilización de trazadores. Consisten en pulverizar una solución con una concentración conocida del 
trazador y en medir la cantidad depositada sobre las hojas o colectores artificiales. Básicamente se utilizan dos tipos de trazadores: fluorescentes y metálicos.

La mayoría de los trazadores fluorescentes solubles en agua que se emplean en investigación son muy sensibles a la luz, y se degradan rápidamente con la radiación solar (Salyani, 1993). Esto dificulta enormemente las aplicaciones en campo. Puesto que la cubierta vegetal está expuesta a diferentes niveles de radiación, no existe un método fiable para la corrección del error de degradación en los depósitos. Para minimizar este efecto en las experiencias de campo, las muestras deben ser recogidas rápidamente tras la aplicación. No obstante, recientemente han aparecido trazadores fluorescentes que son mucho más estables y están dando prometedores resultados (Furness y Thompson, 2007).

Los trazadores metálicos no se degradan por la radiación solar, sin embargo algunos presentan el inconveniente de que son parcialmente absorbidos por la planta, lo que, además de producir errores en las medidas, puede ser motivo de fitotoxicidad.

Ejemplos de trabajos en los que se emplean trazadores fluorescentes son los de Furness y Newton (1988) y Pergher y Gubiani (1995), que midieron residuos fluorescentes en hojas. Antuniassi et al. (1996) aplicaron cloruro de potasio y un colorante fluorescente y utilizaron la conductividad eléctrica de la solución procedente del lavado de la hoja para cuantificar la deposición de la pulverización. Cross (1991) y Planas et al. (1996) compararon los depósitos fluorescentes en colectores artificiales con los obtenidos en hojas de manzano, obteniendo una correlación del 80\%. Whitney y Roth (1985) y Fox et al. (1993) utilizaron la fluorimetría para comparar diferentes aplicaciones. Solanelles et al. (1996) y Rocamora (1999) utilizaron la sulfoflavina (BSF) como trazador para medir de la deriva de dos equipos de tratamiento en manzano. 
Como ejemplo de trabajos en los que se emplean trazadores metálicos se señalan los de Derksen y Gray (1995), que utilizaron como trazadores micronutrientes de zinc y manganeso y analizaron la solución del lavado de la hoja con un espectrómetro de emisión. Hoffmann y Salyani (1996) y Whitney et al. (1989) usaron trazadores de manganeso y cobre y cuantificaron la deposición en hojas de cítricos con los correspondientes colorímetros. Juste et al. (1990) emplearon quelatos de cobre para la medida de la deposición en hojas de cítricos. Whitney y Salyani (1991) emplearon quelatos de hierro para evaluar la deposición de dos pulverizadores en cítricos. Solanelles et al. (2002) utilizaron quelatos metálicos para evaluar la aplicación de un pulverizador dotado con un sistema electrónico de control. Del mismo modo, Ortí et al. (2005) usaron quelatos de hierro para evaluar la calidad de la pulverización en cítricos. Gil et al. (2005) los emplearon para ajustar las dosis de aplicación en el cultivo de vid.

Salyani y Whitney (1988) compararon la fluorometría y la colorimetría y encontraron una buena relación entre los depósitos fluorescentes y los de cobre, pero recomendaron el empleo de cobre por adaptarse mejor a los trabajos de campo.

El empleo de métodos basados en trazadores requiere mucho tiempo para la obtención de resultados e instrumental costoso. Salyani y Whitney (1990) propusieron otra metodología. Estaba basada en la utilización de unos sensores que diseñaron y que proporcionaban una señal de voltaje proporcional a la cantidad de producto depositado.

\section{Métodos cualitativos}

Los métodos cualitativos estudian la distribución de la pulverización en las diferentes partes del árbol, su homogeneidad, el alcance dentro del árbol, etc. La técnica es la misma que la que se utiliza para caracterizar los impactos de una pulverización y que se basa en el análisis de imagen de colectores. Existe una gran variedad de tipos de colectores, y su elección depende de lo que se pretenda 
estudiar. Blandini y Schillaci (1993) y Val et al. (1993) pusieron colectores de plástico pulverizados con vaselina o silicona, que simulan las condiciones de la superficie de las hojas de cítricos, sobre la superficie de las hojas y pulverizaron con una solución con quelato de hierro. Después fotografiaron los colectores y estudiaron la distribución de impactos obtenida en diferentes partes del árbol por análisis de imagen. Moltó et al., (2000) utilizaron una técnica similar para comparar la distribución obtenida con dos pulverizadores. Coates (1996) fotografió hojas pulverizadas con un colorante fluorescente y analizó las imágenes con un escáner portátil (Franz, 1992).

En estudios de campo se trabaja a menudo con colectores de papel hidrosensible (sensible al agua), y con papel oleosensible (sensible al aceite) en el caso de aplicaciones con aceites minerales. Ambos son una importante herramienta, porque permiten evaluar sencilla y rápidamente la calidad de la distribución y el alcance del producto a través de las manchas que se producen sobre el papel. Sin embargo, estos papeles no sirven para describir de una manera precisa los tamaños de los impactos, puesto que los deforman. No obstante, se pueden utilizar para obtener una idea cualitativa del resultado del tratamiento. Mercader et al. (1995) justificaron su utilización en cítricos para determinar el alcance de una pulverización, pero señalando que estos colectores no reflejan fielmente los tamaños y distribución de los impactos que se producen en las hojas. Godyn et al. (2005) utilizaron papeles hidrosensibles para verificar que el volumen de aplicación estaba adaptado a la estructura del cultivo. Salyani y Fox (1999), utilizaron papeles hidrosensibles y oleosensibles para evaluar la calidad de diversos tratamientos en cítricos.

Sagi y Derksen (1991) compararon las técnicas de análisis de imagen con las de fluorescencia y de espectrofotometría, y concluyeron que en su trabajo existe una relación lineal entre el análisis espectrofotométrico y el análisis de imagen para los parámetros: porcentaje de recubrimiento, diámetro de las gotas y número de impactos por unidad de superficie. 


\subsubsection{Métodos que miden el nivel de control sobre el organismo a combatir}

El objetivo de un tratamiento fitosanitario es obtener el máximo nivel de control sobre la población del organismo a combatir. Existen muchos trabajos en los que los tratamientos se evalúan a través de su eficacia sobre el fitófago, a menudo orientados a la comparación de la eficacia de productos fitosanitarios alternativos, de métodos de aplicación, etc.

La manera de realizar un estudio sobre la eficacia de un tratamiento depende mucho del organismo objeto de estudio. En el caso de los insectos, es muy importante conocer su biología, puesto que influye sobre la manera de medir la eficacia.

En este apartado se describen diferentes métodos que aparecen en la literatura científica para evaluar el efecto de los tratamientos sobre la mosca mediterránea de la fruta y sobre otros tefrítidos.

En general, la eficacia de un tratamiento contra $C$. capitata se evalúa de manera indirecta y de dos formas: estudiando la evolución de la población de moscas y mediante la estimación del nivel de frutos picados.

La evolución de la población de moscas se estudia a través de las capturas en trampas. El sistema de trampeo y el modo en que las trampas se ubican dentro de las plantaciones varían de unos trabajos a otros. En las siguientes referencias se pueden ver algunos ejemplos: Moreno et al. (2001), Peck y Mcquate (2000), Burns et al, (2001) y Navaro-Llopis et al. (2004).

Los adultos de C. capitata tienen una elevada capacidad de vuelo, pueden desplazarse decenas de metros, incluso kilómetros. El estudio de la evolución de la población presenta dificultades, ya que a diferencia de insectos estáticos con poca capacidad de movimiento dentro de un área (como puede ser el caso de las cochinillas), las poblaciones de mosca en un área pueden variar de un momento a otro, no solamente por la eficacia del tratamiento sino por circunstancias ajenas al mismo (reinvasiones, migraciones, variaciones del viento 
dominante). Por este motivo, es difícil valorar la eficacia de un tratamiento simplemente estudiando las diferencias entre la población antes y después del mismo.

Otra dificultad es que los niveles poblacionales pueden ser diferentes entre parcelas aunque estén próximas. Por ejemplo, en plantaciones de cítricos la presencia de determinados frutales aislados (por ejemplo, higueras), que atraen poderosamente a estas moscas, puede modificar la dinámica y la densidad poblacional de los adultos incluso dentro de una misma parcela (Campos, 2007). Es por ello que para comparar los resultados de los tratamientos es necesario tener en cuenta no solo los niveles poblacionales a gran escala, sino también la distribución de las densidades de población.

Por otra parte, las experiencias de campo indican que las capturas de adultos de $C$. capitata en trampas individuales son muy variables, tanto en el número de individuos recogidos en un momento dado, como en su evolución a lo largo del tiempo, incluso cuando se comparan trampas muy próximas. Este hecho influye directamente sobre el número de trampas que se deben colocar en una parcela y su ubicación. En consecuencia, los estudios de eficacia buscan pautas en la población estimada analizando el conjunto de varias trampas y no se basan en la observación de trampas individuales (Martínez-Ferrer, 2007).

\subsubsection{Combinación de ambos métodos}

Los trabajos en los que se utilizan simultáneamente los métodos que describen la distribución de la pulverización y los métodos que evalúan la eficacia en el control de una plaga son de particular interés porque permiten relacionar los parámetros que describen la pulverización con su eficacia.

Smith (1983) empleó un trazador fluorescente junto con el insecticida para evaluar la cantidad de caldo depositada sobre la copa del árbol y estimar el nivel de control sobre la plaga. Pellicer et al. (1994) establecieron, en condiciones de laboratorio, la relación entre las características de las 
deposiciones (porcentaje de recubrimiento, número de impactos por $\mathrm{cm}^{2} \mathrm{y}$ diámetro medio de los impactos) y el nivel de control de la cochinilla algodonosa de los cítricos (Planococcus citri, Risso (Hemiptera: Pseudococcidae). Salyani et al. (1988) estudiaron los efectos del volumen de pulverización sobre la deposición y sobre el control del ácaro del tostado Phyllocoptruta oleivora (Ashmead) (Acari: Eriophyidae). Castillo (2005) modelizó, en condiciones de laboratorio, el efecto que tiene la forma de distribución de tres aceites minerales sobre la mortalidad del piojo rojo de California.

\section{SELECCIÓN DEL DISPOSITIVO DE PULVERIZACIÓN}

Tal y como se ha indicado en la introducción, los tratamientos cebo requieren un tamaño de gota grande que garantice la atracción del insecto y la permanencia del producto. Las condiciones de trabajo de los dispositivos que se emplean actualmente en pulverización neumática, hidráulica o centrífuga dan lugar a tamaños de gota muy pequeños, que a su vez producen deposiciones pequeñas del producto, por lo que es necesario encontrar el dispositivo y las condiciones de trabajo que proporcionen el tamaño de gota requerido para este tipo de tratamientos.

De entre las tres tecnologías para la formación de gotas que se han expuesto, se decidió trabajar con dispositivos de pulverización hidráulicos y centrífugos. Los dispositivos de pulverización neumática se descartaron porque en principio producirían las gotas más pequeñas aunque se modificasen las condiciones de trabajo.

Los dispositivos centrífugos presentan la ventaja de que permiten aplicar volúmenes de caldo muy bajos como se desea en los tratamientos cebo, de hecho, se emplean comúnmente en los tratamientos a Ultra-Bajo Volumen (UBV). El inconveniente para aplicaciones sobre árboles es que se ha de pulverizar de manera horizontal, ya que las gotas alcanzan la vegetación por gravedad. 
Existiría la posibilidad de pulverizar con asistencia de aire, para transportar las gotas hacia las copas, o distribuir el producto desde arriba para que alcanzase las hojas exteriores de los árboles.

Los dispositivos hidráulicos, en principio, no permiten aplicar volúmenes de caldo muy bajos. Sin embargo, para los tratamientos cebo que se pretenden, se ppdrían realizar aplicaciones intermitentes. La ventaja de estos dispositivos es que permiten pulverizar desde un lateral de las copas y alcanzar el follaje gracias a la energía cinética que imprimen a las gotas.

En esta fase del trabajo, con el objetivo de conocer las posibilidades de tamaños de impacto que permiten los dispositivos comerciales, se ensayaron 6 modelos (4 de pulverización hidráulica y 2 de pulverización centrífuga) con diversas configuraciones.

El objetivo de los ensayos fue seleccionar el dispositivo pulverizador más adecuado para la máquina. Para ello, se caracterizaron los dispositivos ensayados a través del estudio de diferentes parámetros de pulverización y se determinaron las funciones de distribución de las poblaciones de tamaños de los impactos producidos. Después se seleccionó el dispositivo en función de estos resultados.

\subsection{MATERIALES Y MÉTODOS}

\subsubsection{Ensayo de caracterización de los dispositivos hidráulicos}

\section{Equipo de emulación}

La pulverización para caracterizar los dispositivos hidráulicos se realizó con un equipo que emula la aplicación de campo (Figura 7). Éste se encuentra en el interior de un recinto cerrado, diseñado para tal fin, situado en el IVIA. Consta de un circuito hidráulico y un sistema que dota al dispositivo de pulverización de movimiento. El circuito hidráulico está formado por:

- Un depósito de 1001 de capacidad. 
- Un bomba de membrana, con un caudal máximo de 18 1/min y una presión máxima de 20 bar. Dispone de dos retornos al depósito, el propio de la bomba para la regulación de la presión, y otro que se ha incorporado para asegurar una mejor agitación de la mezcla.

- Una manguera que lleva el líquido desde la bomba hasta la barra de pulverización.

- Una barra de pulverización de 1,6 m de longitud sobre la que se colocó el dispositivo de pulverización en uno de sus extremos horizontalmente.

- Dos manómetros, uno situado a la salida de la bomba y otro antes de la boquilla.

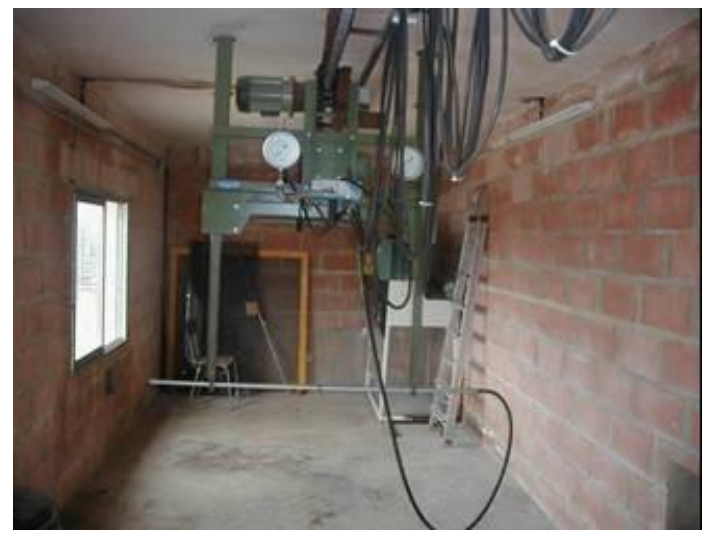

Figura 7. Equipo de emulación.

El sistema que proporciona el movimiento consta de una barra dentada fijada al techo, de $3 \mathrm{~m}$ de longitud, por la que se desplaza mediante unos raíles una estructura formada por dos barras verticales que distan entre si $1 \mathrm{~m}$ y que sujetan a la barra de pulverización. Un motor que está fijado a esta estructura y que engrana con la barra dentada es el que permite el movimiento del sistema hacia adelante y hacia atrás. Un variador de frecuencia permite cambiar la velocidad de desplazamiento. 


\section{Descripción de las boquillas ensayadas}

Tras una revisión de las boquillas hidráulicas que existen en el mercado se seleccionaron cuatro boquillas Teejet (Spraying Systems Co., Wheaton, Illinois) que destacan por la formación de gotas grandes (Figura 8):

- Al-11003VS: Boquilla de inducción de aire de chorro plano

- AI-11004VS: Boquilla de inducción de aire de chorro plano

- FL-5VS: Boquilla granangular de cono lleno

- TT-11004VP: Boquilla granangular de chorro plano

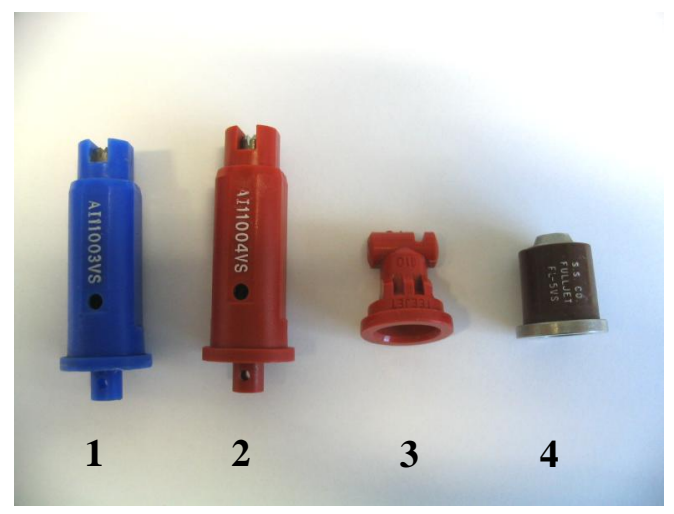

Figura 8. Boquillas AI-11003VS (1), AI-11004VS (2), TT-1004VP (3) y FL-5VS (4).

Las dos primeras boquillas son de efecto Venturi y forman gotas muy gruesas mediante la incorporación de aire. La única diferencia entre ambas es el diámetro de apertura del orificio, lo que condiciona el caudal y el tamaño de gota producido, ya que, en general, a mayor diámetro de boquilla, mayor caudal y mayores gotas. Igualmente, a mayor presión mayor es el caudal, pero el tamaño de las gotas que se produce es menor.

\section{Selección de los parámetros del ensayo}

El dispositivo seleccionado debe dar lugar a impactos de gran tamaño pero que proporcionen el menor caudal posible. Puesto que a menor presión mayor tamaño de gota y menor caudal, se seleccionaron las presiones de trabajo 
más bajas posibles para las cuales las boquillas funcionaran correctamente, es decir, produjeran gotas, no hubiera escurrimientos y, además, tuvieran un alcance superior a $100 \mathrm{~cm}$. Las presiones seleccionadas fueron 1 y 2 bar. En las tablas de los fabricantes, donde se muestra el caudal en función de la boquilla y de la presión, no aparecen los datos para esas presiones tan bajas de trabajo. Por este motivo se midieron los caudales de cada boquilla para dichas presiones durante 1 minuto, realizando un total de 5 repeticiones por boquilla. Los resultados de muestran en la Tabla 1.

Tabla 1. Caudales (media $\pm E S$ ) de las boquillas a 1 y 2 bar.

\begin{tabular}{|c|c|c|}
\hline Presión (bar) & Boquilla & Caudal (l/min) \\
\hline 1 & AI-11003VS & $0,65 \pm 0,01$ \\
\hline 1 & AI-11004VS & $0,83 \pm 0,02$ \\
\hline 1 & TT-11004VP & $0,83 \pm 0,02$ \\
\hline 1 & FL-5VS & $1,19 \pm 0,02$ \\
\hline 2 & AI-11003VS & $0,98 \pm 0,02$ \\
\hline 2 & AI-11004VS & $1,26 \pm 0,01$ \\
\hline 2 & TT-11004VP & $1,28 \pm 0,01$ \\
\hline 2 & FL-5VS & $1,67 \pm 0,01$ \\
\hline
\end{tabular}

Con el fin de estudiar los impactos de todo el ancho de pulverización (cobertura) de las boquillas, en cada experiencia se colocaron 7 colectores dispuestos verticalmente, apoyados en la pared a diferentes alturas relativas: $\mathrm{c} 1$, c2, c3, 0, -c1, -c2, -c3 (Figura 9 y Figura 10). El colector central (denominado colector 0 ) se puso siempre a la altura de la boquilla, separado horizontalmente de ésta $75 \pm 1 \mathrm{~cm}$ (distancia de pulverización). La separación entre los colectores dependió del tipo de boquilla y de la presión. Para determinarla se midió el ancho de trabajo de cada boquilla a las dos presiones de trabajo establecidas y posteriormente, se dividió dicha longitud en 6 partes iguales (Tabla 2) dando lugar a las posiciones c1, c2, c3, 0, -c1, -c2 y -c3.

Los colectores que se utilizaron eran láminas de PVC, blancas y cuadradas, de 4,5 cm de lado, similares a las descritos por Mercader et al. (1995). 
Capítulo III. Mecanización de los tratamientos cebo a bajo volumen
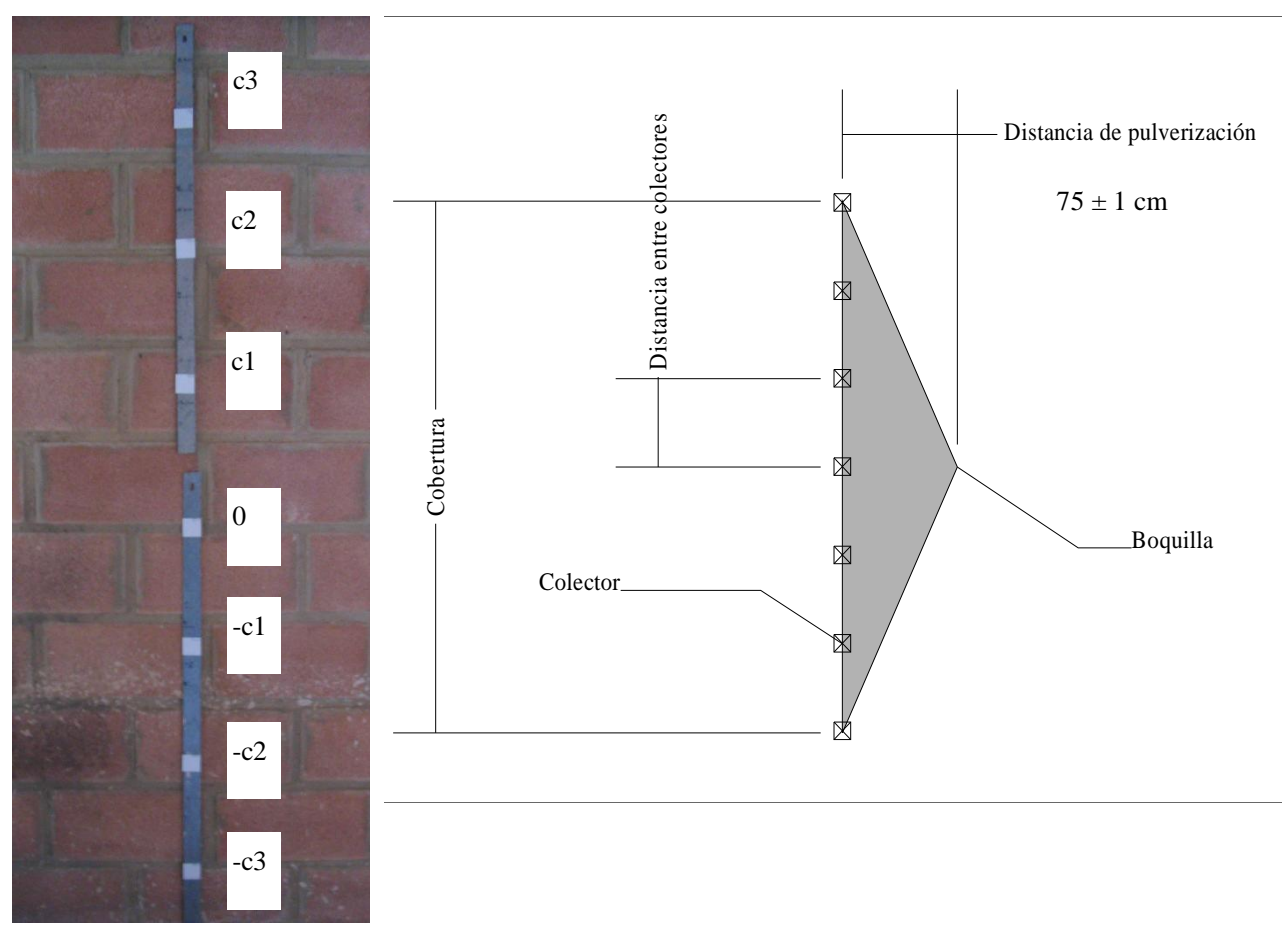

Figura 9. Disposición de colectores en la

Figura 10. Esquema de la disposición de los colectores. pared.

Tabla 2. Ancho de pulverización y distancia entre colectores según tipo de boquilla y presión de trabajo.

\begin{tabular}{|l|c|c|c|}
\cline { 2 - 4 } \multicolumn{1}{c|}{} & Presión (bar) & $\begin{array}{c}\text { Ancho pulverización } \\
(\mathbf{m m})\end{array}$ & $\begin{array}{c}\text { Distancia entre } \\
\text { colectores (mm) }\end{array}$ \\
\hline \multirow{2}{*}{ AI-11003VS } & 1 & 1.300 & 220 \\
\cline { 2 - 4 } & 2 & 1.500 & 250 \\
\hline \multirow{2}{*}{ AI-11004VS } & 1 & 1.400 & 230 \\
\cline { 2 - 4 } & 2 & 1.800 & 300 \\
\hline \multirow{2}{*}{ TT-11004VP } & 1 & 1.800 & 300 \\
\cline { 2 - 4 } & 2 & 2.000 & 330 \\
\hline \multirow{2}{*}{ FL-5VS } & 1 & 1.800 & 300 \\
\cline { 2 - 4 } & 2 & 2.200 & 370 \\
\hline
\end{tabular}


Con el objeto de emular las aplicaciones de productos fitosanitarios en campo, y debido a que la deposición de los impactos sobre los colectores depende de la velocidad de avance a que se haga la aplicación, las experiencias se realizaron en movimiento con el equipo de emulación descrito. Para establecer la velocidad de desplazamiento de cada experiencia se aplicó la Ecuación 7.

$$
v=\frac{q \times 60.000}{a \times V}
$$

Ecuación 7

\section{Donde:}

$\mathrm{v}=$ velocidad de avance $(\mathrm{km} / \mathrm{h})$.

$\mathrm{V}=$ volumen de caldo que se pretende distribuir (1/ha). Al ser un tratamiento cebo de bajo volumen se partió de un volumen de 20 l/ha.

$\mathrm{q}=\operatorname{caudal}(1 / \mathrm{min})$

$\mathrm{a}=$ ancho de calles del cultivo $(\mathrm{cm})$. Se tomó como valor representativo $5 \mathrm{~m}$, ya que es bastante común en la mayoría de las parcelas de cítricos preparadas para la mecanización. Hemos de indicar que en la actualidad se recomiendan valores de ancho de calle algo superiores (entre 5,5 y 6 m) (Juste et al., 1998).

Las velocidades de avance obtenidas, al pretender pulverizar 20 1/ha con las condiciones establecidas y con las boquillas ensayadas, fueron muy elevadas, entre 4 y $10 \mathrm{~km} / \mathrm{h}$. Por tanto, se decidió aumentar el volumen de caldo de 20 1/ha a 40 1/ha. Esto tiene una repercusión directa sobre el diseño del equipo, ya que en caso de seleccionar una boquilla hidráulica como dispositivo de pulverización para llevar a cabo el tratamiento cebo, si se desea aplicar volúmenes inferiores a 40 1/ha habrá que pulverizar de forma discontinua. En la Tabla 3 se muestran las velocidades obtenidas para pulverizar el volumen de caldo de 40 1/ha. 
Tabla 3. Velocidad de desplazamiento para pulverizar un volumen de caldo de 40l/ha.

\begin{tabular}{|c|c|c|}
\cline { 2 - 3 } \multicolumn{1}{c|}{} & Presión (bar) & Velocidad $(\mathbf{k m} / \mathbf{h})$ \\
\hline \multirow{2}{*}{ AI-11003VS } & 1 & 2,04 \\
\cline { 2 - 3 } & 2 & 2,88 \\
\hline \multirow{2}{*}{ TT-11004VS } & 1 & 2,73 \\
\cline { 2 - 3 } & 2 & 3,87 \\
\hline \multirow{2}{*}{ FL-5VS } & 1 & 2,73 \\
\cline { 2 - 3 } & 2 & 3,87 \\
\cline { 2 - 3 } & 2 & 3,57 \\
\hline
\end{tabular}

\section{Diseño experimental}

Para determinar la boquilla más adecuada y estudiar el efecto de la presión se realizó un diseño factorial equilibrado de tres factores:

- $\quad$ Tipo de boquilla a 4 variantes.

- Presión a 2 niveles: 1 y 2 bar.

- Posición del colector (altura) a 7 niveles.

Siendo las variables respuesta los siguientes parámetros de la pulverización: el recubrimiento, el número de impactos por unidad de superficie, el volumen por unidad de superficie y la mediana, los cuartiles $\left(D_{25}\right.$ y $\left._{75}\right)$ y el intervalo intercuartílico del diámetro.

Cada experiencia consistió en pulverizar sobre los 7 colectores dispuestos en la pared con una de las boquillas, a una presión y una velocidad. Cada tratamiento se repitió 6 veces, 3 para caracterizar los impactos depositados sobre los colectores y 3 para estimar el volumen pulverizado por unidad de superficie, cuyo cálculo se describe posteriormente, llevándose a cabo un total de 
48 experiencias que se ordenaron aleatoriamente para evitar posibles errores sistemáticos.

Es importante señalar que el factor presión está asociado a la velocidad de avance. El aumento de 1 a 2 bar aumenta del caudal expulsado por la boquilla, y dado que el volumen de caldo que se desea pulverizar es el equivalente a $40 \mathrm{l} / \mathrm{ha}$, es necesario aumentar la velocidad del carro.

\subsubsection{Ensayo de caracterización de los dispositivos centrífugos}

\section{Equipo de emulación}

La pulverización se realizó en el mismo recinto donde se ensayaron los dispositivos hidráulicos y se utilizó el mismo sistema que dotaba de movimiento al dispositivo de pulverización. Sin embargo, debido a que en estos dispositivos se puede regular el caudal no se empleó el circuito hidráulico del ensayo de pulverización hidráulica, sino un sistema formado por los siguientes elementos (Figura 11):

- Un depósito de 51 de capacidad.

- Una bomba eléctrica (Figura 11b) con un voltaje nominal de $12 \mathrm{~V}$, un caudal máximo de 1,5 1/min y una presión máxima de 2,5 bar.

- Un regulador de voltaje (Figura 11a) conectado a la bomba para poder ajustar el caudal.

- Una fuente de alimentación con dos salidas. Una conectada al motor del cabezal de $30 \mathrm{~V} / 2 \mathrm{~A}$, con limitador de intensidad y regulador de voltaje que permitía variar la velocidad de giro del motor. Y otra conectada a la bomba de $15 \mathrm{~V} / 0,5 \mathrm{~A}$, a la que se le conectó el regulador de voltaje para poder ajustar el caudal. 


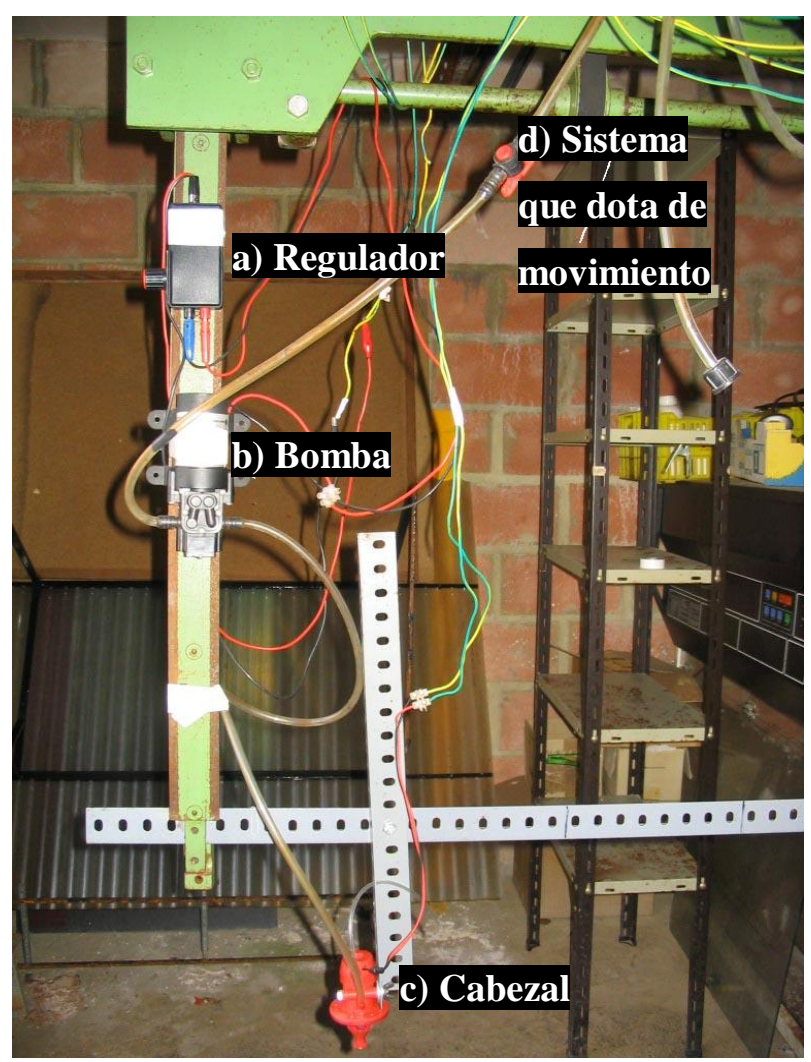

Figura 11. Esquema de los elementos empleados para la pulverización centrífuga.

\section{Descripción de los cabezales centrífugos ensayados}

Se probaron 5 cabezales centrífugos diseñados por la empresa Sanz Hermanos, S.L. (Valencia, España). Como el objetivo era que el dispositivo de pulverización produjera impactos grandes, se decidió trabajar con bajas velocidades de giro del disco.

En primer lugar, se realizó una selección de la boquilla, que es la que regula el caudal. Los ensayos aparecen en el Anejo 1. Como consecuencia de éstos, se seleccionó la boquilla roja de 4 dientes que era la de mayor diámetro $\left(\varnothing_{\text {interior }}=2 \mathrm{~mm}\right)$.

Posteriormente se realizó una selección previa de los cabezales, descartando aquellos que no funcionaban correctamente, es decir, aquellos que a 
bajas velocidades de giro del motor no eran capaces de producir gotas, dando lugar al escurrimiento del líquido, o que, a simple vista, proporcionaban impactos de pequeño tamaño. Los ensayos se describen en el Anejo 2.

Como consecuencia de estas pruebas se seleccionaron dos cabezales que tenían el mismo motor (modelo RS-360SH, Mabuchi motor Co. Ltd., Chiba, Japón), y que se diferenciaban únicamente en el disco que produce las gotas. Llamaremos cabezal 1 al que posee el disco más grande (d1), y que tiene un total de 40 dientes y un diámetro de $50 \mathrm{~mm}$ medido entre las puntas de los dientes, y cabezal 2 al que posee el disco menor (d2), con 30 dientes y un diámetro entre las puntas de los dientes de $28 \mathrm{~mm}$ (Figura 12).

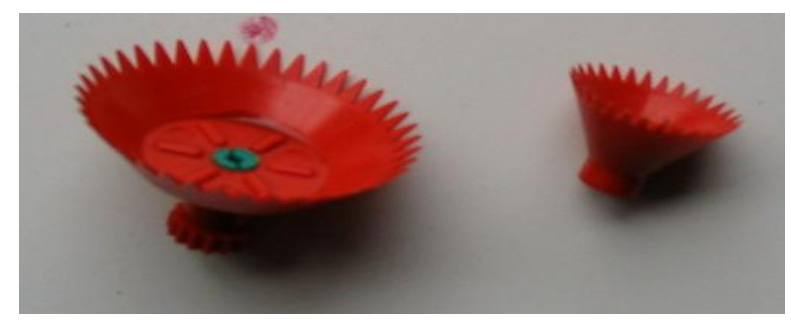

Figura 12. Discos, dl (derecha) y d2 (izquierda).

\section{Selección de los parámetros ensayados}

Debido a que estos dispositivos permiten aplicar volúmenes de caldo muy pequeños, se decidió utilizar los caudales correspondientes para unos volúmenes de caldo de 20 1/ha y 40 1/ha. Fijando la velocidad de avance en $2,5 \mathrm{~km} / \mathrm{h}$ y el marco de plantación en $5 \mathrm{~m}$, los caudales para el ensayo, calculados mediante la Ecuación 7, fueron 0,42 1/min y 0,83 1/min respectivamente.

Cada combinación de cabezal y caudal puede trabajar en un intervalo de velocidad de giro del motor dando lugar a gotas con diferentes tamaños. Se escogieron velocidades a las que el cabezal convertía todo el líquido que le llegaba en gotas, la pulverización era homogénea y los impactos grandes a simple vista. Los ensayos se describen en el Anejo 2. En la Tabla 4 se muestran las 
3 velocidades de giro, r1, r2 y r3 que se escogieron para cada cabezal y el voltaje que se proporcionaba al motor para conseguirlas.

Tabla 4. Velocidad de giro (r/min) escogidas para cada cabezal y caudal. Entre paréntesis se indica el voltaje con que se alimentaba el motor para conseguir dicha velocidad.

\begin{tabular}{|c|c|c|c|c|c|}
\cline { 3 - 6 } \multicolumn{2}{c|}{} & \multicolumn{2}{c|}{ Cabezal C1 } & \multicolumn{2}{c|}{ Cabezal C2 } \\
\cline { 2 - 6 } \multicolumn{2}{c|}{} & $\mathbf{0 , 4 2}$ l/min & $\mathbf{0 , 8 3}$ l/min & $\mathbf{0 , 4 2}$ l/min & $\mathbf{0 , 8 3 ~ 1 / m i n}$ \\
\hline \multirow{2}{*}{$\begin{array}{c}\text { Velocidad } \\
\text { de giro }\end{array}$} & $\mathbf{r 1}$ & $520(2,00 \mathrm{~V})$ & $760(2,50 \mathrm{~V})$ & $1.010(3,00 \mathrm{~V})$ & $1.274(3,50 \mathrm{~V})$ \\
\cline { 2 - 6 }$(\mathbf{r} / \mathbf{m i n})$ & $\mathbf{r 2}$ & $760(2,50 \mathrm{~V})$ & $1.010(3,00 \mathrm{~V})$ & $1.274(3,50 \mathrm{~V})$ & $1.545(4,00 \mathrm{~V})$ \\
\cline { 2 - 6 } & $\mathbf{r 3}$ & $1.010(3,00 \mathrm{~V})$ & $1.274(3,50 \mathrm{~V})$ & $1.545(4,00 \mathrm{~V})$ & $1.810(4,50 \mathrm{~V})$ \\
\hline
\end{tabular}

Para estudiar los impactos en todo el ancho de pulverización de los cabezales centrífugos, se colocaron 4 colectores dispuestos horizontalmente sobre el suelo, ya que este tipo de pulverización no permite aplicar el producto sobre una superficie vertical. Los colectores se situaron respecto al punto central debajo del disco, a distancias relativas denominadas: c1, c2, -c1, -c2. La altura de pulverización, es decir, la distancia entre el suelo y el disco, era de $75 \mathrm{~cm}$ (Figura 13 y Figura 14). La separación entre los colectores dependió del ancho de pulverización, que se midió para cada disco a las velocidades de giro y los caudales establecidos, y a la altura de pulverización de $75 \mathrm{~cm}$. El ancho de pulverización para cada cabezal fue el mismo, indistintamente del caudal aplicado (Tabla 5).

Para determinar la distancia entre los colectores se decidió despreciar 12,5 cm de cada lado del ancho de pulverización, porque llegaba un número muy pequeño de impactos, y se dividió el resultado entre 3 (Tabla 5). Por tanto, los colectores centrales distaban del punto imaginario situado debajo del disco la mitad de esta distancia.

Los colectores que se emplearon fueron los mismos que los utilizados en el ensayo de los dispositivos hidráulicos pero de mayor tamaño (PVC blanco de 
$15 \mathrm{~cm}$ de lado), con el fin de disponer de una población de impactos suficiente por colector.
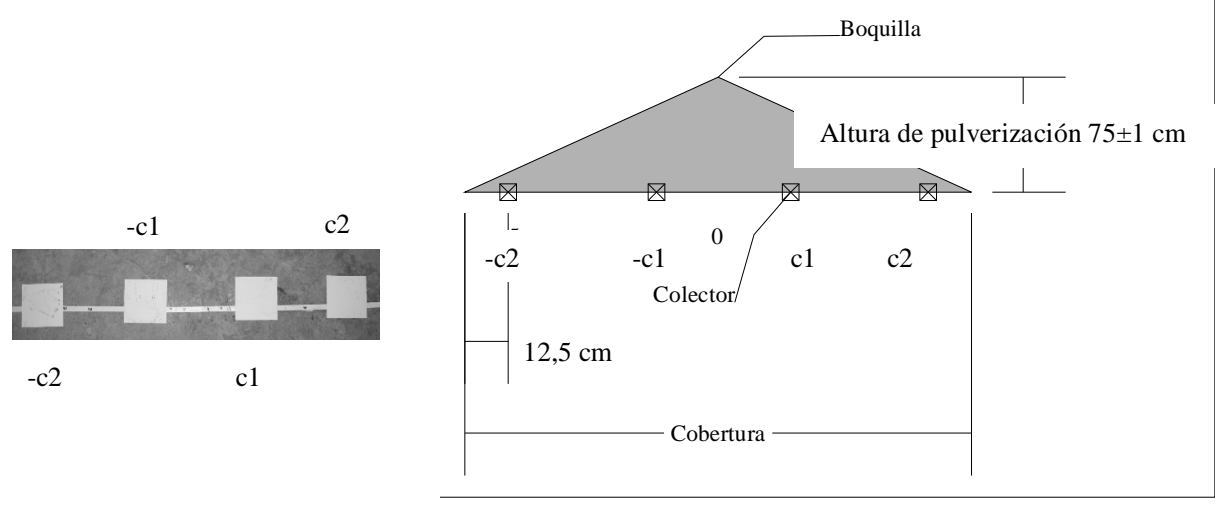

Figura 13.

Disposición de los colectores en el suelo.

Figura 14. Esquema de la disposición de los colectores.

Tabla 5. Ancho de pulverización y distancia entre colectores según tipo de disco y velocidad de giro.

\begin{tabular}{|l|l|c|c|}
\cline { 2 - 4 } \multicolumn{1}{c|}{} & \multicolumn{1}{c|}{$\begin{array}{c}\text { Velocidad de giro } \\
\text { (r/min) }\end{array}$} & $\begin{array}{c}\text { Ancho de } \\
\text { pulverización }(\mathbf{m m})\end{array}$ & $\begin{array}{c}\text { Distancia entre los } \\
\text { colectores (mm) }\end{array}$ \\
\hline \multirow{3}{*}{ Disco 1 } & $\mathbf{r 1}$ & 950 & 233,33 \\
\cline { 2 - 4 } & $\mathbf{r 2}$ & 1.400 & 383,33 \\
\cline { 2 - 4 } & $\mathbf{r 3}$ & 1.500 & 416,66 \\
\hline \multirow{3}{*}{ Disco 2 } & $\mathbf{r 1}$ & 900 & 216,66 \\
\cline { 2 - 4 } & $\mathbf{r 2}$ & 1.200 & 316,66 \\
\cline { 2 - 4 } & $\mathbf{r 3}$ & 1.450 & 400 \\
\hline
\end{tabular}

\section{Diseño experimental}

Para determinar el cabezal y las condiciones de trabajo más adecuadas (velocidad de giro y caudal) se realizó un experimento con un diseño factorial equilibrado de cuatro factores:

- Tipo de cabezal a 2 variantes.

- Caudal a 2 niveles. 
- Velocidad de giro del disco a 3 niveles.

- Posición del colector (distancia relativa) a 4 niveles.

Las variables estudiadas fueron los mismos parámetros de pulverización que en el ensayo de los dispositivos hidráulicos y que son: el recubrimiento, el número de impactos por unidad de superficie, el volumen por unidad de superficie y la mediana, los cuartiles $\left(D_{25}\right.$ y $\left.D_{75}\right)$ y el intervalo intercuartílico del diámetro.

Cada experiencia consistió en pulverizar sobre los 4 colectores colocados sobre el suelo, a una velocidad de avance de $2,5 \mathrm{~km} / \mathrm{h}$, con un cabezal, a una velocidad de giro y un caudal. Del mismo modo que en el ensayo de los dispositivos hidráulicos cada tratamiento se repitió 6 veces, 3 para obtener los impactos depositados sobre los colectores y 3 para estimar el volumen depositado por unidad de superficie cuyo cálculo se describe posteriormente, llevándose a cabo un total de 72 experiencias que se ordenaron aleatoriamente para evitar errores sistemáticos.

\subsubsection{Descripción del caldo pulverizado}

La mezcla del caldo para pulverizar se compuso de agua, quelato de hierro (Sequestrene 138 Fe G-100, Syngenta Agro S.A., Madrid, España) al $2,5 \%$ en peso y, como insecticida, Spintor $\mathrm{Cebo}^{\circledR}$ (Dow Agrosciencies Ibérica S.A., Madrid, España) al $5 \%$ en volumen. El quelato se empleó como colorante, para aumentar el contraste entre las gotas y el fondo del colector y facilitar el análisis de imagen.

\subsubsection{Estimación del volumen depositado por unidad de superficie}

Para conocer el volumen depositado sobre los colectores, se pesó el colector antes y después de pulverizar, con una báscula de precisión de $0,1 \mathrm{mg}$ (modelo XR205SM-DR, Precisa Instruments Ltd., Suiza), se halló la diferencia y se dividió por la densidad del caldo. La densidad del caldo se calculó a partir del peso de un volumen de caldo conocido y fue igual a $1 \mathrm{~kg} / \mathrm{l}$. 
Posteriormente, se dividió el volumen depositado estimado por la superficie del colector, obteniendo así el volumen por unidad de superficie. En el ensayo de pulverización centrífuga, los colectores medían $15 \mathrm{~cm}$ de lado y no cabían en el protector paravientos de cristal que la báscula posee, por lo que en su lugar se usaron placas Petri de $88 \mathrm{~mm}$ de diámetro interior.

\subsubsection{Descripción de los impactos}

\section{Análisis de imagen y parámetros que se extraen}

Una vez pulverizados los colectores y antes de que se secaran, se tomaron imágenes con una cámara digital cuyas características y ajustes se detallan en el Anejo 3. Para realizar todas las fotos en las mismas condiciones (misma iluminación y misma altura), la cámara se montó sobre un soporte Polaroid MP-4 Land Camera a una altura de $30 \mathrm{~cm}$ sobre las muestras. Se utilizó un sistema de iluminación formado por una caja con dos tubos fluorescentes (ver características en el Anejo 3) en la parte superior.

Posteriormente, las imágenes se analizaron con un programa comercial (Matrox Inspector, versión 2.2., Matrox Electronic Systems Ltd., Québec, Canada). En primer lugar, para obtener medidas reales se calibraron las imágenes. Para ello se fotografió una regla de la misma forma que se había hecho con los colectores y se obtuvo la relación entre el píxel y la distancia. Después se realizó el proceso de análisis de las imágenes (Figura 15), que consta de 3 fases:

- Recorte de la imagen: Consiste en recortar el área de estudio, en este caso se selecciona una zona representativa de los colectores.

- Conversión a escala de grises (0 a 255 niveles de gris).

- Segmentación: Se basa en encontrar un valor de la escala de grises de tal forma que los valores entre 255 (color blanco) y el umbral escogido se identifiquen como fondo y el resto como impactos. Para encontrar el umbral óptimo se compara la foto original (en color) con el resultado que se obtiene al emplear un determinado valor umbral. Si visualmente se 
Capítulo III. Mecanización de los tratamientos cebo a bajo volumen comprueba que el número de impactos y su tamaño concuerdan aproximadamente con la foto original, se escoge ese valor de umbral para segmentar. El programa también permite escoger un "área mínima" de impacto, de tal forma que los objetos con un valor de gris menor al umbral fijado y una superficie menor que dicha área mínima no se consideran impactos. Cuando se escoge el umbral óptimo sin indicar un "área mínima" aparecen numerosos objetos muy pequeños que son ruido de fondo. La elección del área mínima depende de la población de impactos que se tenga. En el ensayo de pulverización hidráulica, en el que se produjeron impactos muy pequeños, se escogió un área mínima de $8.028 \mu \mathrm{m}^{2}$ (equivalente a un diámetro de $50 \mu \mathrm{m}$ ) mientras que en el ensayo de pulverización centrífuga, en el que no se producían impactos tan pequeños se aumento el área mínima a un valor de $10.877 \mu \mathrm{m}^{2}$ (equivalente a un diámetro de $59 \mu \mathrm{m}$ ). El área mínima se escogió al analizar algunos colectores sin imponer la restricción de área mínima y observar en los resultados los tamaños de los impactos que aparecían.

Como resultado del análisis el programa proporcionaba un archivo con el número de los impactos y el área de cada uno. A partir de estos datos, en cada colector se estimó el porcentaje de recubrimiento a través del área ocupada por los impactos dividida por el área total de la región del colector estudiada y multiplicada por 100. También se calculó el número de impactos por centímetro cuadrado y el diámetro del área proyectada, definido como el diámetro de un círculo cuya área coincide con el área proyectada del impacto. 


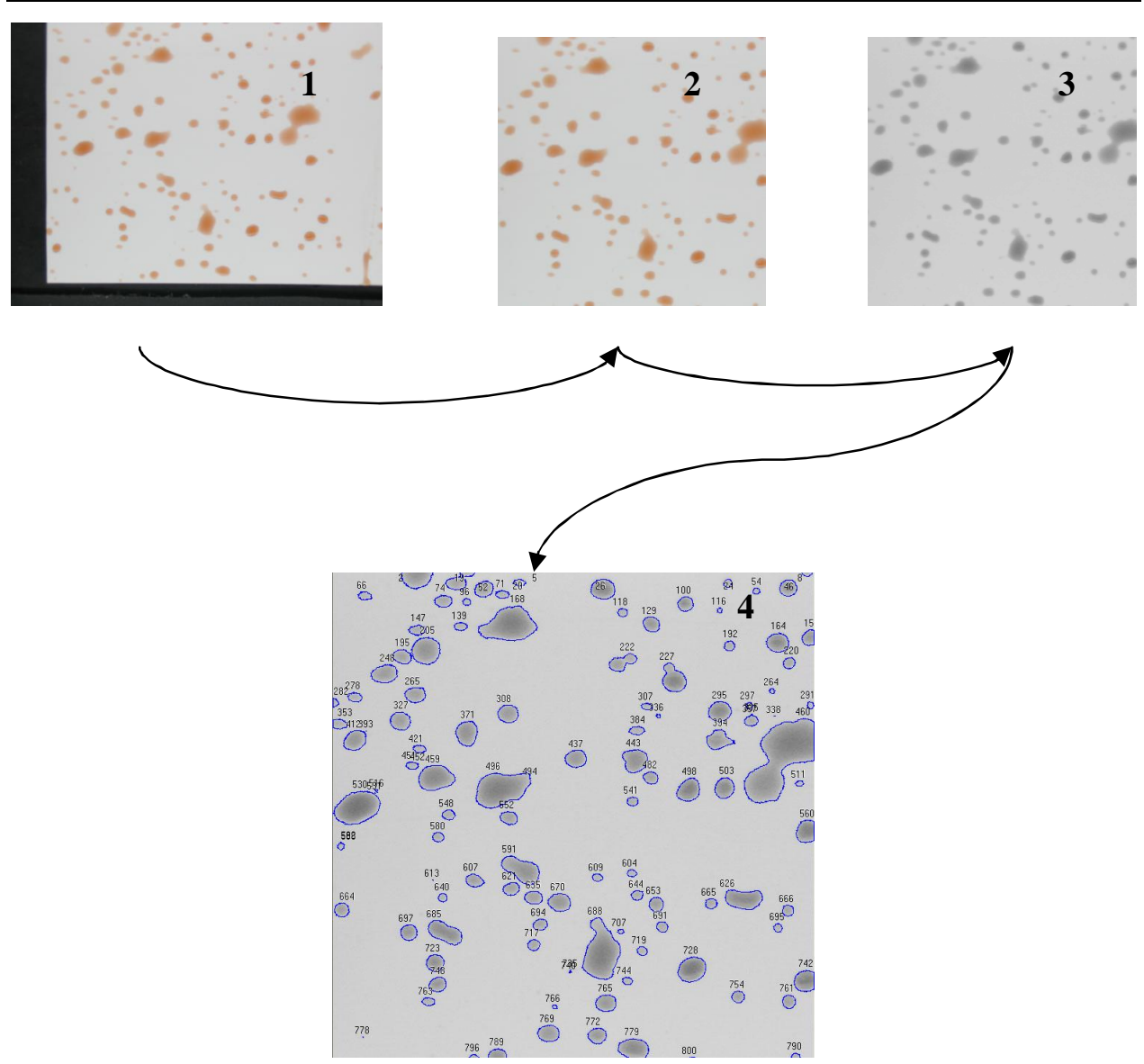

Figura 15. Secuencia del proceso de análisis de imagen: 1. Foto original; 2. Foto recortada; 3. Foto en escala de grises; 4. Foto segmentada. Cada impacto está etiquetado con un número diferente.

\subsubsection{Análisis de los datos}

En primer lugar, se representó para cada colector la población de impactos, mediante la fracción de área acumulada frente al diámetro del área proyectada. Posteriormente, con ayuda de un programa de cálculo (Matlab versión 6.5. Release 13, The MathWorks, Inc., MA, USA) cada representación se ajustó a las funciones de Rosin-Rammler acumulada y Log-normal acumulada. La bondad de ajuste de cada una de las funciones se determinó mediante el cálculo de la suma de cuadrados debida al error, SSE, también llamada suma de cuadrados de los residuos, y el coeficiente de determinación $\mathrm{R}^{2}$, según la Ecuación 8 y la Ecuación 9 respectivamente. Se escogió la función con menor 
SSE y mayor $\mathrm{R}^{2}$ para cada colector. Por último, se hallaron la mediana y los cuartiles $\mathrm{D}_{25}$ y $\mathrm{D}_{75}$ como indicadores de la posición y el intervalo intercuartílico como indicador de la dispersión.

$$
\begin{aligned}
& S S E=\sum_{i=1}^{n}\left(y_{i}-\hat{y}_{i}\right)^{2} \\
& y_{i} \text { es el valor observado } \mathrm{i} \\
& \hat{y}_{i} \text { es el valor ajustado } \mathrm{i} \\
& R^{2}=\frac{S S R}{S S T}=\frac{\sum_{i=1}^{n}\left(\hat{y}_{i}-\bar{y}\right)^{2}}{\sum_{i=1}^{n}\left(y_{i}-\bar{y}\right)^{2}}=1-\frac{S S E}{S S T} \\
& \bar{y} \text { es la media de los valores observados. } \\
& \text { SSR es la suma de cuadrados explicada por la regresión. } \\
& \text { SST es la suma de cuadrados total. }
\end{aligned}
$$

Las variables sobre las que se estudió el efecto de los factores controlables en los dos ensayos fueron: la mediana, los cuartiles $\left(D_{25}\right.$ y $\left.D_{75}\right)$ y el intervalo intercuartílico del diámetro, el recubrimiento, el volumen pulverizado por unidad de superficie y el número de impactos por centímetro cuadrado.

El efecto de los factores controlables sobre cada variable respuesta se estudió mediante el análisis de la varianza (ANOVA) multifactorial (Statgraphics ${ }^{\circledR}$ Plus versión 5,1, Intershare, S.L., Barcelona, España). Con este análisis se determinaron los factores e interacciones que influían significativamente sobre las variables respuesta. Para evaluar el cumplimiento de la hipótesis de normalidad de este modelo, se estudió la normalidad de los residuos de cada variable empleando la técnica del papel probabilístico normal. Esto permitió, al mismo tiempo, detectar datos anómalos, los cuales, en general, fueron eliminados del estudio. Cuando se detectó la falta de normalidad de los residuos de determinadas variables, los datos se transformaron convenientemente.

Para estudiar las diferencias entre los niveles o las variantes de los factores se utilizó el método de la mínima diferencia significativa (LSD "Least 
Significant Difference”). El nivel de confianza utilizado para el ANOVA y el método LSD fue del $95 \%$.

\subsection{RESULTADOS Y DISCUSIÓN}

En el ensayo de caracterización de dispositivos hidráulicos debido a que la pulverización se realizó verticalmente sobre la pared y que los colectores estaban dispuestos simétricamente respecto a la boquilla, el efecto de la gravedad provocó que llegasen menos gotas a los colectores situados a mayor altura y más gotas en los colectores de la parte inferior. De hecho, resultó que al colector superior (C3) no llegaron gotas, de modo que no se incluyó en el análisis.

En el Anejo 5 se muestra en detalle el resultado del efecto de los factores para cada variable respuesta en el ensayo de dispositivos hidráulicos. En este anejo se detallan los resultados de significación estadística obtenidos a partir del ANOVA factorial para cada una de las variables y se comentan los factores y las interacciones que fueron significativos. Del mismo modo, en el Anejo 7 se presenta el resultado del efecto de los factores para cada variable respuesta en el ensayo de caracterización de dispositivos centrífugos.

En el ajuste de las funciones de distribución de impactos se decidió ajustar las de las 4 boquillas hidráulicas a una función Log-normal, ya que la mayoría de los colectores presentaron valores menores de SSE y mayores de $\mathrm{R}^{2}$ que si se realizaba el ajuste a una función de Rosin-Rammler. Los resultados detallados del análisis se presentan en el Anejo 4. Por el mismo motivo, las poblaciones de impactos procedentes de la pulverización centrífuga se ajustaron mejor a la función de Rosin-Rammler (Anejo 6).

En la Figura 16 se muestra gráficamente la distribución acumulada de los impactos para cada una de las boquillas y presiones. Se observa que al pasar de 1 bar a 2 bar de presión en cada una de las boquillas estudiadas, el tamaño de los impactos disminuye considerablemente, de modo que a la hora de realizar los tratamientos en campo será preferible trabajar a la mínima presión. Respecto a 
Capítulo III. Mecanización de los tratamientos cebo a bajo volumen

las boquillas se observa que las de inducción de aire son las que están más desplazadas hacia la derecha dando lugar a impactos mayores, siendo los impactos de la boquilla AI-11003VS mayores que las de la boquilla AI11004VS. Por orden de tamaño de impactos la siguiente boquilla es la TT11004VP. La boquilla FL-5VS es la más desplazada a la izquierda y por tanto, la que menor tamaño de impactos proporciona. En la Tabla 6 se muestran los valores medios de mediana, $\mathrm{D}_{25}$ y $\mathrm{D}_{75}$ de los impactos producidos por cada boquilla y a cada presión. Entre los dispositivos hidráulicos se consideró que la boquilla AI-1003VS fue la más adecuada para realizar los tratamientos cebo a bajo volumen. A 1 bar de presión bajo las condiciones del ensayo se consiguieron impactos con diámetros medianos de $2.629 \mu \mathrm{m}$, estando el $50 \%$ del área mojada formada por impactos comprendidos ente 1.825 y $3.614 \mu \mathrm{m}$ y el $80 \%$ entre 1.355 у $5.097 \mu \mathrm{m}$.

Tabla 6. Valores medios de mediana, $D_{25}$ y $D_{75}$ de los impactos producidos por cada boquilla y a 1 y 2 bar de presión.

\begin{tabular}{|l|c|c|c|c|}
\hline Boquilla & $\begin{array}{c}\text { Presión } \\
\text { (bar) }\end{array}$ & Mediana $(\boldsymbol{\mu m})$ & $\mathbf{D}_{\mathbf{2 5}}(\boldsymbol{\mu m})$ & $\mathbf{D}_{\mathbf{7 5}}(\boldsymbol{\mu m})$ \\
\hline AI-11003VS & 1 & $2.628,87$ & $1.825,91$ & $3.614,84$ \\
\hline AI-11004VS & 1 & $2.407,12$ & $1.695,55$ & $3.310,42$ \\
\hline FL-5VS & 1 & $1.570,81$ & $1.291,38$ & $2.022,94$ \\
\hline TT-11004VP & 1 & $1.682,35$ & $1.269,79$ & $2.318,47$ \\
\hline AI-11003VS & 2 & $2.136,76$ & $1.551,58$ & $3.092,82$ \\
\hline AI-11004VS & 2 & $1.956,53$ & $1.421,22$ & $2.788,40$ \\
\hline FL-5VS & 2 & $1.276,77$ & $1.017,05$ & $1.500,92$ \\
\hline TT-11004VP & 2 & $1.367,43$ & 995,46 & $1.796,45$ \\
\hline
\end{tabular}




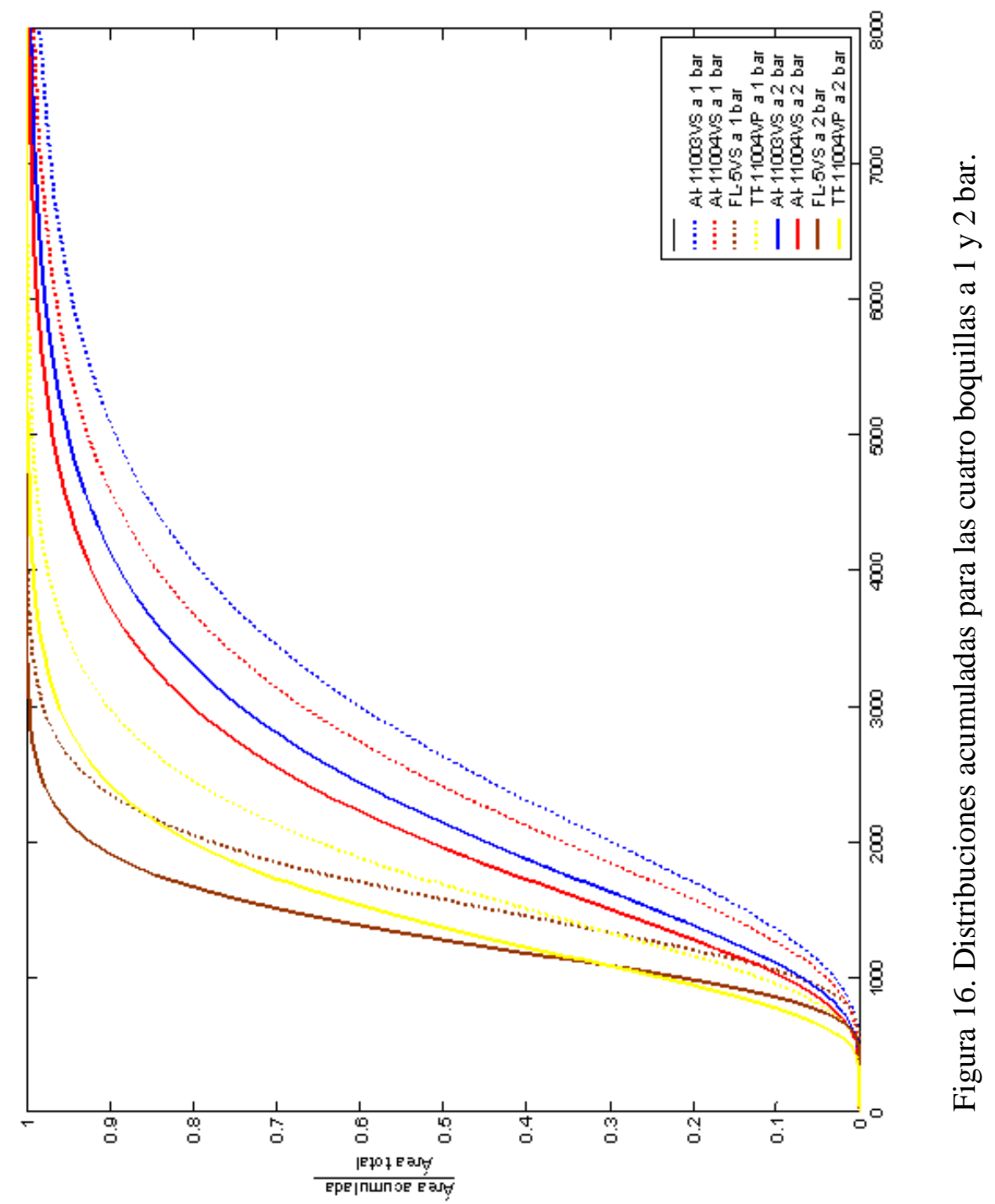


Capítulo III. Mecanización de los tratamientos cebo a bajo volumen

En el ensayo de dispositivos centrífugos el rango de tamaños de impactos producidos fue mayor que en el de dispositivos hidráulicos (Tabla 7).

Tabla 7. Valores medios de mediana, $D_{25}$ y $D_{75}$ de los impactos producidos por cada cabezal y velocidad de giro a $0,42 \mathrm{l} / \mathrm{min}$ y $0,83 \mathrm{l} / \mathrm{min}$.

\begin{tabular}{|c|c|c|c|c|c|c|c|}
\hline \multirow[b]{2}{*}{$\begin{array}{l}\text { Caudal } \\
\text { (l/min) }\end{array}$} & \multirow[b]{2}{*}{ Veloc. } & \multicolumn{2}{|c|}{ Mediana $(\mu m)$} & \multicolumn{2}{|c|}{$\overline{D_{25}(\mu m)}$} & \multicolumn{2}{|c|}{$\mathrm{D}_{75}(\mu m)$} \\
\hline & & C1 & $\mathrm{C} 2$ & C1 & $\mathrm{C} 2$ & C1 & $\mathrm{C2}$ \\
\hline \multirow{3}{*}{$\mathbf{0 , 4 2}$} & $\mathrm{r} 1$ & $5.704,78$ & $5.075,65$ & $3.827,7$ & $3.304,1$ & $7.983,3$ & $7.282,6$ \\
\hline & r2 & $2.903,84$ & $3.643,56$ & $2.143,0$ & $2.346,4$ & $3.745,3$ & $5.218,5$ \\
\hline & r3 & $2.111,71$ & $2.387,09$ & $1.496,6$ & $1.623,7$ & $2.535,4$ & $2.993,5$ \\
\hline \multirow{3}{*}{$\mathbf{0 , 8 3}$} & r1 & $6.347,37$ & $7.154,93$ & $3.866,4$ & $4.303,9$ & $9.251,2$ & 10.548 \\
\hline & r2 & $3.730,88$ & $5.907,29$ & $2.506,3$ & $3.670,8$ & $5.013,2$ & $8.484,2$ \\
\hline & r3 & $2.522,90$ & $4.234,97$ & $1.638,2$ & $2.726,4$ & $3.803,3$ & $6.259,2$ \\
\hline
\end{tabular}

En la Figura 17 se muestra gráficamente la distribución acumulada de los impactos para cada cabezal y velocidad de giro cuando el caudal fue de $0,42 \mathrm{l} / \mathrm{min}$. Se observa que entre las diferentes combinaciones de cabezal y velocidad de giro, el cabezal 2 a la velocidad de giro r2 (1.274 r/min) es el que presenta valores de tamaños de impactos más parecidos a los que buscados. La mediana media de los diámetros de impactos es igual a $3.640 \mu \mathrm{m}$, el $50 \%$ del área mojada esta formada por impactos con diámetros comprendidos entre $2.350 \mu \mathrm{m}$ y $5.220 \mu \mathrm{m}$ y el $80 \%$ entre $1.480 \mu \mathrm{m}$ y $6.470 \mu \mathrm{m}$. El cabezal 1 y el cabezal 2 a la velocidad de giro del motor $\mathrm{r} 1$ producen impactos mayores mientras que el resto de combinaciones da lugar a impactos menores.

En la Figura 18 se muestra la distribución acumulada de los impactos para cada cabezal y velocidad de giro del motor pero cuando el caudal fue de 0,83 1/min. Se observa que al aumentar el caudal las curvas de distribución están más desplazadas a la derecha lo que indica que el tamaño de los impactos de las diferentes combinaciones es mayor que para el caudal de 0,42 1/min. En este caso la combinación de cabezal y velocidad de giro que produce impactos con 
tamaños similares a los deseados es el cabezal 1 a la velocidad de giro r2 (1.010 r/min). La mediana media de los diámetros de los impactos es de $3.730 \mu \mathrm{m}$, estando el $50 \%$ de los diámetros comprendidos entre $2.506 \mu \mathrm{m}$ y $5.013 \mu \mathrm{m}$ y el $80 \%$ entre $1.630 \mu \mathrm{m}$ y $6.320 \mu \mathrm{m}$.

La elección de un cabezal u otro depende del volumen de caldo que se desee pulverizar y la forma en que se haga. Si se quiere distribuir más volumen, se empleará el cabezal 1 y, si se quiere distribuir menos volumen, el 2. Por ejemplo, si se quiere pulverizar de forma continua en todas las calles una cantidad correspondiente a 20 1/ha, la mejor solución será el cabezal 2 a $0,42 \mathrm{l} / \mathrm{min}$, y si se quiere pulverizar solo en calles alternas, con la consiguiente disminución de los costes de pulverización, será mejor el cabezal 1 a 0,831/min. Si se desea pulverizar 40 1/ha se deberá seleccionar el cabezal 1. 


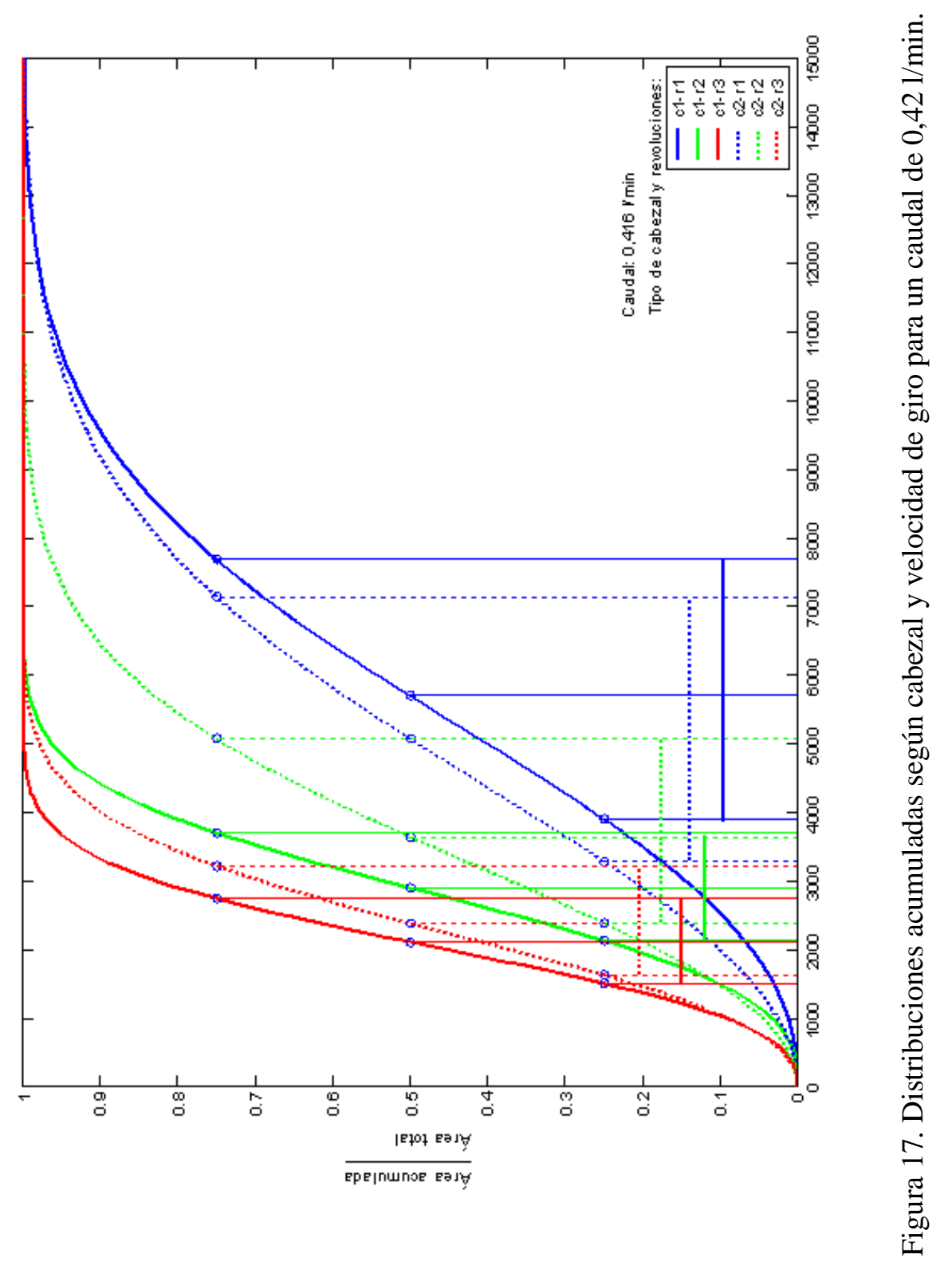




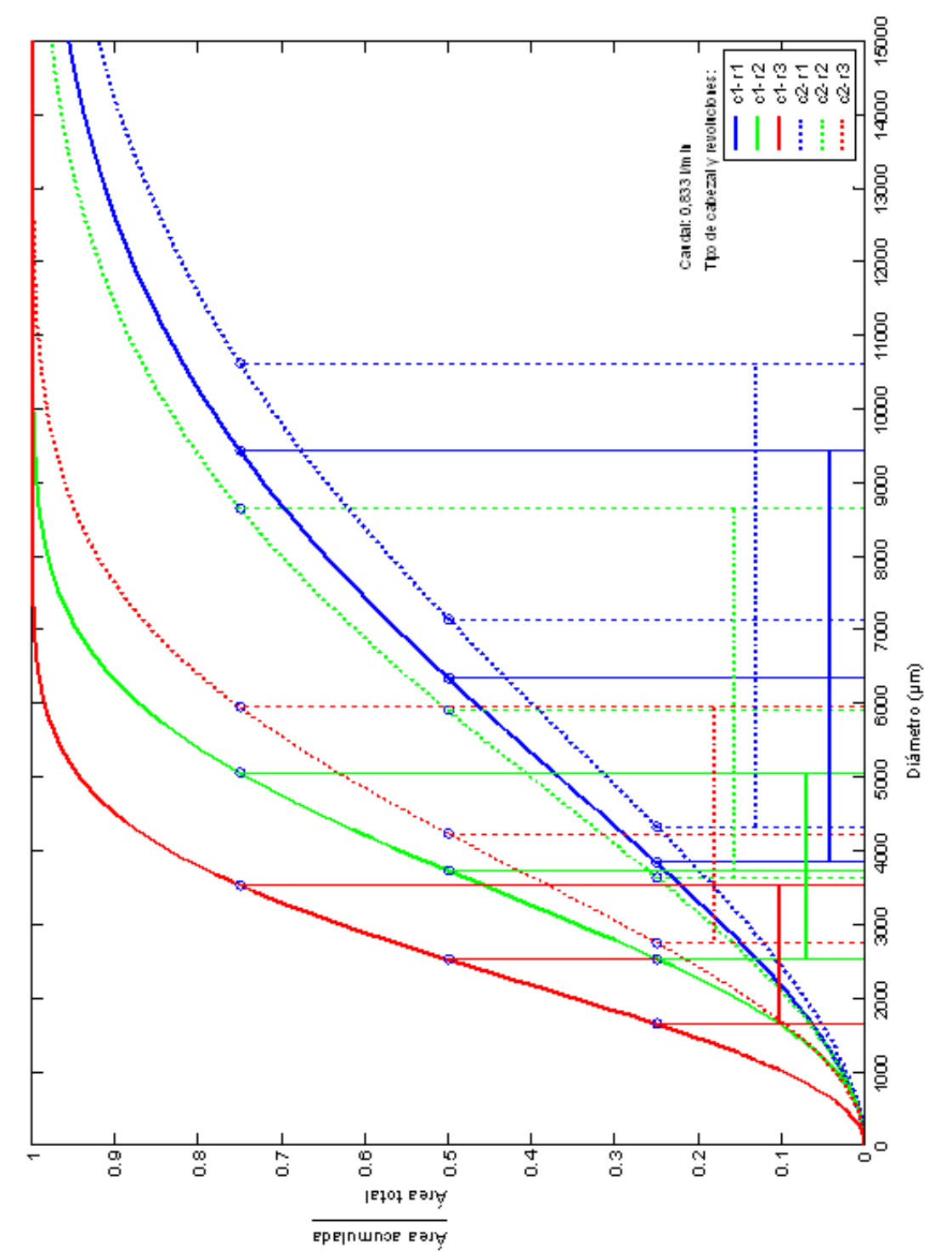

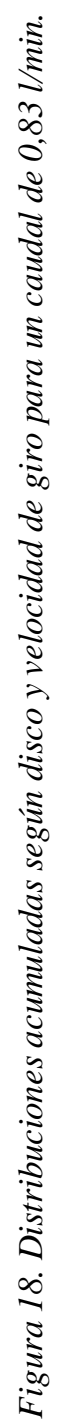


Los ensayos de caracterización han permitido hacer una primera selección de 3 dispositivos que trabajando en condiciones diferentes a las habituales proporcionan impactos de gran tamaño como los que se requieren para los tratamientos cebo. En la Figura 19 se comparan las curvas de distribución de las boquillas de inducción de aire a 1 bar de presión, con las curvas del cabezal 1 a la velocidad de giro $\mathrm{r} 2$ y del cabezal 2 a las velocidades $\mathrm{r} 2$ y r3, para los dos caudales ensayados.

Los cabezales centrífugos, en las condiciones de trabajo descritas, pueden conseguir impactos con diámetros medianos aproximadamente $1.000 \mu \mathrm{m}$ mayores que con la boquilla hidráulica AI-11003VS a 1 bar. Además, son más adecuados para tratamientos a bajo volumen. El inconveniente de estos dispositivos se presenta al querer utilizarlos en cultivos arbóreos, ya que se ha de pulverizar de manera horizontal, siendo la gravedad la encargada de que las gotas alcancen la vegetación. Existe la posibilidad de pulverizar lateralmente, y utilizar la asistencia de aire para transportar las gotas, pero con tamaños de gotas tan grandes no parece tener sentido porque las necesidades de caudal y velocidad de aire serían muy elevadas. Otra posibilidad es pulverizar por encima de los árboles, con las dificultades que ello supone para el diseño de un equipo, dados los diferentes tamaños de los árboles dentro y entre las parcelas y las dificultades que imponen las calles estrechas. La boquilla AI-11003VS a 1 bar puede realizar la aplicación de forma lateral sobre los árboles. Además, aunque los impactos son menores que los producidos por los dispositivos centrífugos, poseen el tamaño suficiente para realizar tratamientos cebo. El inconveniente de este dispositivo es que el volumen de caldo mínimo que se puede pulverizar es 40 1/ha a la velocidad de avance y la anchura de la calle elegidas, por lo que sería necesario el desarrollo de un sistema que permitiera reducir el volumen de caldo aplicado a base de una pulverización intermitente. Dado que ello es posible mediante el control electrónico de la máquina, se decidió escoger esta boquilla. 


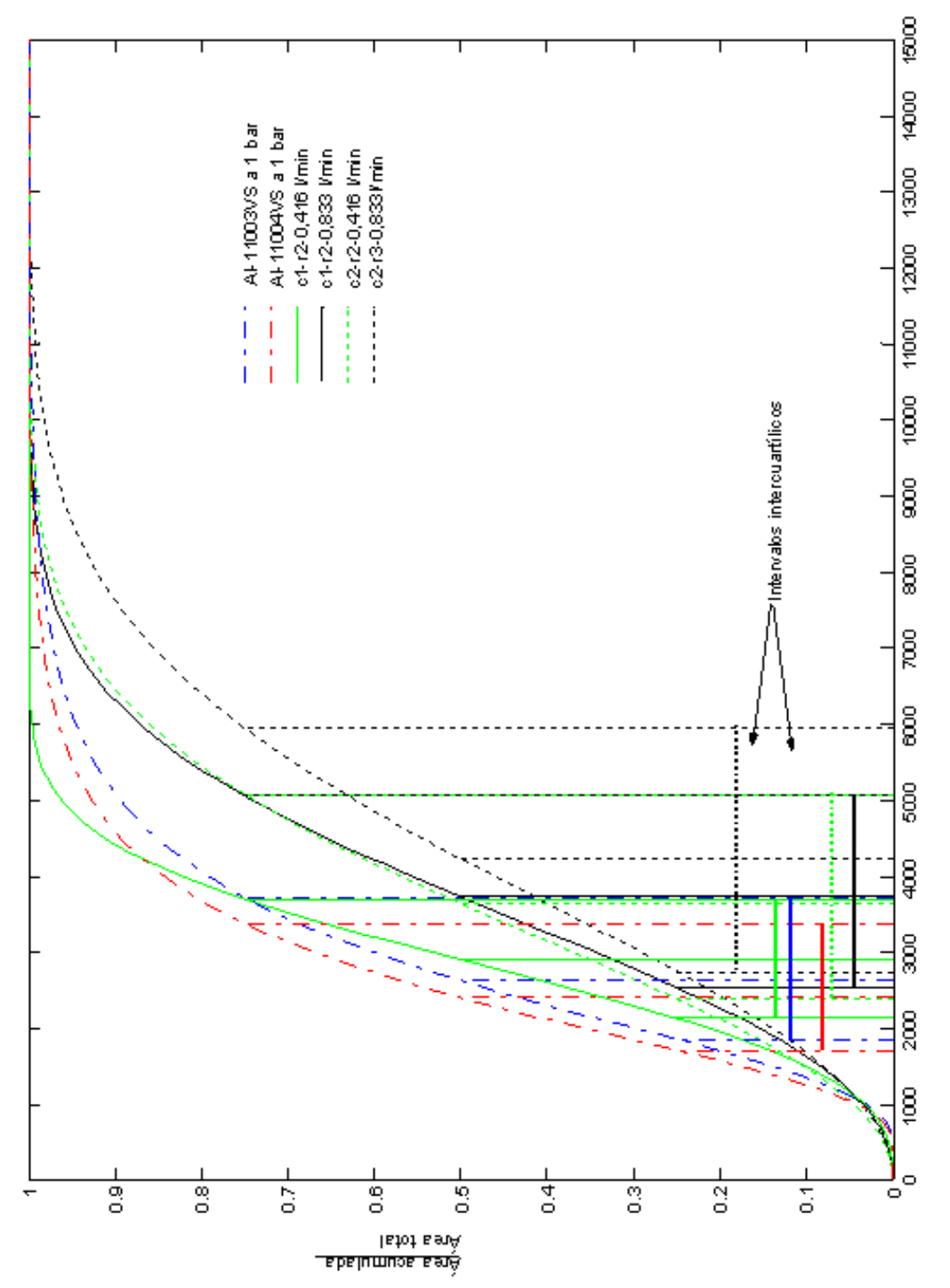

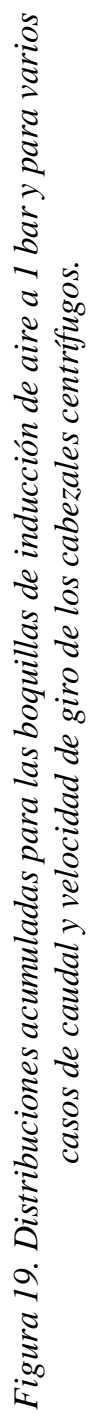




\section{SISTEMA AUTOMÁTICO PARA LA APLICACIÓN A BAJO VOLUMEN}

En este apartado se describe la máquina que se ha diseñado para la aplicación de tratamientos cebo a bajo volumen contra $C$. capitata. En primer lugar, se describen las funciones que se requieren del mismo. Posteriormente, las partes más importantes de la máquina y el algoritmo de control y, por último, el interfaz con el usuario. La maquina debía cumplir con los siguientes requerimientos:

- $\quad$ No necesitar de la atención del conductor durante el trabajo.

- Ser capaz de regular el caudal y dispersar bajos volúmenes de caldo.

- Aplicar todo el producto sobre la vegetación y evitar hacerlo en ausencia. de ésta.

- Adaptarse a las características de la vegetación de los huertos de cítricos, que puede ser continua o no.

- Tener la posibilidad de definir las zonas de la copa sobre la que se desea depositar el producto.

En el diseño del equipo se partió de experiencias previas realizadas en el Centro de Agroingeniería del IVIA con una máquina suspendida para pulverización a distancia constante que consistía en una barra dotada de movimiento horizontal que era capaz de acercarse y alejarse del árbol de manera automática, en función de la distancia entre la barra y la copa del árbol (Moltó et al., 2000).

\subsection{DESCRIPCIÓN FUNCIONAL}

Con el fin de imitar un tratamiento manual con mochilas, la idea básica fue construir una máquina que detectase automáticamente la vegetación y distribuyese el producto continua o intermitentemente, como lo hace una persona 
con una mochila, en los lugares apropiados del árbol (principalmente sobre la copa, en la parte más cercana al centro de la calle).

La máquina trabaja en un entorno estructurado, como es una calle de una plantación de cítricos, y avanza aproximadamente por el centro de la calle, pues es conducida por un operario. A partir de la información de la posición de la vegetación respecto al tractor, se puede detectar por qué parte de la vegetación (al principio de un árbol, por su parte central, por la parte final o entre dos árboles) están pasando las boquillas y programar el momento de inicio y final del tratamiento sobre el árbol. De este modo, se pueden definir las zonas de los árboles que reciben el producto a medida que avanzase el tractor.

Por otra parte, y con el fin de poder variar el volumen aplicado por unidad de superficie, la máquina ha de ser capaz de tratar todos los árboles de una hilera, o solamente uno de cada dos, o uno de cada tres.

En consecuencia, se concibió una máquina capaz de detectar las copas de los árboles, pulverizar automáticamente a partir de un punto prefijado por el usuario, en función del inicio de la detección de la vegetación, y terminar tras un tiempo prefijado, reproduciendo este ciclo en cada árbol, en cada dos o en cada tres.

El trabajo anterior del Centro de Agroingeniería en la detección de la vegetación mediante sensores de ultrasonidos, que miden la distancia entre el sensor y los objetos más cercanos de una manera fiable, hizo que se eligiese esta tecnología para esta máquina.

Además, debido a que las características agronómicas de cada plantación requieren condiciones de trabajo particularizadas (por ejemplo, hay parcelas con árboles grandes, que presentan un continuo de vegetación; o parcelas con árboles pequeños, cuyas ramas no tocan a los árboles adyacentes), el equipo debía dar al usuario la posibilidad de configurarlo fácilmente, con el fin de establecer de 
manera sencilla cuándo se pulveriza, qué partes del árbol deben recibir el producto y cuánto se gasta.

En los próximos apartados se describe con más detalle la forma en que estas ideas se pusieron en práctica sobre el prototipo.

\subsection{DESCRIPCIÓN DEL PROTOTIPO}

El prototipo se montó sobre un pulverizador hidráulico suspendido (Pulverizadores FEDE S.L., Cheste, España), que consta de un depósito de poliéster de 4001 de capacidad, una bomba de tres membranas, una válvula limitadora de presión para regular la presión de trabajo, un manómetro para medir la presión a la salida de la bomba y un sistema de recirculación del líquido que proviene de la bomba a presión. Sobre este equipo se modificó el circuito hidráulico y se instaló el sistema electrónico desarrollados al efecto (Figura 20).

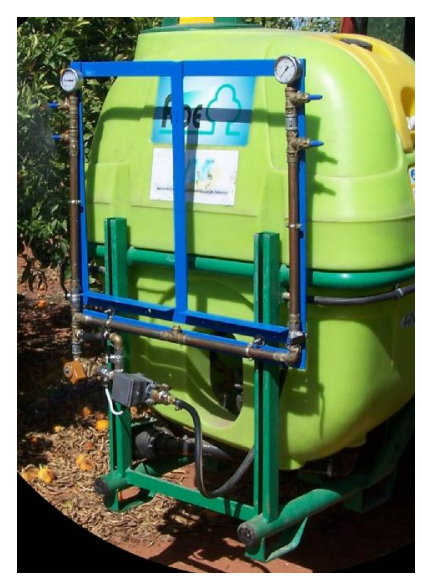

Figura 20. Montaje del sistema hidráulico y electrónico sobre un pulverizador hidráulico suspendido.

\subsubsection{Circuito hidráulico}

El circuito hidráulico, además de por el depósito, la bomba y el manómetro general ya mencionados, está formado por:

- Cuatro boquillas del modelo seleccionado (Teejet AI-11003VS), dos a cada lado del pulverizador. 
- Dos manómetros, uno por lado del pulverizador y cerca de las boquillas, para medir la presión del líquido que llega a la boquilla.

- Una electroválvula de solenoide servomandada (Lucifer, modelo $321 \mathrm{~K}$ 15 03E, Parker Hannifin S.p.A., Gessate, Italia), que abre y cierra el circuito hidráulico. Se encuentra situada entre la bomba del equipo y las boquillas.

\subsubsection{Sistema electrónico}

El sistema electrónico se construyó en el laboratorio de electrónica del Centro de Agroingeniería y consta de:

- La unidad de control. Formada por una placa electrónica cuyo elemento principal es el microcontrolador de arquitectura RISC CPU modelo 16F877A (Microchip Technology Incorporated, Chandler, USA). La unidad de control incorpora un teclado y una pantalla que permiten al usuario introducir los parámetros de pulverización que configuran el tratamiento y visualizarlos. Todo el sistema electrónico se integró en un encapsulado que proporciona un grado de protección IP-65 contra la penetración de polvo y líquidos presentes durante la pulverización (Figura 21). La unidad de control se coloca en la cabina del tractor.

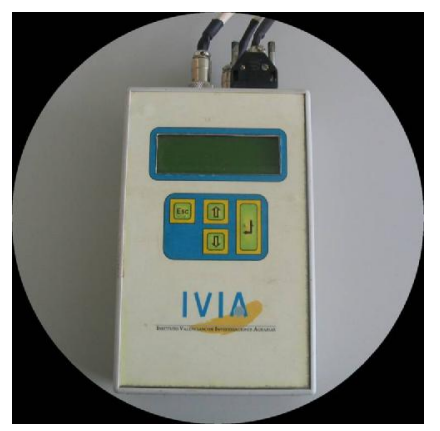

Figura 21. Unidad de control del prototipo.

- Un sensor de ultrasonidos (Sonar-BERO, modelo 3RG6176-6GH00, Siemens, Munich, Alemania), para la detección de la vegetación. Su señal 
de salida analógica, proporcional a la distancia del objeto detectado, se acondicionó a las características eléctricas del microcontrolador a través de un divisor de tensión. Dicha señal es adquirida por el microcontrolador a través de uno de los canales Analógicos/Digitales con un periodo de muestreo de $10 \mathrm{~ms}$.

Al avanzar el tractor, el sensor de ultrasonidos se encuentra adelantado $0,8 \mathrm{~m}$ respecto a las boquillas de pulverización y va proporcionando información sobre el perfil de las copas que se encuentra. Existe un retraso entre el momento en que se está detectando la distancia al follaje y el momento en que se da la orden de pulverizar sobre esa zona. El retraso depende de la velocidad de avance del tractor y es gestionado por el algoritmo de control.

En la Figura 22 se muestra un diagrama de bloques del sistema electrónico, en el que se aprecian las distintas interacciones del microcontrolador con su entorno: recibe la información del sensor de ultrasonidos, así como la configuración de pulverización introducida por el usuario a través del teclado, las procesa y actúa sobre la electroválvula para producir la pulverización. La pantalla sirve para simplificar las comunicaciones con el usuario.

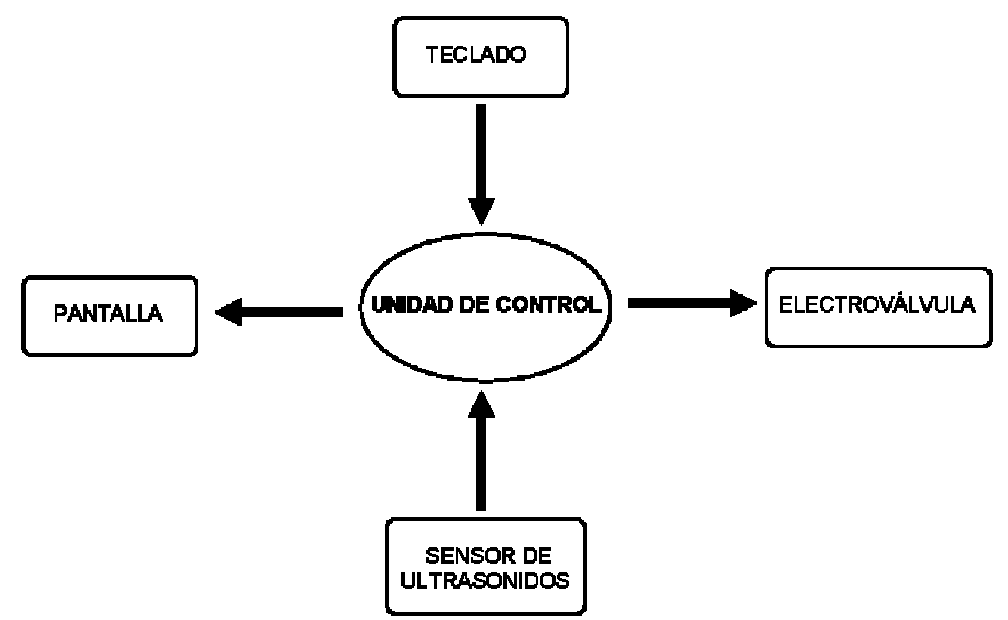

Figura 22. Diagrama de bloques del sistema electrónico. 


\subsection{ALGORITMO DE CONTROL}

El programa de control de la máquina se desarrolló con el compilador PCW (versión 3.26, Custom Computer Services Incorporated, Brookfield, Reino Unido). El programa gestiona la interacción con el usuario a través de la pantalla y el teclado, así como la puesta en marcha del tratamiento. Por otro lado, controla el tratamiento procesando la señal procedente del sensor de ultrasonidos y actuando sobre la electroválvula.

Debido a que se desea realizar la pulverización con la boquilla situada a menos de un metro respecto a la copa de los árboles, el algoritmo de control considera que la detección de objetos a distancias superiores supone la ausencia de vegetación.

En los campos de cítricos es muy frecuente que las copas de los árboles dentro de las filas no presenten discontinuidades, por lo que en estos casos el sensor nunca detecta objetos a distancias superiores a un metro. Dado que se pretende detectar cada uno de los árboles individualmente, el algoritmo de control debe distinguir cada copa. Ello se consigue analizando las tendencias de los datos de distancia que provienen del sensor de ultrasonidos: el final de un árbol se caracteriza por proporcionar una secuencia de datos de distancia que se va incrementando, mientras que el principio del siguiente árbol proporciona una secuencia descendente, al ir aumentando la distancia a la vegetación.

Con el fin de eliminar falsas detecciones el algoritmo de control aplica un filtro de mediana sobre los datos anteriores y posteriores del sensor en cada instante, antes de dar un dato concreto como válido.

El programa de control, además, gestiona el sistema de menús que componen el interfaz con el usuario y configura los parámetros de tratamiento en función de la selección realizada por el usuario a través del teclado. 


\subsection{INTERFAZ CON EL USUARIO}

A través del teclado de la unidad de control, el usuario puede configurar y controlar el tratamiento que va a realizar. A continuación se muestran los menús que aparecen en la pantalla de la unidad de control:

1) Iniciar el tratamiento, aceptando los parámetros operativos que guarda en la memoria el sistema electrónico.

2) Indicar las condiciones de trabajo. El usuario puede elegir las condiciones operativas siguientes:

- $\quad$ El marco de plantación en intervalos de $50 \mathrm{~cm}$ desde $0 \mathrm{~cm}$.

- La velocidad de avance: 1 - 2 - $3 \mathrm{~km} / \mathrm{h}$.

- El modo de pulverización: Todos los árboles - Cada dos árboles - Cada tres árboles.

- Inicio de pulverización en intervalos de $10 \mathrm{~cm}$ desde $0 \mathrm{~cm}$ desde el momento de la detección de la copa.

- Tiempo de apertura de la electroválvula en intervalos de 100 ms desde $0 \mathrm{~ms}$.

\section{ENSAYOS PARA LA EVALUACIÓN DEL EQUIPO EN CONDICIONES DE CAMPO}

Una vez diseñado el prototipo el siguiente paso fue evaluarlo en condiciones de campo y comprobar que realiza adecuadamente el trabajo para el que fue diseñado.

Como ya se ha comentado, en los tratamientos cebo contra $C$. capitata se desea que los impactos se distribuyan en el exterior de la copa del árbol, sobre la cara más soleada, para que las moscas alcancen fácilmente los depósitos de producto. Pulverizar en el interior carece de sentido, pues no mejora la eficacia 
del tratamiento y, por el contrario, puede afectar más a la fauna útil, que se localiza en el interior como ocurre, por ejemplo, con muchos fitoseidos.

Por este motivo, en este apartado se analiza, en primer lugar, cómo el prototipo distribuye el volumen de caldo sobre la copa de los árboles.

Además, es necesario comprobar que el prototipo funciona correctamente en distintas condiciones reales. Para ello, en este apartado también se estudia si el prototipo es capaz de adaptarse a diferentes parcelas comerciales representativas de cítricos, independientemente de sus características (marcos y esquemas de plantación, edad de los árboles) $\mathrm{y}$, por tanto, si es capaz de detectar adecuadamente los árboles en diferentes condiciones de vegetación y de abrir y cerrar la electroválvula según las especificaciones indicadas.

\subsection{MATERIALES Y MÉTODOS}

\subsubsection{Comprobación de la correcta distribución del caldo sobre la copa de}

\section{los árboles}

El ensayo se realizó en la parcela B cuyas características se describen en el Anejo 8.

Para detectar donde se producen las deposiciones se colocaron papeles hidrosensibles de 7,6 x 2,6 cm de tamaño (Spraying Systems Co., Wheaton, IL), ubicados en 16 puntos de la copa de un árbol (Figura 23). Las posiciones son el resultado de la combinación de:

- 2 alturas: plano superior (coincidiendo con la altura de las boquillas y a $120 \mathrm{~cm}$ del suelo) y plano inferior (a $40 \mathrm{~cm}$ por debajo).

- 4 orientaciones: norte (zona de la copa situada hacia la calle), sur (cara soleada y hacia la calle), este (zona entre dos árboles de la misma fila) y oeste (zona entre dos árboles de la misma fila).

- 2 profundidades: exterior e interior (a $40 \mathrm{~cm}$ del exterior). 

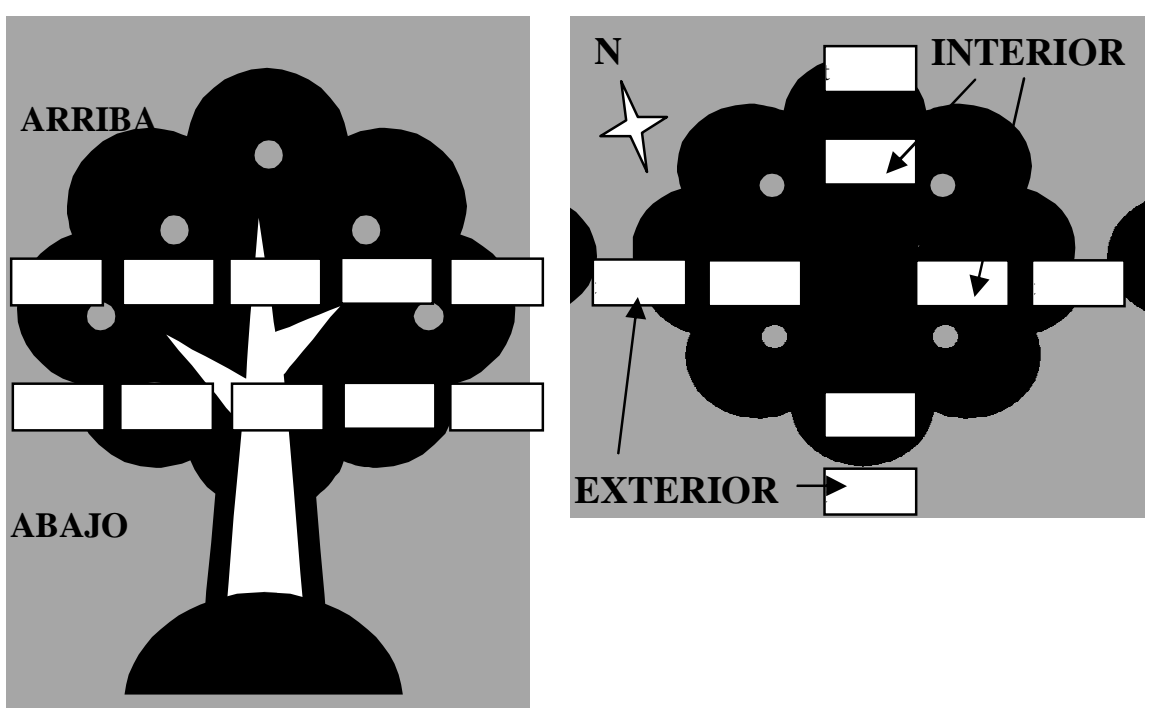

Figura 23. Distribución de los papeles hidrosensibles en el árbol. Vista en alzado (Izquierda). Vista en planta (Derecha).

El tratamiento cebo se realizó sobre la cara sur de los árboles. Se pulverizó un volumen de caldo de 80 1/ha, a 2 bar de presión y a una velocidad de avance de $3,2 \mathrm{~km} / \mathrm{h}$. Se eligió el volumen de 80 1/ha entre los recomendados de 20-100 1/ha porque se consideró un caso desfavorable, puesto que aumentaba la posibilidad de mojar excesivamente las partes no deseadas del árbol.

Tras la aplicación, y una vez que los árboles se habían secado, se recogieron los colectores y se analizaron por análisis de imagen siguiendo el procedimiento descrito anteriormente en los ensayos de caracterización de los dispositivos de pulverización. Se realizaron un total de 5 repeticiones.

Aunque en los tratamientos cebo el recubrimiento que se consigue no es un parámetro importante, se decidió utilizarlo como una estimación de lo manchados que estaban los papeles y, por ende, de la cantidad de caldo recogida en cada punto. Para estudiar el efecto de la zona del árbol sobre el recubrimiento se realizó un ANOVA de dos factores: la altura (a dos niveles) y la posición en el plano a una de las alturas ( 8 variantes, combinación de las cuatro orientaciones y dos profundidades). Para evaluar el cumplimiento de la hipótesis de normalidad 
se estudió la normalidad de los residuos mediante papel probabilístico normal. Para estudiar la separación de medias entre las variantes se aplicó la prueba LSD. El nivel de confianza en ambos análisis fue del $95 \%$.

\subsubsection{Validación del funcionamiento del equipo}

Los ensayos se realizaron en tres parcelas de cítricos comerciales con características agronómicas diferentes, parcela A, parcela C y parcela D (ver características de las parcelas en el Anejo 8).

Los ensayos de verificación consistieron en aplicar tratamientos cebo a bajo volumen sobre 1.000 árboles de cada una de las tres parcelas y comprobar, mediante observación directa, la correcta detección de los árboles y la adecuada apertura y cierre de la electroválvula.

En cada una de las parcelas se realizaron los tratamientos indicados en la Tabla 8, todos ellos en condiciones operativas reales, que supusieron la programación de distintas configuraciones de pulverización en la unidad de control del prototipo. Los parámetros de pulverización comunes para todos los ensayos fueron: velocidad de avance de $3 \mathrm{~km} / \mathrm{h}$, presión de trabajo de 2 bar y volumen aplicado entre 20-30 1/ha. El inicio de la pulverización dentro de cada árbol se situó a $20 \mathrm{~cm}$ desde la detección del comienzo de la copa.

Tabla 8. Configuraciones de pulverización ensayadas en cada parcela.

\begin{tabular}{|c|c|c|}
\cline { 2 - 3 } \multicolumn{1}{c|}{} & Modo de Pulverización & $\begin{array}{c}\text { Tiempo de apertura de } \\
\text { la electroválvula (ms) }\end{array}$ \\
\hline \multirow{4}{*}{ PARCELA A } & Cada árbol & 1.600 \\
\cline { 2 - 3 } & Cada árbol & 3.000 \\
\cline { 2 - 3 } & Cada dos árboles & 1.600 \\
\cline { 2 - 3 } & Cada dos árboles & 3.000 \\
\hline \multirow{2}{*}{ PARCELA C } & Cada árbol & 3.000 \\
\cline { 2 - 3 } & Cada árbol & 3.600 \\
\hline \multirow{2}{*}{ PARCELA D } & Cada árbol & 3.000 \\
\cline { 2 - 3 } & Cada árbol & 3.600 \\
\hline
\end{tabular}




\subsection{RESULTADOS Y DISCUSIÓN}

\subsubsection{Comprobación de la correcta distribución del caldo sobre la copa de los árboles}

En el análisis estadístico de los recubrimientos observados sobre los 16 puntos del árbol, el factor altura no resultó significativo (F-ratio $=0,46$, g.l. $=1-78, \mathrm{P}=0,5007)$ mientras que sí lo fue el factor posición, combinación de la orientación por la profundidad, (F-ratio= 17,20, g. $1 .=7-78, \mathrm{P}=0,0000)$.

En la Figura 24 se muestra la media del recubrimiento observado para cada una de las posiciones, integrando las dos alturas, ya que este factor resultó no ser significativo. El hecho de que aparezcan letras diferentes en dos posiciones de los colectores significa que se encontraron diferencias significativas de recubrimiento entre esas dos posiciones.

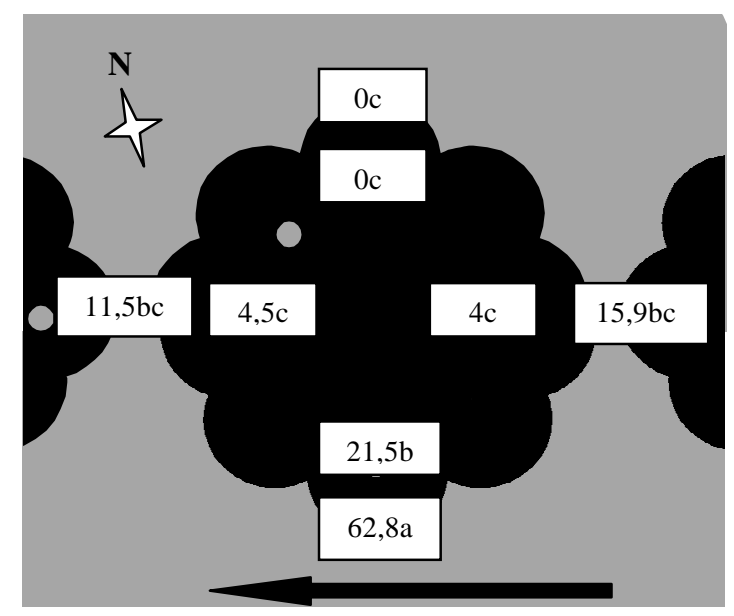

Figura 24. Porcentaje de recubrimiento obtenido en cada posición al promediar las alturas. Valores de la media seguidos de diferente letra muestran diferencias significativas (Prueba LSD a un nivel de confanza del $95 \%$ ). 
Se aprecia que, como se pretende, el caldo no se distribuyó homogéneamente por toda la copa: la mayor parte del producto pulverizado se distribuyó en la cara sur y en el exterior del árbol (recubrimiento del papel del $62,8 \%$ ) y significativamente mayor que en el resto de posiciones. En la misma cara, pero en el interior, el recubrimiento se redujo de manera significativa $(21,5 \%)$. La cara oeste y este se encuentran dentro de la fila y en el exterior se obtuvieron recubrimientos similares $(11,5 \%$ y $15,9 \%$ respectivamente). En la parte interior de estas zonas, los recubrimientos fueron muy bajos (4 y 4,5\%), no llegando prácticamente nada del caldo pulverizado. En la cara norte, al otro lado de la copa los recubrimientos, tanto en el exterior como en el interior del árbol, fueron nulos.

Estos resultados muestran que la mayoría del caldo pulverizado por el equipo se distribuye en cítricos en el exterior de la copa, sin excesiva penetración, dejando los depósitos de producto fácilmente accesibles para $C$. capitata. Es importante recordar que el volumen del tratamiento fue alto ( 80 1/ha), por lo que en tratamientos cebo con volúmenes inferiores se obtendrían menores deposiciones en el interior de los árboles.

\subsubsection{Validación del funcionamiento del equipo}

El sistema electrónico desarrollado fue capaz de detectar los 8.000 árboles tratados de las diferentes parcelas, hubiera separación o no entre ellos, por tanto, demostró su robustez y fiabilidad

La electroválvula produjo más de 6.000 ciclos de apertura y cierre sin error. Además, los tiempos de apertura de la electroválvula predefinidos se cumplieron.

Estos resultados indican que el prototipo funcionó correctamente en las distintas configuraciones ensayadas en cada una de las parcelas y demostraron que el pulverizador automático se adaptó a explotaciones comerciales de cítricos con diferentes características agronómicas. 


\section{ENSAYOS DE EFICACIA DE CONTROL DE $C$. capitata}

Tras el desarrollo del prototipo para la aplicación de tratamientos cebo a bajo volumen y la comprobación de su correcto funcionamiento en condiciones de campo, en este apartado se analiza la eficacia de los tratamientos realizados con el equipo sobre el control de $C$. capitata en plantaciones de cítricos comerciales.

Como se ha explicado anteriormente, Spintor $\mathrm{Cebo}^{\circledR}$ es un insecticida con elevada eficacia para el control de $C$. capitata y buenas características ecotoxicologías y que puede ser una buena alternativa al empleo de malation. Sin embargo, tras su uso, en algunas parcelas se ha detectado la aparición de negrilla $y$, en otras manchas, en los frutos durante el virado de color.

Estos problemas se atribuyen a algún aditivo del cebo de la formulación. Por este motivo, se pensó que una alternativa a este tratamiento podría ser emplear la materia activa spinosad (formulada sin el cebo), comercialmente denominada Spintor $480 \mathrm{SC}^{\circledR}$, y mezclarla con un cebo comercial que se emplea comúnmente para tratamientos cebo en cítricos. Spintor $480 \mathrm{SC}^{\circledR}$ no está registrado contra $C$. capitata ni en el cultivo de cítricos, por lo que no hay información disponible sobre la concentración y a la forma de aplicar esta mezcla. Por este motivo, en el primer apartado de este capítulo se pretende determinar la concentración y comparar su persistencia con el producto Spintor $\mathrm{Cebo}^{\circledR}$.

La evaluación de la eficacia de los tratamientos contra $C$. capitata a través del análisis de la evolución de las capturas en trampas presenta grandes dificultades, debido a las continuas reinvasiones y al movimiento natural de la plaga, tal y como ya se ha indicado en la introducción. Por esa razón, en este apartado se plantean y evalúan varios métodos para realizar los ensayos. 
En primer lugar, se intentó aislar la población de una parcela, ya que esto permitiría valorar el efecto del tratamiento a través de la estimación de la población antes y después de la aplicación de insecticida.

En caso de que este método no funcionase, se pensó en la posibilidad de determinar la eficacia mediante la comparación de los tratamientos entre si, pero para ello había que contar con que los niveles poblacionales iniciales entre las parcelas destinadas a cada tratamiento pueden ser diferentes. No considerar este aspecto puede dar lugar a una interpretación de los resultados errónea.

Paralelamente, dado que el número de capturas entre trampas próximas puede ser muy variable, es importante estudiar la distribución y evolución en el tiempo de las mismas en el interior de las parcelas, con el fin de determinar el número y situación de las trampas que se deben colocar y conocer si existen zonas que, por cualquier causa, parecen tener un mayor atractivo para el insecto.

El número y tipo de capturas depende del sistema de trampeo. Por este motivo, con el fin de decidir cual utilizar, de entre los actualmente comercializados, se hizo una experiencia para comparar los resultados entre los dos sistemas que actualmente más se emplean en la Comunidad Valenciana.

Por último, una vez resueltas todas estas cuestiones, al final del apartado se presentan los resultados de los ensayos que se realizaron para conocer la eficacia de los tratamientos cebo a bajo volumen sobre $C$. capitata en cítricos.

\subsection{AJUSTE DE LA CONCENTRACIÓN DE Spintor 480 $\mathrm{SC}^{\circledR}$ EN LABORATORIO}

El objetivo de los ensayos que se presentan en este punto es determinar la concentración adecuada de Spintor $480 \mathrm{SC}^{\circledR}$ para los tratamientos contra la mosca mediterránea de la fruta, ya que el producto no está registrado en cítricos contra esta plaga y, por lo tanto, no existen recomendaciones por parte del 
fabricante. Además se desconoce cuál es la persistencia de su efecto, lo cual es una información esencial para establecer la frecuencia de las aplicaciones.

\subsubsection{Materiales y métodos}

\section{Diseño experimental}

Se estudió el efecto de la concentración de Spintor $480 \mathrm{SC}^{\circledR}$ sobre la mortalidad de adultos de $C$. capitata, a través de un diseño experimental de un factor (tratamiento) con 5 variantes:

1) Tratamiento estándar: Spintor $\mathrm{Cebo}^{\circledR}$ al $10 \%$ (Spintor Cebo ${ }^{\circledR}$; Dow Agrosciencies).

2) Spintor $480 \mathrm{SC}^{\circledR}$ (Dow Agrosciencies) al 0,05\% más proteína hidrolizada Nu-lure (Miller Chemical and Fertilizer Co., Hanover, PA) al 0,5 \% como cebo.

3) Spintor $480 \mathrm{SC}^{\circledR}$ al 0,1 \% más la proteína hidrolizada Nu-lure al 0,5\%.

4) Spintor $480 \mathrm{SC}^{\circledR}$ a $0,15 \%$ más la proteína hidrolizada Nu-lure al 0,5\%.

5) Control con agua mineral.

Con el objeto de estimar la persistencia del efecto insecticida de los cuatro niveles del tratamiento se realizaron, siguiendo el mismo diseño, 3 experimentos complementarios, que consistieron en la exposición de los adultos de $C$. capitata a: 1) residuo fresco, 2) residuo de 3 días y 3) residuo de 6 días. En todos los casos se realizaron 10 repeticiones por tratamiento.

\section{Metodología}

El método que se empleó para conocer el efecto de los tratamientos sobre la mortalidad de adultos fue el descrito por Medina et al. (2004). Para ello, se recolectaron hojas de naranjo (Citrus sinensis (L) Osb. var. Navelina) que procedían de árboles situados en un invernadero del IVIA y que no habían sido sometidos a ningún tratamiento fitosanitario. Inmediatamente después, se lavaron 
las hojas. El peciolo de cada una se insertó en un tubo de Eppendorf que contenía una solución nutritiva $\left(\right.$ Triton $^{\circledR}$ con agua $(3 \%)$ ), descrita por Moutous y Fos (1973), para mantener la turgencia de la hoja durante los experimentos. El tubo se selló con plastilina (Plastilina Jovi ${ }^{\circledR}$ JOVI, S.A., Barcelona, España) para evitar la salida de la mezcla. Posteriormente, con una micropipeta se aplicaron 5 gotas de $5 \mu 1$ del tratamiento, que se distribuyeron aleatoriamente en cada hoja (Figura 25).

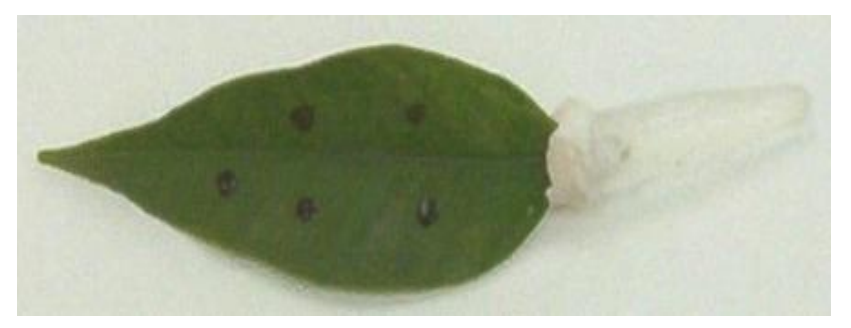

Figura 25. Hoja de clementino con las 5 gotas de 5 ul aplicadas mediante micropipeta, unidas por el peciolo a una disolución de Triton ${ }^{\circledR}(3 \%)$.

Cada hoja tratada se introdujo en una caja de plástico rectangular, de $15 \times 10 \times 7 \mathrm{~cm}$, con cierre hermético, formando la unidad experimental (Figura 26). Para permitir la ventilación de la caja, la tapa poseía una abertura sellada con tela muselina $(12 \times 8 \mathrm{~cm})$. El tubo de Eppendorf se fijaba dentro de ella con plastilina.

Antes de la introducción de las moscas, en cada caja se puso, como alimentación alternativa al cebo, una mezcla de agua y miel (1:1), dentro de un Eppendorf cerrado con algodón, que también se fijó con plastilina. Del mismo modo, se colocó un Eppendorf con agua para bebida (Figura 26).

En la experiencia con residuo fresco se introdujeron 10 moscas por unidad experimental una vez las gotas se habían secado. En las experiencias con residuo de 3 y 6 días, el mismo número de moscas se introdujo en las correspondientes cajas pasados los días establecidos. 
Durante el ensayo, las unidades experimentales permanecieron en una cámara climática a $25 \pm 2{ }^{\circ} \mathrm{C}$, con un $60 \pm 10 \%$ de humedad relativa y con un fotoperiodo de 16:8 h (L:O).

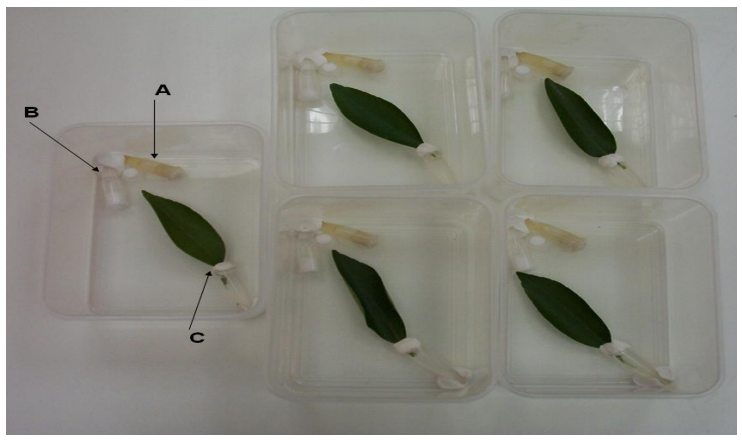

Figura 26. Unidades de ensayo. A) Eppendorf con miel y agua, B) Eppendorf con agua,

C) Hoja con tratamiento insertada en tubo Eppendorf con solución nutritiva.

Las moscas empleadas en los ensayos procedieron de las crías en cautividad mantenidas en las instalaciones de la Unidad de Entomología del IVIA. Para obtener adultos de la misma edad en cada experimento, se recolectaron aproximadamente 1.000 pupas de menos de 24 horas y se mantuvieron en bandejas de plástico de $20 \times 20 \times 20 \mathrm{~cm}$, con tierra húmeda esterilizada, hasta la emergencia de adultos. Para los ensayos se utilizaron adultos emergidos de menos de 24 horas de edad.

\section{Evaluación de la mortalidad y análisis de los datos}

La evaluación de la mortalidad para cada experiencia se realizó diariamente, hasta el sexto día después de introducir los adultos, y se basó en contar el número de individuos muertos en cada unidad experimental. Posteriormente, se calculó el porcentaje de mortalidad y, por último, el porcentaje de mortalidad corregida respecto al tratamiento control mediante la ecuación de Schneider-Orelli (Abbott, 1925) (Ecuación 10). 
$\%$ Mort.Corregida $=\left(\frac{\% \text { Mort }_{\text {Tratamiento }}-\% \text { Mort }_{\text {Control }}}{100-\% \text { Mort }_{\text {Control }}}\right) \times 100 \quad$ Ecuación 10

Donde:

$\%$ Mort $_{\text {Tratamiento }}$ es el porcentaje de mortalidad obtenido en el tratamiento.

$\%$ Mort $_{\text {Control }}$ es el porcentaje de mortalidad obtenido en el control.

En cada experimento, para estudiar el efecto de los tratamientos sobre la mortalidad de adultos de $C$. capitata se realizó un ANOVA de un factor y se aplicó la prueba de LSD para la separación de las medias. El nivel de confianza en los análisis fue del $95 \%$. Para evaluar el cumplimiento de la hipótesis de normalidad se estudió la normalidad de los residuos mediante papel probabilístico normal. Cuando la hipótesis no se cumplió, los datos se transformaron con la función arcosen $(\sqrt{ }(\mathrm{x}))$.

\subsubsection{Resultados}

En la Tabla 9 se muestra el porcentaje de mortalidad de adultos de C. capitata para cada tratamiento y para los tres experimentos de persistencia. En todos ellos se puede observar que, a partir del segundo día de evaluación, hubo diferencias significativas con el control. Por ello se concluye que todos los tratamientos cebo ensayados resultaron tóxicos para los adultos de $C$. capitata.

En el experimento con residuo fresco, a partir del segundo día de evaluación, no hubo diferencias significativas de mortalidad entre los cuatro tratamientos. En los experimentos con residuo de 3 y de 6 días ocurrió lo mismo, pero a partir del tercer día de evaluación.

Durante el primer y segundo día de evaluación, el tratamiento con Spintor $480 \mathrm{SC}^{\circledR}$ al $0,05 \%$, que es el que menos spinosad aporta, presentó los menores porcentajes de mortalidad en las tres experiencias de persistencia (excepto con residuo fresco el primer día de evaluación). El tratamiento que produjo mayor mortalidad fue el de Spintor $\mathrm{Cebo}^{\circledR}$, excepto en el segundo día de 
evaluación con residuo fresco. Los tratamientos de Spintor $480 \mathrm{SC}^{\circledR}$ al 0,1\% y al $0,15 \%$ dieron resultados muy similares.

Los resultados de los ANOVAS se muestran en el Anejo 9.

La Figura 27 muestra la mortalidad corregida para cada tratamiento y cada experimento. Se observa que, después del tercer día de evaluación, la mortalidad corregida alcanzó valores mayores al 90\% para todos los tratamientos, excepto para el de Spintor $480 \mathrm{SC}^{\circledR}$ al $0,05 \%$ en el experimento con residuo de 3 días ( $82 \%$ ). El último día de evaluación, los cuatro tratamientos produjeron mortalidades corregidas cercanas al $100 \%$. 


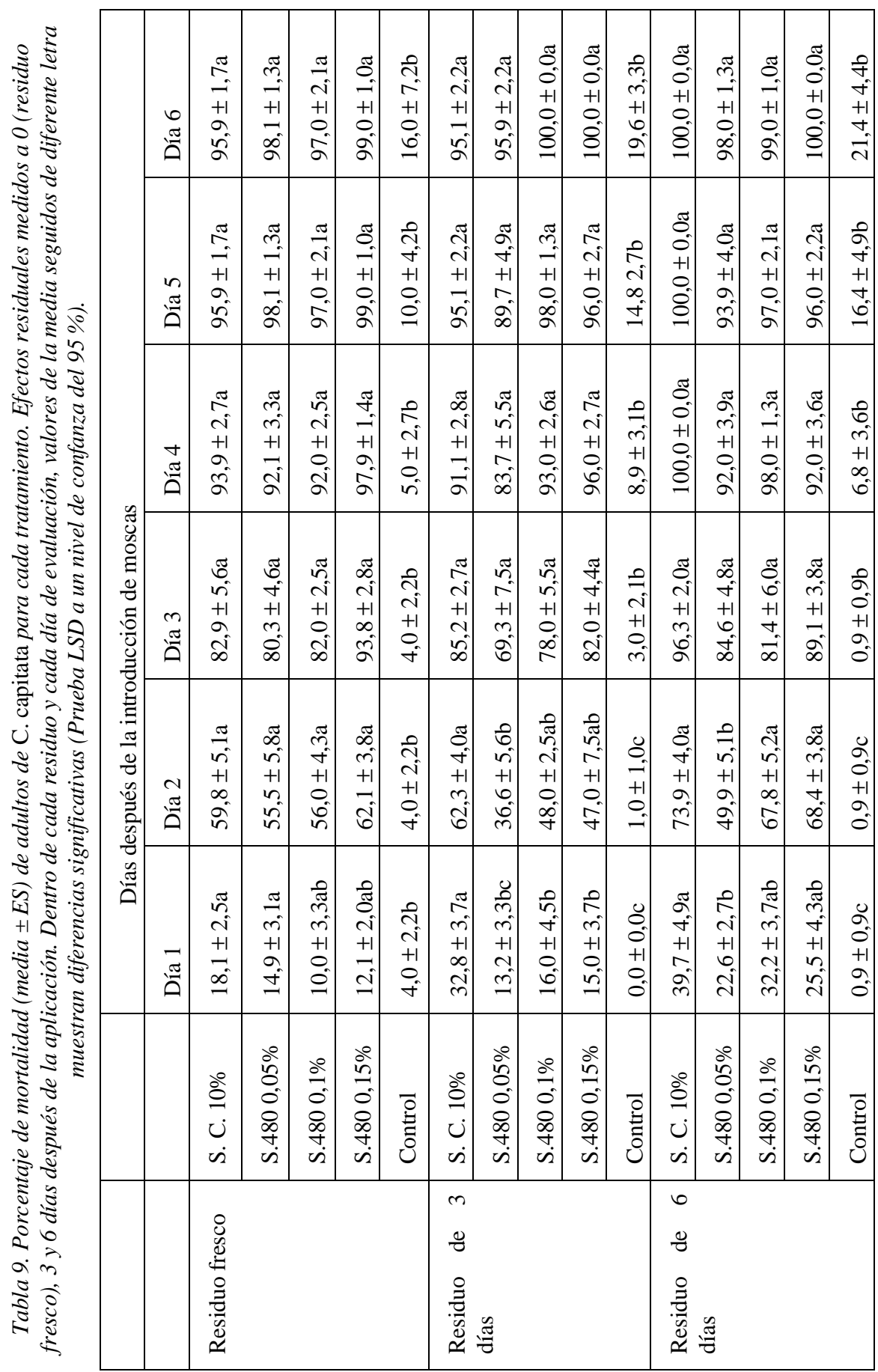



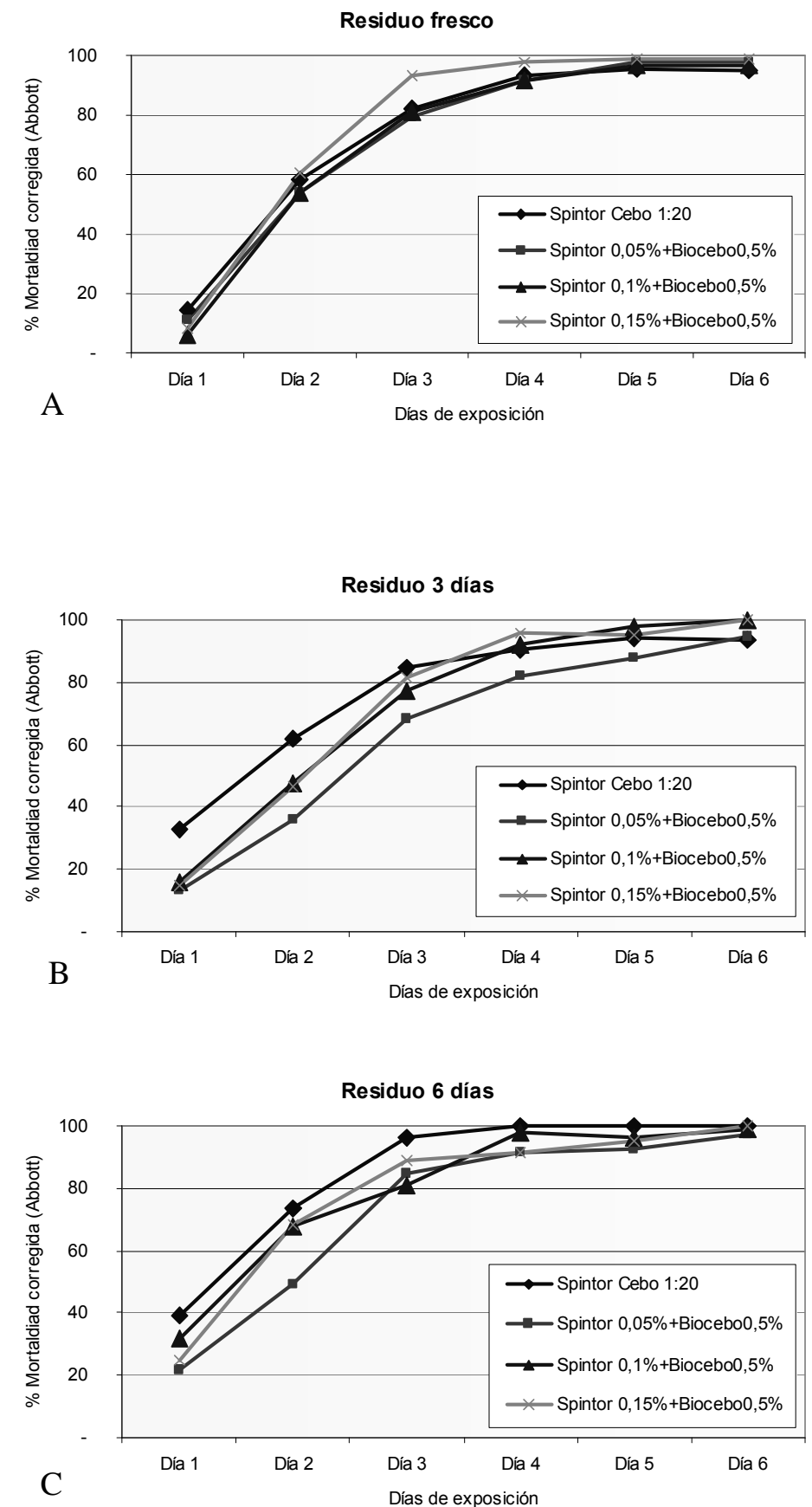

Figura 27. Mortalidad corregida de adultos de C. capitata para cada tratamiento. Experimentos con A) Residuo fresco, B) residuo de 3 días y C) residuo de 6 días. 


\subsubsection{Discusión}

Es importante destacar que todos los tratamientos resultaron eficaces para el control de $C$. capitata. En general, entre las tres concentraciones de Spintor $480 \mathrm{SC}^{\circledR}$ ensayadas no se encontraron diferencias estadísticamente significativas de eficacia. Sin embargo, con la concentración al 0,05\% generalmente se obtuvieron menores valores medios de mortalidad. Por este motivo, para realizar los tratamientos en condiciones de campo, y dado que los ensayos de eficacia se iban a realizar en parcelas comerciales destinadas a exportación, se decidió seleccionar la concentración al 0,1\%.

También es conveniente recalcar el efecto residual de los productos, aunque teniendo en cuenta que los resultados se obtuvieron en condiciones de laboratorio. Los tratamientos tuvieron efecto insecticida hasta 6 días después de haber realizado las aplicaciones.

\subsection{EXPERIMENTOS PARA AJUSTAR LOS PROCEDIMIENTOS DE CAMPO}

En este apartado se presentan los dos ensayos que se realizaron para ajustar el procedimiento para la medida de la eficacia de los tratamientos sobre C. capitata en condiciones de campo.

El primer ensayo está orientado a investigar la posibilidad de aislar la población de una parcela. El segundo sirve para conocer si se pueden comparar los efectos de los tratamientos realizados en dos parcelas. A lo largo del mismo, también se comparan los resultados de dos sistemas de trampeo y se estudia la distribución de las capturas dentro de una parcela, con la finalidad de determinar las trampas que se utilizarán, en qué cantidad y dónde ubicarlas. 


\subsubsection{Materiales y métodos}

\section{Descripción de las parcelas y de los tratamientos}

Se eligieron dos parcelas comerciales contiguas, parcela A y parcela B (Anejo 8).

Al tratarse de parcelas comerciales, se realizaron tratamientos con malatión por parte del agricultor, que han de ser considerados a la hora de analizar los resultados de las experiencias. Concretamente se realizaron tratamientos de parcheo los días 11, 21 y 29 de agosto de 2003, que consistieron en la aplicación de un volumen de caldo de 500 1/ha sobre la cara sur de los árboles a una concentración del 0,5\% de Malafin 50 ${ }^{\circledR}$ (Malatión, 50\%) (Agrodan, S.A., Madrid, España) y del $0,5 \%$ de Nu-lure ${ }^{\circledR}$. También se realizaron tratamientos de cobertura total los días 10,17 , y 26 de septiembre y el 1 y 8 de octubre de 2003, que consistieron en la aplicación de 1000 1/ha con una concentración del $0,2 \%$ de Malafin $50^{\circledR}$. La recolección tuvo lugar el 10 de octubre.

\section{Descripción de los sistemas de trampeo}

Se probaron los dos sistemas de trampeo que más se usan actualmente en la C. Valenciana:

1) Trampas Tephri-trap ${ }^{\circledR}$ (Sorygar, S.L. Madrid, España) con atrayentes alimenticios Tri-pack ${ }^{\circledR}$ (5 g i.a. Acetato amónico, 50 mg i.a. Putrescina, y 2,50 g i.a. Trimetilamina) (Kenogard S.A., Barcelona, España) y una vapona insecticida de diclorvos (DDVP) $[0,5$ g i.a. Dimetil 2,2dicloroetenil fosfato por tableta] (Biagro, S.L., Valencia, España).

2) Trampas Nadel con el atrayente sexual Trimedlure (ácido tert-butil4(ó 5)-cloro-2-metil-ciclohexanocarboxilico) y una vapona insecticida (diclorvos). 
Los atrayentes alimenticios atraen tanto a hembras como a machos, mientras que los atrayentes sexuales sólo atraen a los machos. El cambio de atrayentes se realizó cada mes y medio en el caso de Tri-pack ${ }^{\circledR}$ y cada 2 meses en el caso de Trimedlure, siguiendo las recomendaciones de los fabricantes.

\section{Ensayo para investigar la posibilidad de aislar la población de una parcela}

El ensayo se realizó en la parcela A. El aislamiento consistió en colocar trampas en el perímetro de la parcela, con el objetivo de formar una barrera que impidiera la entrada de moscas desde el exterior.

En el perímetro de la parcela se colocaron 16 sistemas de trampeo Tephri separadas 20 m unas de otras. En el centro de la parcela se colocó otra trampa del mismo tipo. La colocación de las trampas se realizó el 25 de septiembre de 2003. En las dos semanas siguientes, el 1 de octubre y el 8 de octubre se realizaron por parte del agricultor dos tratamientos de cobertura total. Los conteos de las trampas se realizaron semanalmente, desde el 1 de octubre hasta el 5 de noviembre.

Se supuso que si la estrategia de aislamiento funcionase, las capturas en la trampa ubicada en el centro se reducirían respecto a las capturas de las trampas perimetrales después de los tratamientos.

Ensayo para comparar las capturas entre parcelas, seleccionar el sistema de trampeo y determinar su ubicación

En la parcela A se colocaron 12 trampas de los dos tipos descritos, distribuidas por toda la parcela. En la parcela B se colocaron 12 trampas Tephri en los extremos de la parcela y 11 trampas Nadel en la parte central de la parcela (Figura 28). Los conteos se realizaron semanalmente, desde el 23 de julio hasta el 23 de septiembre de 2003, contabilizando el número de machos y de hembras capturado. 

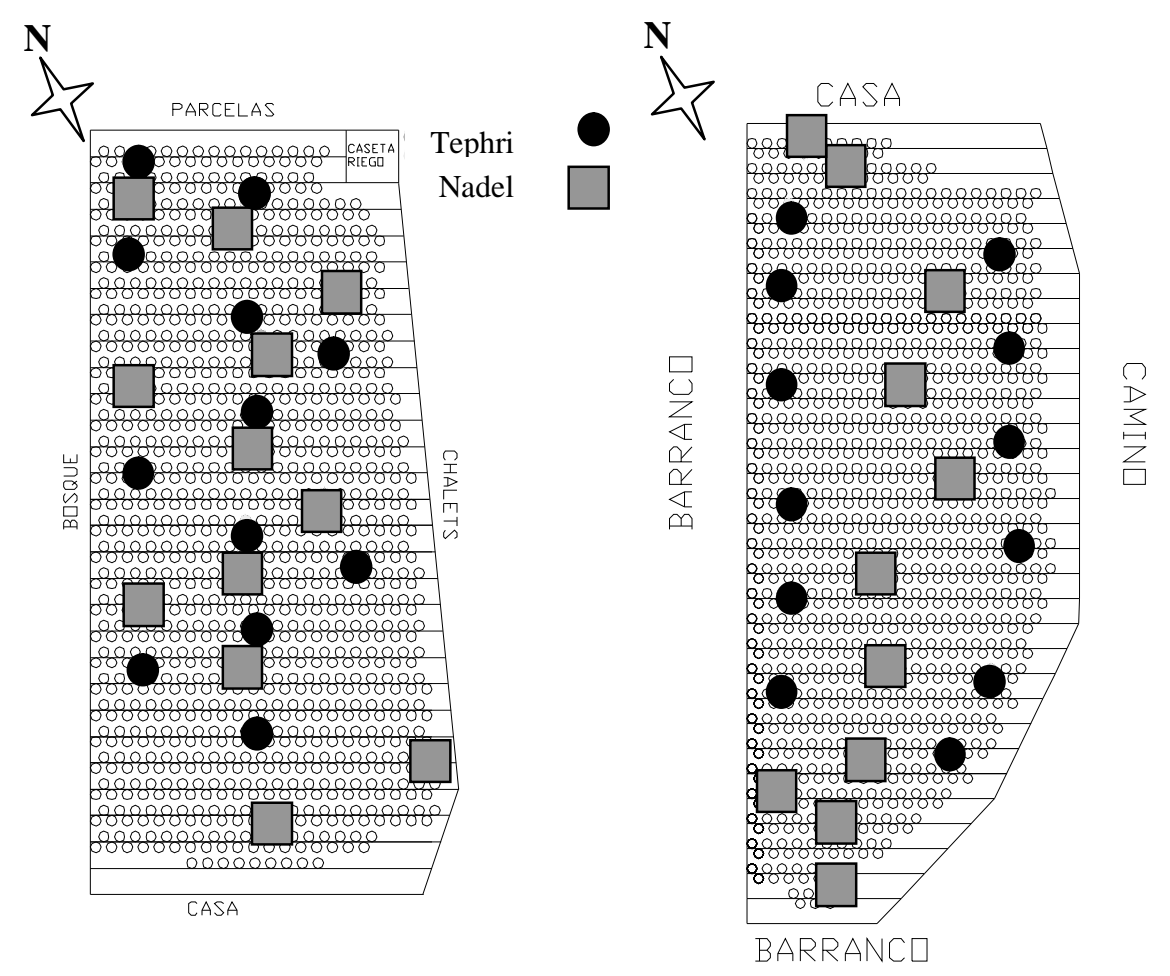

Figura 28. Plano de situación de las trampas en la parcela A (izquierda) y en la parcela $B($ derecha $)$.

Se estudiaron los siguientes aspectos:

- El nivel de capturas en cada parcela.

- La evolución de capturas en cada parcela.

- La diferencia de nivel de capturas entre sistemas de trampeo.

- La diferencia de capturas entre trampas ubicadas en la misma parcela.

\subsubsection{Resultados y discusión}

\section{Ensayo para investigar la posibilidad de aislar la población de una parcela}

Durante los tratamientos, el número de moscas por mosquero y día en las trampas perimetrales y en la trampa central fue similar (Figura 29). Sin embargo, 
después del último tratamiento, el nivel de capturas en la trampa central fue mayor que en las trampas perimetrales.

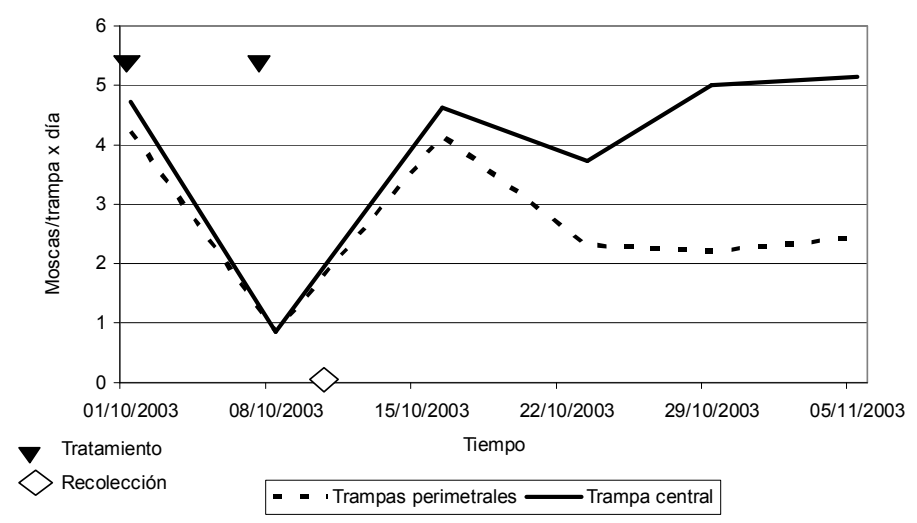

Figura 29. Evolución de las capturas de moscas entre la parcela control, la parcela aislada y la trampa indicadora.

Esto contradice la idea de que se ha aislado la parcela: las capturas en la trampa central hubieran tenido que ser menores que las del perímetro. Suponemos entonces que moscas procedentes del exterior han superado fácilmente la barrera de protección perimetral y se han establecido por toda la parcela.

Experimentos posteriores de Fibla et al. (2007), en los que se emplea el trampeo masivo perimetral como un método de control de la mosca mediterránea de la fruta en parcelas de cítricos de 1 ha, han dado resultados similares y los autores también lo atribuyen a que la barrera de trampas no fue suficiente para evitar la reinfestación de moscas del exterior.

\section{Ensayo para comparar las capturas entre parcelas, seleccionar el sistema de trampeo y determinar su ubicación}

El nivel de capturas en la parcela B fue mayor que en la parcela A para los dos sistemas de trampeo, a pesar, de que se trata de dos parcelas idénticas en cuanto a características agronómicas (Figura 30). El número de capturas totales en trampas Tephri en la parcela B fue, en promedio, un $44 \%$ mayor que en la 
parcela A. Sin embargo, se observa que la tendencia en la evolución de las capturas de $C$. capitata fue similar en ambas parcelas.

Por lo tanto, la eficacia de los tratamientos se puede determinar mediante la comparación de las evoluciones de las capturas, aunque siempre se tendrán que tener en cuenta las diferencias iniciales en los niveles poblacionales.

El número de capturas totales con el sistema de trampeo Tephri fue mayor que con el Nadel (Figura 30). Esto es normal, puesto que, en principio, el primero atrae a machos y hembras y el segundo solamente a machos.
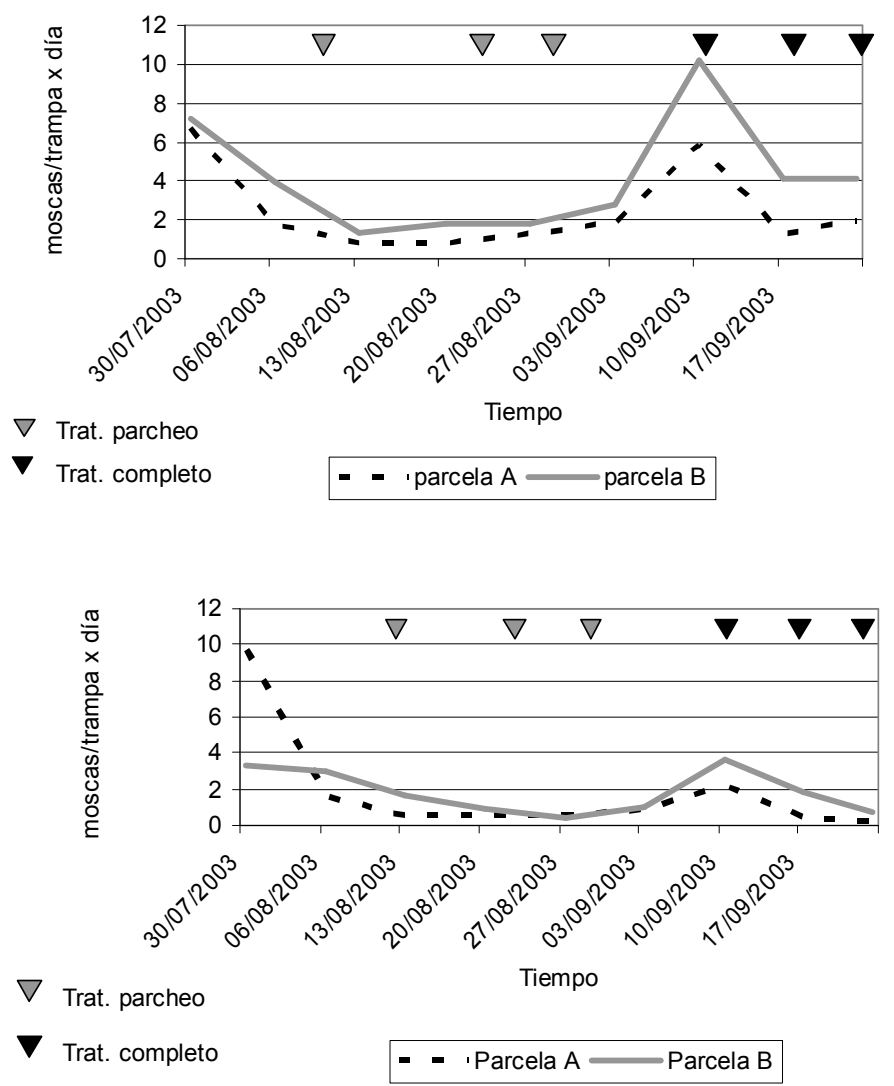

Figura 30. Comparación de las capturas de moscas totales en las parcelas A y B con sistemas de trampeo Nadel (abajo) y con Tephri (arriba). 
Cuando se compararon únicamente las capturas de machos, ambos tipos de trampas presentaron valores similares en las dos parcelas (Figura 31). El aumento de capturas en el sistema Tephri se debe, por tanto, a las capturas de hembras Es de destacar que el porcentaje de hembras capturadas fue un $70 \%$ mayor que el de machos.
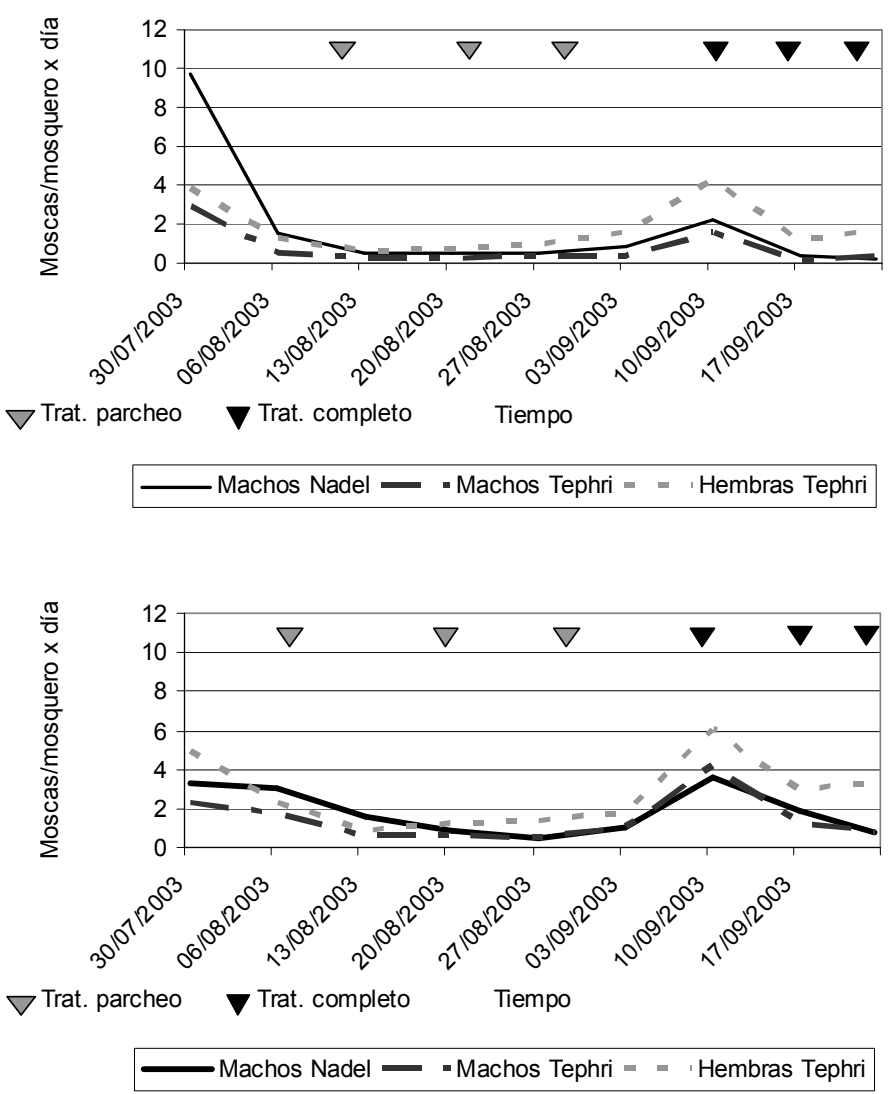

Figura 31. Comparación de las capturas entre sistemas de trampeo Tephri y Nadel en la parcela A (arriba) y en la parcela B (abajo).

A pesar de las diferencias en el número de capturas entre los dos sistemas de trampeo, la evolución de éste fue paralela, por lo que se supone que los dos sistemas de trampeo ensayados darán lugar a los mismos resultados cuando se desee comparar la eficacia de los tratamientos. Sin embargo, con el sistema Tephri, con el que se produce un mayor número de capturas, normalmente se 
detectarán mejor los incrementos y descensos de los mismos, por lo que se seleccionó este sistema para los ensayos siguientes.

En la parcela A las variaciones en la cantidad de capturas entre las distintas trampas fueron muy grandes: en general, se capturaron más moscas en las trampas situadas en los extremos, sobretodo en una esquina sureste de la parcela. En la Figura 32 se muestra como ejemplo la distribución de las capturas en la parcela mediante curvas de isomoscas durante una semana de conteo. Esta tendencia se repitió a lo largo del tiempo durante el periodo estudiado.

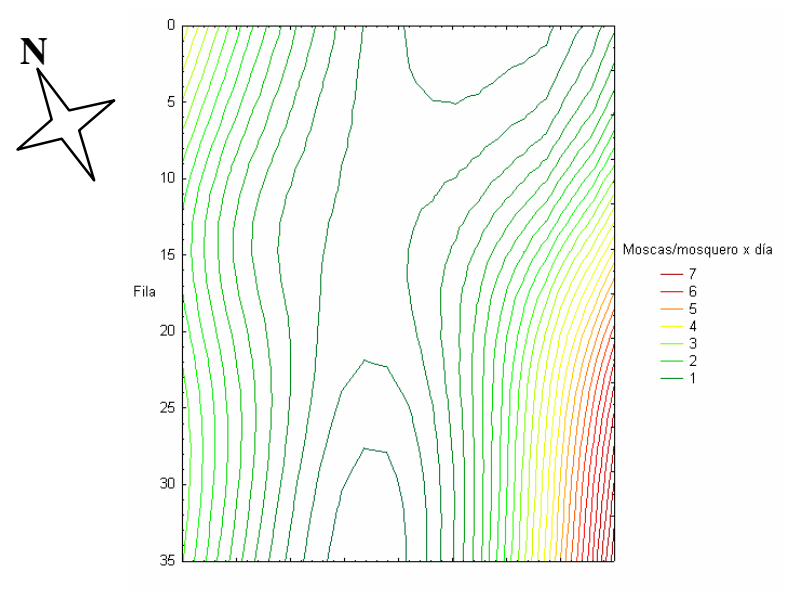

Figura 32. Distribución de C. capitata mediante curvas isomoscas en la parcela A con trampas Tephri la semana del27de agosto de 2003. El plano XY representa el plano de la parcela.

En la parcela B tampoco también se observó una gran variabilidad entre las capturas de las trampas. Al igual que en la parcela $\mathrm{A}$, se capturaron más moscas en las trampas de los extremos. En este caso los mayores niveles se produjeron en dos esquinas, la noreste y la noroeste (Figura 33). La esquina con el mayor número de capturas variaba de una semana de estudio a otra. 

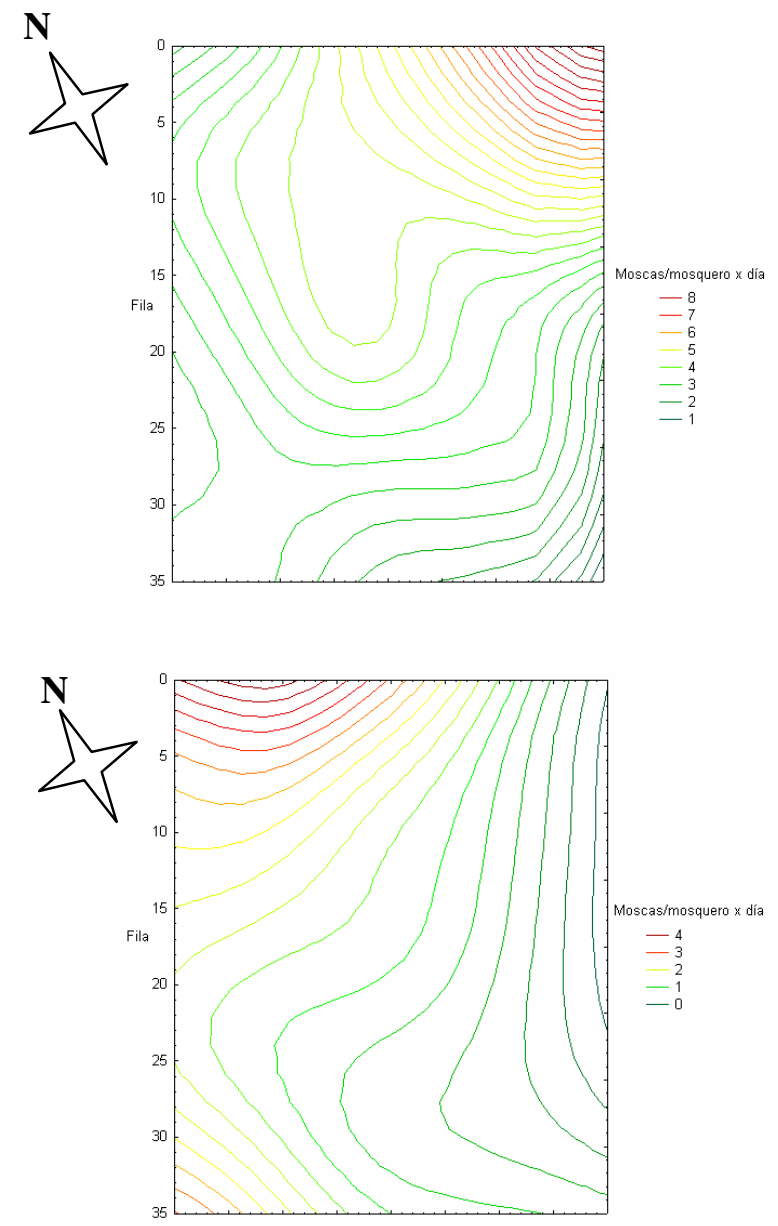

Figura 33. Distribución de machos de C. capitata mediante curvas isomoscas en la parcela B con trampas Tephri y Nadel las semanas del 10 (arriba) y del 17 (abajo) de septiembre de 2003. El plano XY representa el plano de la parcela.

Similares variaciones del número de las capturas entre trampas próximas también han sido observadas posteriormente por Martínez-Ferrer et al. (2007). Este hecho parece indicar que la población de $C$. capitata no se distribuye homogéneamente dentro de una parcela, sino que las moscas tienen preferencia por algunas zonas o los vientos dominantes tienden a acumularlas en ellas. Por ello, parece conveniente que en los ensayos de eficacia se ubique el suficiente número de trampas y se distribuyan éstas homogéneamente por toda la parcela, de manera que toda la superficie de la misma pueda ser representada. 


\subsection{EFICACIA DE LOS TRATAMIENTOS REALIZADOS EN EL CONTROL DE C. capitata}

El objetivo final de cualquier tratamiento fitosanitario es obtener la máxima eficacia sobre el fitófago a controlar. En este punto se explican y analizan los ensayos que se realizaron para comparar la eficacia de diferentes tratamientos.

En primer lugar, se presentan las experiencias que comparan la eficacia de dos tratamientos cebo a bajo volumen frente a la eficacia de tratamientos convencionales a base de malatión.

En segundo lugar, se comparan las eficacias de distintos tratamientos cebo entre sí, aplicados con turbo y con el equipo desarrollado.

Asimismo, para que el trabajo resulte completo, al evaluar la eficacia de los tratamientos no solamente se utilizan las curvas que representan la evolución de las capturas a las que nos hemos referido en el apartado anterior, sino que también se tienen en cuenta el porcentaje de frutos picados, el análisis de los residuos sobre la fruta y la valoración de la cantidad de negrilla y manchas producidas por los productos.

\subsubsection{Ensayo de comparación entre los tratamientos convencionales y dos tratamientos cebo a bajo volumen}

El objetivo de este ensayo fue comparar la eficacia en el control de C. capitata de dos tratamientos cebo a bajo volumen, aplicados con el prototipo diseñado, frente a los tratamientos a base de malatión que realizan tradicionalmente los agricultores, en los que se emplean altos volúmenes de agua.

El ensayo se realizó en las parcelas A y B descritas en el apartado anterior, durante los años 2004 y 2005.

En el año 2004, en la parcela A se realizaron tratamientos cebo a bajo volumen, mientras que en la parcela B se trató de manera convencional. En el 
año 2005 los tratamientos en parcelas se intercambiaron, de modo que los tratamientos cebo a bajo volumen se realizaron en la parcela B y los tratamientos convencionales en la parcela A (Tabla 10).

Tabla 10. Características de los tratamientos realizados en el ensayo de comparación entre tratamientos convencionalesl y dos tratamientos cebo a bajo volumen.

\begin{tabular}{|c|c|c|c|c|c|}
\hline Año & $\begin{array}{c}\text { Tipo de } \\
\text { tratamiento }\end{array}$ & $\begin{array}{c}\text { Producto } \\
\text { comercial }\end{array}$ & Concentración & $\begin{array}{c}\text { Volumen } \\
\text { de caldo }\end{array}$ & $\begin{array}{c}\text { Dosis } \\
\text { de i.a }\end{array}$ \\
\hline 2004 y 2005 & $\begin{array}{c}\text { 1A: cebo } \\
\text { convencional }\end{array}$ & $\begin{array}{c}\text { Malafin } 50^{\circledR} \\
\text { Nu-lure }^{\circledR}\end{array}$ & $\begin{array}{c}0,5 \% \\
0,5 \%\end{array}$ & $500 \mathrm{l} / \mathrm{ha}$ & $\begin{array}{c}1.250 \\
\mathrm{~g} / \mathrm{ha}\end{array}$ \\
\hline 2004 y 2005 & $\begin{array}{c}\text { 1B:completo } \\
\text { convencional }\end{array}$ & Malafin $50^{\circledR}$ & $0,2 \%$ & $1.000 \mathrm{l} / \mathrm{ha}$ & $\begin{array}{c}1.000 \\
\mathrm{~g} / \mathrm{ha}\end{array}$ \\
\hline 2004 & $\begin{array}{c}\text { 2: cebo a bajo } \\
\text { volumen (parcela A) }\end{array}$ & Spintor Cebo $^{\circledR}$ & $1 \mathrm{l} / \mathrm{ha}(0,33 \%)$ & $30 \mathrm{l} / \mathrm{ha}$ & $0,24 \mathrm{~g} / \mathrm{ha}$ \\
\hline 2005 & $\begin{array}{c}\text { 3: cebo a bajo } \\
\text { volumen (parcela B) }\end{array}$ & $\begin{array}{c}\text { Spintor 480SC } \\
\text { + Nu-lure }^{\circledR}\end{array}$ & $0,1 \%$ & $801 / \mathrm{ha}$ & $3,84 \mathrm{~g} / \mathrm{ha}$ \\
\hline
\end{tabular}

En 2004 se realizaron un total de 6 aplicaciones, desde mediados de agosto hasta finales de septiembre, concretamente el 18 y 25 de agosto y el 1, 13, 22 y 29 de septiembre. La fruta se recolectó entre el 8 y 9 de octubre. Hay que indicar que, por inclemencias meteorológicas, el 5 de septiembre se perdió cerca del $50 \%$ de la producción. En 2005 se realizaron 9 aplicaciones, el 24 y 31 de agosto, el 7, 12, 16 21, 26 y 30 de septiembre y el 5 de octubre. La fruta se recolectó entre el 11 y 14 de octubre.

Los tratamientos convencionales fueron realizados por el propietario de las parcelas, siguiendo las indicaciones del técnico de la cooperativa a la que pertenece (CoPuzol, Puzol, España). En 2004, las dos primeras aplicaciones se realizaron en forma de cebo y el resto de cobertura total. En el 2005, las tres primeras aplicaciones del tratamiento convencional fueron en forma de cebo y el resto de cobertura total. La aplicación en forma de cebo consistió en pulverizar, sobre la cara soleada de los árboles, un volumen de caldo 500 1/ha con un 0,5\% de malatión (Malafin 50 ${ }^{\circledR}$, Agrodan, S.A., Madrid, España) y 0,5\% de proteína hidrolizada $\left(\mathrm{Nu}\right.$-lure $\left.{ }^{\circledR}\right)$. En el tratamiento de cobertura total se utilizó un volumen de caldo de 1.000 1/ha a una concentración del $0,2 \%$ de Malafin $50^{\circledR}$ sobre toda 
la superficie del árbol. Para realizar estas aplicaciones se empleó el pulverizador hidráulico asistido por aire que posee el agricultor, de 2.0001 de capacidad y dotado de boquillas de cerámica cónicas de 1,8 $\mathrm{mm}$ de diámetro. La presión de trabajo fue de 18 bar y la velocidad de avance del tractor de $3 \mathrm{~km} / \mathrm{h}$.

El tratamiento cebo a bajo volumen de 2004 consistió en la pulverización de un volumen de caldo de 30 1/ha, compuesto por 291 de agua y 11 de Spintor Cebo $^{\circledR}$ (concentración del 3,33\%). El tratamiento cebo a bajo volumen de 2005 consistió en la pulverización de 80 1/ha, de un caldo compuesto por 0,5\% de proteína hidrolizada $\left(\mathrm{Nu}-\right.$ lure $^{\circledR}$ ) y $0,1 \%$ de Spintor $480 \mathrm{SC}^{\circledR}$. Los tratamientos se realizaron con el prototipo automático desarrollado, dotado de las boquillas de inducción de aire modelo AI-3001VS seleccionadas. Se utilizaron dos boquillas para aplicar 80 1/ha, mientras que para aplicar 30 1/ha se empleó solamente una. El tratamiento se realizó a una velocidad de avance de $3 \mathrm{~km} / \mathrm{h}$ y la presión de trabajo fue de 2 bar para el tratamiento de 80 l/ha y de 1,5 bar para el de 30 l/ha.

\subsubsection{Ensayo de comparación entre tratamientos cebo a bajo volumen}

En este ensayo se comparó la eficacia de tres tratamientos cebo a bajo volumen, utilizando diferentes insecticidas: Malafin $50^{\circledR}$, Spintor $\mathrm{Cebo}^{\circledR}$ y Spintor $480 \mathrm{SC}^{\circledR}$.

Se seleccionaron dos parcelas con diferentes características agronómicas, Parcela C y Parcela D (Anejo 8). Cada parcela se subdividió en tres unidades experimentales, de aproximadamente 1 ha de superficie, y se realizaron tres tipos de tratamientos, uno por unidad experimental, cuyas características se muestran en la Tabla 11.

Se realizaron un total de 8 tratamientos, que se aplicaron entre septiembre y diciembre de 2004, época en que los cítricos eran susceptibles de ser infestados por C. capitata, concretamente el 14, 23, 30 de septiembre, el 7, $15,22,29$ de octubre y 5 de noviembre. Debido a que los tres tratamientos eran 
en forma de cebo, el producto se pulverizó únicamente sobre la cara soleada de los árboles.

Tabla 11. Características de los tratamientos realizados en el ensayo de comparación entre tratamientos cebo a bajo volumen.

\begin{tabular}{|c|c|c|c|c|}
\hline \multicolumn{2}{|c|}{ Tratamiento } & \multirow{2}{*}{\begin{tabular}{|c|}
$\begin{array}{c}\text { Concentración de } \\
\text { producto }\end{array}$ \\
$0,5 \%$ \\
$0,5 \%$ \\
\end{tabular}} & \multirow{2}{*}{$\begin{array}{c}\begin{array}{c}\text { Volumen de } \\
\text { caldo }\end{array} \\
80 \mathrm{l} / \mathrm{ha} \\
\end{array}$} & \multirow{2}{*}{$\begin{array}{l}\text { Dosis (i.a) } \\
200 \mathrm{~g} / \mathrm{ha}\end{array}$} \\
\hline 1 & $\begin{array}{c}\text { Malafin } 50^{\circledR}+ \\
\text { Proteína hidrolizada }\left(\mathrm{Nu}-\text { lure }^{\circledR}\right)\end{array}$ & & & \\
\hline 2 & $\begin{array}{c}\text { Spintor } 480 \mathrm{SC}^{\circledR}+ \\
\text { Proteína hidrolizada }\left(\mathrm{Nu}-\text { lure }^{\circledR}\right)\end{array}$ & $\begin{array}{l}10 \mathrm{~g} / \mathrm{hl} \\
0,5 \%\end{array}$ & 80 l/ha & $3,84 \mathrm{~g} / \mathrm{ha}$ \\
\hline 3 & $\begin{array}{c}\text { Spintor cebo }^{\circledR} \\
\text { (contiene su propio cebo) }\end{array}$ & $3,3 \mathrm{l} / \mathrm{hl}$ & 30 1/ha & $0,24 \mathrm{~g} / \mathrm{ha}$ \\
\hline
\end{tabular}

Las aplicaciones con malatión (tratamiento 1) se realizaron con un pulverizador hidráulico asistido por aire, de 2.0001 de capacidad. Las otras dos aplicaciones se realizaron con el prototipo diseñado. En los tres tratamientos se empleó la boquilla de inducción de aire AI-11003VS.

Para las aplicaciones de 80 1/ha (tratamiento 1 y 2 ) se utilizaron 2 boquillas, mientras que sólo se utilizó una en la aplicación de 30 1/ha (tratamiento 3). La presión de trabajo fue de 2 bar para el volumen de 30 1/ha y de 3 bar el de 80 1/ha. La velocidad de avance del tractor fue en todos los casos de $3 \mathrm{~km} / \mathrm{h}$.

\subsubsection{Metodología para evaluar de la eficacia de los tratamientos}

\section{Evolución de la población de $C$. capitata}

Para conocer una estimación de la evolución de la población de C. capitata se colocaron 6 sistemas de trampeo Tephri, repartidos uniformemente en cada unidad experimental. La distancia de separación entre trampas fue de alrededor de 16,5 m, ya que el límite de acción de los atrayentes es de $20 \mathrm{~m}$ (Martínez-Ferrer et al., 2007). Se colocaron a 1,5 m de altura, en la parte sureste 
de la copa del árbol. En la Figura 34 se muestra un ejemplo de cómo se situaron las trampas dentro de una unidad experimental.

Las moscas capturadas se contaron semanalmente.

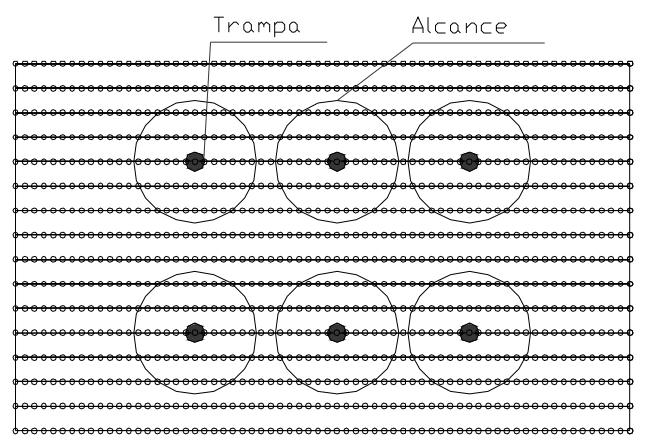

Figura 34. Plano de situación de las trampas en una unidad experimental.

\section{Porcentaje de frutos picados por C. capitata}

En cada uno de los ensayos y en cada unidad experimental se evaluó el daño producido por $C$. capitata mediante el conteo de frutos picados con y sin presencia de larvas en su interior, una semana después de la última aplicación y en el momento de la cosecha.

En el ensayo de comparación de tratamientos convencionales frente a tratamientos cebo a bajo volumen, en 2004 se revisaron aleatoriamente el 8\% de los frutos recolectados en cada unidad experimental. Dado el bajo nivel de picaduras observadas, en 2005 se cambió la metodología y se realizó un muestreo bietápico, que consistió en escoger al azar 30 árboles distribuidos homogéneamente de cada unidad experimental y examinar aleatoriamente 10 frutos por árbol, repartidos por todo el perímetro de la copa. Así pues, se revisaron un total de 300 frutos por unidad experimental.

En el ensayo de comparación de tratamientos cebo a bajo volumen, el muestreo de frutos picados se realizó del mismo modo que el descrito en el 
ensayo anterior para 2005. En cada unidad experimental se calculó el porcentaje de infestación, una vez conocido el número de frutos infestados y sabiendo el total de frutos evaluados.

\subsubsection{Análisis de residuos de los insecticidas}

En el ensayo de comparación del tratamiento convencional frente al tratamiento cebo a bajo volumen, y con el fin de analizar el caso más desfavorable, se realizó un análisis sobre frutos seleccionados solamente de la parte del árbol que había sido pulverizada. En cada unidad experimental se seleccionaron al azar 24 árboles y se cogieron 3 frutos de la cara tratada (72 frutos), que posteriormente se dividieron en tres muestras de 24 frutos, obteniendo así los $2 \mathrm{~kg}$ de fruta que se requieren para los análisis.

En el ensayo de comparación entre tratamientos cebo a bajo volumen, el análisis de residuos se realizó únicamente en la parcela de mandarinas. Además de analizar el caso más desfavorable tomando las muestras tal y como se ha descrito anteriormente, se determinó el nivel de residuo en condiciones comerciales. Para ello, en cada unidad experimental se seleccionaron 12 árboles al azar y se cogieron 6 frutos de todo el perímetro del árbol, obteniéndose al igual que en el otro ensayo tres muestras de 24 frutos.

Las muestras se analizaron en el Laboratorio Agroalimentario de la Consellería de Agricultura, Pesca y Alimentación situado en Burjassot (Valencia) acreditado por la Entidad Nacional de Acreditación (ENAC).

\subsubsection{Valoración de la presencia de negrilla y manchas}

En el ensayo de comparación de eficacia entre tratamientos cebo a bajo volumen en la parte tratada con Spintor $\mathrm{Cebo}^{\circledR}$, se detectó la presencia de negrilla en los frutos y hojas donde había depósitos del producto pulverizado.

Asimismo, en la parcela de mandarinas también se detectó la aparición de manchas en la fruta en los tratamientos con este producto. Estas manchas aparecieron cuando los frutos comenzaron a virar de color, observándose que 
donde se había depositado el producto la piel del fruto no cambió su color. Por tanto, se decidió realizar una valoración de la cantidad de frutos con negrilla o con manchas en cada caso.

Se empleó el mismo método en ambas valoraciones. Consistió en estimar la superficie ocupada por el defecto en la mitad del fruto según 5 niveles establecidos (Tabla 12). La valoración se hizo para los tres tratamientos de cada una de las parcelas y en cada uno se comparó la cara del árbol tratada frente a la no tratada. En cada unidad experimental se seleccionaron aleatoriamente 30 árboles y se evaluaron 10 frutos tomados al azar de cada cara del árbol. Posteriormente, para cada árbol en cada una de las caras, y para cada tratamiento se calculó el índice de daño (Townsend y Heuberger, 1943) (Ecuación 11).

$$
\% \text { daño }=\frac{\sum n^{\mathrm{o}} \text { plantas } \times \text { indice_asignado }}{n^{\mathrm{o}} \text { plantas_total } \times \text { indice_máximo_de_la_escala }}
$$

Tabla 12. Niveles establecidos de presencia de negrilla o de manchas según el porcentaje de superficie ocupada en la mitad de cada fruto.

\begin{tabular}{|c|c|}
\hline $\begin{array}{c}\text { Porcentaje de superficie ocupada en la } \\
\text { mitad del fruto }(\%)\end{array}$ & $\begin{array}{c}\text { Nivel de presencia de negrilla o de } \\
\text { manchas }\end{array}$ \\
\hline 0 & 0 \\
\hline 25 & 1 \\
\hline 50 & 2 \\
\hline 75 & 3 \\
\hline 100 & 4 \\
\hline
\end{tabular}

\subsubsection{Tratamiento de los datos}

\section{Evolución de la población de $C$. capitata}

Como ya se ha indicado, los niveles poblacionales pueden ser diferentes en cada parcela y esto se debe considerar en el análisis para no obtener resultados erróneos. Por ello, se desarrollo el método que se describe a continuación, que es una aportación novedosa de esta tesis. 
En primer lugar, se estandarizaron los datos de cada una, restando a las capturas obtenidas en cada tratamiento la media de capturas correspondiente a dicho tratamiento y dividiendo el resultado entre esa media de capturas correspondiente a dicho tratamiento, obteniendo así, un porcentaje de incremento/decremento del número de capturas. En el análisis se compararon únicamente los datos correspondientes a las fechas en que se realizaron los tratamientos (desde el 18-8-04 hasta el 20-10-04 y desde el 23-8-05 hasta el 1110-05 para el ensayo de comparación del tratamiento convencional frente a cebo a bajo volumen; desde el 14-9-04 hasta el 5-11-04 para el ensayo de comparación de tratamientos cebo a bajo volumen), no los datos de todo el período de ensayos, que había empezado varias semanas antes.

La comparación entre los tratamientos se basó en un análisis de regresión lineal de los porcentajes mencionados en el párrafo anterior. Se asumió que los tratamientos eran igual de eficaces si los coeficientes de regresión no eran significativamente diferentes a 1 y la ordenada en el origen no era significativamente diferente de 0 , en ambos casos con un nivel de probabilidad menor de 0,01 .

\section{Valoración de la presencia de negrilla y manchas}

Para cada valoración se realizó un ANOVA de dos factores, factor tratamiento a tres niveles (Spintor Cebo ${ }^{\circledR}$, Spintor $480 \mathrm{SC}^{\circledR}$ y Malafin $50^{\circledR}$ ) y factor cara del árbol a dos niveles (tratada y no tratada).Se aplicó la prueba LSD para la separación de las medias (SPSS, 1999). El nivel de confianza en ambos análisis fue del $95 \%$. Para evaluar el cumplimiento de la hipótesis de normalidad se estudió la normalidad de los residuos mediante papel probabilístico normal, cuando la hipótesis no se cumplió los datos se transformaron con la función $\operatorname{arcosen}(\sqrt{ }(\mathrm{x}))$. 


\subsection{7 $\quad \underline{\text { Resultados }}$}

\section{Ensayo de comparación entre los tratamientos convencionales y dos tratamientos cebo a bajo volumen}

\section{Evolución de las capturas de C. capitata}

La Figura 35 muestra la evolución de las capturas por trampa y día desde mediados de marzo hasta finales de octubre para cada parcela. Las flechas indican la fecha en que se realizaron los tratamientos. Se aprecia que en el año 2004 el nivel de capturas de moscas por trampa y día varía entre 0 y 70 . Sin embargo, en el año 2005, el nivel de capturas es mucho menor, oscilando entre 0 y 25. En los dos años de estudio, se observa que la parcela B, tratada en el 2004 con el tratamiento convencional y en el 2005 con el cebo a bajo volumen, presenta niveles de capturas superiores a la parcela A, y que existen desfases en los máximos de capturas entre los dos años. Sin embargo, la tendencia general es similar. 


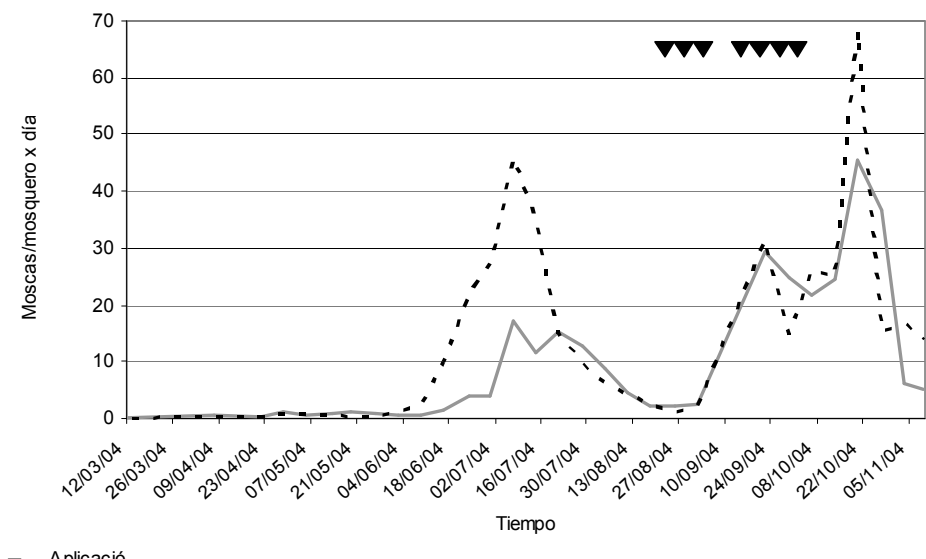

Aplicació

— Tratamiento cebo bajo volumen (Parcela A) - - - . Tratamiento convencional (Parcela B)

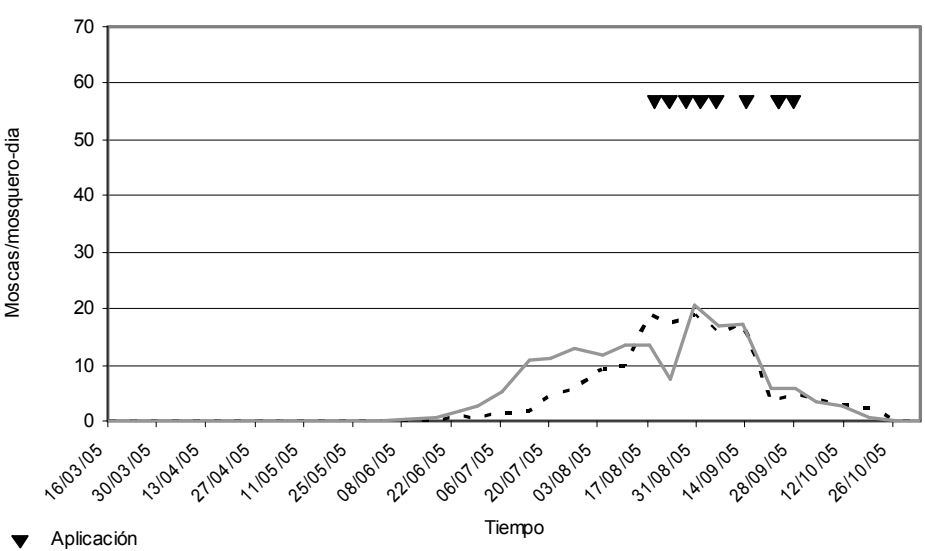

- - - Tratamiento convencional (parcela A) — Tratamiento cebo bajo volumen (parcela B)

Figura 35. Comparación de las capturas de C. capitata entre el tratamiento convencional y el cebo a bajo volumen durante las aplicaciones de 2004 (arriba) y 2005 (abajo).

Una vez estandarizados los datos, los resultados de los análisis de regresión mostraron, para los dos años estudiados, una elevada correlación entre las capturas de los tratamientos comparados (Tabla 13). En todos los casos el coeficiente de determinación no fue significativamente diferente de 1 y el término independiente no fue significativamente distinto de 0 , lo que indica un elevado grado de similitud entre los resultados de los tratamientos. 
Capítulo III. Mecanización de los tratamientos cebo a bajo volumen

Tabla 13. Coeficientes de regresión lineal entre los resultados estandarizados de cada tratamiento en 2004 y 2005.

\begin{tabular}{|c|c|c|c|c|c|c|c|}
\hline & \multicolumn{7}{|c|}{ Coeficientes de la regresión lineal $y=a x+b$} \\
\hline Tratamientos & \multicolumn{2}{|c|}{$\begin{array}{c}\text { Término } \\
\text { independiente } \\
\text { (a) }\end{array}$} & \multicolumn{3}{|c|}{ Coeficiente de regresión (b) } & \multicolumn{2}{|c|}{$\begin{array}{c}\text { Factor de } \\
\text { correlación }\left(\mathbf{R}^{2}\right)\end{array}$} \\
\hline $\begin{array}{l}\text { Conventional vs. } \\
\text { Cebo a bajo } \\
\text { volumen }\end{array}$ & $\mathrm{a}$ & p-level & $\mathrm{b}$ & Std. Error & p-level & $\mathrm{R}^{2}$ & p-level \\
\hline 2004 & $5 \mathrm{E}-17$ & 1,0000 & 0,8632 & 0,1695 & 0,0018 & 0,8781 & 0,0018 \\
\hline 2005 & $1 \mathrm{E}-16$ & 1,0000 & 0,8646 & 0,2116 & 0,0076 & 0,7213 & 0,0076 \\
\hline
\end{tabular}

Porcentaje de frutos picados por C. capitata

El porcentaje de frutos infestados en 2004 fue muy bajo, no llegando al $0,02 \%$ en ninguna de las parcelas. En la parcela tratada con el tratamiento cebo a bajo volumen, donde el nivel de capturas de $C$. capitata fue mayor, se obtuvo el porcentaje más alto $(0,019 \%)$. En la parcela tratada con el tratamiento convencional el porcentaje de frutos infestados fue $0,014 \%$.

En 2005, aunque las capturas de C. capitata se redujeron, el porcentaje de frutos infestados fue mayor, seguramente debido a la diferente manera de realizar los muestreos. En este año, el porcentaje de fruta infestada fue mayor donde se había realizado el tratamiento convencional (4\%), lo que coincide con el hecho de que fue la parcela en la que las capturas de mosca fueron mayores. En la parcela donde se realizó el tratamiento cebo a bajo volumen la fruta picada fue $1 \%$.

Análisis de los residuos de los insecticidas

A pesar de seleccionar los frutos de la cara pulverizada y de estar en el caso más desfavorable, en todos los tratamientos los niveles de residuos de los insecticidas fueron inferiores al nivel máximo de residuos legalmente admitido. Los spinosines A y D, materia activa de Spintor Cebo ${ }^{\circledR}$ y Spintor $480 \mathrm{SC}^{\circledR}$, se encontraron por debajo del límite de cuantificación $(0,01 \mathrm{mg} / \mathrm{kg})$, mientras que el 
malation se encontró en una concentración media de $1,38 \mathrm{mg} / \mathrm{kg}$ en 2004 y de $1,74 \mathrm{mg} / \mathrm{kg}$ en 2005 .

\section{Ensayo de comparación entre los tratamientos cebo a bajo volumen}

Evolución de las capturas de C. capitata

La evolución de las capturas de C. capitata se muestra en la Figura 36. Las flechas verticales indican la fecha de cuando se produjeron los tratamientos.

Se puede observar que los valores absolutos de las figuras son muy diferentes en ambas parcelas. En la de Clemenules, el nivel de capturas de moscas por trampa y día varía entre 0-10 antes y durante las aplicaciones. Sin embargo, en la parcela de Navel el nivel varía entre 9-80 antes de los tratamientos y entre 0-14 durante su aplicación. Por otra parte, se aprecia que los niveles poblacionales de las unidades experimentales de cada parcela son diferentes. No obstante, la tendencia es similar entre las unidades experimentales y entre las parcelas. 

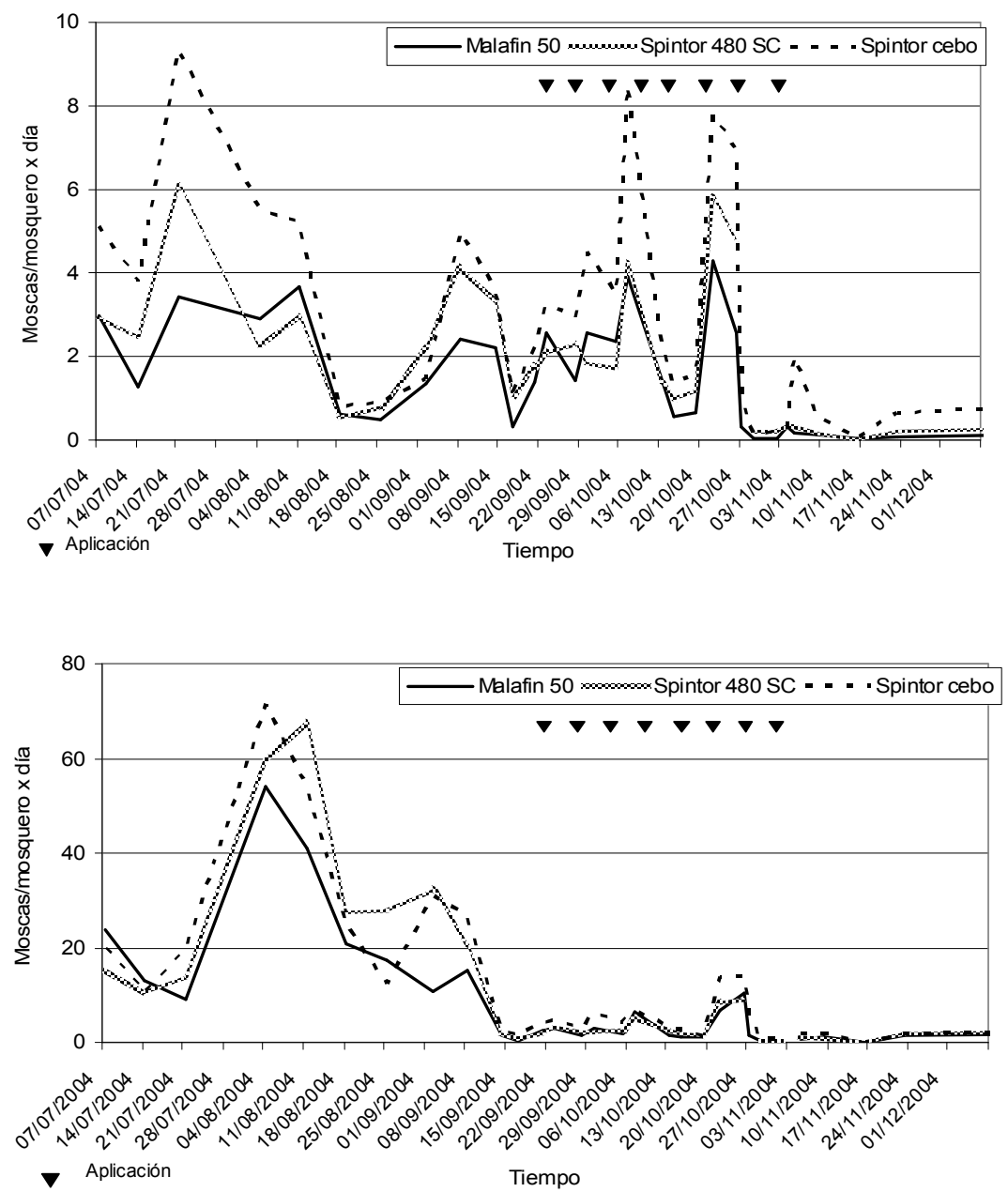

Figura 36. Evolución de capturas de C. capitata durante los tratamientos cebo a bajo volumen en la parcela de Clemenules (arriba) y de Navel (abajo).

Los resultados de los análisis de regresión de los datos estandarizados se muestran en la Tabla 14. Como se puede apreciar, en las dos variedades existe una elevada correlación entre los tratamientos $\left(\mathrm{R}^{2}\right.$ varía entre 0,8 y 0,9$)$. Además, en todos los casos, el término independiente (a) toma valores que no son significativamente diferentes a 0 (p-levels entre 0,47 y 1,00$)$ y el coeficiente de regresión no es significativamente diferente de 1 . Si tenemos en cuenta el error 
Capítulo III. Mecanización de los tratamientos cebo a bajo volumen

estándar de la estimación de este último parámetro, debemos concluir que el efecto de los tratamientos realizados en cada unidad experimental fue similar referido al porcentaje de incremento/decremento de moscas capturadas.

Tabla 14. Coeficientes de regresión lineal entre cada tratamiento en la parcela de Clemenules y Navel.

\begin{tabular}{|c|c|c|c|c|c|c|c|c|}
\hline & \multirow[b]{3}{*}{ Tratamientos } & \multicolumn{7}{|c|}{ Coeficientes de regresión lineal } \\
\hline & & \multicolumn{2}{|c|}{$\begin{array}{c}\text { Término } \\
\text { independiente (a) }\end{array}$} & \multicolumn{3}{|c|}{ Coeficiente de regresión (b) } & \multicolumn{2}{|c|}{$\begin{array}{c}\text { Factor de } \\
\text { correlación }\left(\mathbf{R}^{2}\right)\end{array}$} \\
\hline & & $\mathbf{a}$ & p-level & b & $\begin{array}{c}\text { Error } \\
\text { estándar }\end{array}$ & p-level & $\mathbf{R}^{2}$ & p-level \\
\hline \multirow{3}{*}{ 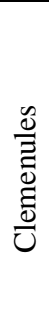 } & $\begin{array}{c}\text { Malafin } 50 \text { vs } \\
\text { S 480SC }\end{array}$ & 0,0514 & 0,5900 & 0,9250 & 0,1127 & $<0,0001$ & 0,8082 & $<0,0001$ \\
\hline & $\begin{array}{c}\text { Malafin } 50 \text { vs } \\
\text { S Cebo }\end{array}$ & $2 \mathrm{E}-16$ & 1,0000 & 0,9595 & 0,0882 & $<0,0001$ & 0,8809 & $<0,0001$ \\
\hline & $\begin{array}{l}\text { S 480SC vs } \\
\text { S Cebo }\end{array}$ & 0,0556 & 0,4705 & 0,9257 & 0,0902 & $<0,0001$ & 0,8681 & $<0,0001$ \\
\hline \multirow{3}{*}{$\begin{array}{l}\stackrel{\Xi}{\Xi} \\
\stackrel{\Xi}{\Xi} \\
\text { Z }\end{array}$} & $\begin{array}{c}\text { Malafin } 50 \text { vs } \\
\text { S 480SC }\end{array}$ & 0,064 & 0,4375 & 1,0756 & 0,0875 & $<0,0001$ & 0,9043 & $<0,0001$ \\
\hline & $\begin{array}{c}\text { Malafin } 50 \text { vs } \\
\text { S Cebo }\end{array}$ & 0,0067 & 0,9448 & 1,1214 & 0,1121 & $<0,0001$ & 0,8621 & $<0,0001$ \\
\hline & $\begin{array}{l}\text { S } 480 \text { SC vs } \\
\text { S Cebo }\end{array}$ & 0,0566 & 0,5382 & 0,9815 & 0,1052 & $<0,0001$ & 0,8448 & $<0,0001$ \\
\hline
\end{tabular}

$\underline{\text { Porcentaje de frutos picados por C. capitata }}$

En cuanto al porcentaje de frutos picados por la mosca de la fruta del Mediterráneo, se han obtenido valores muy bajos en todos los tratamientos y para las dos variedades (

Tabla 15), a pesar de la presencia significativa de la plaga. Por tanto, podemos concluir que todos los tratamientos han sido adecuados para el control de la mosca del Mediterráneo, y que todos ellos son una buena alternativa a los tratamientos clásicos que realizan coberturas totales. 
Tabla 15. Porcentaje de frutos picados por $\mathrm{C}$. capitata.

\begin{tabular}{|c|c|c|}
\hline Tratamiento & Parcela de Navelina & Parcela de Clemenules \\
\hline Malafin $50^{\circledR}$ & $0 \%$ & $0.33 \%$ \\
\hline Spintor $480 \mathrm{SC}^{\circledR}$ & $0 \%$ & $0.66 \%$ \\
\hline Spintor Cebo $^{(\circledR)}$ & $0.66 \%$ & $0.33 \%$ \\
\hline
\end{tabular}

Análisis de residuos de los insecticidas

Respecto a los niveles de residuos, en los tratamientos de Spintor 480 SC $^{\circledR}$ y Spintor Cebo ${ }^{\circledR}$ no se encontraron residuos de Spinosad, ni en las muestra de los frutos más expuestos ni en las muestras tomadas aleatoriamente de toda la superficie del árbol. Sin embargo, se encontraron 0,2 ppm de malafin $50^{\circledR}$ en las muestras más expuestas al producto y 0,08 ppm en las muestras comerciales.

$\underline{\text { Valoración de la presencia de negrilla y manchas }}$

En la valoración de la presencia de negrilla tanto el factor tratamiento $(\mathrm{F}=77,10, \mathrm{~g} .1 .=2-179, \mathrm{P}=0,0000)$ como el factor cara del árbol $(\mathrm{F}=183,88$, g.l. $=1-179, \mathrm{P}=0,0000)$ y su interacción $(\mathrm{F}=71,06$, g.l. $=2-179, \mathrm{P}=0,0000)$ resultaron significativos para el porcentaje de infestación de negrilla.

Al estudiar los intervalos LSD de la interacción se observa que en la cara no tratada del árbol no hay diferencias significativas entre los tratamientos (Figura 37). Sin embargo, en la cara tratada, el tratamiento con Spintor Cebo ${ }^{\circledR}$ presenta un porcentaje de infestación de negrilla medio igual a un 48,08\%, que es significativamente mayor que el de los tratamientos de malafin $50^{\circledR}$ y Spintor $480 \mathrm{SC}^{\circledR}$, entre los que no hay diferencias significativa, y cuyos valores medios de porcentaje de infestación de negrilla son $9,75 \%$ y $12,58 \%$ respectivamente.

En cada uno de los tratamientos también hay diferencias significativas entre la cara tratada y la no tratada. En el tratamiento con malafin $50^{\circledR}$, la cara no 
tratada presenta un porcentaje de infestación de negrilla medio de un 4,42\%, que es significativamente menor al de la cara tratada del árbol (9,75\%). Del mismo modo, en el tratamiento con Spintor $480 \mathrm{SC}^{\circledR}$ hay un aumento significativo de porcentaje infestación de negrilla al comparar la cara no tratada, cuyo valor medio es de un $3,08 \%$, con la cara tratada $(12,58 \%)$. Pero en el tratamiento con Spintor $\mathrm{Cebo}^{\circledR}$ las diferencias entre la cara no tratada y tratada son mayores $(4,58 \%$ frente a $48,08 \%)$.

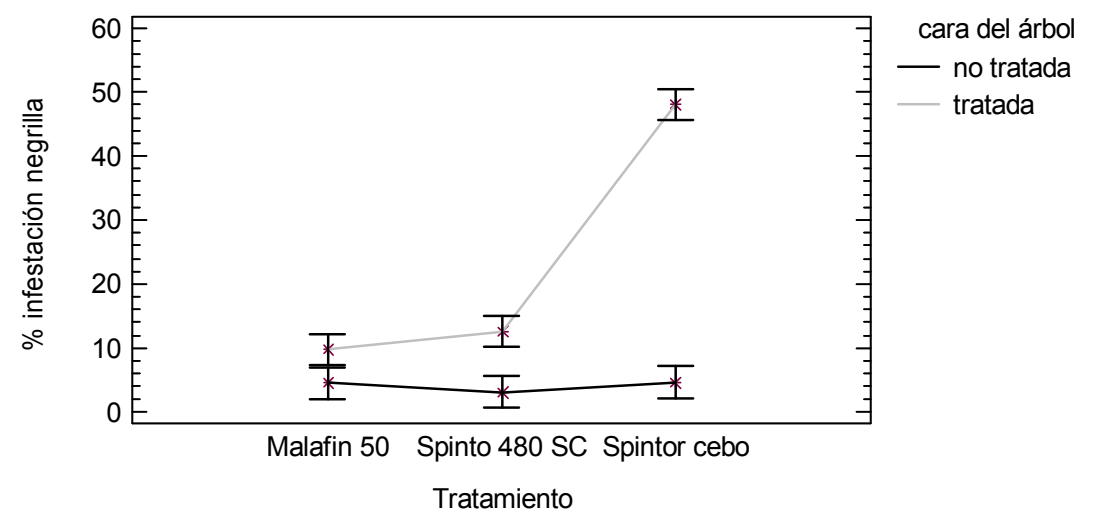

Figura 37. Interacción del factor tratamiento por el factor cara del árbol para la variable porcentaje de infestación de negrilla. Intervalos LSD a un nivel de confianza del $95 \%$.

En cuanto a la valoración de la presencia de manchas en la parcela de Clemenules tanto el factor tratamiento $(\mathrm{F}=84,62$, g.l. $=2-179, \mathrm{P}=0,0000)$ como el factor cara del árbol $(\mathrm{F}=40,82$, g.l. $=1-179, \mathrm{P}=0,0000)$ y su interacción $(\mathrm{F}=50,84$, g.l. $=2-179, \mathrm{P}=0,0000)$ resultaron significativos para el porcentaje de presencia de manchas.

La Figura 38 muestra los intervalos LSD de la interacción. Se observa que en la cara no tratada del árbol el tratamiento con malafin $50^{\circledR}$ presentó un porcentaje de presencia de manchas medio de 5,08\%. Éste valor fue significativamente menor que en los tratamientos de Spintor $480 \mathrm{SC}^{\circledR}$ y Spintor $\mathrm{Cebo}^{\circledR}$, entre los que no hubo diferencias significativas, y cuyos valores fueron $15,50 \%$ y $13,66 \%$ respectivamente. 
En la cara tratada hubo diferencias significativas entre los tres tratamientos. El tratamiento con Spintor Cebo ${ }^{\circledR}$ presentó un área de manchas mayor $(49,92 \%)$, el de malafin $50^{\circledR}$ el menor $(2,83 \%)$ y el de Spintor $480 \mathrm{SC}^{\circledR}$ intermedio $(15,16 \%)$.

Al comparar la cara tratada y no tratada en cada uno de los tratamientos, se observa que no hubo diferencias entre ellas en las parcelas tratadas con malafin $50^{\circledR}$ o con Spintor $480 \mathrm{SC}^{\circledR}$. Sin embargo, en la parcela en que se aplicó Spintor $\mathrm{Cebo}^{\circledR}$, la cara tratada presentó un porcentaje de presencia de manchas significativamente mayor que la cara no tratada.

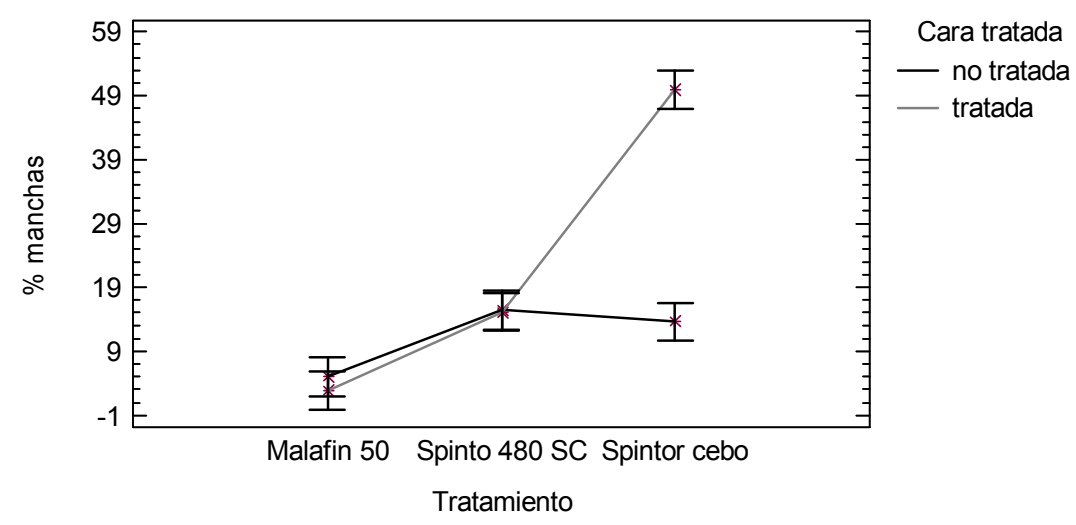

Figura 38. Interacción del factor tratamiento por el factor cara del árbol para la variable porcentaje de presencia de manchas. Intervalos LSD a un nivel de confianza del $95 \%$.

\subsubsection{Discusión}

No hubo diferencias significativas en el número de capturas entre los tratamientos cebo a bajo volumen y los convencionales ni entre los tratamientos cebo a bajo volumen con diferentes insecticidas. Además aunque hubo presencia de plaga en todas las unidades experimentales, el porcentaje de frutos infestados 
fue muy bajo en todos los tratamientos. Por lo tanto, se concluye que todos los tratamientos controlaron adecuadamente a la mosca mediterránea de la fruta.

La aplicación de tratamientos cebo a bajo volumen respecto a tratamientos convencionales reduce el volumen de caldo entre un $84 \%$ y un $97 \%$. Esto se traduce en una disminución del tiempo de aplicación y de los costes. También en un menor impacto medioambiental, las gotas son grandes y por lo tanto la deriva se reduce. Además, el área mojada se limita a un área de la cara soleada del exterior de la copa por lo que el impacto sobre la fauna útil es menor.

Una de las ventajas de reemplazar spinosad por malatión es que presenta un mejor perfil toxicológico. Además, bajo las condiciones del ensayo no se detectaron residuos de spinosad en la fruta. En cambio se detectaron residuos de malatión, aunque en concentraciones menores que el máximo nivel de residuos permitido en la fruta cosechada en España (2 ppm).

En la parcela de Navel donde se aplicó Spintor Cebo ${ }^{\circledR}$ apareció negrilla sobre las gotas depositadas en los frutos. Este hecho se asoció a que en la parcela ya se encontraba negrilla debido a la melaza que producía la cochinilla algodonosa (Planococcus citri (Risso) (Homoptera: Pseudococcidae)) que estaba presente. En el resto de parcelas ensayadas no se detectó ningún daño en los frutos por negrilla. En la parcela de Clemenules donde se aplicó Spintor Cebo ${ }^{\circledR}$ se produjeron manchas en los frutos durante el virado de color, pues la fruta cambiaba de color excepto en las zonas donde se habían depositado las gotas. En el resto de parcelas este problema no se detectó. Esto muestra la ventaja de utilizar Spintor $480 \mathrm{SC}^{\circledR}$ junto a una proteína hidrolizada sobre Spintor Cebo ${ }^{\circledR}$.

\section{CONCLUSIONES}

En esta parte de la tesis se ha propuesto una alternativa a los tratamientos con malatión para el control de las poblaciones de C.capitata, basada en la aplicación mecanizada de tratamientos cebo a bajo volumen. Para ello, en primer lugar se han caracterizado experimentalmente seis dispositivos de pulverización, 
hidráulicos y centrífugos, con el fin de determinar cual es el más adecuado para obtener impactos de gran tamaño $(1-6 \mathrm{~mm})$ como son los que requieren los tratamientos cebo, y para depositarlos sobre la copa de los cítricos. Se concluyó que, bajo las condiciones ensayadas, la boquilla AI-11003VS a 1 bar de presión, era la más adecuada para realizar estos tratamientos.

Además, se ha propuesto un sistema de control electrónico para automatizar la aplicación de los tratamientos cebo a bajo volumen. Este sistema está basado en un microcontrolador y en un algoritmo de control que gestiona la pulverización de la boquilla seleccionada. Todo ello se ha implementado sobre una máquina que es capaz de regular el caudal aplicado y dispersar bajos volúmenes de caldo, pulverizando sobre zonas definidas de los árboles y adaptándose a distintas configuraciones de parcelas de cítricos, incluso en casos en que no hay separación física entre árboles.

La evaluación del equipo en condiciones de campo ha servido para demostrar que la máquina distribuye la mayoría del caldo pulverizado en el exterior de la copa de los árboles, y localiza el tratamiento únicamente en los puntos programados, por lo que disminuye los riesgos de afectar a fauna útil que se encuentra en el interior de la copa y minimiza el impacto ambiental del mismo. También se ha demostrado que el pulverizador automático desarrollado es robusto, después de haber trabajado adecuadamente sobre más de 8.000 árboles, y es versátil, pues ha funcionado correctamente en tres parcelas con configuraciones de cultivo muy diferentes.

Debido a la gran movilidad de la plaga ha sido necesario desarrollar un método para evaluar la eficacia de distintos tratamientos sobre $C$. capitata. Este método se ha basado en la comparación de la evolución de las capturas observadas en trampas teniendo en cuenta las poblaciones iniciales. Para ello, se ha desarrollado una técnica novedosa de análisis, que consiste, en primer lugar, en la estandarización de los niveles de captura respecto a los niveles encontrados antes de los tratamientos. De este modo se evita el efecto que se observa en el 
campo, por el cual en algunas parcelas se aprecia constantemente un mayor número de capturas. En segundo lugar, se comparan los datos estandarizados mediante regresión lineal y se estudia si los datos transformados evolucionan de manera paralela, de forma estadísticamente significativa.

Una vez determinada la manera de comparar los resultados de los tratamientos sobre las poblaciones de la mosca, se proponen diferentes tratamientos cebo a bajo volumen, a base de spinosad, y aplicados con la máquina diseñada. Los resultados demuestran que éstos son igual de eficaces que los tratamientos convencionales con malation: en los ensayos de campo el número de capturas fue similar en todos los tratamientos y el porcentaje de frutos infestados fue muy bajo. Además, se comprobó que en los tratamientos con spinosad no aparecieron residuos sobre los frutos en el momento de la cosecha.

Paralelamente, se ha demostrado que la aplicación de spinosad formulada como Spintor $480 \mathrm{SC}^{\circledR}$ más la adición de un atrayente es una buena alternativa a la formulación de Spintor $\mathrm{Cebo}^{\circledR}$ ya que no se producen problemas de negrilla y manchado.

En conclusión, se ha demostrado que la propuesta realizada para la mecanización de los tratamientos cebo a bajo volumen, basada en el pulverizador automático desarrollado y con la aplicación de spinosad, es una alternativa racional a los tratamientos tradicionales con malatión, que resulta más respetuosa con el ecosistema y con la salud humana que las actuales prácticas de control. 


\section{Capítulo IV. MECANIZACIÓN DE LOS MÉTODOS CULTURALES}

\section{INTRODUCCIÓN}

Antiguamente recolectar y enterrar la fruta que no se iba a comercializar y que podía ser un reservorio de moscas era una práctica habitual. El objetivo de esta práctica era eliminar las larvas que se encuentran en el interior del fruto durante el invierno y que dan lugar a la primera generación en la primavera siguiente. Asimismo se buscaba que las hembras grávidas no encontraran hospedantes donde realizar la puesta. Sin embargo, la recolección y enterrado de la fruta de manera manual es una práctica muy costosa que en la actualidad es económicamente inviable, por lo que en esta tesis se pretende proponer alguna solución a través de su mecanización.

En un principio se consideró recoger la fruta del suelo con equipos que ya existen en el mercado y que se utilizan, por ejemplo, para la recolección de manzanas y peras destinadas a industria. Esta alternativa, sin embargo, presenta dos inconvenientes: por un lado, se trata de equipos caros que no se utilizan en citricultura y que, por tanto, se comprarían expresamente para realizar esta labor, por lo que sería difícil su amortización y, por otro lado, los costes de transporte y destrucción de los frutos encarecerían aún más el proceso.

Otra solución consiste en enterrar toda la fruta en la propia parcela, con los aperos empleados tradicionalmente para el movimiento de tierras. La dificultad, en este caso, está relacionada con la profundidad de enterrado a la cual pueden emerger los adultos recién formados y que depende tanto de la humedad como de la textura del suelo. Según Gómez-Clemente (1932), si el tercer estadio larvario se entierra unos pocos centímetros en el suelo, aunque la pupa puede llegar a completar su desarrollo, la mayoría de los adultos mueren antes de abandonar el suelo, incluso aunque éstos sean arenosos y estén sueltos. Sin 
embargo, Bodenheimer (1951) señala que la larva se entierra entre 5 y $15 \mathrm{~cm}$ para pupar, y que los adultos pueden emerger de hasta $45 \mathrm{~cm}$ de profundidad en suelos sueltos. Del Pino (2000) concluye que los adultos son capaces de atravesar $40 \mathrm{~cm}$ de suelo suelto y seco, tras salir del pupario. Además de la necesidad de enterrar a gran profundidad, en algunos reglamentos de Producción Integrada se contempla el mantenimiento de la cubierta vegetal durante todo el año, para evitar la erosión de los suelos, y por tanto, se descartó el enterrado.

Por estos motivos se propuso estudiar la posibilidad de llevar a cabo la destrucción de los frutos in situ, utilizando las máquinas que se emplean normalmente para la trituración de los restos de poda en las plantaciones de cítricos. Se trata de aperos que muchos agricultores poseen y, si se emplean adecuadamente, no producen ninguna alteración del suelo. Puesto que esta última alternativa parece en principio factible, se decidió investigarla.

A continuación se hace una breve descripción de las trituradoras de leña que actualmente se emplean en citricultura y de la eficiencia de este tipo de equipos.

\subsection{LAS TRITURADORAS QUE SE EMPLEAN EN CITRICULTURA}

Las trituradoras de restos de poda son máquinas evolucionadas a partir de las desbrozadoras, que golpean las ramas y consiguen reducir su tamaño no por corte sino por impacto. En función de la orientación del rotor que disponen se clasifican en dos tipos: de eje vertical y de eje horizontal. Las que más se emplean para eliminar los restos de poda de los cítricos son las de eje horizontal (Figura 39), que se caracterizan por obtener un material triturado de mayor calidad que las de eje vertical (Ortí, 2001). En estas trituradoras el eje se encuentra dispuesto transversalmente a la dirección de avance y paralelo al suelo. Sobre él se colocan las herramientas de corte, existen dos tipos: cuchillas y martillos. 


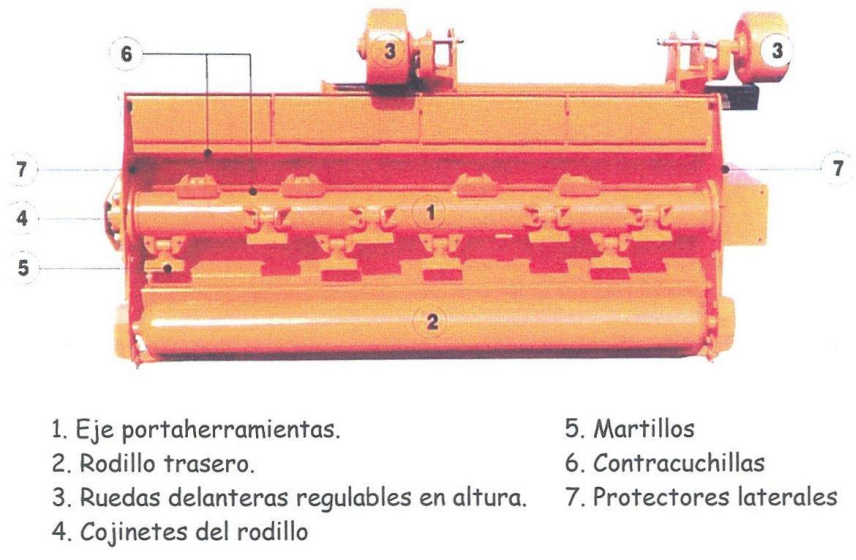

Figura 39. Trituradora de eje horizontal. Vista inferior.

Las cuchillas tienen diversas formas en función del modelo pero, por lo general, son ligeramente acodadas y con sus bordes cortantes en bisel (Figura 40). Los martillos son más robustos y también varían su forma en función del modelo (Figura 41).

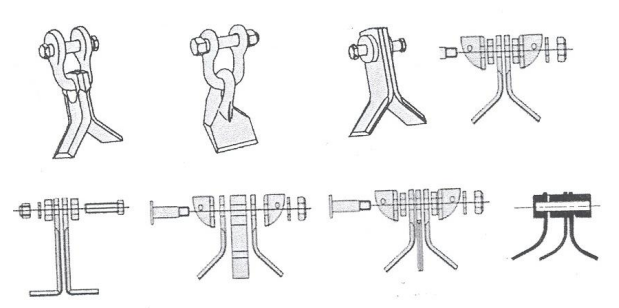

Figura 40. Diferentes diseños de cuchillas.

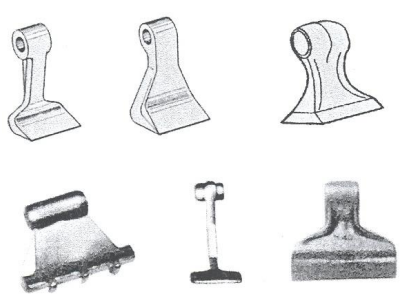

Figura 41. Diferentes diseños de martillos.

Para evitar la proyección de piedras y restos vegetales hacia el exterior una carcasa protectora cubre el eje portaherramientas. En algunos casos la parte inferior está cerrada y dispone de un alimentador en la parte delantera, formado por un eje horizontal con paletas o resaltes y un enrejado en la parte trasera para limitar el tamaño de los fragmentos. Algunas poseen en el interior de la carcasa unas contracuchillas, con el fin de limitar la salida de restos vegetales y mejorar su triturado. 
La mayoría de las trituradoras se apoyan en su parte trasera sobre un rodillo metálico pesado, por lo que además de triturar los restos de poda los aplastan. También las hay que se apoyan sobre ruedas.

Las trituradoras generalmente se enganchan al tripuntal del tractor y se accionan con la toma de fuerza. En la transmisión desde la toma de fuerza hasta el eje portaherramientas se puede encontrar un limitador de par en el eje cardánico o en la propia máquina (embrague de seguridad), una caja de engranajes y un juego de poleas y correas que transmite el movimiento al eje portaherramientas, y que protege las partes débiles de la máquina de las sobrecargas que se producen durante el trabajo. Las trituradoras con carcasa cerrada también poseen un motor hidráulico o una transmisión mecánica que acciona el sistema de alimentación. Otros equipos presentan una caja de engranajes que permiten la conexión por la parte trasera de la máquina e invertir el giro del eje portaherramientas.

La eficiencia de las trituradoras de leña depende de su rendimiento y de la energía que requieren. A su vez, el rendimiento y la energía utilizada varía en función del equipo empleado, de las condiciones de trabajo y del tipo de material y calidad del triturado que se desea. En la literatura científica aparecen diversos trabajos en este sentido y a continuación se citan algunos ejemplos.

Kuran y Hubac (1984) determinaron la calidad del triturado de ramas de poda de manzano y la energía requerida en función de la cantidad de leña $(2,2,5$, $3,3,5$ y $4 \mathrm{~kg} / \mathrm{m}$ lineal de cordón) y dos velocidades de avance (0,66 y 1,06 m/s) midiendo en cada caso el par y la potencia requerida en la toma de fuerza y el porcentaje de fragmentos con longitud superior a $10 \mathrm{~cm}$. Concluyeron que con la mayor cantidad de leña y a la mayor velocidad de avance ensayada el porcentaje de fragmentos con longitud superior a $10 \mathrm{~cm}$ fue menor, pero el par y la potencia aumentaron. De manera similar, Mimura y Yamada (1990) compararon la potencia requerida por una trituradora entre dos tipos de bambú. Observaron que 
el triturado de Pleioblastus chino requirió un 20-30 \% más de potencia que Sasa kurilensis.

Ya en cítricos, Ortí (2001) determinó la calidad del triturado y la energía requerida para triturar restos de poda en función de 3 velocidades de avance $(0,56 \mathrm{~m} / \mathrm{s}, 0,80 \mathrm{~m} / \mathrm{s}$ y $1,17 \mathrm{~m} / \mathrm{s}), 3$ velocidades de giro del rotor $(1.491 \mathrm{r} / \mathrm{min}$, $2.180 \mathrm{r} / \mathrm{min}$ y $2.964 \mathrm{r} / \mathrm{min}$ ), dos tipos de herramienta (cuchillas o martillos) y dos contenidos de humedad de los restos de poda (leña seca (15-20\% de humedad) y leña verde (50-65 \%de humedad). Concluyó que las condiciones que minimizaron la energía específica y obtuvieron una longitud media de triturado menor a $145 \mathrm{~mm}$ fueron: leña seca, cuchillas, velocidad máxima de avance ensayada $(1,17 \mathrm{~m} / \mathrm{s})$ y mínima velocidad de giro del rotor ensayada $(1.491 \mathrm{r} / \mathrm{min})$.

Es muy importante señalar que no existen antecedentes en la literatura científica sobre el empleo de estas máquinas para triturar frutas, por lo que todo lo que se avance en este sentido resulta novedoso.

\section{OBJETIVOS}

En esta parte de la tesis se pretende proponer una solución mecanizada para eliminar la fruta que queda tras la cosecha y que puede ser reservorio de C. capitata. En principio, como se comenta en la introducción del capítulo, la solución más apropiada parece ser la trituración de los frutos en la propia parcela, puesto que el agricultor no tiene que invertir en equipos nuevos, no hay costes de transporte de la fruta y además, su uso es compatible con las prácticas de producción integrada.

Dado que no existen antecedentes de trabajos relacionados con el propósito de esta tesis, es necesario, en primer lugar, evaluar si realmente esta solución puede permitir un control sobre las poblaciones de $C$. capitata y, en caso afirmativo, realizar la trituración de los frutos en campo de una manera eficiente. Por este motivo, en este capítulo de la tesis se han planteado los siguientes objetivos: 
- Determinar la eficacia del triturado de la fruta sobre la mortalidad de larvas de C. capitata.

- Ajustar las condiciones de trabajo de una trituradora de eje horizontal para eliminar los frutos cítricos de una manera eficiente, es decir, maximizando la calidad de la trituración y minimizando el consumo de energía.

- Estudiar del efecto del triturado sobre la población de C. capitata en condiciones de campo.

Cada uno de los objetivos anteriores se desarrolla en los apartados que vienen a continuación.

\section{EFICACIA DE LA TRITURACIÓN DE LA FRUTA EN EL CONTROL DE LARVAS DE $C$. capitata EN CONDICIONES DE LABORATORIO}

En este apartado se evalúa hasta qué punto la trituración de la fruta puede ser un método de control eficaz para C. capitata.

La mayoría de las máquinas trituradoras que se emplean en citricultura tienen dos funciones: en primer lugar, triturar los restos de poda y, en segundo lugar, aplastarlos mediante el rodillo trasero, que es con el que se apoyan sobre el suelo.

La destrucción de los frutos con estos equipos puede ser, por tanto mediante trituración y, dado que los frutos son más frágiles que los restos de poda, también cabe la posibilidad de destruirlos únicamente por aplastamiento. Este segundo método, en el que no se acciona el eje de la máquina, tiene un consumo energético mucho más reducido y, por ello, debe ser investigado.

En este apartado se tratará acerca de la eficacia de los dos métodos de destrucción de frutos (trituración y aplastamiento) para controlar a C. capitata. 
Los experimentos se realizaron en condiciones de laboratorio, porque de ese modo se reducen los factores externos (temperatura y humedad ambientales, presencia de depredadores, etc.) que pueden influir sobre los resultados.

\subsection{MATERIALES Y MÉTODOS}

Para estudiar la eficacia de los métodos de destrucción de los frutos y estudiar si los resultados son reproducibles en el tiempo, se realizó un experimento con un diseño factorial equilibrado, en el que la variable respuesta fue el porcentaje de supervivencia de larvas de C. capitata. Los dos factores estudiados fueron:

- Tratamiento, con tres variantes (Triturado de los frutos, aplastado de los frutos y control).

- Semana, con tres variantes. El ensayo se repitió durante tres semanas consecutivas para determinar la reproducibilidad de los tratamientos.

Para el ensayo se recolectaron naranjas Citrus sinensis (L.) Osb. var. Lanelate de una parcela perteneciente al IVIA y se seleccionaron 150 que no presentaban ningún tipo de daño externo. Una vez en laboratorio, se desinfectaron con un baño de imazalil al 0,2\% durante un minuto, con el fin de impedir la proliferación de hongos durante el ensayo, ya que, en ensayos previos, se observó que las larvas introducidas en frutos que se infectaron de manera natural de Penicilium sp. no evolucionaron al estadio siguiente. Tras el baño fungicida, se dejaron secar los frutos al aire durante 24 horas.

Posteriormente, se infestó cada fruto manualmente con larvas de C. capitata. Todas las larvas que se utilizaron tenían 10 días de edad desde la puesta de huevos y se encontraban en los estadios $\mathrm{L}_{2}$ y $\mathrm{L}_{3}$. La infestación de cada fruto se realizó a través de un agujero, de un centímetro de diámetro, producido con un sacabocados, en la corteza de la naranja. El agujero se hizo de modo que se alcanzó la pulpa. Dentro de cada fruto se introdujeron 15 larvas con ayuda de unas pinzas y, por último, se taparon con un algodón. 
El tratamiento denominado de trituración (Figura 42) consistió en cortar el fruto infestado por la mitad, siendo el corte perpendicular al eje imaginario por donde se ha realizado la infestación, y posteriormente triturarlo con una trituradora eléctrica de uso doméstico (Minipimer MR 555 CA, Braun, Braun España, S.A., Barcelona, España) durante 8 segundos a la velocidad 1 (455 r/min).
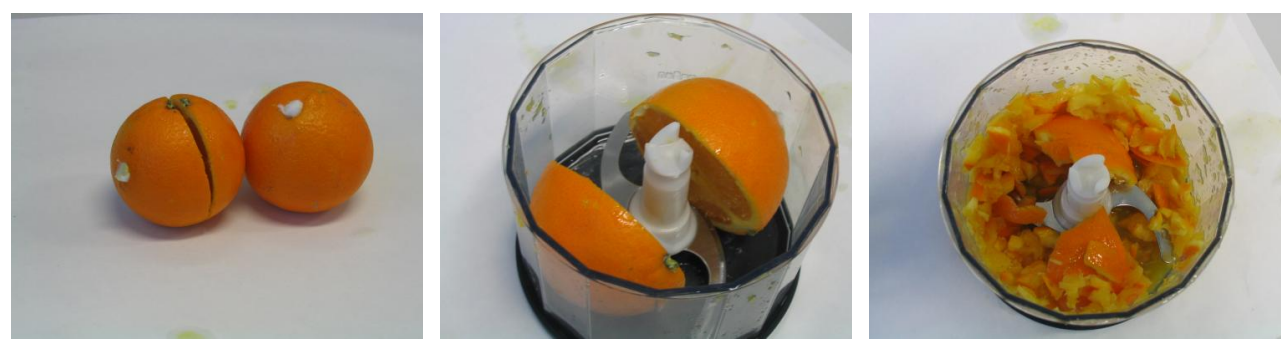

Figura 42. Proceso del tratamiento de trituración en condiciones de laboratorio.

El tratamiento denominado de aplastado consistió en meter el fruto en una bolsa de plástico y posteriormente aplastarlo con un rodillo de madera. En este proceso se observó que, debido a la presión del rodillo sobre la fruta, algunas de las larvas introducidas se salieron del fruto junto con el jugo, así que se decidió colocar dichas larvas de nuevo en el interior del fruto (Figura 43).

Los frutos destinados al control fueron frutos enteros e infestados del mismo modo que los anteriores. Cada tratamiento tuvo 50 repeticiones, considerando cada fruto como una unidad experimental.
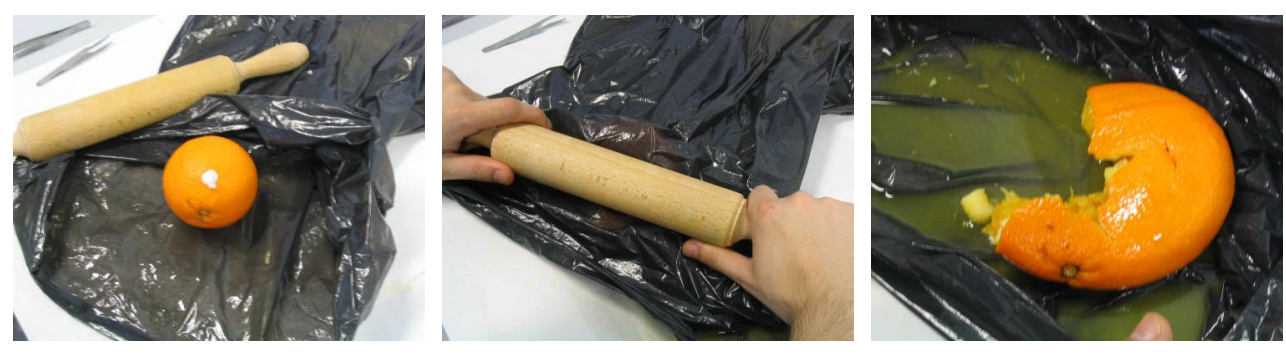

Figura 43. Proceso del tratamiento de aplastado en condiciones de laboratorio. 
Tras aplicar el tratamiento correspondiente, cada fruto se colocó en un recipiente de plástico, cuya base se agujereó con una aguja para permitir la salida del jugo de la fruta. El fruto se dispuso sobre una rejilla elevada, de modo que las larvas saltaran a la base del recipiente para pupar. Los recipientes se taparon con tela de muselina, para evitar que las larvas se salieran al saltar (Figura 44). Después se introdujeron los recipientes en una cámara climática, y se mantuvieron en las condiciones ambientales teóricamente idóneas para el desarrollo de las larvas C. capitata $\left(25 \pm 3{ }^{\circ} \mathrm{C}\right.$ y $75 \pm 10 \%$ H.R.) (Putruele, 1998) hasta el estado de pupa.
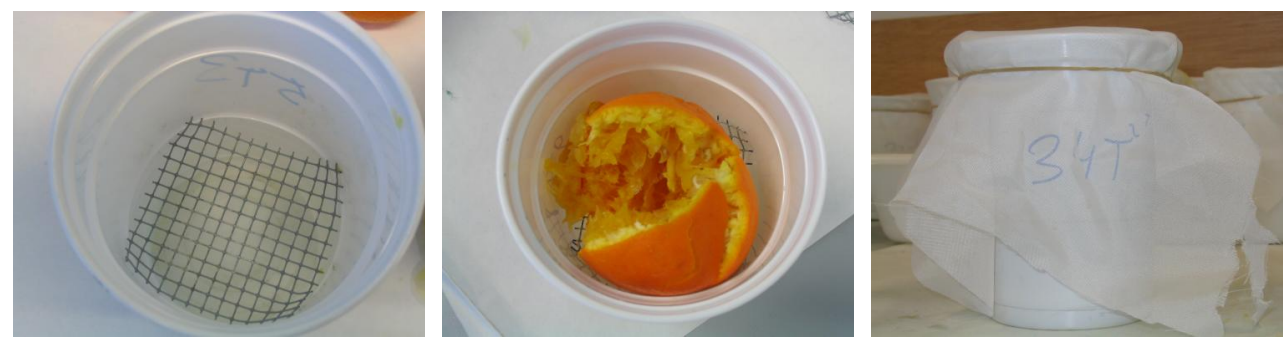

Figura 44. Colocación de la fruta en recipientes de plástico sobre rejilla y tapados con muselina, para su almacenamiento en cámaras climáticas.

Todas las frutas se inspeccionaron periódicamente y se anotó el número de pupas por fruto. El experimento concluyó cuando ya no se formaban pupas.

La eficacia de cada tratamiento se determinó a través del porcentaje de supervivencia de larvas, dado que se conocía el número de larvas introducidas en cada fruto, y el número de ellas que habían evolucionado a pupa y, por tanto, habían sobrevivido al tratamiento.

El tratamiento de los datos consistió en un ANOVA multifactorial. Para evaluar el cumplimiento de la hipótesis de normalidad se estudió la normalidad de los residuos mediante papel probabilístico normal. Para estudiar la separación de medias entre las variantes se aplicó la prueba LSD. El nivel de confianza en ambos análisis fue del $95 \%$. 


\subsection{RESULTADOS}

El factor semana resultó significativo para la supervivencia de larvas $(\mathrm{F}=8,16$, g.l. $=2-449, \mathrm{P}=0,00)$. Entre la primera y la segunda semana no se observaron diferencias significativas en la supervivencia de larvas. Sin embargo, en la tercera semana el porcentaje de supervivencia de larvas fue significativamente menor. No obstante, la interacción con el factor tratamiento no resultó significativa $(\mathrm{F}=2,13$, g.l. $=4-449, \mathrm{P}=0,08)$, ya que las larvas utilizadas en el ensayo de la tercera semana presentaron un incremento de mortalidad igual para todos los tratamientos. Por tanto, el efecto del tratamiento puede considerarse independiente de la semana de ensayo (Figura 45).

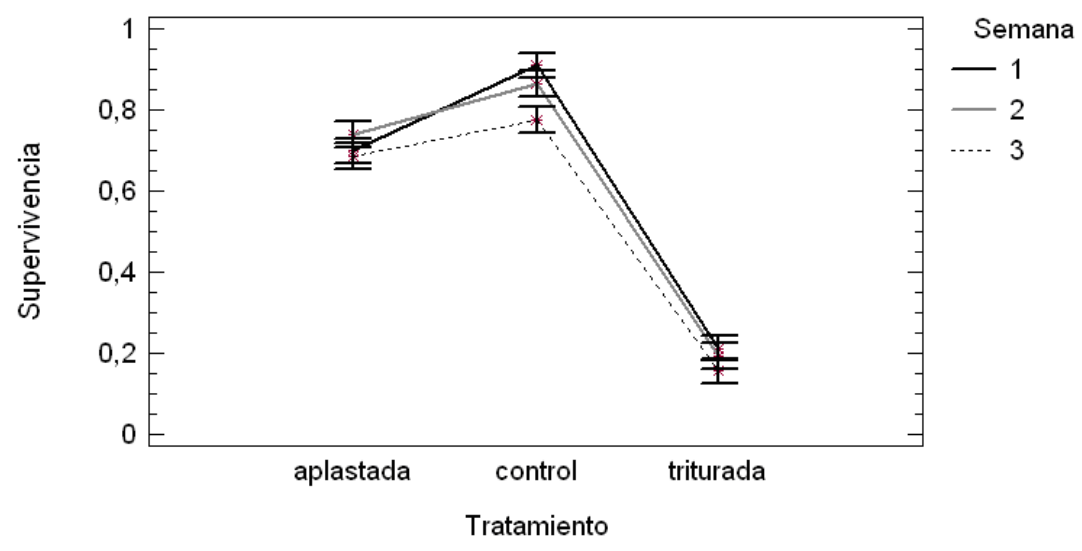

Figura 45 Interacción entre el factor tratamiento y el factor semana para la variable supervivencia de larvas. Intervalos LSD con un nivel de confianza del 95\%.

El factor tratamiento resultó significativo para la supervivencia de larvas $(\mathrm{F}=719,42$, g.l. $=2-449, \mathrm{P}=0,00)$. La supervivencia de las larvas en el control fue significativamente mayor que en los tratamientos de aplastamiento y trituración. Entre estos tratamientos, el de trituración presentó una supervivencia de larvas significativamente menor (Tabla 16). 
Tabla 16. Ratio de supervivencia de larvas de C. capitata (Media \pm ES) en función de factor tratamiento. Valores de la media seguidos de diferente letra muestran diferencias significativas (Prueba LSD a un nivel de confanza del $95 \%$ ).

\begin{tabular}{|l|c|}
\hline Tratamiento & Supervivencia (tanto por uno) \\
\hline Control & $0,85 \pm 0,01 \mathrm{a}$ \\
\hline Fruta aplastada & $0,71 \pm 0,02 \mathrm{~b}$ \\
\hline Fruta triturada & $0,19 \pm 0,01 \mathrm{c}$ \\
\hline
\end{tabular}

\subsection{DISCUSIÓN}

Tanto la trituración como el aplastado fueron tratamientos eficaces para disminuir la supervivencia de $C$. capitata. Sin embargo, la mortalidad de las larvas en el tratamiento de aplastamiento fue del $29 \%$ mientras que en el de trituración fue del $81 \%$. Por tanto, para realizar la destrucción de los frutos en el campo parece más aconsejable utilizar la trituración.

Es probable que la eficacia de estos tratamientos fuese mayor en experiencias de campo. Por una parte, allí no se dan continuamente las condiciones idóneas para el desarrollo de las larvas, como ocurre en el laboratorio. Además, los frutos normalmente son atacados por hongos, como Penicillium sp., y, como se observó en ensayos previos, estos afectan al desarrollo larvario.

En el caso de la fruta aplastada, hay que tener en cuenta también que en el proceso de aplastamiento muchas de las larvas salieron del fruto y se reintrodujeron manualmente (lo que favorece al insecto), mientras que en condiciones de campo esto no ocurriría y quedarían expuestas a la intemperie sin un sustrato adecuado, lo que aumentaría su mortalidad.

Además, los ensayos se han realizado con larvas de los estadios $\mathrm{L}_{2}$ y $\mathrm{L}_{3}$. Los huevos y las larvas $\mathrm{L}_{1}$ son más sensibles a la desecación por lo que es de esperar que la eficacia de los tratamientos aumente si en los frutos se encuentra C.capitata en estos estados. 
4 DETERMINACIÓN DE LAS CONDICIONES DE TRABAJO DE UNA TRITURADORA DE EJE HORIZONTAL PARA DESTRUIR CÍTRICOS

En el apartado anterior se ha demostrado que la trituración y el aplastado de la fruta reducen significativamente la supervivencia de las larvas. Por este motivo se abordó el estudio de la mecanización de esta tarea.

En este apartado se pretenden seleccionar los parámetros de trabajo con los que debe trabajar una trituradora de eje horizontal para impedir que los frutos caídos sean un reservorio de larvas de la mosca mediterránea de la fruta.

El estudio se orienta a determinar las condiciones de trabajo que produzcan una destrucción adecuada de la fruta con un consumo mínimo de energía. Por este motivo, en primer lugar hace falta establecer una metodología para evaluar la calidad del trabajo de la trituradora sobre los frutos y, en segundo lugar, determinar el consumo de energía.

\subsection{MATERIALES Y MÉTODOS}

Como se ha visto en la introducción de este capítulo, el tipo de herramienta, la velocidad de giro de la toma de fuerza y la velocidad de avance del tractor influyen sobre la trituración. Para determinar el efecto de estos factores sobre las variables respuesta: calidad de la fruta triturada y potencia requerida por la trituradora, se decidió realizar un diseño factorial equilibrado de 3 factores:

- Tipo de herramienta de corte a 2 variantes: cuchillas y martillos.

- Velocidad de avance a 2 niveles: baja y alta.

- Velocidad de giro la toma de fuerza a 2 niveles: baja y alta.

La mosca mediterránea de la fruta ataca a naranjas y mandarinas. Dado que el tipo de material también puede influir sobre la calidad de la trituración, los 
ensayos se realizaron para las dos especies de cítricos. Cada experiencia se repitió 3 veces, llevándose a cabo un total de 24 pruebas por tipo de fruto que se realizaron en orden aleatorio para evitar posibles errores sistemáticos.

El ensayo con mandarinas se realizó en una parcela experimental perteneciente al IVIA plantada con mandarinos del grupo satsumas Citrus unshiu (Mak.) Marc. var. Clausellina, cuyos frutos fueron utilizados para el ensayo. El ensayo con naranjas se realizó en una parcela contigua a la anterior plantada con naranjos Citrus sinensis (L.) Osb. var. Navelina cuyos frutos fueron utilizados.

\subsubsection{Tractor y trituradoras. Establecimiento de las velocidades de avance} y de giro la toma de fuerza para el ensayo

El tractor (John Deere 2035, John Deere Ibérica S.A. Madrid, España) empleado en el ensayo es propiedad del Departamento de Mecanización y Tecnología Agraria de la Universidad Politécnica de Valencia. Sus principales características se muestran en la Tabla 17. Características del tractor empleado.. El tractor está equipado con neumáticos traseros especiales 13.6/12-30.

Tabla 17. Características del tractor empleado.

\begin{tabular}{|l|c|}
\hline Motor & John Deere, modelo 4219 DCE 03 \\
\hline Par máximo a 1800 r/min & $196 \mathrm{Nm}$ \\
\hline Potencia máxima homologada a 2500 r/min & $50 \mathrm{~kW}$ \\
\hline Caja de cambios & $\begin{array}{c}\text { 4 velocidades marcha atrás } \\
\text { 8 velocidades marcha adelante (4 cortas y 4 } \\
\text { largas) }\end{array}$ \\
\hline
\end{tabular}

Para conocer la velocidad de avance del tractor con diferentes combinaciones de la caja de cambio se hizo una serie de ensayos en los que se midió el tiempo que tardaba el tractor, con la trituradora en funcionamiento, en recorrer una distancia de $100 \mathrm{~m}$ a $540 \mathrm{r} / \mathrm{min}$ en la toma de fuerza. La velocidad se calculó dividiendo la distancia entre el tiempo empleado. Los resultados se muestran en la Tabla 18. 
Capítulo IV. Mecanización de los métodos culturales

Tabla 18. Velocidades de avance del tractor a $540 \mathrm{r} / \mathrm{min}$ en función de diferentes combinaciones de la caja de cambio.

\begin{tabular}{|c|c|c|c|}
\hline $\begin{array}{c}\text { Velocidad TDF } \\
(\mathbf{r} / \mathbf{m i n})\end{array}$ & Grupo & Marcha & $\begin{array}{c}\text { Velocidad } \\
(\mathbf{k m} / \mathbf{h})\end{array}$ \\
\hline $\mathbf{5 4 0}$ & $\mathbf{C}$ & $\mathbf{1}^{\mathbf{a}}$ & 2,09 \\
\hline $\mathbf{5 4 0}$ & $\mathbf{C}$ & $\mathbf{2}^{\mathbf{a}}$ & 3,00 \\
\hline $\mathbf{5 4 0}$ & $\mathbf{C}$ & $\mathbf{3}^{\mathbf{a}}$ & 4,39 \\
\hline $\mathbf{5 4 0}$ & $\mathbf{C}$ & $\mathbf{4}^{\mathbf{a}}$ & 6,00 \\
\hline $\mathbf{5 4 0}$ & $\mathbf{L}$ & $\mathbf{1}^{\mathbf{a}}$ & 8,18 \\
\hline $\mathbf{5 4 0}$ & $\mathbf{L}$ & $\mathbf{2}^{\mathbf{a}}$ & 11,25 \\
\hline
\end{tabular}

A partir de los resultados de la Tabla 18 se descartaron las velocidades de avance más altas y se calcularon más velocidades de avance, utilizando otros regímenes razonables en la toma de fuerza. Sobre estos datos se decidieron las velocidades de avance y de régimen en la toma de fuerza que se emplearían en los ensayos (Tabla 19). Las velocidades de la toma de fuerza seleccionadas son $400 \mathrm{r} / \mathrm{min}$ y $540 \mathrm{r} / \mathrm{min}$ y equivalen en la trituradora empleada a una velocidad de giro del eje portaherramientas de $1.850 \mathrm{r} / \mathrm{min}$ y $2.500 \mathrm{r} / \mathrm{min}$ respectivamente.

Tabla 19. Velocidades de avance y de la toma de fuerza establecidas para el ensayo.

\begin{tabular}{|c|c|c|c|}
\hline $\begin{array}{c}\text { Velocidad TDF } \\
(\mathbf{r} / \mathbf{m i n})\end{array}$ & Marcha & $\begin{array}{c}\text { Velocidad } \\
(\mathbf{k m} / \mathbf{h})\end{array}$ & $\begin{array}{c}\text { Velocidad de ensayo } \\
(\mathbf{k m} / \mathbf{h})\end{array}$ \\
\hline $\mathbf{5 4 0}$ & $\mathbf{1}^{\mathrm{a}} \mathbf{C}$ & 2,09 & 2 \\
\hline $\mathbf{5 4 0}$ & $\mathbf{3}^{\mathrm{a}} \mathbf{C}$ & 4,39 & 4,4 \\
\hline $\mathbf{4 0 0}$ & $\mathbf{2}^{\mathrm{a}} \mathbf{C}$ & 2,22 & 2 \\
\hline $\mathbf{4 0 0}$ & $\mathbf{4}^{\mathrm{a}} \mathbf{C}$ & 4,44 & 4,4 \\
\hline
\end{tabular}

Para la trituración se emplearon dos trituradoras suspendidas de eje horizontal iguales (Enguix, modelo TRR-150, Enguix, S.L., Valencia, España), que se diferenciaban únicamente en el número y en el tipo de herramientas de corte. Una iba dotada con cuchillas (Figura 46) y la otra con martillos (Figura 47). Sus características se describen en la Tabla 20. 


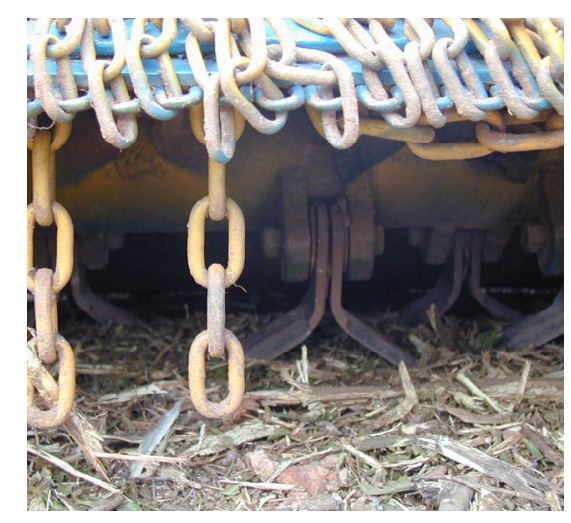

Figura 46. Detalle de las cuchillas.

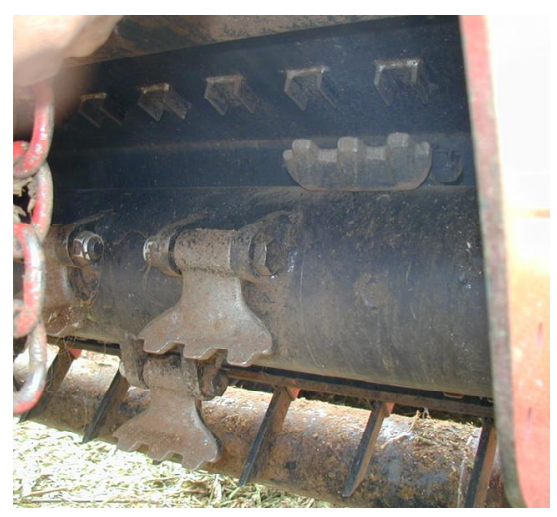

Figura 47. Detalle de los martillos.

Tabla 20. Características de las trituradoras de leña de eje horizontal empleadas en los ensayos.

\begin{tabular}{|l|c|c|}
\hline & $\begin{array}{c}\text { Trituradora } \\
\text { de cuchillas }\end{array}$ & $\begin{array}{c}\text { Trituradora } \\
\text { de martillos }\end{array}$ \\
\hline Peso (kg) & \multicolumn{2}{|c|}{650} \\
\hline Ancho de trabajo (m) & \multicolumn{2}{|c|}{1,5} \\
\hline Relación de desmultiplicación (r/min) & 32 & - \\
\hline Número de cuchillas en el eje portacuchillas & - & 16 \\
\hline Número de martillos en el eje portamartillos & \multicolumn{2}{|c|}{222} \\
\hline Diámetro del rodillo de hierro macizo (mm) & \\
\hline
\end{tabular}

\subsubsection{Metodología}

Para cada experiencia se colocaron 300 frutos en el caso de mandarinas y 200 frutos en el caso de naranjas, situados en el centro de una calle de la parcela correspondiente formando una hilera a lo largo de $100 \mathrm{~m}$. Los frutos habían sido recolectados en la misma parcela 1 día antes.

Posteriormente, se procedió a su trituración (Figura 48). Como la altura de la base de la trituradora respecto del suelo influye sobre el triturado, en todas las experiencias se colocó a $1 \mathrm{~cm}$ de altura. 

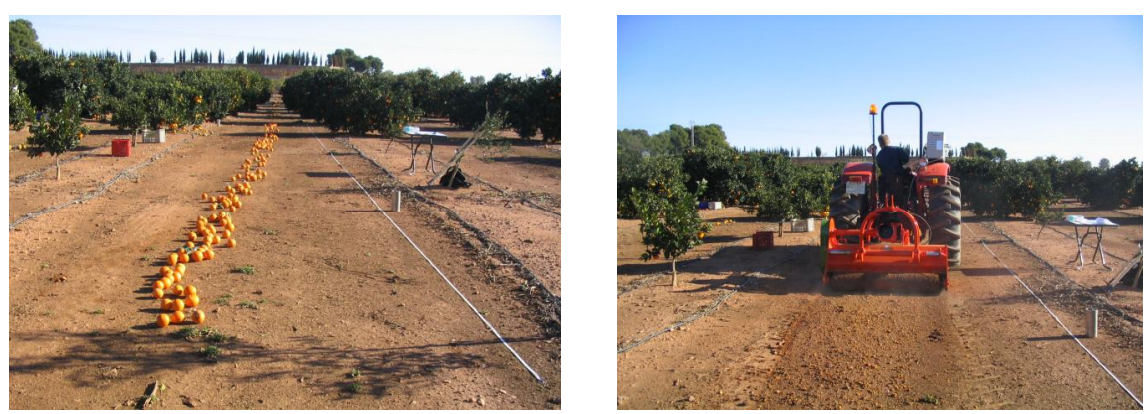

Figura 48. Proceso de la trituración de los frutos en campo. Colocación de los frutos en el centro de la calle y su trituración.

\subsubsection{Calidad de la fruta triturada}

Para definir un índice de la calidad del triturado en cada experiencia, tras la trituración se clasificaron los restos del material en 4 niveles:

- Frutos enteros. Son frutos que quedaron intactos.

- Frutos enteros dañados. Son frutos enteros que presentaron cortes o golpes.

- Medios frutos (M. F.). Son trozos de fruta que representan entre el $40 \%$ y el $60 \%$ del fruto inicial.

- Cuartos de fruto (C. F.). Son trozos de fruta que representan entre el $15 \%$ y el $35 \%$ del fruto inicial.

Posteriormente, se calculó el porcentaje de unidades de cada nivel dividiendo el número de unidades encontradas en cada nivel por el número de frutos total utilizado en la experiencia. En el caso de los medios frutos y los cuartos de fruto, los porcentajes se dividieron entre 2 y 4 respectivamente. A partir de los porcentajes en cada nivel se calculó el porcentaje de fruta totalmente triturada mediante la Ecuación 12.

$\%$ F.Triturada $=100-(\%$ F.Entera $\%$ F.Dañada+\%M.F.+\%C.F.) 


\subsubsection{Medida de la potencia requerida. Coste energético}

La potencia requerida durante la trituración de la fruta se calculó a partir de la medición de la velocidad de giro y el par en la toma de fuerza del tractor (Ecuación 13). En cada una de las experiencias se registraron los datos de ambos parámetros cada $0,5 \mathrm{~s}$ y se promediaron.

$$
\text { Potencia }=\frac{M \times n}{9.550}
$$

Donde:

Potencia $=$ la potencia media requerida en la toma de fuerza $(\mathrm{kW})$.

$\mathrm{M}=$ el valor medio del par en la toma de fuerza $(\mathrm{Nm})$.

$\mathrm{n}=$ el valor medio de la velocidad de giro en la toma de fuerza $(\mathrm{r} / \mathrm{min})$.

Para la medición del par en la toma de fuerza se empleó un sensor de par de anillos rozantes (Lebow modelo 1248, Honeywell Sensing \& Control, Freeport, USA) (Figura 49) y un acondicionador de la señal del medidor de par (Daytronic modelo 3270, Daytronic Corporation, Ohio, USA).

Para medir la velocidad de giro de la toma de fuerza se utilizó un sensor magnético de pulsos (Lebow modelo 550, Honeywell Sensing \& Control, Freeport, USA) (Figura 49).

La adquisición de los datos de los dos sensores se realizó mediante un datalogger con software de visualización de los datos (Yokohama modelo DC 100, Technol Seven, Yokohama, Japan). 


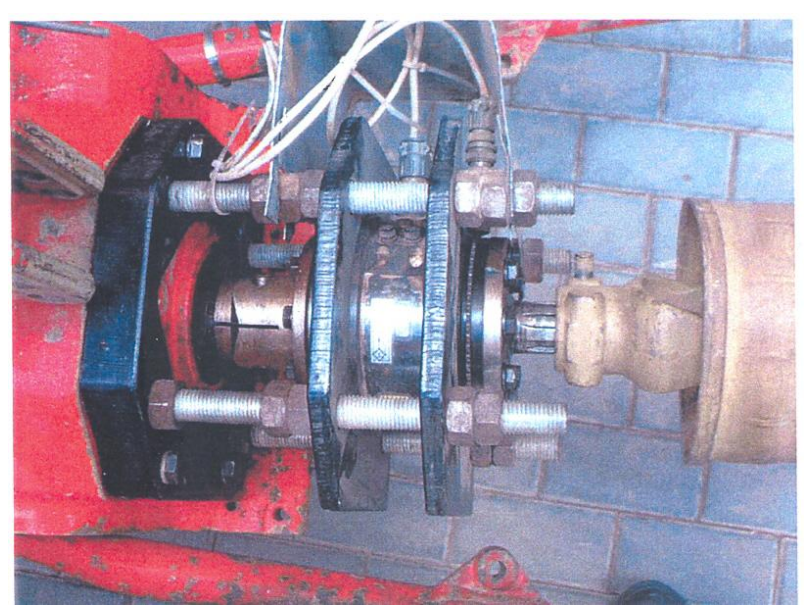

Figura 49. Sensores para medir el par y la velocidad de giro de la toma de fuerza del tractor.

Para traducir los valores de potencia requerida en coste económico se estimó el coste energético mediante la Ecuación 14. De esta forma se puede conocer el coste energético que supone el cambio de las condiciones de trabajo de la trituradora.

$$
C_{t}=\frac{10 \times h}{a \times v \times \eta_{p}}
$$

Ecuación 14

Donde:

$\mathrm{C}_{\mathrm{t}}=$ Coste energético por unidad de superficie (€/ha).

$\mathrm{h}=$ Coste horario del combustible $(€ / \mathrm{h})($ Ecuación 15$)$.

$\mathrm{a}=$ Ancho de trabajo (m).

$\mathrm{v}=$ Velocidad de avance $(\mathrm{km} / \mathrm{h})$.

$\eta_{\mathrm{p}}=$ Rendimiento de la parcela (\%). Se supuso un valor de $75 \%$. 


$$
h=\frac{N_{t d f} \times C_{s} \times C_{l}}{\delta}
$$

Ecuación 15

Donde:

$\mathrm{N}_{\mathrm{tdf}}=$ Potencia requerida en la toma de fuerza $(\mathrm{kW})$.

$\mathrm{C}_{\mathrm{s}}=$ Consumo específico medio $(\mathrm{g} / \mathrm{kW} \cdot \mathrm{h})$. Se supuso de $250 \mathrm{~g} / \mathrm{kWh}$.

$\mathrm{C}_{1}=$ Coste del combustible $(€ / 1)$. Se tomó el valor de $0,7 € / 1$.

$\delta=$ Densidad del combustible (g/l). Se tomó el valor de $840 \mathrm{~g} / \mathrm{l}$.

\subsubsection{Análisis de los datos}

Para analizar el efecto de los factores estudiados sobre las dos variables dependientes, porcentaje de fruta triturada y potencia media requerida por el tractor, se realizó un ANOVA multifactorial para cada variable respuesta y cada especie de cítrico. Para evaluar el cumplimiento de la hipótesis de normalidad de este modelo se estudió la normalidad de los residuos mediante papel probabilístico normal. Se utilizó la prueba LSD para la separación de las medias. El nivel de confianza en los dos análisis fue del $95 \%$.

\subsection{RESULTADOS}

\subsubsection{Calidad de la fruta triturada}

La Tabla 21 muestra la distribución de los restos de fruta tras la trituración en los 4 niveles definidos, más el porcentaje de fruta totalmente triturada, para la experiencia realizada con mandarinas. Se observa que el porcentaje de fruta entera es prácticamente cero en todos los casos, es decir, que todos los frutos se vieron afectados por el paso de la trituradora. El porcentaje de fruta entera dañada presenta valores bajos. Se observa que son menores en el caso de la trituradora de martillos $(1,14 \%)$ que en el de la trituradora de cuchillas $(4,16 \%)$. Porcentajes similares se han encontrado de medios frutos y cuartos de 
Capítulo IV. Mecanización de los métodos culturales

fruto. Por este motivo el porcentaje de fruta totalmente triturada es elevado y los valores oscilan entre un $84,81 \%$ y un $97,25 \%$.

Tabla 21. Distribución de los restos observados tras la trituración en los ensayos con mandarinas.

\begin{tabular}{|l|r|r|r|r|r|r|c|}
\cline { 5 - 9 } \multicolumn{1}{c|}{} & \multicolumn{5}{c|}{ Porcentaje de fruta en cada nivel (\%) } \\
\hline Herramienta & $\begin{array}{c}\text { Velocidad } \\
\text { avance } \\
\text { Cuchillas }\end{array}$ & $\begin{array}{c}\text { Velocidad } \\
\text { giro tdf } \\
\text { (r/min) }\end{array}$ & Entera & Dañada & M.F. & C.F. & $\begin{array}{c}\text { Totalmente } \\
\text { Triturada }\end{array}$ \\
\hline Cuchillas & $\mathbf{2}$ & $\mathbf{4 0 0}$ & 0,00 & 4,58 & 4,13 & 2,65 & 88,65 \\
\hline Cuchillas & $\mathbf{2}$ & $\mathbf{5 4 0}$ & 0,00 & 3,11 & 4,17 & 3,14 & 89,58 \\
\hline Cuchillas & $\mathbf{4}$ & $\mathbf{4 0 0}$ & 0,56 & 5,78 & 5,22 & 3,64 & 84,81 \\
\hline Martillos & $\mathbf{4}$ & $\mathbf{5 4 0}$ & 0,00 & 3,17 & 1,17 & 0,75 & 94,92 \\
\hline Martillos & $\mathbf{2}$ & $\mathbf{4 0 0}$ & 0,00 & 1,67 & 1,06 & 0,81 & 96,47 \\
\hline Martillos & $\mathbf{2}$ & $\mathbf{5 4 0}$ & 0,00 & 1,56 & 1,06 & 0,64 & 96,75 \\
\hline Martillos & $\mathbf{4}$ & $\mathbf{4 0 0}$ & 0,00 & 0,22 & 1,94 & 2,61 & 95,22 \\
\hline
\end{tabular}

En el caso de las naranjas (Tabla 22), el porcentaje de fruta entera es también prácticamente nulo. Como ocurre con las mandarinas, todos los frutos son dañados por la trituradora. El porcentaje de fruta entera dañada es mayor cuando se emplea la trituradora de cuchillas $(11,65 \%)$ que cuando se emplea la de martillos ( $3 \%)$. Además, los valores que se observan son mayores que en el caso de las mandarinas. Se han obtenido porcentajes muy pequeños de medios frutos y cuartos de fruto.

Tabla 22. Distribución de los restos observados tras la trituración en los ensayos con naranjas.

\begin{tabular}{|l|r|r|c|c|c|c|c|}
\cline { 5 - 9 } \multicolumn{1}{c}{} & \multicolumn{5}{c|}{ Porcentaje de fruta en cada nivel (\%) } \\
\hline Herramienta & $\begin{array}{c}\text { Velocidad } \\
\text { avance } \\
\text { (km/h) }\end{array}$ & $\begin{array}{c}\text { Velocidad } \\
\text { giro tdf } \\
\text { (r/min) }\end{array}$ & Entera & Dañada & M.F. & C.F. & $\begin{array}{c}\text { Totalmente } \\
\text { Triturada }\end{array}$ \\
\hline Cuchillas & $\mathbf{2}$ & $\mathbf{4 0 0}$ & 0,33 & 15,50 & 3,67 & 2,00 & 78,50 \\
\hline Cuchillas & $\mathbf{2}$ & $\mathbf{5 4 0}$ & 0,17 & 13,67 & 2,42 & 2,87 & 80,86 \\
\hline Cuchillas & $\mathbf{4}$ & $\mathbf{4 0 0}$ & 0,00 & 11,17 & 2,58 & 2,42 & 83,83 \\
\hline Martillos & $\mathbf{4}$ & $\mathbf{5 4 0}$ & 0,00 & 6,33 & 1,67 & 1,42 & 90,58 \\
\hline Martillos & $\mathbf{2}$ & $\mathbf{4 0 0}$ & 0,00 & 1,00 & 0,75 & 1,25 & 97,00 \\
\hline Martillos & $\mathbf{2}$ & $\mathbf{5 4 0}$ & 0,00 & 4,00 & 0,67 & 1,75 & 93,58 \\
\hline Martillos & $\mathbf{4}$ & $\mathbf{4 0 0}$ & 0,00 & 1,17 & 1,00 & 2,17 & 95,67 \\
\hline
\end{tabular}


En el ensayo de mandarinas el único factor estadísticamente significativo sobre el porcentaje de fruta triturada fue el tipo de herramienta. La calidad del triturado fue significativamente mayor cuando se emplearon martillos que cuchillas. La velocidad de avance del tractor no resultó significativa. Tampoco la velocidad de giro de la toma de fuerza (Tabla 23).

Tabla 23. Porcentaje de fruta triturada (Media \pm ES) en función de factor tipo de herramienta, velocidad de avance y velocidad de giro de la toma de fuerza en el ensayo de mandarinas. Dentro de cada factor, valores de la media seguidos de diferente letra muestran diferencias significativas (Prueba LSD a un nivel de confanza del $95 \%$ ).

\begin{tabular}{|l|c|c|}
\hline \multicolumn{2}{|l|}{ Factores } & Porcentaje fruta triturada (\%) \\
\hline Tipo de herramienta & Cuchillas & $91,95 \pm 1,17 \mathrm{~b}$ \\
\cline { 2 - 3 }$(\mathrm{F}=25,79$, g.l. $=1-21, \mathrm{P}=0,00)$ & Martillos & $97,60 \pm 0,36 \mathrm{a}$ \\
\hline $\begin{array}{l}\text { Velocidad de avance del tractor }(\mathrm{km} / \mathrm{h})(\mathrm{F}= \\
\text { 0,01, g.l.=1 - 21, P=0,92) }\end{array}$ & 2 & $95,17 \pm 1,04 \mathrm{~A}$ \\
\cline { 2 - 3 } & 4 & $94,89 \pm 1,33 \mathrm{~A}$ \\
\hline $\begin{array}{l}\text { Velocidad de giro de la t.d.f. (r/min) } \\
(\mathrm{F}=2,64, \mathrm{~g} .1 .=1-21, \mathrm{P}=0,12)\end{array}$ & 400 & $94,12 \pm 1,37 a$ \\
\cline { 2 - 3 } & 540 & $95,93 \pm 0,90 a$ \\
\hline
\end{tabular}

Del mismo modo, en el ensayo realizado con naranjas, la trituradora de martillos produjo significativamente mayor porcentaje de fruta triturada que la de cuchillas. Los factores velocidad de avance y velocidad de giro de la toma de fuerza del tractor no fueron significativos (Tabla 24).

Tabla 24. Porcentaje de fruta triturada (Media \pm ES) en función de factor tipo de herramienta, velocidad de avance y velocidad de giro de la toma de fuerza en el ensayo de naranjas. Dentro de cada factor, valores de la media seguidos de diferente letra muestran diferencias significativas (Prueba LSD a un nivel de confanza del $95 \%$ ).

\begin{tabular}{|l|c|c|}
\hline \multicolumn{2}{|l|}{ Factores } & Porcentaje fruta triturada (\%) \\
\hline Tipo de herramienta & Cuchillas & $89,24 \pm 0,84 \mathrm{~b}$ \\
\cline { 2 - 3 }$(\mathrm{F}=63,02$, g.l.=1 - 23, P=0,00) & Martillos & $97,33 \pm 0,55 \mathrm{a}$ \\
\hline $\begin{array}{l}\text { Velocidad de avance del tractor (km/h) }(\mathrm{F}= \\
\text { 0,38, g.l.=1 - 23, P=0,55) }\end{array}$ & 2 & $92,97 \pm 1,60 \mathrm{~A}$ \\
\cline { 2 - 3 } & 4 & $93,60 \pm 1,19 \mathrm{~A}$ \\
\hline $\begin{array}{l}\text { Velocidad de giro de la t.d.f. (r/min) } \\
(\mathrm{F}=1,04, \text { g.l.=1 - 23, P=0,32) }\end{array}$ & 400 & $93,81 \pm 1,58 a$ \\
\cline { 2 - 3 } & 540 & $92,76 \pm 1,20 a$ \\
\hline
\end{tabular}




\subsubsection{Potencia requerida por la trituradora y coste energético}

En el Anejo 10 se muestran los resultados del ANOVA para los dos ensayos, el de mandarinas y el de naranjas. A continuación se comentan únicamente las interacciones o factores que resultaron significativas para la variable potencia.

En el ensayo de mandarinas la potencia requerida durante el proceso fue significativamente mayor cuando se emplearon los martillos como herramienta de corte. Al aumentar la velocidad de giro de la toma de fuerza de $400 \mathrm{r} / \mathrm{min}$ a $540 \mathrm{r} / \mathrm{min}$ la potencia requerida por la trituradora aumentó significativamente, tanto para la trituración de cuchillas como de martillos. No obstante, este aumento fue mayor en el caso de la trituradora de martillos (Figura 50). En el ensayo de trituración de naranjas, la interacción entre el tipo de herramienta y la velocidad de giro fue también significativa. Las tendencias fuero similares a las del ensayo sobre mandarinas, pero los valores de potencia requerida fueron mayores (Figura 51).

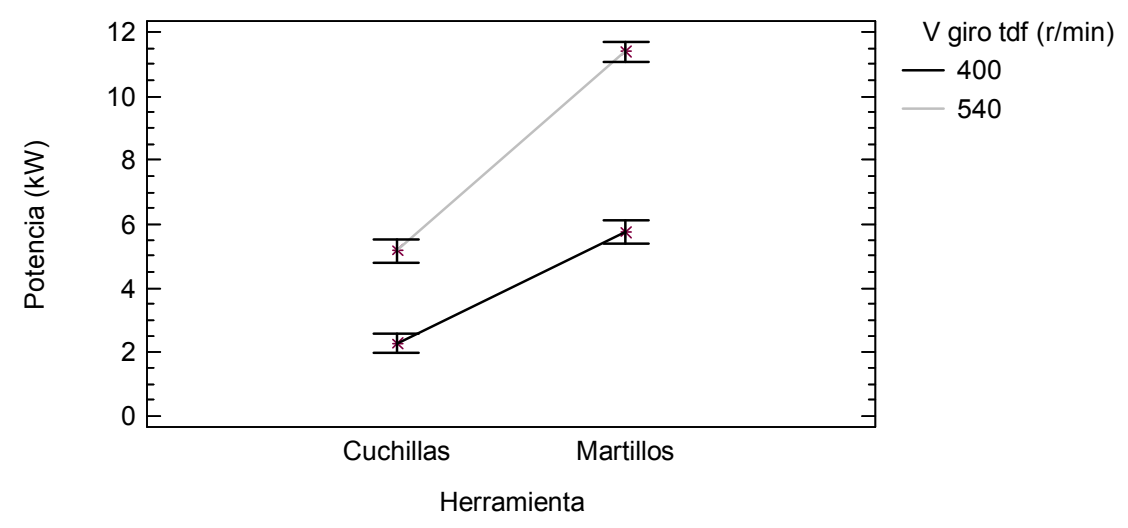

Figura 50. Interacción entre el tipo de herramienta y la velocidad de giro para la potencia requerida. Intervalos LSD con un nivel de confianza del $95 \%$. 


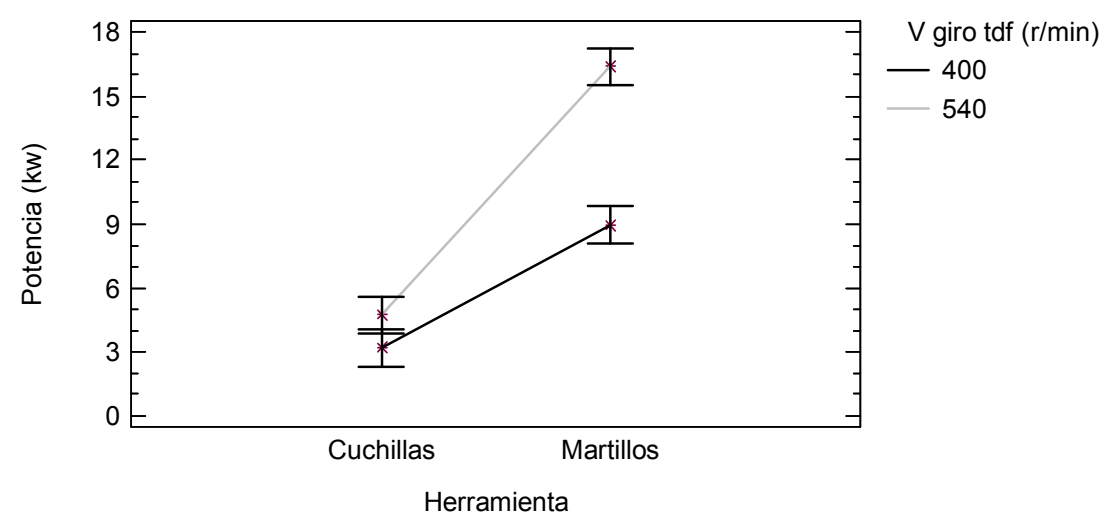

Figura 51. Interacción entre el tipo de herramienta y la velocidad de giro para la potencia requerida. Intervalos LSD con un nivel de confianza del 95\%.

En cuanto a la velocidad de avance del tractor, no se encontraron diferencias significativas de potencia requerida entre las dos velocidades de avance ensayadas cuando la velocidad de giro en la toma de fuerza fue $400 \mathrm{r} / \mathrm{min}$. Sin embargo, cuando régimen fue de $540 \mathrm{r} / \mathrm{min}$, se produjo un aumento significativo de potencia al pasar de una velocidad de avance de $2 \mathrm{~km} / \mathrm{h}$ a una de 4 km/h (Figura 52). Lo mismo ocurrió en el ensayo con naranjas (Figura 53).

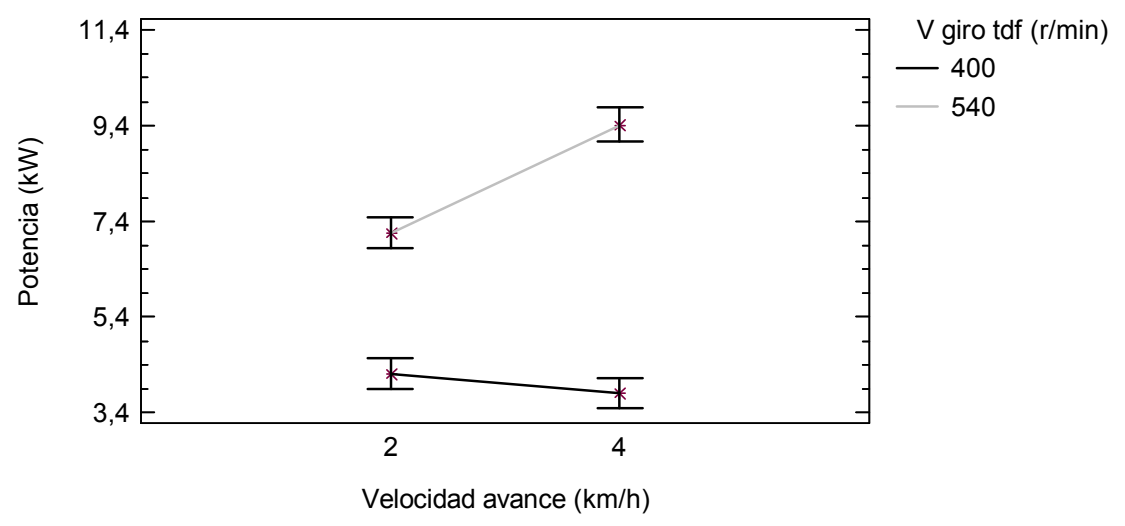

Figura 52. Interacción entre la velocidad de avance del tractor y la velocidad de giro de la toma de fuerza. Intervalos LSD con un nivel de confianza del 95\%. 


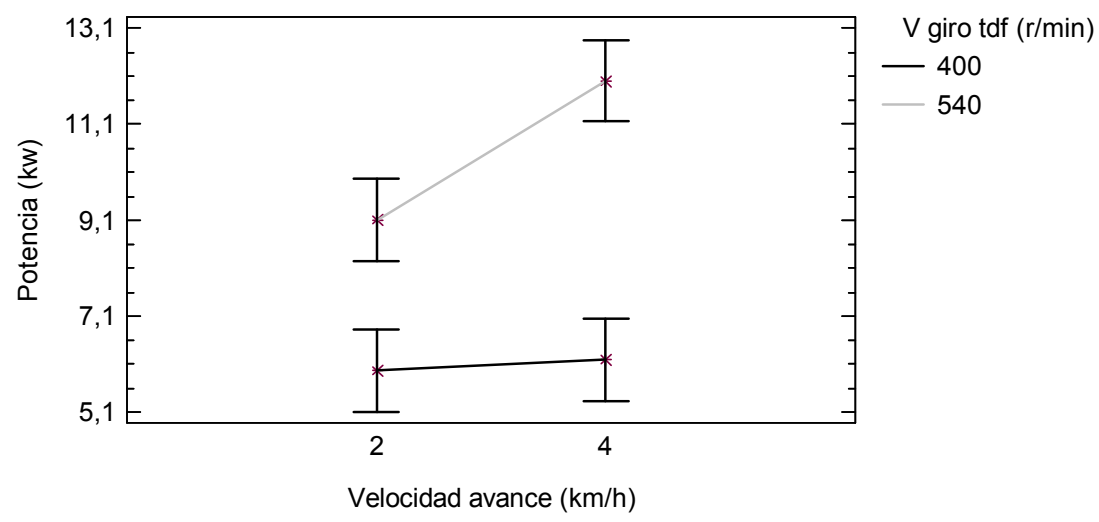

Figura 53. Interacción entre la velocidad de avance del tractor y la velocidad de giro de la toma de fuerza. Intervalos LSD con un nivel de confianza del 95\%.

En la Tabla 25 y Tabla 26 se muestra el coste energético del tratamiento de trituración de mandarinas y naranjas respectivamente, en función del tipo de herramienta, velocidad de avance y velocidad de giro de la toma de fuerza.

Tabla 25. Coste energético de la trituración de mandarinas en función del tipo de herramienta, velocidad de avance y velocidad de giro de la toma de fuerza.

\begin{tabular}{|l|r|r|c|}
\hline Herramienta & $\begin{array}{c}\text { Velocidad } \\
\text { avance } \\
\text { (km/h) }\end{array}$ & $\begin{array}{c}\text { Velocidad } \\
\text { giro tdf } \\
(\mathbf{r} / \mathbf{m i n})\end{array}$ & Coste energético (€/ha) \\
\hline Cuchillas & $\mathbf{2}$ & $\mathbf{4 0 0}$ & 0,67 \\
\hline Cuchillas & $\mathbf{2}$ & $\mathbf{5 4 0}$ & 1,06 \\
\hline Cuchillas & $\mathbf{4}$ & $\mathbf{4 0 0}$ & 1,17 \\
\hline Cuchillas & $\mathbf{4}$ & $\mathbf{5 4 0}$ & 3,67 \\
\hline Martillos & $\mathbf{2}$ & $\mathbf{4 0 0}$ & 1,88 \\
\hline Martillos & $\mathbf{2}$ & $\mathbf{5 4 0}$ & 2,92 \\
\hline Martillos & $\mathbf{4}$ & $\mathbf{4 0 0}$ & 3,06 \\
\hline Martillos & $\mathbf{4}$ & $\mathbf{5 4 0}$ & 6,81 \\
\hline
\end{tabular}


Capítulo IV. Mecanización de los métodos culturales

Tabla 26. Coste energético de la trituración de naranjas en función del tipo de herramienta, velocidad de avance y velocidad de giro de la toma de fuerza.

\begin{tabular}{|l|r|c|c|}
\hline Herramienta & $\begin{array}{c}\text { Velocidad } \\
\text { avance } \\
(\mathbf{k m} / \mathbf{h})\end{array}$ & $\begin{array}{c}\text { Velocidad } \\
\text { giro tdf } \\
(\mathbf{r} / \mathbf{m i n})\end{array}$ & Coste energético (€/ha) \\
\hline Cuchillas & $\mathbf{2}$ & $\mathbf{4 0 0}$ & 0,81 \\
\hline Cuchillas & $\mathbf{2}$ & $\mathbf{5 4 0}$ & 1,13 \\
\hline Cuchillas & $\mathbf{4}$ & $\mathbf{4 0 0}$ & 1,94 \\
\hline Cuchillas & $\mathbf{4}$ & $\mathbf{5 4 0}$ & 3,00 \\
\hline Martillos & $\mathbf{2}$ & $\mathbf{4 0 0}$ & 2,51 \\
\hline Martillos & $\mathbf{2}$ & $\mathbf{5 4 0}$ & 3,93 \\
\hline Martillos & $\mathbf{4}$ & $\mathbf{4 0 0}$ & 4,93 \\
\hline Martillos & $\mathbf{4}$ & $\mathbf{5 4 0}$ & 10,33 \\
\hline
\end{tabular}

\subsubsection{Selección de las condiciones de trabajo a raíz de los resultados}

De entre los factores estudiados, el único que ha influido de modo estadísticamente significativo sobre la calidad del triturado ha sido el tipo de herramienta, tanto en el ensayo sobre mandarinas como sobre naranjas. Por esta razón, para realizar la trituración será recomendable emplear la velocidad de giro de la toma de fuerza y la velocidad de avance del tractor que requieran menor potencia.

La velocidad de giro de la toma de fuerza de $400 \mathrm{r} / \mathrm{min}$ requiere significativamente menor potencia que la de $540 \mathrm{r} / \mathrm{min}$ y, por tanto, el coste energético es menor. A $400 \mathrm{r} / \mathrm{min}$ no se encontraron diferencias significativas de potencia requerida entre las velocidades de avance, por lo que desde el punto de vista económico será más aconsejable realizar el tratamiento a la mayor velocidad de avance de entre las ensayadas $(4,4 \mathrm{~km} / \mathrm{h})$. Aunque el coste energético es algo mayor a esta velocidad, el tiempo de tratamiento disminuye a la mitad y por tanto, se reducen los costes totales del tratamiento.

En mandarinas se consiguió, con la trituradora de cuchillas, un porcentaje de frutos triturados de $84,81 \%$, empleando una potencia de $2,1 \mathrm{~kW}$ que supone aproximadamente un coste energético de 1,17 €/ha. El mismo tratamiento, pero empleando como herramienta de corte los martillos, aumentó el porcentaje de fruta totalmente triturada al 95,22\%, pero requirió una potencia de $5,5 \mathrm{~kW}$ con 
un coste energético aproximado de 3,06 €/ha. En el caso de triturar naranjas, el uso de cuchillas produjo un $83,83 \%$ de frutos triturados, con una potencia de $3,5 \mathrm{~kW}$, lo que supone un cose energético de 1,94 €/ha. El triturado con martillos aumentó al 95,67 \% el porcentaje de frutos triturados, pero incrementó la potencia requerida a $8,86 \mathrm{~kW}$ y, por tanto, su coste energético alcanzó 4,93 €/ha.

Tanto con la trituradora de martillos como con la trituradora de cuchillas se consiguen elevados porcentajes de fruta totalmente triturada, aunque con la trituradora de martillos se obtuvieron los valores más altos. Así pues, se decidió realizar el tratamiento con este tipo de herramienta. En ese caso la potencia requerida será mayor y por lo tanto el coste energético.

\section{EFECTO DEL TRITURADO SOBRE LA POBLACIÓN DE $C$. capitata EN CONDICIONES DE CAMPO}

Una vez que se ha determinado que la trituración en condiciones de laboratorio tiene una eficacia de control sobre las larvas de la mosca mediterránea de la fruta y se han establecido las condiciones de trabajo de la trituradora, en este apartado se realizan experimentos de campo para valorar el efecto de la trituración de los frutos que quedan tras la cosecha sobre la población de la primera generación de $C$. capitata de la campaña siguiente.

\subsection{MATERIALES Y MÉTODOS}

Este estudio se realizó en dos parcelas comerciales contiguas, la parcela A y parcela B (Anejo 8). En una de ellas se procedió a la trituración de los frutos tras la cosecha y la otra parcela se utilizó como control.

La eficacia del tratamiento de trituración se evaluó mediante la comparación de las capturas acumuladas de moscas durante la primavera siguiente al tratamiento entre la parcela control y la parcela donde se realizó la 
trituración. Para las capturas de las moscas se colocaron 6 sistemas de trampeo Tephri repartidos uniformemente en cada parcela.

En estudios anteriores se ha observado que la parcela B presenta mayor nivel de capturas que la parcela A. Por lo tanto, se decidió realizar el ensayo durante dos años y alternar los tratamientos en las parcelas: en 2004 la eliminación de los frutos se realizó en la parcela A y en 2005 en la parcela B. Los trabajos de trituración se llevaron a cabo el 10 de noviembre de 2004 y el 23 de diciembre de 2005.

La trituración se realizó con la trituradora de martillos descrita en el apartado anterior y en las condiciones de trabajo establecidas en el apartado anterior: velocidad de avance de $4,4 \mathrm{~km} / \mathrm{h}$ y velocidad de giro de la toma de fuerza de $400 \mathrm{r} / \mathrm{min}$.

El periodo de evaluación del ensayo se seleccionó en función de la evolución de las capturas y fue desde marzo cuando las capturas eran muy bajas o nulas hasta que se producía un incremento considerable de las capturas debido a la aparición de adultos de posteriores generaciones. En 2005 el periodo de evaluación fue desde el 16 de marzo hasta el 17 de junio y en 2006 desde el 1 de marzo hasta el 31 de mayo.

Para estudiar el efecto del tratamiento los datos se analizaron mediante la prueba de chi-cuadrado a un nivel de confianza del $95 \%$.

\subsection{RESULTADOS}

En la primavera del 2005, el numero de capturas acumuladas en la parcela triturada fue significativamente menor que en la parcela control. La reducción de la población debida al tratamiento de trituración fue de un $46 \%$. Del mismo modo ocurrió en la primavera de 2006 (Figura 54) aunque el número de capturas acumuladas fue mayor que en 2005. En este año la reducción de la población de moscas fue de un $27 \%$. 
Estos resultados indican que el tratamiento de destrucción de los frutos mediante su trituración con el empleo de trituradoras de leña tuvo un efecto de control sobre la primera generación de $C$. capitata. Por lo tanto, su aplicación a mayor escala, por ejemplo en todas las parcelas de una comarca, daría lugar a una disminución de la población en las primeras generaciones. Esta practica es adecuada para combinarla con técnicas como la suelta de machos estériles o trampeo masivo, que son capaces de controlar la población de $C$. capitata cuando los niveles poblacionales son bajos.
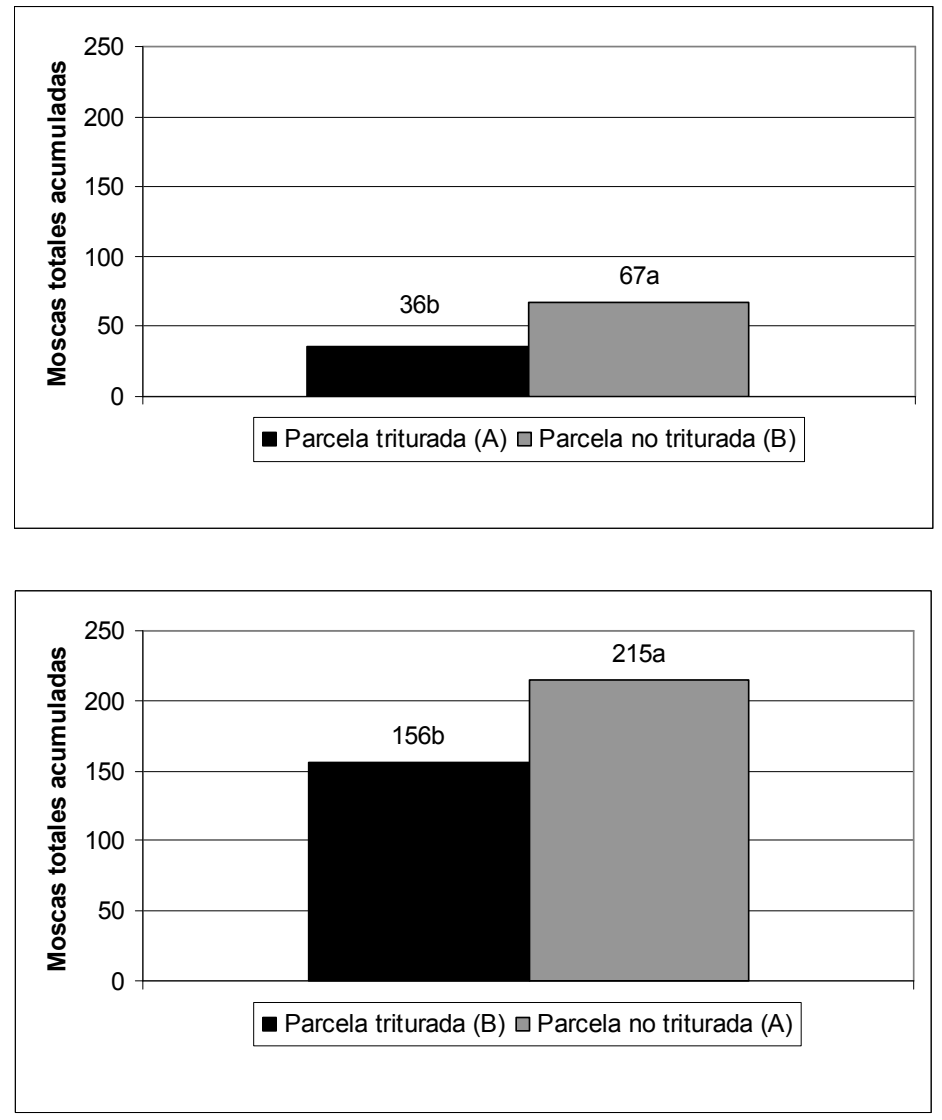

Figura 54. Comparación de las moscas totales acumuladas entre la parcela triturada y la parcela control. Arriba: primavera de 2005. Abajo: primavera 2006. 


\section{CONCLUSIONES}

En este capítulo de la tesis se ha demostrado en condiciones de laboratorio que la destrucción de la fruta a través del aplastamiento y la trituración son dos métodos eficaces para disminuir la supervivencia de las larvas de $C$. capitata en los estadios $\mathrm{L}_{2}$ y $\mathrm{L}_{3}$ cuando se encuentran en el interior de los frutos. La trituración demostró ser un método más eficaz que el aplastamiento ya que produjo una mortalidad de larvas mayor (de un $81 \%$ frente a un $29 \%$ ).

Con el propósito de ajustar las condiciones de trabajo de una trituradora de eje horizontal para realizar esta labor de una forma eficiente en condiciones de campo, es decir, maximizando la destrucción de la fruta y minimizando la potencia requerida, se ha establecido una metodología para evaluar la calidad del triturado.

Asimismo, con las máquinas ensayadas y en las condiciones descritas en el apartado correspondiente, se ha determinado que los parámetros operativos de la trituradora de eje horizontal que suponen menor coste y mejor triturado son la velocidad de giro de la toma de fuerza a $400 \mathrm{r} / \mathrm{min}$ y una velocidad de avance del tractor de 4,4 km/h. También se demostró que los dos tipos de herramientas empleados (martillos y cuchillas) producen un elevado porcentaje de frutos totalmente triturados, aunque los martillos fueron más eficaces, ya que produjeron un porcentaje del $95 \%$, frente al $85 \%$ obtenido con las cuchillas.

Una importante y novedosa aportación de este trabajo es que se ha demostrado cuantitativamente que con la trituración de la fruta existe un efecto de control sobre la población de $C$. capitata. En las experiencias de campo se observa que, tras el tratamiento, se redujo entre un $27 \%$ y un $46 \%$ la primera generación de adultos de la siguiente primavera.

Así pues, la solución para eliminar la fruta que queda tras la cosecha que se propone en esta tesis, basada en la trituración de los frutos mediante máquinas 
Capítulo IV. Mecanización de los métodos culturales

trituradoras de restos de poda, disminuye efectivamente la población de C. capitata y puede ser viable desde el punto de vista económico. 


\section{Capítulo V. CONCLUSIONES GENERALES}

En esta tesis se han aportado soluciones mecanizadas factibles a dos métodos de control de $C$. capitata en cítricos que desde el punto de vista económico no eran viables: la aplicación de tratamientos cebo a bajo volumen y la eliminación de los frutos reservorio de moscas. Los dos métodos propuestos se caracterizan por tener bajo impacto ambiental y suponer pocos riesgos para la salud humana.

Se ha demostrado que la mecanización de los tratamientos cebo a bajo volumen, utilizando un equipo automático diseñado para tal fin, junto con la aplicación de productos menos agresivos para el ecosistema y con menos riesgos para la salud, es una buena alternativa a los métodos convencionales de control con organofosforados.

Asimismo, la mecanización de la eliminación de la fruta mediante su trituración con máquinas convencionales permite que este método pueda ser considerado como una práctica de cultivo más con el fin de reducir los niveles poblacionales de la primera generación de moscas.

Los dos métodos que se proponen, en combinación con otros ya existentes, pueden formar parte de cualquier estrategia de producción integrada de cítricos. 



\section{Capítulo VI. BIBLIOGRÁFIA}

Abbott, W. S. 1925. A method of computing the effectiveness of an insecticide. J Econ Entomol 18:265-267.

Abramowitz, M.; Stegun, I. A. 1964. Handbook of mathematicals functions. http://lawr.ucdavis.edu/classes/hyd256/erf.pdf. (6/2004).

Adán, A.; Del Estal, P.; Budia, F.; González, M. y Viñuela, E. 1996. Laboratory evaluation of the novel naturally derived compound Spinosad against Ceratitis capitata. Pestic. Sci. 48: 261-268.

Ade, G.; Fabbri, A. 2000. Indagine teorica sul legame tra grado di copertura, numerositá e distribuzione della popolazione delle impronte sulle carte idrosensibili. Riv. di Ing. Agr. 31:104-108.

Alonso-Muñoz, A.; García-Marí, F. 2003. Evolución de la abundancia de Ceratitis capitata (Diptera: Tephritidae) a lo largo del año y comparación de diversos tipos de mosqueros. Levante Agrícola. 368: 384-390.

Aluja, M. 1993. Manejo integrado de la mosca de la fruta. Trillas (Ed.), México D. F., 251 pp.

Angeli, P.; Hewitt, G. F. 2000. Drop size distributions in horizontal oilwater dispersed flows. Chemical Engineering Science, 55: 31333143.

Antuniassi, U. R.; Velini, E. D.; Martins, D. 1996. Spray deposition and drift evaluation of air-carrier peachorchard sprayers. International Conference on Agricultural Engineering, AgEng 96, Madrid, Spain. Paper 96-A-136: 279-280. 
Argilés, R.; Tejedo, V. 2007. La lucha contra la mosca de la fruta mediante la técnica del insecto estéril en la Comunitat Valenciana. Levante agrícola 385: 157-162.

Back, E. A.; Pemberton, C. E. 1918. The Mediterranean fruit fly in Hawaii.. United Status Department of Agricultura. Bull. 536: 1-119.

Balsari, P.; Tamagnone, M. 1997. An automatic spray control for airblaster sprayers: First results. $1^{\text {st }}$ European Conference on Precision Agriculture 1997, Coventry, UK. Proceedings, volume 2: 619-626.

Balsari, P.; Tamagnone, M. 1998. An ultrasonic airblast sprayer. International Conference on Agricultural Engineering, AgEng 98, Oslo, Norway. Paper 98-A-017: 585-586.

Barnby, M. A.; Yamasaki, R. B.; Klocke, J. A. 1989. Biological activity of azadirachtin, three derivates, and their ultraviolet radiation degradation products against tobacco budworm (Lepidoptera: Noctuidae) larvae. J. Econ. Entomol. 82: 58-63.

Barry, J. D.; Dowell, R. V.; Morse, J. G. 2002. Comparison of two sterile Mediterranean fruit fly (Diptera: Tephritidae) strains released in California's preventative release program. J. Econ. Entomol. 95: 936-944.

Bateman, M. A. 1972. The ecology of fruit flies. Annu. Rev. Entomol. 17: 493-518.

Bateman, M. A. 1978. Chemical methods for suppression or eradication of fruit fly populations. En: Economic Fruit Flies of the South Pacific Region (Drew R. A. I., Hooper G. H. S., Bateman M. A. (Ed.)), Queensland Department of Primary Industries, Brisbane,Australia, pp. 111-125. 
Bateman, R. 1993. Simple, standardised methods for recording droplet measurement and estimation of deposits from controlled droplet applications. Crop Prot. 12: 201-205.

Bautista, R. C.; Mochizuki, N.; Spencer, J.P.; Harris, E. J.; Ichimura, D. M. 1999. Mass rearing of the tephritid fruit fly parasitoid Fopius arisanus (Hymenoptera: Braconidae). Biol. Control 15: 137-144.

Beck, J. C.; Watkins, A. P. 2003. The droplet number moments approach to spray modelling: The development of heat and mass transfer submodels. Int. J. Heat Flui. Flow. 24: 242-259.

Beitia, F.; Pérez-Hinarejos, M.; Garzón, E.; Santiago, S.; Tarazona, I.; Falcó, J. V.; 2006a. Lucha biológica contra Ceratitis capitata: Himenópteros parasitoides exóticos. Terralia 56: 38-45.

Beitia, F.; Pérez-Hinarejos, M.; Santiago, S.; Garzón, E.; Tarazona, I.; Malagón, J.; Falcó, J. V. 2006b. Expectativas en el control biológico de Ceratitis capitata: Parasitoides exóticos y autóctonos. Levante Agrícola 379: 1-6.

Blandini, G.; Schillaci, G. 1993. Parameters influencing spray deposition in citrus pest control. $4^{\text {th }}$ International Symposium on Fruit, Nut and Vegetable Production Engineering 1993, Valencia, Spain. Proceedings volume 1: 133-140.

Bodenheimer, F. S. 1951. Citrus entomology in the Middle East. W. Junk (Ed.), The Hague, Netherlands. 663 pp.

Brittain, H.G. 2001. Particle-Size Distribution, Part I: Representations of particle shape, size, and distribution. Pharm. Technol. 25: 38-45.

Burns, R. E.; Harris, D. S.; Moreno, D. S.; Eger, J. E. 2001. Efficacy of spinosad bait sprays to control mediterranean and caribbean fruit 
flies (Diptera: Tephritidae) in commercial citrus in Florida. Fla. Entomol. 84: 672-678.

CAPA (Conselleria de Agricultura, Pesca y Alimentación). 2001. Servicio de publicaciones del CAPA. Butlletí dávisos agrícoles 9, 8 pp.

Casaña-Giner, V.; Gandía-Balaguer, A.; Mengod-Puerta, C.; Primo-Millo, J.; Primo-Yúfera, E. 1999. Insect growth regulators as chemosterilants for Ceratitis capitata (Diptera: Tephritidae). J. Econ. Entomol. 92 : 303-308.

Castillo, B. 2005. Modelización de la pulverización de aceites minerales y su relación con el control del piojo rojo de California. Tesis doctoral. Universidad Politécnica de Valencia.

Cayol, J. P.; Vilardi, E.; Rial, E.; Vera, M. T. 1999. New indices and method to measure the sexual compatibility and mating performance of Ceratitis capitata (Diptera: Tephritidae) laboratory-reared strains under field cage conditions. J. Econ. Entomol. 92: 140-145.

Cerruto, E. 2001. Caratterizzazione mediante analisi di immagine di bersagli in PVC prove di irrorazione. Riv. di Ing. Agr. 32: 101-107.

Chinery, M. 1980. Guía de campo de insectos de España y de Europa. Omega S. A. (Ed.), Barcelona, España, 402 pp.

Christenson, L. D.; Foote, R. H. 1960. Biology of fruit flies. Annu. Rev. Entomol. 5: 171-192.

Cirio, U.; De Murtas, I.; Gozzo, S; Enkerlin, D. 1972. Preliminary ecological observation of Ceratitis capitata Wied. on the island of Procida with an attempt to control the species using the sterile male technique. Boll. Lab. Entomol. Agrar. Filipo Silvestre 30: 175-188.

Coates, W. 1996. Spraying technologies for cotton: Deposition and efficacy. Appl. Eng. Agric. 12: 287-296. 
COM (Commission Communication) 372, 2006. A thematic strategy on the sustainable use of pesticides. Communication from the commission to the council, the European parliament, the European economic and socila committee and the committee of the regions. http://ec.europa.eu/environment/ppps/home.htm. (3/2007)

COM (Commission Communication) 373. 2006. A thematic strategy on the sustainable use of pesticides. Communication from the commission to the council, the European parliament, the European economic and socila committee and the committee of the regions. http://ec.europa.eu/environment/ppps/home.htm. (3/2007)

Cross, J. V. 1991. Patternation of spray mass flux from axial fan airblast sprayers in the orchard. En: Air-assisted spraying in crop protection. British Crop Protection Council.Monograph 46, pp. 15-22.

Cunningham, R. T. 1989. Parapheromones. En: Fruit flies, their biology, natural enemies and control. World crop pest, vol.3B. (Robinson A. S.; Hooper, G. (Ed.), Elsevier, Amsterdam, Holland. pp. 221-230.

Daane, K. M.; Dahlsten, D. D.; Dreastadt, S. H. 1990. Effects of Mediterranean fruit fly malation bait spray on the longevity and oviposition of parasitoids of linden and tuliptree aphids (Homoptera: Aphididae). Environ. Entomol. 19: 1130-1134.

Degré, A.; Mostade, O.; Huyghebaert, B.; Tissot, S.; Debouche, C. 2001. Comparison by Image Processing of Target Supports of Spray Droplets. Trans. ASAE 44:217-222.

De Andrés, M; García-Marí, F. 2007. Observaciones sobre la invernación de Ceratitis capitata en la Comunidad Valenciana. Levante Agrícola 385: 108-114.

De Liñán, C. 2007. Registro único europeo. Terralia 60: 20-39. 
Del Pino, A. 2000. Efecto de factores abióticos y edáficos naturales en el ciclo biológico de Ceratitis capitata (Wiedemann) (Diptera: Tephritidae). Tesis Doctoral. Universidad Politécnica de Valencia.

Derksen, R. C.; Gray, R. L. 1995. Deposition and air speed patterns of aircarrier apple orchard sprayers. Trans.ASAE 38: 5-11.

Di Ilio, V.; Cristofaro, M; Marchini, D.; Nobili, P.; Dallai, R. 1999. Effects of a Neem compound on the fecundity and longevity of Ceratitis capitata (Diptera; Tephritidae). J. Econ. Entomol. 92 (1): 76-82.

DOGV (Documento Oficial de la Generalitat Valenciana), 2001. Resolución de 23 de noviembre de 2000, del director general de Innovación Agraria y Ganadería, por la que se establecen las normas para la producción integrada en cítricos, en el ámbito de la Comunidad Valenciana. [2000/9741]DOGV nº 3909, 3/1/2001.

Doruchowski, G.; Jaeken, P.; Holownicki, R. 1998. Target detection as a tool of selective spray application on trees and weeds in orchards. Conference on Precision Agriculture and Biological Quality, 1998, Boston, EE.UU. Proceedings volume 3543: 290-301.

Dow Agrosciences 2007. http://www.dowagro.com/homepage/index.htm. (2/2007).

Ebeling, W. 1959. Subtropical Fruit Pests. Univ. of Calif. 436 pp.

Economopoulos, A. P. 1989. Use of traps based on color and/or shape. En: Fruit flies, their biology, natural enemies and control. World crop pest, vol.3B. (Robinson A. S.; Hooper, G. (Ed.), Elsevier, Amsterdam, Holland. pp 315-327.

Ehler, L. E.; Endicott, P. C. 1984. Effect of malathion bait sprays on biological control of insect pest of olive, citrus, and walnut. Hilgardia 52: 1-47. 
ENAC (Entidad Nacional de Acreditación) (2005) Alcance de acreditación Laboratorio Agroalimentario. Conselleria de Agricultura, Pesca y Alimentación de la Generalitat Valenciana. http://www.enac.es/html/anx/le/AGROVALENCIA LE405 REV4. pdf. (11/2006).

EPPO (European and Mediterranean Plant Protection Organization), 2007. http://www.eppo.org/QUARANTINE/insects/Ceratitis capitata/CE RTCA map.htm . (03/2007).

Falcó, J. V.; Garzón-Luque, E.; Pérez-Hinarejos, M.;Tarazona, I.; Malagón, F.;Beitia, F. 2006. Two native pupal parasitoids of Ceratitis capitata (diptera, tephritidae) found in Spain. IOBC wprs Bulletin 29: 71-74.

Fibla, J. M.; Martínez-Ferrer, M. T.; Campos, J. M.; Monfort, R.; Colell, R. 2007. Control de Ceratitis capitata Wied en variedades tempranas de cítricos y pequeñas superficies, mediante diferentes estrategias de trampeo masivo. Levante agrícola 385: 126-134.

Fimiani, P. 1989. Mediterranean region. En: Fruit flies, their biology, natural enemies and control. World crop pest, vol.3B. (Robinson A. S.; Hooper, G. (Ed.), Elsevier, Amsterdam, Holland, pp 39-50.

Flessel, P.; Quintana, P. J. E.; Hooper, K. 1993. Genetic toxicity of malathion: a review. Environ. Mol. Mutagen. 22:7-17.

Fondren, J. E.; Heitz, J. R. 1978. Light intensity as a critical parameter in the dye-sensitized photooxidation of the house fly, Musca domestica. Environ. Entomol. 7: 891-894.

Fox, R. D.; Reichard, D. L.; Brazee, R. D.; Krause, C. R.; Hall, F. R. 1993. Downwind residues from spraying a semi-dwarf apple orchard. Trans.ASAE 36: 333-340. 
Franz, E. 1992. A simple spray coverage analyzer. Trans. ASAE 36: 12711278.

Furness, G. O.; Newton, M. R. 1988. A leaf surface scanning technique using a fluorescence spectrophotometer for the measurement of spray deposits. Pestic. Sci. 24:123-137.

Furness, G. O.; Thompson, A. J. 2007. Two way airstream convergence to improve spray deposition on citrus canopies with multi fan sprayers. $9^{\text {th }}$ Workshop on Spray Application Techniques in Fruit Growing 2007, Alnarp, Suecia. Book of abstracts pp. 51-52.

Gandhi, M.; Lal, R.; Sankaranarayanan, A.; Banerjee, C. K.; Sharma, P. L. 1988. Acute toxicity study of the oil from seed (neem oil). J. Etnopharmacol. 23: 39-51.

Ghate, S. R.; Perry, C. D. 1994. Ground speed control of pesticide application rates in a compressed air direct injection sprayer. Trans. ASAE 37: 33-38.

Gil, E.; Bernat, C.; Queraltó, M.; López, A.; Planas, S.; Rosell, Jr.;Val, L. 2005. Pesticide dose adjustment in vineyard: Relationship between crop characteristics and quality of the applications. $8^{\text {th }}$ Workshop on Spray Application Techniques in Fruit Growing, 2005, Barcelona, España. Proceedings pp. 29-36.

Giles, D. K.; Delwiche, M. J.; Dodd, R. B. 1988. Electronic measurement of tree canopy volume. Trans. ASAE 31: 264-272.

Giles, D. K.; Slaughter, D. C. 1997. Precision band spraying with machine-vision guidance and adjustable yaw nozzles. Trans. ASAE 40: 29-36.

Godyn, A.; Doruchowski, G.; Holownicki, R.; Swiechowski, W. 2005. A method for verification of spray volume adapted to crop structure in 
orchards. $8^{\text {th }}$ Spray ApplicationTechniques in Fruit Growing, 2005, Barcelona, España. Proceedings pp. 17-22.

Gómez-Clemente, F. 1932. Un ensayo de lucha biológica contra Ceratitis capitata. Bol. Pat. Veg. y Ent. Agr. 6: 80-89.

Gómez-Clemente, F. 1934. Los parasitoides de la Ceratitis capitata (Wied). Nuevos ensayos de importación y aclimatación. Bol. Pat. Veg. y Ent. Agr. 7: 69-80.

Gómez-Clemente, F. 1948. Experiencias sobre el empleo de DDT contra "mosca de las frutas"(Ceratitis capitata). Bol. Pat. Veg. y Ent. Agr. 16: 253-272.

Gómez-Clemente, F.; Planes-García, S. 1951-1952. Algunas notas sobre la ecología de Ceratitis capitata en el levante español sobre naranjos. Bol. Pat. Veg. y Ent. Agr. 14: 37-48.

Headrick, D. H.; Goeden, R. D. 1996. Issues concerning the eradication or establishment and biological control of the Mediterranean fruit fly, Ceratitis capitata (Wiedemann) (Diptera: tephritidae), in California. Biol. Control 6: 412-421.

Heath, R. R.; Epsky, N. D.; Dueben, B. D.; Rizzo, J.; Felipe, J. 1997. Adding methyl substituted ammonia derivatives to food based synthetic attractant on capture of mediterranean and mexican fruit flies. J. Econ. Entomol. 90: 1584-1589.

Heitz, J. R. 1995. Pesticidal applications of photoactivated molecules. En: Light-activated pest control (Heitz J. R.; Downum, K. R. (Ed.)), ACS Symposium Series 616. American Chemical Society, Washington DC, USA, pp. 1-16.

Hendrichs, J.; Robinson, A. S.; Cayol, J. P.; Enkerlin, W. 2002. Medfly area wide sterile insect technique programmes for prevention, 
suppression or eradication: The importance of mating behavior studies. Fla Entomol. 85: 1-13.

Hoelmer, L.A.; Dahlsten, D.L. 1993. Effects of malathion bait spray on Aleyrodes spiraeoides and its parasitoids in northern California. Environ. Entomol. 22: 49-56.

Hoffmann, W. C.; Salyani, M. 1996. Spray depositions on citrus canopies under different meteorological conditions. Trans. ASAE 39: 17-22.

Holownicki, R.; Doruchowski, G.; Swiechowski, W.; Jaeken, P. 2002. Methods of Evaluation of Spray Deposit and Coverage on Artificial Targets. Electronic J. Polish Agric. Univ., 5.

http://www.ejpau.media.pl/series/volume5/issue1/engineering/art03.html. (05-2004).

Intercitrus. 2002. Informe interno.

Israely, N.; Ritte, U.; Oman, S. D. 2004. Inability of Ceratitis capitata (Diptera: Tephritidae) to overwinter in the Judean hills. J. Econ. Entomol. 97: 33-42.

Israely, N.; Oman, S. D. 2005. Effect of combined insecticida sprays and sanitation techniques on population dinamics of Ceratitis capitata (Diptera: Tephritidae) in the central mountains of Israel. J. Econ. Entomol. 98: 739-748.

Jiang, C.; Derksen, R.C. 1995. Morphological image processing for spray deposit analysis. Trans. ASAE 38:1581-1591.

Jones, E. L.; Skepper, A. H. 1965. Suppression of Queensland fruit fly, Dacus (Strumeta) tryoni (Frogg), Tripetidae (Dip.) in Narradena, New South Wales. Agric. Gazzete N. S. W. 76: 501-503. 
Juste, F.; Sanchez, S.; Ibáñez, R.; Val, L.; Gracia, C. 1990. Measurement of spray deposition and efficiency of pesticide application in citrus orchards. J. Agr. Eng. Res. 46: 187-196.

Juste, F.; Martin, B.; Fabado, F.; Moltó, E. 1998. Estudio sobre la reducción de costes de producción de cítricos mediante la mecanización de las operaciones de cultivo. Comunitat Valenciana Agraria 12: 29-34.

Katsoyannos, D. A.; Kouloussis, N. A.; Carey, J. R. 1998. Seasonal and annual occurrence of Mediterranean fruit fly (Diptera: Tephritidae) in Chios island, Greece: differences between two neighboring citrus orchards. Ann. Entomol. Soc. Am. 91: 43-51.

Knipling, E. F., 1955. Possibilities of insect control or eradication through the isue of sexually sterile males. J. Econ. Entomol. 48: 459-462.

Konstantopoulou, M.; Mazomenos, B. 2005. Evaluation of Beauveria bassiana, B. brongniartii strains and four wild-type fungal species against adults of Batrocera oleae and Ceratitis capitata. Biocontrol 50: 293-305.

Konstantopoulou, M.; Milonas, P.; Mazomenos, B. 2006. Partial purification and insecticidal activity of toxic metabolites secreted by a Mucor hiemalis Strain (SMU-21) against adults of Batrocera oleae and Ceratitis capitata (Diptera: Tephritidae). J. Econ. Entomol. 99: 1657-1664.

Kuran, J.; Hubac, D. 1984. Qualitative and energy relationships of a fruit tree branch crusher. Zemedelska Technika 30: 465-473.

Ladd, T. L.; Reichard, D. L.; Collings, D. L.; Buriff, C. R. 1978. An automatic intermittent sprayer: a new approach to the insecticidal control of horticultural insect pests. J. Econ. Entomol. 71: 789-792. 
Ladd, T. L.; Reichard. 1980. Photoelectrically operated intermittent sprayers for insecticidal control of horticultural pest. J. Econ. Entomol. 73: 525-528.

Lake, J. 1979. An apparatus for photographing sprays. J. Agr. Eng. Res. 24: $215-218$.

Lance, D. R.; McInnis, D. O.; Rendon, P.; Jackson, C. G. 2000. Courtship among sterile and wild Ceratitis capitata (Diptera: Tephritidae) in the field cages in Hawaii and Guatemala. Ann. Entomol. Soc. Am. 93: 1179-1185.

Lefebvre, A.H. 1989. Atomization and Sprays. Hemisphere Publishing Corporation, New York, USA. 231 pp.

Lefebvre, A.H. 1993. Droplet production. En: Application Technology for Crop Protection. (Matthews, G.A.; Hislop, E.C. (Ed.). CAB International, UK. pp. 85-100

Lindquist, D. 2000. Pest management stratedies: area-wide and conventional. En: Area-wide management of fruit flies and other major insect pests. (Tan, K. H. (Ed.), University Sains Malaysia Press, Penang, Malaysia. pp: 13-19.

Liquido, N. J.; Shinoda, L. A.; Cunningham, R.T. 1991. Host plants of the Mediterranean fruit fly (Diptera: Tephritidae): an annotated world review. Miscellaneous Publication 77. Entomological Society of America, Lanham, MD, USA.

Liquido, N. J.; McQuate, G. T.; Cunningham, R. T. 1995. Light-activated toxicity of phloxine B and uranine to Mediterranean fruit fly, Ceratitis capitata (Wiedemann) (Diptera: Tephritidae) adults. En: Light-activated pest control (Heitz J. R.; Downum, K. R. (Ed.)), ACS Symposium Series 616. American Chemical Society, Washington DC, USA, pp. 82-105. 
Lloréns, J. M.; Lloréns, J. 2002. Diferentes tipos de trampas utilizadas para capturer adultos de mosca del Mediterráneo (Ceratitis capitata Wied.). Levante agrícola 360: 165-176.

Lund, I. 1994. Laser-based equipment for the analysis of size and velocity distribution of liquid drops. Combined Proceedings International Plant Propagator's Society 44: 16-18.

Lund, I.; Matzen, R. 1996. Analysis of droplets in a three-dimensional pattern in the spray from a field sprayer. International Conference on Agricultural Engineering, AgEng 96, Madrid, España. Paper 96-A123: 253-254.

Maddison, P.; Bartlett, B. 1989. Contribution towards the zoogeography of the tephritidae. En: Fruit flies, their biology, natural enemies and control. World crop pest, vol.3B. (Robinson A. S.; Hooper, G. (Ed.), Elsevier, Amsterdam, Holland, pp. 27-35.

Maitland, D. P. 1992. Locomotion by jumping in the Mediterranean fruit fly larvae Ceratitis capitata. Nature 355: 159-161.

Marchini, L.; Wood, R. J. 1983. Laboratory studies on oviposition and on the structure of the ovipositor in the Mediterranean fruit fly Ceratitis capitata (Wied). Proceedings of the CEC/IONC International Symposium, Athens, Greece, pp.113-119.

Martínez, F.; Martín, C. 1984. A comparative study of brush clearing by means of rotary mulching machine equipped with chains or knives. Annales de Mecanisation Forestiere, ARMEF, France. Pp.265-311.

Martínez-Ferrer, M. T.; Alonso, A; Campos, J. M.; Fibla, J. M.; GarcíaMarí, F. 2007. Dinámica poblacional de la mosca de la fruta 
Ceratitis capitata en tres zonas citrícolas mediterráneas. Levante Agrícola 385: 92-98.

Marty, M. A.; Dawson, S. V.; Bradman, M. A.; Harnly, M. E.; Dibartolomeis, M. J. 1994. Assessment of exposure to malathion and maloxon due to aerial application over urban areas of Southern California. J. Exp. Anal. Environ. Epiddemiol. 4:65-81.

McConnell, R. L.; Elliot, K. C.; Blizzard, S. H.; Kosten, K. H. 1983. Electronic measurement of tree row volume. Agricultural electronics 1: 85-90.

Medina, P.; López, I.; Budia, F.; Adán, A.; Viñuela, E. 2004. Development of an extended-laboratory method to test bait treatments. IOBC/WPRS Bulletin 27: 59-66.

Mellado, L. 1971. La técnica de machos esteriles en el control de la mosca del Mediterráneo. Programas realizados en España. En: Sterility principle for insect control or eradication. International atomic energy agency, Vienna, Austria. STI/Pub./265: 49-54.

Mellado, L.; Arroyo, M.; Ros, P. 1974. Control de Ceratitis capitata Wied. by the sterile technique in Spain. En: The sterile-male technique and its field applications. International atomic energy agency, Vienna, Austria. STI/Pub./364: 63-73.

Mercader, G.; Pellicer, J.; Fabado, F; Moltó, E.; Juste, F. 1995. Influencia de los colectores sobre los parámetros característicos de la pulverización en cítricos. VI Congreso de la sociedad española de ciencias hortícolas, Barcelona, España. Vol. 1: 32.

Mimura, K.; Yamada, T. 1990. Brush cutting performance of the forest shredder with flail type cutters. Journal of the Japanese forestry society $72: 513-519$. 
Moner, J. P.; Petit, V. R.; Bernat, J. M. 1988. La mosca de las frutas (Ceratitis capitata Wied.). Generalitat Valenciana (Ed.), Servicio de publicaciones CAPA, Servei de Protecció del Vegetals, 60 pp..

Moltó, E.; Martín, B.; Gutiérrez, A. 2000. Design and testing of an automatic machine for spraying at a constant distance from the tree canopy. J. Agr. Eng. Res. 77: 379-384.

Moltó, E.; Martín, B.; Gutiérrez, A. 2001. Pesticida loss reduction by automatic adaptation of spraying on globular trees. J. Agr. Eng. Res. 78: $35-41$

Moreno, D. S.; Celedonio, H.; Mangan, R. L.; Zavala, J. L.; Montoya, P. 2001. Field evaluation of a phototoxic dye, phloxine B, against three species of fruit flies (Diptera: Tephritidae). J. Econ. Entomol. 94: $1419-1427$.

Moutous, G.; Fos, A. 1973. Essais de rhizogénèse chez la feuille de vigne isolée. Revue de Zoologie Agricole et de Pahtologie végétale. Premier trimestre1973: 27-28.

Navarro-Llopis, V.; Sanchis-Cabanes, J.; Ayala, I.; Casaña-Giner, V.; ; Primo-Yúfera, E. 2004. Efficacy of lufenuron as chemosterilant against Ceratitis capitata in field trials. Pest Manag. Sci. 60: 914920.

Navarro-Llopis, V.; Sanchis-Cabanes, J.; Primo-Millo, J.; Primo-Yufera, E. 2007. Chemosterilants as control agents of Ceratitis capitata (Wiedemann) (Diptera: Tephritidae) in field trials. Bull. Entomol. Res. 91. In press.

Ortego, C.; Magaña, P.; Hernández-Crespo, P.; Castañera, P. 2005. Detección de resistencia a insecticidas en "Ceratitis capitata": bases bioquímicas y moleculares. Phytoma España 173: 63-66. 
Ortí García, E. 2001. Determinación y análisis de las condiciones óptimas de trabajo de una trituradora de eje horizontal sobre restos de poda de cítricos. Tesis doctoral. Universidad Politécnica de Valencia.

Ortí, E.; Molina, J. M.; Val, L.; De Miquel, E. 2005. Effect of different sprayer settings on doplet deposition in 4 different citrus varieties. $8^{\text {th }}$ Workshop on Spray Application Techniques in Fruit Growing. 2005, Barcelona, España. Proceedings pp.23-28.

Ortiz-Cañavate, J.; Hernanz, J.L. 1989. Técnica de la mecanización agraria. Mundi-Prensa (Ed), Madrid, España. 654 pp.

Palacios, P. 1993. Optimización de los tratamientos fitosanitarios mediante pulverización hidroneumática en plantaciones de cítricos. Tesis Doctoral. Universidad Politécnica de Valencia.

Papadopoulos, N. T.; Carey, J. R.; Katsoyannos, B. I.; Kouloussis, N. A. 1996. Overwintering of the Mediterranean fruit fly (Diptera: Tephritidae) in Northern Greece. Ann. Entomol. Soc. Am. 89: 526534.

Papadopoulos, N. T.; Katsoyannos, B. I.; Carey, J. R. 1998. Temporal changes in the composition of the overwintering larval population of the Mediterranean fruit fly (Diptera: Tephritidae) in Northern Greece. Ann. Entomol. Soc. Am. 91: 430-434.

Peck, S. L.; McQuate, G. T. 2000. Field test of environmentally friendly malathion replacements to suppress wild Mediterranean fruit fly (Diptera: Tephritidae) populations. J. Econ. Entomol. 93:280-289.

Pellicer, J.; Ibañez, R.; Mercader, G.; Moltó, E.; Juste, F.; Segura, A. 1994. Relationship between mechanical and biological efficiency in plant protection treatments. International Conference on Agricultural Engineering, AgEng 94, Milan, Italy. Paper 94-D-158. 
Pérez-Hinarejos, M.; Santiago, S.; Falcó, J. V.; Beitia, F. 2006. Laboratory experiments with Fopius arisanus, an exotic egg-pupal parasitoid of Ceratitis capitata. IOBC wprs Bulletin 29: 209-213.

Pergher, g.; Gubiani, R. 1995. The effect of spray application rate and airflow on foliar deposition in a hedgerow vineyard. J. Agr. Eng. Res. 61: 205-216.

Planas, S.; Solanelles, F.; Fillat, A.; Pifarré, C. 1996. A proposal of methodology for air-assisted sprayer assessment in apple orchards. International Conference on Agricultural Engineering, AgEng 96, Madrid, España. Paper 96-A-149: 305-306.

Planas, S. 2001. Prevención de la deriva en los tratamientos fitosanitarios. Vida rural, 123: 54-57.

Porras, A.; Gómez, J.; Arnal, J. M.; Tobes, B.; Lorite, S. 1986. Mejoras producidas por la electrónica en las máquinas de pulverización. $2^{\circ}$ Symposium Nacional de Agroquímicos. Sevilla, España. pp. 378388.

Primo, E.; Alfaro, F.; Argilés, R. 2003. Plan de actuación contra la mosca de las frutas (Ceratitis capitata) en la Comunidad Valenciana. Phytoma España. 153: 127-130.

Prokopy, R. J.; Hendrichs, J. 1979. Mating behaviour of Ceratitis capitata on a field-caged host tree. Ann. Ent. Soc. Amer. 72: 642-648.

Prokopy, R. J.; Vargas, R. I. 1996. Attraction of Ceratitis capitata (Diptera: Tephritidae) flies to odor of coffee fruit. J. Chem. Ecol. 22: 807-820.

Putruele, M. T. G. 1996. Influencia de la temperatura sobre los estados inmaduros de huevo y pupa de Ceratitis capitata (Wiedemann) (Diptera: Tephritidae). Umbrales, velocidad de desarrollo, 
constantes térmicas y mortalidad. Tesis de Master, Universidad Politécnica de Valencia.

Putruele, M. T. G. 1998. Estudios bioecológicos de Ceratitis capitata Wiedemann (Diptera: Tephritidae): Influencia de la temperatura sobre el estado larvario, dinámica poblacional y validación de un modelo epidemiológico para predecir su fenología. Tesis doctoral. Universidad Politécnica de Valencia.

Raga, A.; Sato, M. S. 2005. Effect of Spinosad bait against Ceratitis capitata (Wied.) and Anastrepha fraterculus (Wied.) (Diptera: Tephritidae) in laboratory. Neotrop. Entomol. 34: 815-822.

Reichard, D. L., Hall, F. R., Retzer, H. 1978. Distributions of droplets sizes delivered by orchard air sprayers. J. Econ. Entomol. 71: 53-57.

Reichard, D. L.; Tennes, B. R.; Burton, C. L.; Brown, G. K. 1982. Experimental orchard sprayer. Trans. ASAE 25: 33-41.

Rivnai, E. 1954. Studies on the effect of various poisons on the Mediterranean fruit fly, its mass immigrations and methods of control in Israel. Ktavim 4: 3-38.

Robinson, A. S.; Cirio, U.; Hooper, G. H. S.; Capparella, M. 1986. Field cage studieswith a genetic sexing strain in the Mediterranean fruit fly, Ceratitis capitata. Entomol. Exp. Applic. 41: 231-236.

Robles-Chillida, E. M. 1975. Contribución al estudio micromorfológico del huevo y la larva de Ceratitis capitata (Wied., 1824). Graellsia 29: 211-224.

Rocamora, M.C., 1999. Análisis de la eficiencia mecánica en tratamientos fitosanitarios sobre cultivos hortícolas mediante pulverización hidroneumática. Tesis doctoral. Universidad Politécnica de Valencia. 
Roessler, Y. 1989. Insecticidal bait and cover sprays. En: Fruit flies, their biology, natural enemies and control. World crop pest, vol.3B. (Robinson A. S.; Hooper, G. (Ed.), Elsevier, Amsterdam, Holland. pp. 329-336.

Rosell, J. R.; Nogues, A.; Planas, S. 1996. Development of an electronic slective orchard spraying system based on the control of applied flow rate. International Conference of Agricultural Engineering. AgEng 96, Madrid, España. Paper 96-A-120: 247-248.

Rudolph, W. 1983. Controlled application. Agricultural Electronics, 1: 9198.

Sagi, Z.; Derksen, R. 1991. Detecting spray droplets on leaves with machine vision. Paper ASAE: 91-3050, 22 pp.

Salyani, M.; McCoy, C. W.; Hedden, S. L. 1988. Spray volume effects on deposition and citrus rust mite control. Pesticide formulations and application systems. 8:254-263.

Salyani, M.; Whitney, J. 1988. Evaluation of methodologies for field studies of spray deposition. Trans. ASAE 31: 390-395.

Salyani, M.; Whitney, J. 1990. Ground speed effect on spray deposition inside citrus trees. Trans. ASAE 33: 361-366.

Salyani, M. 1993. Degradation of fluorescent tracer dyes used in spray applications. Pesticide formulations and application systems 13: 215-226. Salyani, M.; Fox, R.D. 1999. Evaluation of Spray Quality by Oil and Water-Sensitive Papers. Trans. ASAE 42: 37-43

Santiago, S.;Pérez-Hinarejos, M.; Garzón-Luque, E.; Beitia, F.; Falcó, J. V.2006. Parasitism of Diachasmimorpha tryoni on Mediterranean fruits infested with Ceratitis capitata larvae in the laboratory. IOBC wprs Bulletin, 29: 205-208. 
Sanz, R.; Llorens, J.; Ribes-Dasi, M.; Masip, J.; Arnó, J.; Vallés, J. M.; Escolà, A.; Massana, P.; Camp, F.; Palacín, J.; Solanelles, F.; Gil, E.; Planas, S.; Val, L.; Rosell, J. R. 2005. First results of a nondestructive LIDAR system for the characterization of tree crops as a support for the optimization of pesticide treatments. $8^{\text {th }}$ Workshop on Spray Application Techniques in Fruit Growing. 2005 Barcelona, España. Proceedings pp. 121-128.

Schmutterer, H. 1990. Properties and potencial of natural pesticides from the Neem tree, Azadirachta indica. Annu. Rev. Entomol. 35: 271297.

Schoonover, J. R.; Larson, L. L. 1995. Laboratory activity of spinosad on non-target beneficial arthropods. Arthropod management test, 20: 357.

Schroder, R. P. W.; DeMilo, A. B.; Lee, C.; Martin, P. A. 1998. Evaluation of a water-soluble bait for corn root-worm (Coleoptera: Chrysomelidae) control. J. Entomol. Sci. 33: 355-364.

Shelly, T. E.; Whittier, T. S.; Kaneshiro, K. Y. 1994. Sterile insect release and the natural mating system of Mediterranean fruit fly, Ceratitis capitata (Diptera: Tephritidae). Ann. Entomol. Soc. Am. 97: 470481.

Sivinski, J. M.; 1996. The past and potential of biological control of fruit flies. En: Fruit Fly Pest, a world assessment of their biology and management. (Mc Pheron. A.; Steck, G.J. (Ed.)). St. Lu-cie Press, USA. pp. 369-375.

Smith, D., 1983. Evaluation of broadcast spray deposits. Trans. ASAE 83-1512.

Solanelles, F.; Fillat, A.; Pifarré, C.; Planas, S. 1996. A method of drift measurement for spray applications in tree crops. International 178 
Conference of Agricultural Engineering AgEng 96, Madrid, España. Paper 96-A-133: 273-274.

Solanelles, F.; Planas, S.; Escola, A.; Rosell, R. 2002. Spray application effeciency of an electronic system for proportional application to the canopy volume. Aspect. Appl. Biol. 66: 139-146.

SPSS (1999) SPSS Manual del usuario, versión 10.0 para Windows 98. SPSS, Chicago, IL. pp.581

Stark, J.D.; Vargas, R.; Miller, N. 2004. Toxicity of Spinosad in protein bait to three economically important tephritid fruit fly species (Diptera: Tephritidae) and their parasitoids (Hymenoptera: Braconidae). J. Econ. Entomol. 97: 911-915.

Steiner, L. F., Mitchell, W. C., Baumhover, A. H. 1962. Progress of fruitfly control by irradiation sterilization in Hawaii and the Mariana Islands. Int. J. Appl. Rad. Isotopes, 13: 427-434.

Talhouk, A. M. S. 1969. Insects and mites injurious to crops in the middle eastern countries. Verlag Paul Parey, Hamburg, Germany, 239 pp.

Teske, M. E.; Thisle, H. W. 2000. Droplet size scaling of agricultural spray material by dimensional analysis. Atomization and Sprays 10: 147158.

Thompson, G. D.; Hutchins S. H.; Sparks T. C. 1999. Desarrollo de spinosad y atributos de una nueva clase de productos para control de insectos. Regentes de la Universidad de Minnesota, 1999. http://ipmworld.umn.edu/cancelado/Spchapters/SpinosadSp.htm (03/2003).

Townsend, G. R.; Heuberger, J. W. 1943. Methods for estimating losses caused by diseases in fungicide experiments. Pl. Dis. Rep. 27: 340343. 
Tragsa. 2007. Comunicación personal de Rafael Argilés. (3/2007)

Urbaneja, A.; Dembilio, O.; Tortosa, D.; Viñuela, E.; Castañera, P. 2004. Efectos secundarios de tratamientos cebo usados para el control de Ceratitis capitata, sobre fauna útil. Phytoma España. 160: 28-40.

Urbaneja, A.; García-marí, F.; Tortosa, D.; Navarro, C.; Vanaclocha, P.; Vargues L.; Castañera, P. 2006. Influence of ground predators on the survival of the Mediterranean fruit fly pupae, Ceratitis capitata, in Spanish citrus orchards. Biocontrol 51: 611-626.

Urbaneja, A.; Montón, H.; Pascual-Ruiz, S.; Vanaclocha, P.; Chueca, P.; Moltó, E.; Pina, T.; Castañera, P. 2007 Alternativas químicas al malatión para el control de la mosca mediterránea de la fruta Ceratitis capitata (WIEDEMANN). Levante Agrícola 385: 169-176.

Val, L.; De Miquel, E.; Palacios, P.; Segura, A.; Pellicer, J.; Juste, F. 1993. The use of air-assisted equipment spraying citrus orchards in the Valencia region. $4^{\text {th }}$ International Symposium on Fruit, Nut and Vegetable Production Engineering 1993, Valencia, Spain. Proceedings volume 1: 187-194.

Vargas, R. I.; Peck, S. L.; McQuate, G. T.; Jackson, C. G.; Stark, J. D.; Armstrong, J. W. 2001. Potencial for areawide integrated management of Mediterranean fruit fly (Diptera: Tephritidae) with a braconid parasitoid and a novel bait spray. J. Econ. Entomol. 94: 817-825.

Vergoulas, P.; Torné, M. 2003 SPINOSAD CEBO*: un sistema innovador para el control de la mosca del Mediterráneo. Phytoma España 153: 134-138.

Verheijen, P.J.T. 2001. Statistical Distributions in Particle Technology. Department of Chemical Engineering, Technical University Delft, The Netherlands. 
http://www.dct.tudelft.nl/ verheijen/education/partstat/partstat.pdf (06/2004).

Viñuela, E.; Adán, A.; González, M.; Budia, F.; Smagghe, G.; Del Estal, P. 1998. Spinosad y azadiractina: efectos de dos plaguicidas de origen natural en el chinche depredador Podisus maculiventris (Say). Bol. San. Veg. Plagas 24: 57-66.

Walklate, P. J.; Cross, J. V.; Richardson G. M.; Murray, R. A.; Daker, D. E. 2002. Comparison of different spray volume deposition models using LIDAR measurements of apple orchards. Biosyst. Eng. 82(3), 253-267.

Wharton, R. A. 1989. Classical biological control of fruit-infesting Tephritidae. En: Fruit flies, their biology, natural enemies and control. World crop pest, vol.3B. (Robinson A. S.; Hooper, G. (Ed.), Elsevier, Amsterdam, Holland. pp 303-313.

White, I. M.; Elson-Harris, M. M. 1992. Fruit Flies of Economic Significance: their Identification and Bionomics. CAB International, Wallingford, UK. $601 \mathrm{pp}$.

Whitney, R. W.; Roth, L. O. 1985. String collectors for spray pattern analysis. Trans. ASAE 28: 1749-1753.

Whitney, J. D.; Salyani, M.; Churchill, D. B.; Knapp, J. L.; Whiteside, J. O.; Littell, R. C.1989. A field investigation to examine the effects of sprayer type, ground speed, and volume rate on spray deposition in Florida citrus. J. Agric. Eng. Res. 42: 275-283.

Whitney, J.; Salyani, M. 1991. Deposition Characteristics of Two AirCarrier Sprayers in Citrus Trees. Trans. ASAE 34:47-50. 
Williams, T.; Valle, J.; Viñuela, E. 2003. Is the naturally derived insecticide spinosad compatible with insect natural enemies? Biocontrol Sci. Technol. 0:1-17

Woglum, R. S., 1929. The Mediterranean fruit fly. Citrus Fruit Conference Exchange, California, Bull. 6: 33-48.

Wong, T. T. Y.; Ramadan, M. M.; Mcinnis, D. O.; Mochizuki, N.; Nishimoto, J. I.; Herr, J. C. 1991. Augmentative releases of Diachasmimorpha tryoni (Hymenoptera: Braconidae) to suppress a Mediterranean fruit fly (Diptera: Tphritidae) population in Kula, Maui, Hawaii. Biol. Control 1: 2-7.

Young, B. W. 1991. A method for assessing the drift potential of hydraulic nozzle spray clouds, and the effect of air assistance. En: Air Assisted Spraying in Crop Protection. British Crop Protection Council, UK pp. 77-86.

Zapata, N.; Budia, F.; Viñuela, E.; Medina, P. 2006. Insecticidal effects of various concentrations of selected extractions of Cestrum parqui on adult and immature Ceratitis capitata. J. Econ. Entomol. 99: 359365.

Zervas, G.; Kateva, A. X.; Christopoulos, A. 1995. Ways of overwintering of Medfly Ceratitis capitata (Wied.) (Dipt.; Tephritidae). The overwintering of larvae suspended fruits of citrus trees in Attica Greece. $5^{\text {th }}$ Panhellenic Entomological Congress, 1995, Athens, Greece. Greek Entomological Society, Proceedings pp. 105-112. 


\section{ANEJO 1. SELECCIÓN PREVIA DE BOQUILLAS CENTRÍFUGAS}

Se comprobaron los caudales de siete tipos de boquillas de la empresa Sanz Hermanos S.L. (Valencia, España) que se diferencian únicamente en el diámetro de apertura (Figura A. 1y Tabla A. 1).

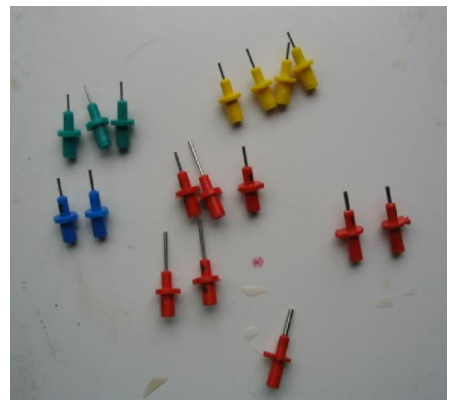

Figura A. 1. Boquillas de Sanz Hermanos.

Para ello, se montó un circuito formado por un depósito de 5 l, una tubería de $6 \mathrm{~mm}$ de polietileno, una llave de paso y la boquilla. La altura entre el depósito y la boquilla era de $95 \mathrm{~cm}$. Las mediciones consistieron en determinar el volumen que caía durante $30 \mathrm{~s}$ en una probeta con cada una de las boquillas. Se hicieron cinco repeticiones para cada boquilla, utilizándose varias boquillas de cada tipo. El ensayo se realizó con agua y con una mezcla de agua y Spintor Cebo $^{\circledR}$ al 0,05\% aunque se comprobó que el caldo formado no afecto al caudal.

Posteriormente se calculó el volumen de caldo para cada caudal en función de la velocidad del tractor y suponiendo una anchura de calles de $5 \mathrm{~m}$ con la Ecuación 5. Los resultados se muestran en la Tabla A. 1. 
Tabla A. 1. Caudales de las boquillas Sanz. Hermanos y volúmenes de caldo por unidad de superficie en función del marco de plantación y la velocidad del tractor al realizar el tratamiento.

\begin{tabular}{|c|c|c|c|c|c|c|c|}
\hline \multirow[b]{3}{*}{ Boquillas } & \multicolumn{7}{|c|}{ Volumen de caldo (l/ha) } \\
\hline & \multirow{2}{*}{$\begin{array}{l}\text { Caudal } \\
\text { (l/min) }\end{array}$} & \multicolumn{6}{|c|}{ Velocidad del tractor $(\mathrm{km} / \mathrm{h})$} \\
\hline & & $\mathbf{1 , 5}$ & 2 & 2,5 & 3 & $\mathbf{3 , 5}$ & 4 \\
\hline roja tipo $4\left(\varnothing_{\text {int }}=2 \mathrm{~mm}\right)$ & 0,49 & 39,69 & 29,77 & 23,81 & 19,84 & 17,01 & 14,88 \\
\hline roja tipo $3\left(\varnothing_{\text {int }}=1,7 \mathrm{~mm}\right)$ & 0,37 & 29,84 & 22,38 & 17,90 & 14,92 & 12,79 & 11,19 \\
\hline roja tipo $2\left(\varnothing_{\text {int }}=1,4 \mathrm{~mm}\right)$ & 0,25 & 20,24 & 15,18 & 12,14 & 10,12 & 8,67 & 7,59 \\
\hline roja tipo $1\left(\varnothing_{\mathrm{int}}=1,22 \mathrm{~mm}\right)$ & 0,18 & 14,41 & 10,81 & 8,65 & 7,21 & 6,18 & 5,41 \\
\hline $\operatorname{Azul}\left(\varnothing_{\mathrm{int}}=1,1 \mathrm{~mm}\right)$ & 0,17 & 13,34 & 10,01 & 8,00 & 6,67 & 5,72 & 5,00 \\
\hline Amarilla $\left(\varnothing_{\text {int }}=1 \mathrm{~mm}\right)$ & 0,11 & 8,83 & 6,62 & 5,30 & 4,41 & 3,78 & 3,31 \\
\hline Verde $\left(\varnothing_{\text {int }}=0,9 \mathrm{~mm}\right)$ & 0,06 & 5,17 & 3,88 & 3,10 & 2,59 & 2,22 & 1,94 \\
\hline
\end{tabular}

Se seleccionó la boquilla roja tipo 4 de mayor diámetro ya que dio lugar a los volúmenes de caldo más próximos a los que se pretendían pulverizar, 20 y 40 1/ha. En caso de necesitar mayor caudal aplicaremos la presión necesaria al circuito. 


\section{ANEJO 2. SELECCIÓN PREVIA DE CABEZALES CENTRÍFUGOS}

Los cabezales de pulverización centrífuga están formados por un motor, que se encuentra dentro de un recipiente estanco, cuyo eje proporciona movimiento de rotación a un disco que es el encargado de romper el caudal que le llega de una boquilla gracias a la fuerza centrífuga y de formar las gotas. En general, trabajan a altas velocidades de giro produciendo gotas muy pequeñas. Puesto que nuestro objetivo era formar impactos grandes, se decidió estudiar a bajas velocidades de giro el funcionamiento y la pulverización de varios cabezales centrífugos.

Se partió de cinco cabezales proporcionados por Sanz Hermanos S.L. (Figura A. 2).

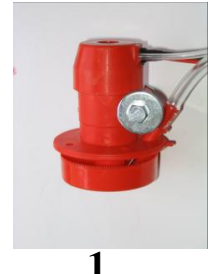

1

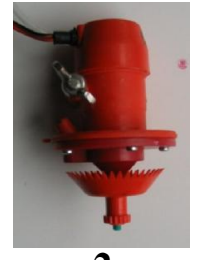

2

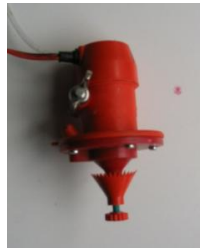

3

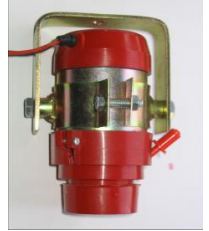

4

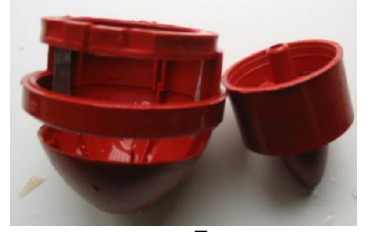

5

Figura A. 2. Cabezales 1, 2, 3, 4, 5.

El cabezal C1 tiene un motor Johnson modelo HC315G-35220 de 7,5 V. El cabezal 2 y el 3 un motor Mabuchi modelo RS-360SH de $12 \mathrm{~V}$, solo se diferencian en el disco utilizado. El cabezal 4 y el 5 tienen un motor Doga modelo 161.3109.2B.09 de $12 \mathrm{~V}$ y solo se diferencian en que el 5 es sectorial y solamente pulveriza un ángulo de $180^{\circ}$.

Para ver que cabezales eran adecuados para los objetivos del trabajo se observó a simple vista los impactos formados y su distribución. Se fijaron dos 
parámetros, el caudal de 1 1/min y la velocidad de avance de $3 \mathrm{~km} / \mathrm{h}$ y se varió la velocidad de giro de los cabezales.

El cabezal 1 se probó a 6 y $4 \mathrm{~V}$. A menos de $4 \mathrm{~V}$ se observó un mal funcionamiento a la hora de formar las gotas, debido a que el cabezal no podía pulverizar todo el líquido y este rebosaba del disco cayendo al suelo. Este cabezal se descartó porque los tamaños de gota conseguidos eran demasiado pequeños (Figura A. 3 y Figura A. 4).
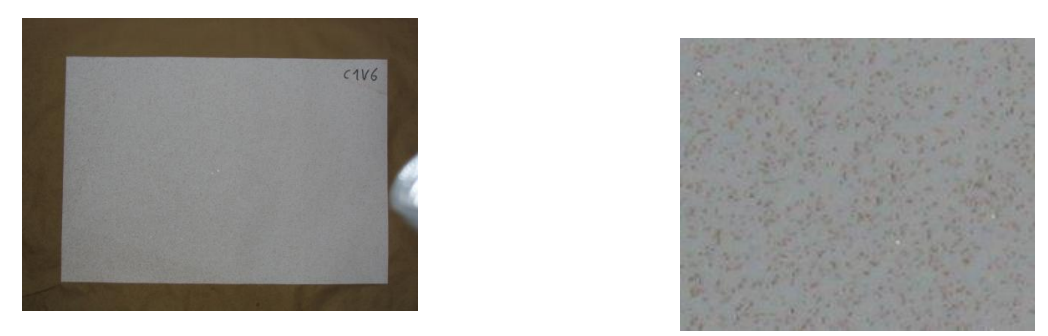

Figura A. 3. Cabezal 1 a 6 V.
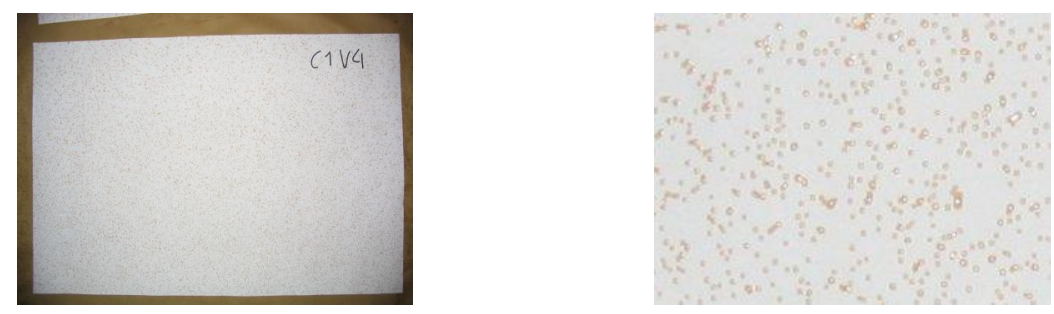

Figura A. 4. Cabezal 1 a 4 V.

El cabezal 2 se probó a 10, 7, 6, 5, 4 y $3 \mathrm{~V}$. A más de $5 \mathrm{~V}$ las gotas formadas eran demasiado pequeñas para los objetivos buscados (Figura A. 5, Figura A. 6 y Figura A. 7). A 4 y a $3 \mathrm{~V}$ el tamaño de gota formado fue interesante (Figura A. 8). A $4 \mathrm{~V}$ el alcance máximo fue de $1,4 \mathrm{~m}$ y el mínimo de 0,8 m. A $3 \mathrm{~V}$ los alcances fueron de 1 y $0,6 \mathrm{~m}$ respectivamente. 

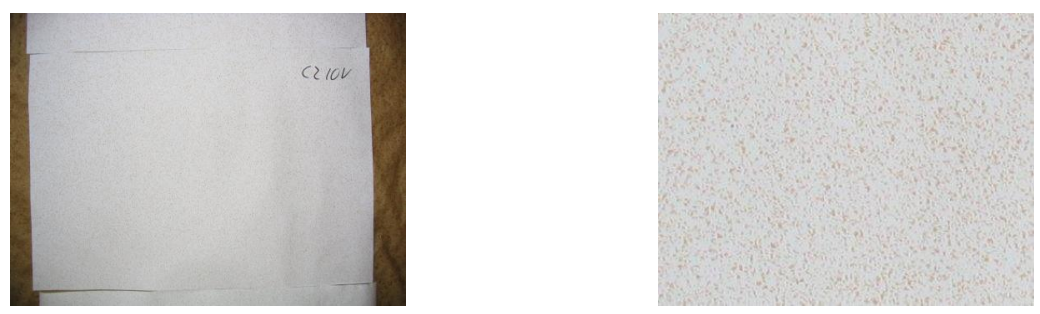

Figura A. 5. Cabezal 2 a $10 \mathrm{~V}$.
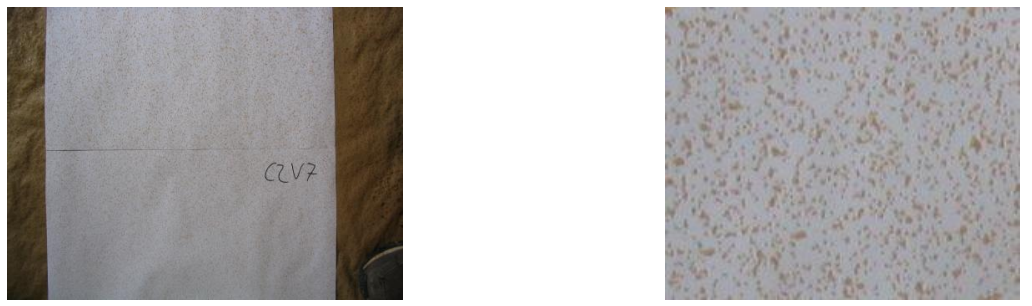

Figura A. 6. Cabezal 2 a $7 \mathrm{~V}$.
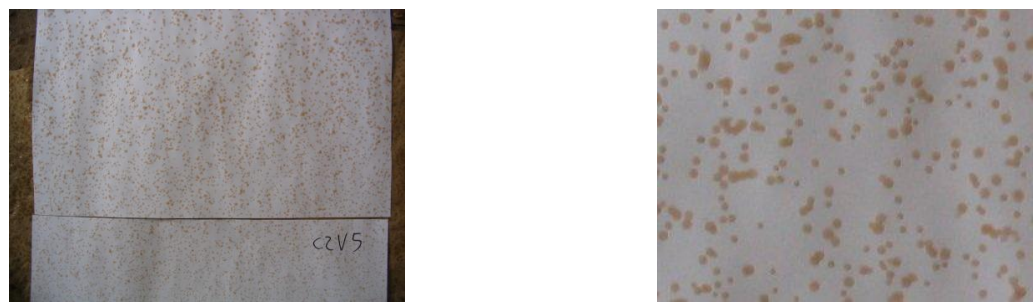

Figura A. 7. Cabezal 2 a 5 V.
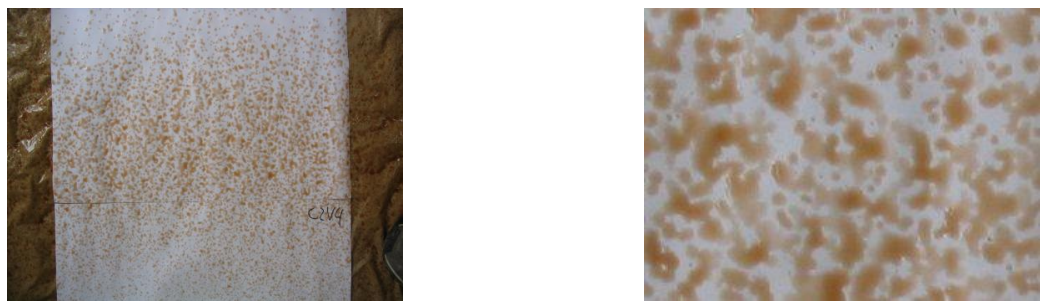

Figura A. 8. Cabezal 2 a 4 V.

El cabezal 3 se probó a 10, 8, 7, 6 y 5 V. De $10 \mathrm{~V}$ a $7 \mathrm{~V}$ las gotas fueron muy pequeñas debido a la gran velocidad de giro del disco (Figura A. 9). Los voltajes de 6 y $5 \mathrm{~V}$ fueron más interesantes. A $6 \mathrm{~V}$ se formaron gotas del tamaño adecuado pero también muchas pequeñas (Figura A. 10); a $5 \mathrm{~V}$ la distribución 
Anejo 2

fue más uniforme y las gotas más grandes (Figura A. 11). A $6 \mathrm{~V}$ el alcance máximo fue de $1,15 \mathrm{~m}$ y el mínimo de $0,75 \mathrm{~m}$. A $5 \mathrm{~V}$ los alcances fueron de 0,6 y $0,9 \mathrm{~m}$.
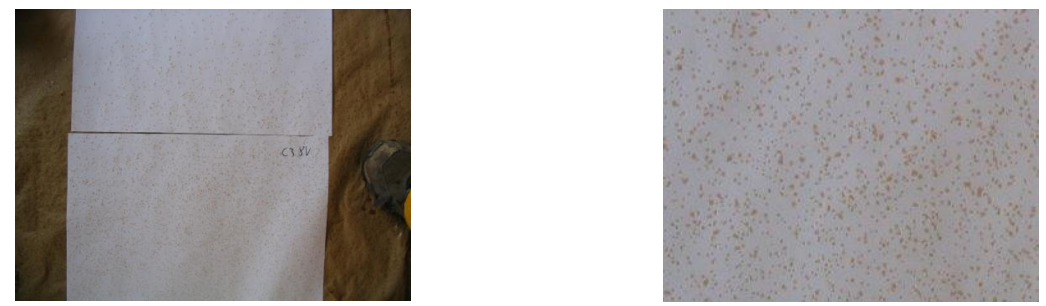

Figura A. 9. Cabezal 3 a 8 V.
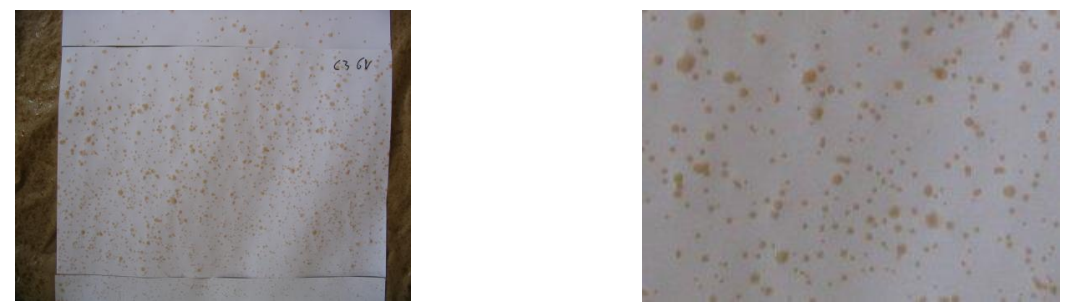

Figura A. 10. Cabezal 3 a $6 \mathrm{~V}$.
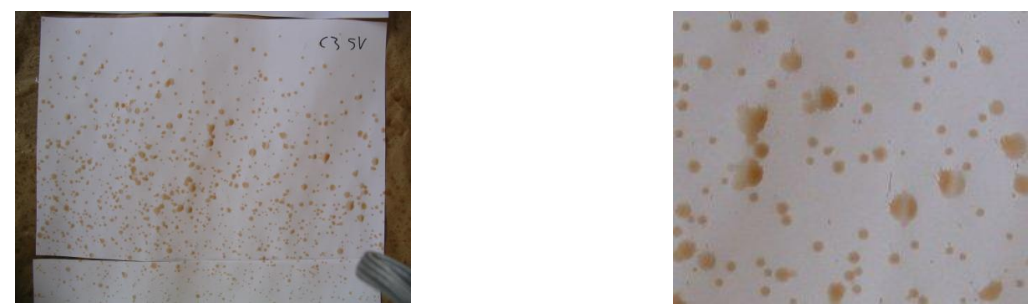

Figura A. 11. Cabezal 3 a 5 V.

El cabezal 4 se probó a 10 y $7 \mathrm{~V}$. A menor voltaje se produjo un mal funcionamiento del cabezal al formar las gotas, estas eran demasiado pequeñas tanto a $10 \mathrm{~V}$ como a $7 \mathrm{~V}$ por lo que este cabezal no se seleccionó para el ensayo (Figura A. 12). 

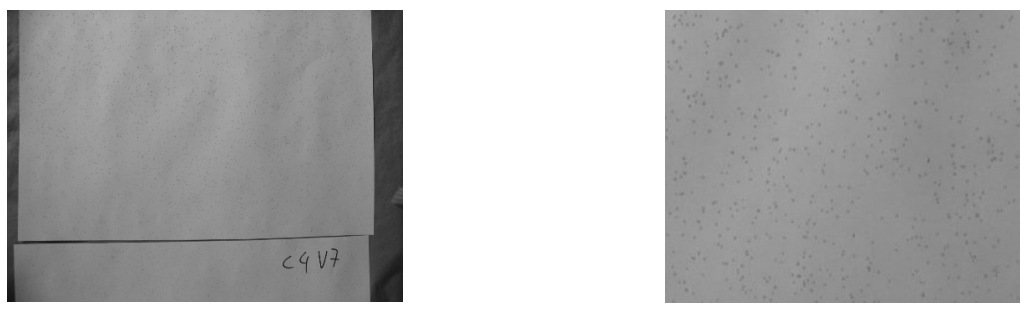

Figura A. 12. Cabezal 4 a 7 V.

El cabezal 5 no funcionó para pulverizar un caudal de 1 1/min ya que el líquido rebosaba del disco incluso a $12 \mathrm{~V}$.

Por lo tanto, se seleccionaron para su estudio más detallado los cabezales C2 y C3 (Motor Mabuchi). En la Tabla A. 2 se puede observar la relación entre la tensión y la velocidad de giro por minuto, obtenida mediante un tacómetro (en el Anejo 3 se detallan sus características). Para el cabezal 2 interesaría la velocidad de giro a $4 \mathrm{~V}$ y a $5 \mathrm{~V}$; en el cabezal 3 la velocidad de giro a $5 \mathrm{~V}$ y a $6 \mathrm{~V}$.

Tabla A. 2. Velocidades de giro ( $r / m i n)$ en función del voltaje.

\begin{tabular}{|c|c|c|c|}
\hline $\begin{array}{c}\text { Voltaje } \\
\text { (V) }\end{array}$ & $\begin{array}{c}\text { Velocidad giro } \\
(\mathrm{r} / \mathrm{min})\end{array}$ & $\begin{array}{c}\text { Voltaje } \\
\text { (V) }\end{array}$ & $\begin{array}{c}\text { Velocidad giro } \\
(\mathrm{r} / \mathrm{min})\end{array}$ \\
\hline 2 & 520 & 7,5 & 3.375 \\
\hline 2,5 & 760 & 8 & $3.728,5$ \\
\hline 3 & 1.010 & 8,5 & $3.972,5$ \\
\hline 3,5 & 1.274 & 9 & $4.242,5$ \\
\hline 4 & 1.545 & 9,5 & 4.495 \\
\hline 4,5 & 1.810 & 10 & $4.677,5$ \\
\hline 5 & 2.055 & 10,5 & 5.000 \\
\hline 5,5 & $2.322,5$ & 11 & 5.269 \\
\hline 6 & 2.590 & 11,5 & 5.495 \\
\hline 6,5 & 2.850 & 12 & 5.805 \\
\hline 7 & $3.107,5$ & & \\
\hline
\end{tabular}





\section{ANEJO 3. CARACTERÍSTICAS DE LOS EQUIPOS EMPLEADOS}

\section{Características de la cámara digital y ajustes realizados:}

Marca: Cannon.

Modelo: PowerShot A70.

Los ajustes realizados para tomar las fotografías fueron los siguientes:

Resolución de la cámara: 2048 × 1536 (Máxima, modo L).

Compresión: superfina.

Teleobjetivo: se encuadró completamente el colector según el ensayo.

Modo: macro.

Modo de disparo: manual.

Velocidad de obturación: 1/60 (la velocidad se adaptó al periodo de los tubos fluorescentes empleados).

Apertura: F8.0.

Balance de blancos y sensitividad: auto.

Modo de medir la luz: spot AE point.

Características de los tubos fluorescentes utilizados en el sistema de iluminación:

Marca: OSRAM.

Modelo: L18W/965 25X1.

Base: G13.

Código de energía: B.

Potencia: $18 \mathrm{~W}$.

Luminosidad: $1.000 \mathrm{~lm}$.

Longitud: $590 \mathrm{~mm}$.

Diámetro del tubo: $26 \mathrm{~mm}$.

Características del tacómetro:

Modelo 8803.001 
Anejo 3

Rango: 50-20.000 r/min.

Precisión: $10.000 \pm 1$ r/min./ 10.000-20.000 \pm 2 r/min

Tiempo de medida: $1 \mathrm{~s}$.

Rango de temperatura: $0-45^{\circ} \mathrm{C}$. 
ANEJO 4. VALORES DE SSE Y R2 EN EL ENSAYO DE DISPOSITIVOS HIDRAÚLICOS 

Anejo 4

Tabla A. 3. Valores de SSE y R2 para los colectores del ensayo de pulverización hidráulica.

\begin{tabular}{|c|c|c|c|c|c|c|c|}
\hline \multirow[b]{2}{*}{ Boquilla } & \multirow[b]{2}{*}{$\begin{array}{l}\text { Presión } \\
\text { (bar) }\end{array}$} & \multirow[b]{2}{*}{ Repetición } & \multirow[b]{2}{*}{ Altura } & \multicolumn{2}{|l|}{$\begin{array}{l}\text { Ajuste } \\
\text { normal }\end{array}$} & \multicolumn{2}{|c|}{$\begin{array}{l}\text { Ajuste } \\
\text { Rammler }\end{array}$} \\
\hline & & & & SSE & $\mathbf{R}^{2}$ & SSE & $\mathbf{R}^{2}$ \\
\hline AI-11003VS & 1 & 1 & 0,5 & & & & \\
\hline AI-11003VS & 1 & 1 & 0,333 & 0,0361 & 0,9843 & 0,0127 & 0,9945 \\
\hline AI-11003VS & 1 & 1 & 0,166 & 0,0370 & 0,9901 & 0,0438 & 0,9882 \\
\hline AI-11003VS & 1 & 1 & 0 & 0,0337 & 0,9928 & 0,0892 & 0,9808 \\
\hline AI-11003VS & 1 & 1 & $-0,166$ & 0,1158 & 0,9834 & 0,0552 & 0,9921 \\
\hline AI-11003VS & 1 & 1 & $-0,333$ & 0,0352 & 0,9939 & 0,0989 & 0,9829 \\
\hline AI-11003VS & 1 & 1 & $-0,5$ & 0,1089 & 0,9640 & 0,0876 & 0,9710 \\
\hline AI-11003VS & 1 & 2 & 0,5 & & & & \\
\hline AI-11003VS & 1 & 2 & 0,333 & 0,0231 & 0,9862 & 0,0215 & 0,9871 \\
\hline AI-11003VS & 1 & 2 & 0,166 & 0,0430 & 0,9901 & 0,0937 & 0,9783 \\
\hline AI-11003VS & 1 & 2 & 0 & 0,0297 & 0,9947 & 0,0632 & 0,9888 \\
\hline AI-11003VS & 1 & 2 & $-0,166$ & 0,0912 & 0,9857 & 0,0453 & 0,9929 \\
\hline AI-11003VS & 1 & 2 & $-0,333$ & 0,0455 & 0,9918 & 0,0866 & 0,9844 \\
\hline AI-11003VS & 1 & 2 & $-0,5$ & 0,0386 & 0,9910 & 0,0592 & 0,9862 \\
\hline AI-11003VS & 1 & 3 & 0,5 & & & & \\
\hline AI-11003VS & 1 & 3 & 0,333 & 0,0205 & 0,9745 & 0,0198 & 0,9754 \\
\hline AI-11003VS & 1 & 3 & 0,166 & 0,1812 & 0,9570 & 0,0981 & 0,9767 \\
\hline AI-11003VS & 1 & 3 & 0 & 0,0291 & 0,9948 & 0,0332 & 0,9940 \\
\hline AI-11003VS & 1 & 3 & $-0,166$ & 0,0326 & 0,9925 & 0,0636 & 0,9853 \\
\hline AI-11003VS & 1 & 3 & $-0,333$ & 0,0395 & 0,9923 & 0,1177 & 0,9772 \\
\hline AI-11003VS & 1 & 3 & $-0,5$ & 0,1507 & 0,9485 & 0,1006 & 0,9656 \\
\hline AI-11003VS & 2 & 1 & 0,5 & 0,0322 & 0,9510 & 0,0349 & 0,9469 \\
\hline AI-11003VS & 2 & 1 & 0,333 & 0,0381 & 0,9934 & 0,0347 & 0,9940 \\
\hline AI-11003VS & 2 & 1 & 0,166 & 0,0228 & 0,9982 & 0,0718 & 0,9945 \\
\hline AI-1 1003VS & 2 & 1 & 0 & 0,0750 & 0,9929 & 0,2303 & 0,9783 \\
\hline AI-11003VS & 2 & 1 & $-0,166$ & 0,2003 & 0,9767 & 0,1139 & 0,9867 \\
\hline AI-11003VS & 2 & 1 & $-0,333$ & 0,0496 & 0,9952 & 0,0474 & 0,9954 \\
\hline AI-11003VS & 2 & 1 & $-0,5$ & 0,0418 & 0,9925 & 0,0476 & 0,9914 \\
\hline AI-11003VS & 2 & 2 & 0,5 & 0,0002 & 0,9996 & 0,0000 & 1,0000 \\
\hline AI-11003VS & 2 & 2 & 0,333 & 0,0562 & 0,9878 & 0,0744 & 0,9839 \\
\hline
\end{tabular}


Anejo 4

\begin{tabular}{|c|c|c|c|c|c|c|c|}
\hline \multirow[b]{2}{*}{ Boquilla } & \multirow[b]{2}{*}{$\begin{array}{l}\text { Presión } \\
\text { (bar) }\end{array}$} & \multirow[b]{2}{*}{ Repetición } & \multirow[b]{2}{*}{ Altura } & \multicolumn{2}{|l|}{$\begin{array}{l}\text { Ajuste } \\
\text { normal }\end{array}$} & \multicolumn{2}{|c|}{$\begin{array}{l}\text { Ajuste } \\
\text { Rammler }\end{array}$} \\
\hline & & & & SSE & $\mathbf{R}^{2}$ & SSE & $\mathbf{R}^{2}$ \\
\hline AI-11003VS & 2 & 2 & 0,166 & 0,0484 & 0,9941 & 0,1739 & 0,9789 \\
\hline AI-11003VS & 2 & 2 & 0 & 0,1100 & 0,9898 & 0,1154 & 0,9893 \\
\hline AI-1 1003VS & 2 & 2 & $-0,166$ & 0,0732 & 0,9923 & 0,1332 & 0,9860 \\
\hline AI-11003VS & 2 & 2 & $-0,333$ & 0,0616 & 0,9929 & 0,0940 & 0,9891 \\
\hline AI-11003VS & 2 & 2 & $-0,5$ & 0,0683 & 0,9858 & 0,0394 & 0,9918 \\
\hline AI-11003VS & 2 & 3 & 0,5 & & & & \\
\hline AI-11003VS & 2 & 3 & 0,333 & 0,0398 & 0,9912 & 0,0255 & 0,9944 \\
\hline AI-11003VS & 2 & 3 & 0,166 & 0,0359 & 0,9925 & 0,0918 & 0,9809 \\
\hline AI-11003VS & 2 & 3 & 0 & 0,0318 & 0,9958 & 0,1499 & 0,9804 \\
\hline AI-11003VS & 2 & 3 & $-0,166$ & 0,0200 & 0,9973 & 0,0505 & 0,9931 \\
\hline AI-11003VS & 2 & 3 & $-0,333$ & 0,0552 & 0,9888 & 0,0678 & 0,9863 \\
\hline AI-1 1004VS & 2 & 3 & $-0,5$ & 0,0909 & 0,9748 & 0,0591 & 0,9836 \\
\hline AI-11004VS & 1 & 1 & 0,5 & & & & \\
\hline AI-11004VS & 1 & 1 & 0,333 & 0,0339 & 0,9892 & 0,0793 & 0,9748 \\
\hline AI-11004VS & 1 & 1 & 0,166 & 0,0486 & 0,9912 & 0,1494 & 0,9731 \\
\hline AI-11004VS & 1 & 1 & 0 & 0,0965 & 0,9884 & 0,1811 & 0,9782 \\
\hline AI-11004VS & 1 & 1 & $-0,166$ & 0,0297 & 0,9958 & 0,0297 & 0,9958 \\
\hline AI-11004VS & 1 & 1 & $-0,333$ & 0,0332 & 0,9945 & 0,0712 & 0,9883 \\
\hline AI-11004VS & 1 & 1 & $-0,5$ & 0,0534 & 0,9906 & 0,0226 & 0,9960 \\
\hline AI-11004VS & 1 & 2 & 0,5 & & & & \\
\hline AI-11004VS & 1 & 2 & 0,333 & 0,0156 & 0,9926 & 0,0205 & 0,9903 \\
\hline AI-11004VS & 1 & 2 & 0,166 & 0,0269 & 0,9959 & 0,0869 & 0,9866 \\
\hline AI-11004VS & 1 & 2 & 0 & 0,0326 & 0,9954 & 0,0493 & 0,9930 \\
\hline AI-11004VS & 1 & 2 & $-0,166$ & 0,2322 & 0,9638 & 0,2021 & 0,9685 \\
\hline AI-11004VS & 1 & 2 & $-0,333$ & 0,0350 & 0,9902 & 0,1117 & 0,9688 \\
\hline AI-11004VS & 1 & 2 & $-0,5$ & 0,0879 & 0,9802 & 0,0681 & 0,9846 \\
\hline AI-11004VS & 1 & 3 & 0,5 & & & & \\
\hline AI-11004VS & 1 & 3 & 0,333 & 0,0472 & 0,9829 & 0,0310 & 0,9888 \\
\hline AI-11004VS & 1 & 3 & 0,166 & 0,0426 & 0,9931 & 0,1103 & 0,9822 \\
\hline AI-11004VS & 1 & 3 & 0 & 0,0275 & 0,9947 & 0,0718 & 0,9861 \\
\hline AI-11004VS & 1 & 3 & $-0,166$ & 0,0344 & 0,9931 & 0,0446 & 0,9910 \\
\hline AI-1 1004VS & 1 & 3 & $-0,333$ & 0,0281 & 0,9932 & 0,0563 & 0,9864 \\
\hline
\end{tabular}


Anejo 4

\begin{tabular}{|c|c|c|c|c|c|c|c|}
\hline \multirow[b]{2}{*}{ Boquilla } & \multirow[b]{2}{*}{$\begin{array}{l}\text { Presión } \\
\text { (bar) }\end{array}$} & \multirow[b]{2}{*}{ Repetición } & \multirow[b]{2}{*}{ Altura } & \multicolumn{2}{|c|}{$\begin{array}{ll}\begin{array}{l}\text { Ajuste } \\
\text { normal }\end{array} & \text { Log- }\end{array}$} & \multicolumn{2}{|c|}{$\begin{array}{l}\text { Ajuste } \\
\text { Rammler }\end{array}$} \\
\hline & & & & SSE & $\mathbf{R}^{2}$ & SSE & $\mathbf{R}^{2}$ \\
\hline AI-11004VS & 1 & 3 & $-0,5$ & 0,0607 & 0,9787 & 0,0566 & 0,9801 \\
\hline AI-11004VS & 2 & 1 & 0,5 & 0,0015 & 0,9974 & 0,0001 & 0,9998 \\
\hline AI-11004VS & 2 & 1 & 0,333 & 0,0255 & 0,9945 & 0,0259 & 0,9944 \\
\hline AI-11004VS & 2 & 1 & 0,166 & 0,0307 & 0,9964 & 0,1421 & 0,9831 \\
\hline AI-11004VS & 2 & 1 & 0 & 0,0235 & 0,9977 & 0,0767 & 0,9926 \\
\hline AI-11004VS & 2 & 1 & $-0,166$ & 0,0428 & 0,9945 & 0,1884 & 0,9757 \\
\hline AI-11004VS & 2 & 1 & $-0,333$ & 0,0467 & 0,9940 & 0,1083 & 0,9861 \\
\hline AI-1 1004VS & 2 & 1 & $-0,5$ & 0,0720 & 0,9837 & 0,0292 & 0,9934 \\
\hline AI-11004VS & 2 & 2 & 0,5 & & & & \\
\hline AI-11004VS & 2 & 2 & 0,333 & 0,0515 & 0,9875 & 0,0417 & 0,9899 \\
\hline AI-1 1004VS & 2 & 2 & 0,166 & 0,0262 & 0,9963 & 0,0950 & 0,9866 \\
\hline AI-11004VS & 2 & 2 & 0 & 0,0757 & 0,9917 & 0,0819 & 0,9910 \\
\hline AI-11004VS & 2 & 2 & $-0,166$ & 0,0262 & 0,9970 & 0,0851 & 0,9903 \\
\hline AI-11004VS & 2 & 2 & $-0,333$ & 0,0653 & 0,9911 & 0,2013 & 0,9726 \\
\hline AI-11004VS & 2 & 2 & $-0,5$ & 0,1004 & 0,9779 & 0,1086 & 0,9761 \\
\hline AI-11004VS & 2 & 3 & 0,5 & & & & \\
\hline AI-11004VS & 2 & 3 & 0,333 & 0,0245 & 0,9933 & 0,0564 & 0,9845 \\
\hline AI-11004VS & 2 & 3 & 0,166 & 0,0512 & 0,9950 & 0,1671 & 0,9836 \\
\hline AI-11004VS & 2 & 3 & 0 & 0,0432 & 0,9951 & 0,0941 & 0,9893 \\
\hline AI-11004VS & 2 & 3 & $-0,166$ & 0,0361 & 0,9954 & 0,0922 & 0,9883 \\
\hline AI-11004VS & 2 & 3 & $-0,333$ & 0,0253 & 0,9959 & 0,0591 & 0,9905 \\
\hline FL-5VS & 2 & 3 & $-0,5$ & 0,1124 & 0,9689 & 0,0831 & 0,9770 \\
\hline FL-5VS & 2 & 1 & 0,5 & 0,0197 & 0,9698 & 0,0161 & 0,9753 \\
\hline FL-5VS & 2 & 1 & 0,333 & 0,0442 & 0,9835 & 0,0903 & 0,9663 \\
\hline FL-5VS & 2 & 1 & 0,166 & 0,0690 & 0,9887 & 0,1888 & 0,9691 \\
\hline FL-5VS & 2 & 1 & 0 & 0,0344 & 0,9963 & 0,0857 & 0,9907 \\
\hline FL-5VS & 2 & 1 & $-0,166$ & 0,0322 & 0,9974 & 0,1777 & 0,9856 \\
\hline FL-5VS & 2 & 1 & $-0,333$ & 0,0164 & 0,9980 & 0,0693 & 0,9917 \\
\hline FL-5VS & 2 & 1 & $-0,5$ & 0,0206 & 0,9949 & 0,0307 & 0,9924 \\
\hline FL-5VS & 1 & 2 & 0,5 & & & & \\
\hline FL-5VS & 1 & 2 & 0,333 & 0,0305 & 0,9675 & 0,0269 & 0,9713 \\
\hline FL-5VS & 1 & 2 & 0,166 & 0,0306 & 0,9879 & 0,0295 & 0,9884 \\
\hline
\end{tabular}


Anejo 4

\begin{tabular}{|c|c|c|c|c|c|c|c|}
\hline \multirow[b]{2}{*}{ Boquilla } & \multirow[b]{2}{*}{$\begin{array}{l}\text { Presión } \\
\text { (bar) }\end{array}$} & \multirow[b]{2}{*}{ Repetición } & \multirow[b]{2}{*}{ Altura } & \multicolumn{2}{|l|}{$\begin{array}{l}\text { Ajuste } \\
\text { normal }\end{array}$} & \multicolumn{2}{|c|}{$\begin{array}{l}\text { Ajuste } \\
\text { Rammler }\end{array}$} \\
\hline & & & & SSE & $\mathbf{R}^{2}$ & SSE & $\mathbf{R}^{2}$ \\
\hline FL-5VS & 1 & 2 & 0 & 0,0338 & 0,9949 & 0,0733 & 0,9889 \\
\hline FL-5VS & 1 & 2 & $-0,166$ & 0,0801 & 0,9891 & 0,2364 & 0,9679 \\
\hline FL-5VS & 1 & 2 & $-0,333$ & 0,0262 & 0,9944 & 0,0401 & 0,9914 \\
\hline FL-5VS & 1 & 2 & $-0,5$ & 0,0465 & 0,9917 & 0,1278 & 0,9771 \\
\hline FL-5VS & 2 & 3 & 0,5 & & & & \\
\hline FL-5VS & 2 & 3 & 0,333 & 0,0241 & 0,9851 & 0,0250 & 0,9846 \\
\hline FL-5VS & 2 & 3 & 0,166 & 0,0746 & 0,9917 & 0,1985 & 0,9778 \\
\hline FL-5VS & 2 & 3 & 0 & 0,0477 & 0,9971 & 0,2444 & 0,9854 \\
\hline FL-5VS & 2 & 3 & $-0,166$ & 0,0496 & 0,9962 & 0,1015 & 0,9923 \\
\hline FL-5VS & 2 & 3 & $-0,333$ & 0,0205 & 0,9977 & 0,0816 & 0,9909 \\
\hline FL-5VS & 2 & 3 & $-0,5$ & 0,0328 & 0,9918 & 0,0835 & 0,9792 \\
\hline FL-5VS & 1 & 1 & 0,5 & & & & \\
\hline FL-5VS & 1 & 1 & 0,333 & 0,0191 & 0,9833 & 0,0095 & 0,9916 \\
\hline FL-5VS & 1 & 1 & 0,166 & 0,0658 & 0,9802 & 0,0214 & 0,9936 \\
\hline FL-5VS & 1 & 1 & 0 & 0,0270 & 0,9943 & 0,0659 & 0,9861 \\
\hline FL-5VS & 1 & 1 & $-0,166$ & 0,0472 & 0,9919 & 0,0334 & 0,9942 \\
\hline FL-5VS & 1 & 1 & $-0,333$ & 0,0961 & 0,9847 & 0,2159 & 0,9655 \\
\hline FL-5VS & 1 & 1 & $-0,5$ & 0,0578 & 0,9754 & 0,0985 & 0,9581 \\
\hline FL-5VS & 2 & 2 & 0,5 & & & & \\
\hline FL-5VS & 2 & 2 & 0,333 & 0,0250 & 0,9784 & 0,0261 & 0,9774 \\
\hline FL-5VS & 2 & 2 & 0,166 & 0,0573 & 0,9913 & 0,0431 & 0,9935 \\
\hline FL-5VS & 2 & 2 & 0 & 0,0679 & 0,9941 & 0,0599 & 0,9948 \\
\hline FL-5VS & 2 & 2 & $-0,166$ & 0,0523 & 0,9952 & 0,1126 & 0,9896 \\
\hline FL-5VS & 2 & 2 & $-0,333$ & 0,0259 & 0,9962 & 0,0931 & 0,9863 \\
\hline FL-5VS & 2 & 2 & $-0,5$ & 0,0185 & 0,9969 & 0,0245 & 0,9958 \\
\hline FL-5VS & 1 & 3 & 0,5 & & & & \\
\hline FL-5VS & 1 & 3 & 0,333 & & & & \\
\hline FL-5VS & 1 & 3 & 0,166 & 0,0303 & 0,9936 & 0,0870 & 0,9815 \\
\hline FL-5VS & 1 & 3 & 0 & 0,0738 & 0,9928 & 0,2299 & 0,9777 \\
\hline FL-5VS & 1 & 3 & $-0,166$ & 0,0241 & 0,9980 & 0,0979 & 0,9917 \\
\hline FL-5VS & 1 & 3 & $-0,333$ & 0,0837 & 0,9852 & 0,2192 & 0,9612 \\
\hline TT-11004VP & 1 & 3 & $-0,5$ & 0,0833 & 0,9823 & 0,1569 & 0,9667 \\
\hline
\end{tabular}


Anejo 4

\begin{tabular}{|c|c|c|c|c|c|c|c|}
\hline \multirow[b]{2}{*}{ Boquilla } & \multirow[b]{2}{*}{$\begin{array}{l}\text { Presión } \\
\text { (bar) }\end{array}$} & \multirow[b]{2}{*}{ Repetición } & \multirow[b]{2}{*}{ Altura } & \multicolumn{2}{|l|}{$\begin{array}{l}\text { Ajuste } \\
\text { normal }\end{array}$} & \multicolumn{2}{|c|}{$\begin{array}{l}\text { Ajuste } \\
\text { Rammler }\end{array}$} \\
\hline & & & & SSE & $\mathbf{R}^{2}$ & SSE & $\mathbf{R}^{2}$ \\
\hline TT-11004VP & 1 & 1 & 0,5 & 0,0008 & 0,9990 & 0,0008 & 0,9990 \\
\hline TT-11004VP & 1 & 1 & 0,333 & 0,0631 & 0,9843 & 0,0635 & 0,9842 \\
\hline TT-11004VP & 1 & 1 & 0,166 & 0,0592 & 0,9938 & 0,1562 & 0,9837 \\
\hline TT-11004VP & 1 & 1 & 0 & 0,0462 & 0,9961 & 0,1234 & 0,9897 \\
\hline TT-11004VP & 1 & 1 & $-0,166$ & 0,0585 & 0,9940 & 0,1861 & 0,9809 \\
\hline TT-11004VP & 1 & 1 & $-0,333$ & 0,0227 & 0,9965 & 0,0458 & 0,9929 \\
\hline TT-11004VP & 1 & 1 & $-0,5$ & 0,0304 & 0,9929 & 0,0833 & 0,9806 \\
\hline TT-11004VP & 1 & 2 & 0,5 & 0,0746 & 0,9688 & 0,1280 & 0,9465 \\
\hline TT-11004VP & 1 & 2 & 0,333 & 0,1262 & 0,9721 & 0,2251 & 0,9502 \\
\hline TT-11004VP & 1 & 2 & 0,166 & 0,0654 & 0,9917 & 0,1287 & 0,9836 \\
\hline TT-11004VP & 1 & 2 & 0 & 0,1821 & 0,9837 & 0,0881 & 0,9921 \\
\hline TT-11004VP & 1 & 2 & $-0,166$ & 0,0594 & 0,9934 & 0,0855 & 0,9905 \\
\hline TT-11004VP & 1 & 2 & $-0,333$ & 0,0207 & 0,9963 & 0,0384 & 0,9931 \\
\hline TT-11004VP & 1 & 2 & $-0,5$ & 0,0511 & 0,9900 & 0,0497 & 0,9903 \\
\hline TT-11004VP & 1 & 3 & 0,5 & 0,0111 & 0,9934 & 0,0094 & 0,9944 \\
\hline TT-11004VP & 1 & 3 & 0,333 & 0,1537 & 0,9658 & 0,2776 & 0,9382 \\
\hline TT-11004VP & 1 & 3 & 0,166 & 0,2005 & 0,9785 & 0,4370 & 0,9531 \\
\hline TT-11004VP & 1 & 3 & 0 & 0,0703 & 0,9939 & 0,1134 & 0,9901 \\
\hline TT-11004VP & 1 & 3 & $-0,166$ & 0,0309 & 0,9972 & 0,1773 & 0,9839 \\
\hline TT-11004VP & 1 & 3 & $-0,333$ & 0,0340 & 0,9961 & 0,1093 & 0,9876 \\
\hline TT-11004VP & 1 & 3 & $-0,5$ & 0,0232 & 0,9960 & 0,0356 & 0,9938 \\
\hline TT-11004VP & 2 & 1 & 0,5 & 0,0322 & 0,9851 & 0,0636 & 0,9707 \\
\hline TT-11004VP & 2 & 1 & 0,333 & 0,0803 & 0,9884 & 0,1716 & 0,9752 \\
\hline TT-11004VP & 2 & 1 & 0,166 & 0,0645 & 0,9949 & 0,2236 & 0,9824 \\
\hline TT-11004VP & 2 & 1 & 0 & 0,1012 & 0,9941 & 0,0610 & 0,9964 \\
\hline TT-11004VP & 2 & 1 & $-0,166$ & 0,0332 & 0,9974 & 0,1117 & 0,9914 \\
\hline TT-11004VP & 2 & 1 & $-0,333$ & 0,0161 & 0,9983 & 0,0775 & 0,9919 \\
\hline TT-11004VP & 2 & 1 & $-0,5$ & 0,0745 & 0,9874 & 0,0840 & 0,9857 \\
\hline TT-11004VP & 2 & 2 & 0,5 & 0,0400 & 0,9888 & 0,0610 & 0,9828 \\
\hline TT-11004VP & 2 & 2 & 0,333 & 0,0449 & 0,9947 & 0,1148 & 0,9865 \\
\hline TT-11004VP & 2 & 2 & 0,166 & 0,1886 & 0,9867 & 0,1398 & 0,9901 \\
\hline TT-11004VP & 2 & 2 & 0 & 0,1831 & 0,9888 & 0,1656 & 0,9899 \\
\hline
\end{tabular}


Anejo 4

\begin{tabular}{|c|c|c|c|c|c|c|c|}
\hline \multirow[b]{2}{*}{ Boquilla } & \multirow[b]{2}{*}{$\begin{array}{l}\text { Presión } \\
\text { (bar) }\end{array}$} & \multirow[b]{2}{*}{ Repetición } & \multirow[b]{2}{*}{ Altura } & \multicolumn{2}{|l|}{$\begin{array}{l}\text { Ajuste } \\
\text { normal }\end{array}$} & \multicolumn{2}{|c|}{$\begin{array}{l}\text { Ajuste } \\
\text { Rammler }\end{array}$} \\
\hline & & & & SSE & $\mathbf{R}^{2}$ & SSE & $\mathbf{R}^{2}$ \\
\hline TT-11004VP & 2 & 2 & $-0,166$ & 0,0876 & 0,9932 & 0,0575 & 0,9955 \\
\hline TT-11004VP & 2 & 2 & $-0,333$ & 0,0468 & 0,9950 & 0,0657 & 0,9931 \\
\hline TT-11004VP & 2 & 2 & $-0,5$ & 0,0611 & 0,9885 & 0,0176 & 0,9967 \\
\hline TT-11004VP & 2 & 3 & 0,5 & 0,0502 & 0,9738 & 0,0555 & 0,9710 \\
\hline TT-11004VP & 2 & 3 & 0,333 & 0,0806 & 0,9883 & 0,2118 & 0,9692 \\
\hline TT-11004VP & 2 & 3 & 0,166 & 0,0541 & 0,9948 & 0,2347 & 0,9775 \\
\hline TT-11004VP & 2 & 3 & 0 & 0,0651 & 0,9959 & 0,0921 & 0,9942 \\
\hline TT-11004VP & 2 & 3 & $-0,166$ & 0,0298 & 0,9981 & 0,1149 & 0,9929 \\
\hline TT-11004VP & 2 & 3 & $-0,333$ & 0,0370 & 0,9949 & 0,1323 & 0,9816 \\
\hline TT-11004VP & 2 & 3 & $\begin{array}{l}-0,5 \\
\end{array}$ & 0,0281 & 0,9942 & 0,0189 & 0,9961 \\
\hline
\end{tabular}




\section{ANEJO 5. RESULTADOS DEL EFECTO DE LOS FACTORES SOBRE LAS VARIABLES EN EL ENSAYO DE DISPOSITIVOS HIDRAÚLICOS}

\section{Efecto de los factores sobre la variable mediana del diámetro}

La interacción entre la presión y la boquilla resultó estadísticamente significativa para la variable mediana del diámetro de los impactos (Tabla A. 5). Las boquillas de inducción de aire alcanzaron los mayores valores de mediana (Figura A. 13). A 2 bar de presión no hubo diferencias significativas entre estas boquillas, sin embargo la disminución de 1 bar implicó un mayor aumento de la mediana en la boquilla AI-11003VS que en la AI-11004VS. Las boquillas FL5VS y TT-11004VP presentaron impactos con medianas de diámetro significativamente menores a las de inducción de aire. A 1 bar de presión no hubo diferencias significativas entre ellas. Sin embargo, el aumento a 2 bar en la boquilla FL-5VS redujo la mediana de los diámetros en mayor proporción que en la boquilla TT-11004VP, para la que la disminución de 1 bar no influyó significativamente sobre el valor de la mediana.

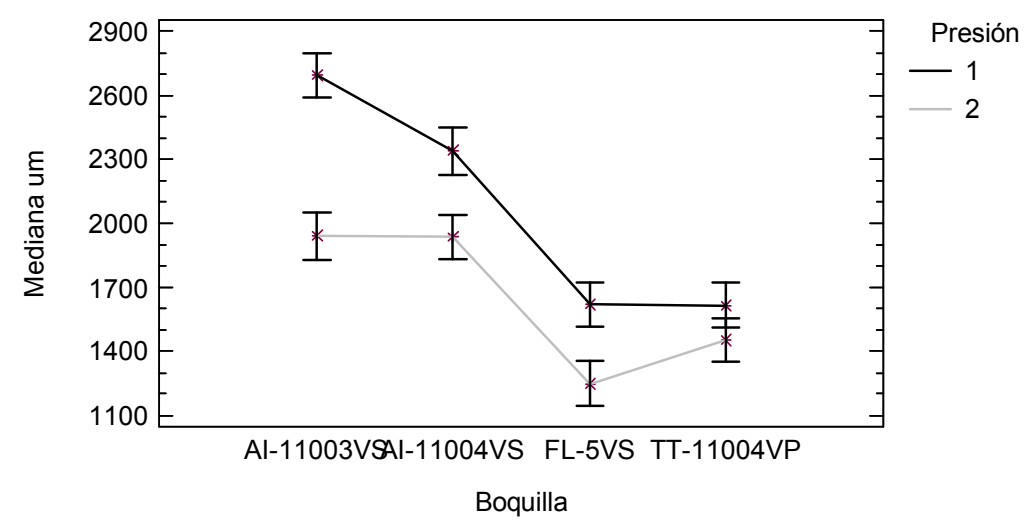

Figura A. 13. Interacción del factor presión por el factor boquilla para la variable mediana del diámetro. Intervalos LSD a un nivel de confianza del $95 \%$. 
La altura a la que se colocaron los colectores influyó significativamente sobre la mediana del diámetro de los impactos (Tabla A. 5). Los impactos tuvieron mayor mediana en los colectores más extremos $(\mathrm{C} 2,-\mathrm{C} 3)$ y en los centrales $(0 \mathrm{y}-\mathrm{C} 1)$ que entre los colectores situados entre ellos (Tabla A. 4).

Tabla A. 4. Mediana del diámetro de impacto (Media \pm ES) en cada posición de colector. Valores de la media seguidos de diferente letra muestran diferencias significativas (Prueba LSD a un nivel de confanza del $95 \%$ ).

\begin{tabular}{|l|l|}
\hline Altura relativa & \multicolumn{1}{|c|}{ Mediana $(\boldsymbol{\mu m})$} \\
\hline C2 & $2013,25 \pm 152,84 \mathrm{a}$ \\
\hline $\mathrm{C} 1$ & $1760,29 \pm 95,16 \mathrm{bc}$ \\
\hline 0 & $1864,24 \pm 111,73 \mathrm{abc}$ \\
\hline$-\mathrm{C} 1$ & $1923,38 \pm 108,95 \mathrm{ab}$ \\
\hline$-\mathrm{C} 2$ & $1688,37 \pm 79,81 \mathrm{c}$ \\
\hline$-\mathrm{C} 3$ & $1840,30 \pm 127,83 \mathrm{abc}$ \\
\hline
\end{tabular}

Tabla A. 5. Resultado del ANOVA para la variable mediana a un nivel de confianza del $95 \%$.

Fuente Suma de cuadrados GL Cuadrado Medio Cociente-F P-Valor

EEECTOS PRINCIPALES

$\begin{array}{lrrrrr}\text { A: Boquilia } & 1,95465 \mathrm{E} 7 & 3 & 6,51549 \mathrm{E} 6 & 65,77 & 0,0000 \\ \text { B:Colector } & 1,4558 \mathrm{E} 6 & 5 & 291159,0 & 2,94 & 0,0159 \\ \text { C:Presión } & 6,14132 \mathrm{E} 6 & 1 & 6,14132 \mathrm{E} 6 & 61,99 & 0,0000\end{array}$

INTERACCIONES

$\begin{array}{lrrcrr}\mathrm{AB} & 2,36528 \mathrm{E} 6 & 15 & 157686,0 & 1,59 & 0,0882 \\ \mathrm{AC} & 1,51193 \mathrm{E} 6 & 3 & 503976,0 & 5,09 & 0,0025 \\ \mathrm{BC} & 373802,0 & 5 & 74760,5 & 0,75 & 0,5845 \\ \text { RESIDUOS } & 1,05013 \mathrm{E} 7 & 106 & 99069,1 & & \end{array}$

TOTAL (CORREGIDO 4,29469E7 138 
Efecto de los factores sobre la variable D25 del diámetro

La interacción entre la presión y la boquilla sobre la variable D25 fue significativa (Tabla A. 6) y muy similar a la obtenida sobre la variable mediana. Los mayores valores de D25 del diámetro se obtuvieron con las boquillas de inducción de aire y los menores valores con la FL-5VS y TT-11004VP (Figura A. 14). A menor presión mayor fue el valor de D25 de los impactos, sin embargo los incrementos variaron en función del tipo de boquilla. La boquilla AI11003VS tuvo un incremento de tamaños mayor que la boquilla AI-11004VS. La boquilla FL-5VS a 2 bar presentó el menor valor de D25, sin embargo a 1 bar aumentó significativamente el tamaño de D25. El aumento de 1 bar de presión no influyó significativamente sobre la boquilla TT-11004VP.

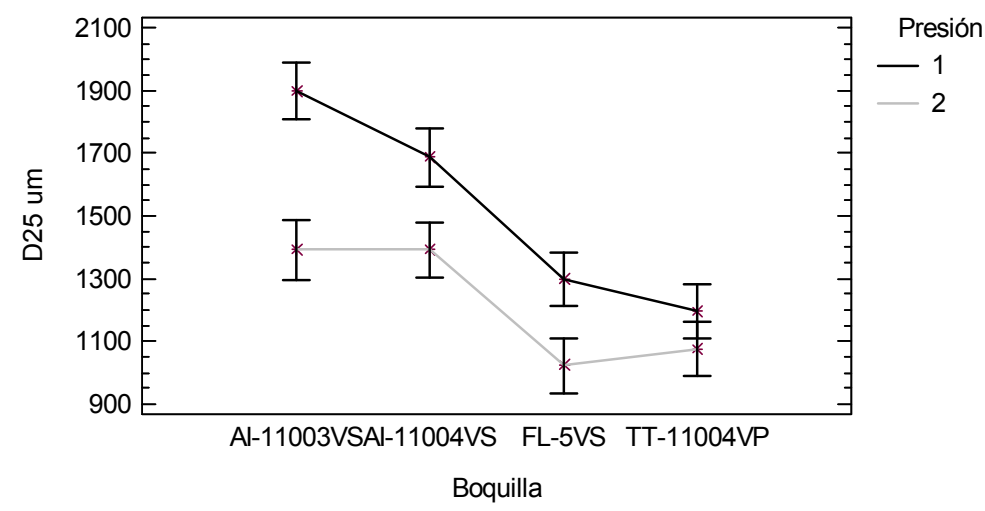

Figura A. 14. Interacción del factor presión por el factor boquilla para la variable D25 del diámetro. Intervalos LSD a un nivel de confianza del $95 \%$.

La interacción entre la boquilla y la altura relativa del colector también resultó significativa para la variable D25 del diámetro (Tabla A. 6). En la Figura A. 15 se observa que la boquilla FL-5VS presentó valores de D25 significativamente iguales para cada una de las alturas donde se colocaron los colectores. De igual manera ocurrió con la boquilla TT-11004VP, aunque en la altura -C3 (colector situado a menor altura) se produjo un descenso en el valor de D25. Por el contrario, en las boquillas de aire inducido, que en general produjeron valores de D25 mayores, se observan valores muy altos para el 
colector C2 (situado a mayor altura) y valores ligeramente menores para el colector $-\mathrm{C} 2$. El resto de colectores presentaron valores de D25 similares.

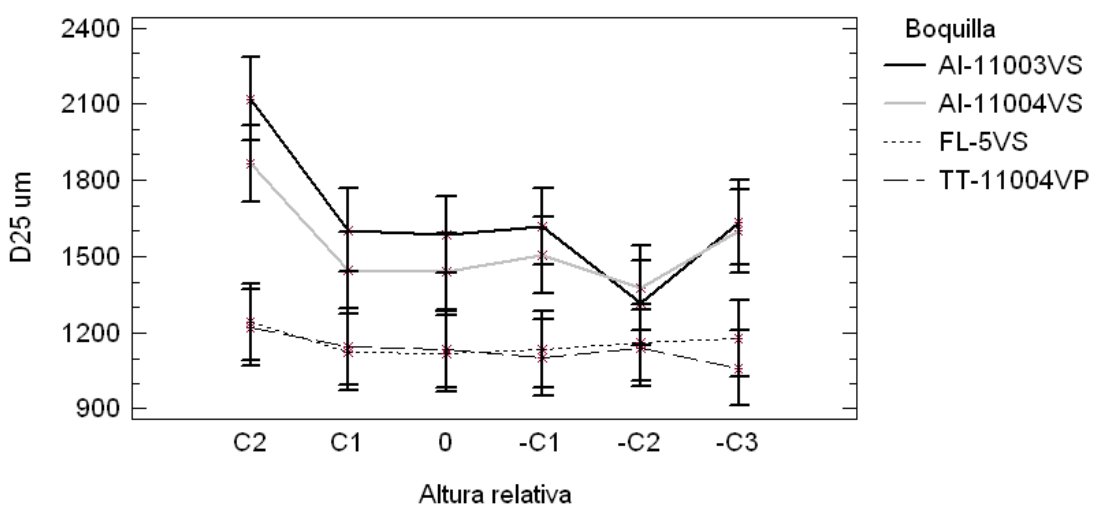

Figura A. 15. Interacción del factor boquilla por el factor altura relativa del colector para la variable D25 del diámetro. Intervalos LSD a un nivel de confianza del $95 \%$.

Tabla A. 6. Resultado del ANOVA para la variable D25a un nivel de confianza del $95 \%$.

\begin{tabular}{|c|c|c|c|c|c|}
\hline Suma de & cuadrados & GL & Cuadrado Medio & Cociente-F & P-Valor \\
\hline \multicolumn{6}{|l|}{ EFECTOS PRINCIPALES } \\
\hline A: Boquilla & $6,89666 \mathrm{E} 6$ & 3 & $2,29889 \mathrm{E} 6$ & 67,07 & 0,0000 \\
\hline B:Colector & $1,76597 \mathrm{E} 6$ & 5 & 353194,0 & 10,30 & 0,0000 \\
\hline C:Presión & $3,06788 \mathrm{E} 6$ & 1 & $3,06788 \mathrm{E} 6$ & 89,51 & 0,0000 \\
\hline \multicolumn{6}{|l|}{ INTERACCIONES } \\
\hline $\mathrm{AB}$ & $1,11854 \mathrm{E} 6$ & 15 & 74569,1 & 2,18 & 0,0115 \\
\hline $\mathrm{AC}$ & 629653,0 & 3 & 209884,0 & 6,12 & 0,0007 \\
\hline $\mathrm{BC}$ & 267788,0 & 5 & 53557,7 & 1,56 & 0,1771 \\
\hline RESIDUOS & $3,59882 \mathrm{E} 6$ & 105 & 34274,5 & & \\
\hline TOTAL (CORREGIDO) & $1,68305 \mathrm{E} 7$ & 137 & & & \\
\hline
\end{tabular}


Efecto de los factores sobre la variable D75 del diámetro

El efecto de la presión y de la boquilla sobre la variable D75 fue significativo ( Tabla A. 8) y mostró tendencias similares a las obtenidas con las otras variables de posición estudiadas: mediana y D25 (Figura A. 16).

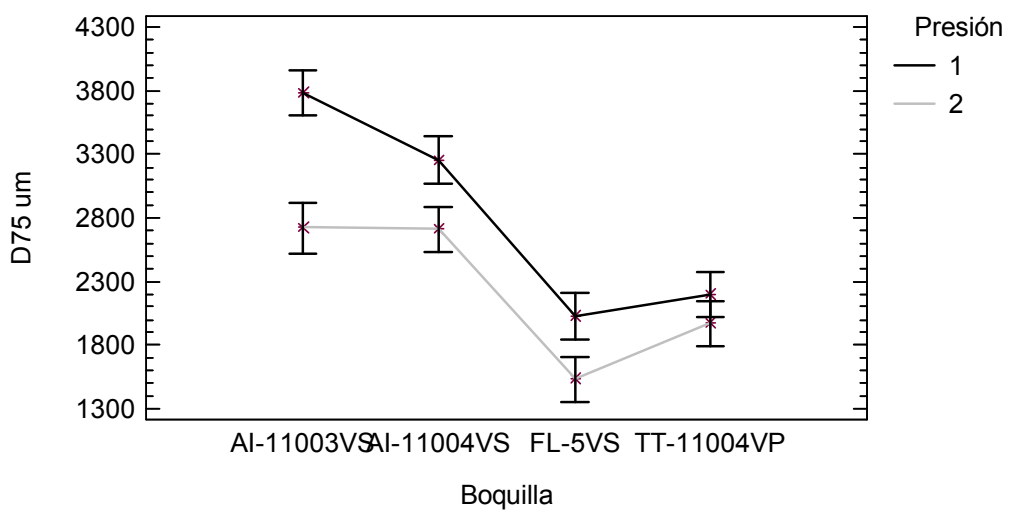

Figura A. 16. Interacción del factor presión por el factor boquilla para la variable D75 del diámetro. Intervalos LSD a un nivel de confianza del $95 \%$.

La altura del colector influyó significativamente sobre la variable D75 (Tabla A. 8). Al igual que ocurrió con la mediana del diámetro, se producen impactos con D75 mayor en las alturas centrales (colectores 0 y -C1) y en los extremos (-C2 y -C3). En los colectores intermedios se observan valores de D75 menores (Tabla A. 7).

Tabla A. 7. D75 del diámetro de impacto (Media \pm ES) en cada posición de colector. Valores de la media seguidos de diferente letra muestran diferencias significativas (Prueba LSD con un intervalo de confanza del $95 \%$ ).

\begin{tabular}{|l|l|}
\hline Altura relativa & \multicolumn{1}{|c|}{ D75 $(\boldsymbol{\mu m})$} \\
\hline C2 & $2479,30 \pm 201,39 \mathrm{abc}$ \\
\hline $\mathrm{C} 1$ & $2340,26 \pm 146,53 \mathrm{bc}$ \\
\hline 0 & $2648,87 \pm 191,66 \mathrm{abc}$ \\
\hline$-\mathrm{C} 1$ & $2772,56 \pm 184,01 \mathrm{ab}$ \\
\hline$-\mathrm{C} 2$ & $2294,50 \pm 134,84 \mathrm{c}$ \\
\hline$-\mathrm{C} 3$ & $2527,80 \pm 226,77 \mathrm{abc}$ \\
\hline
\end{tabular}


Tabla A. 8. Resultado del ANOVA para la variable D75 a un nivel de confianza del $95 \%$.

\begin{tabular}{|c|c|c|c|c|c|}
\hline Suma de & cuadrados & GL & Cuadrado Medio & Cociente-F & P-Valor \\
\hline \multicolumn{6}{|l|}{ EFECTOS PRINCIPALES } \\
\hline A: Boquilla & $5,10629 \mathrm{E} 7$ & 3 & $1,7021 \mathrm{E} 7$ & 59,19 & 0,0000 \\
\hline B: Colector & $3,68912 \mathrm{E} 6$ & 5 & 737824,0 & 2,57 & 0,0312 \\
\hline C:Presión & $1,1658 \mathrm{E} 7$ & 1 & $1,1658 \mathrm{E} 7$ & 40,54 & 0,0000 \\
\hline \multicolumn{6}{|l|}{ INTERACCIONES } \\
\hline $\mathrm{AB}$ & $5,41348 \mathrm{E} 6$ & 15 & 360899,0 & 1,26 & 0,2440 \\
\hline $\mathrm{AC}$ & $3,07065 \mathrm{E} 6$ & 3 & $1,02355 \mathrm{E} 6$ & 3,56 & 0,0168 \\
\hline $\mathrm{BC}$ & 535558,0 & 5 & 107112,0 & 0,37 & 0,8665 \\
\hline RESIDUOS & $3,04805 \mathrm{E} 7$ & 106 & 287552,0 & & \\
\hline TOTAL (CORREGIDO) & $1,08211 \mathrm{E} 8$ & 138 & & & \\
\hline
\end{tabular}

Efecto de los factores sobre la variable intervalo intercuartílico del diámetro

El efecto de la boquilla sobre el intervalo intercuartílico del diámetro fue significativo (Tabla A. 10). Las boquillas de inducción de aire produjeron la población de tamaños de impactos con mayor intervalo intercuartílico, no habiendo diferencias significativas entre ellas (Tabla A. 9). La boquilla TT$11004 \mathrm{VP}$ presentó valores menores de intervalo intercuartílico y la diferencia respecto a las boquillas de inducción de aire fue significativa. La boquilla FL5VS dio lugar a la población de tamaños de impactos con menor intervalo intercuartílico y fue significativamente diferente a la TT-11004VP.

La presión también tuvo efecto significativo sobre el intervalo intercuartílico (Tabla A. 10). A 1 bar de presión la población de impactos presentó tamaños con un intervalo intercuartílico significativamente mayor que a 2 bar (Tabla A. 9). 
Tabla A. 9. Intervalo intercuartílico del diámetro de impacto (Media \pm ES) para los factores: boquilla, presión y posición de colector. Dentro de cada factor, valores de la media seguidos de diferente letra muestran diferencias significativas (Prueba LSD a un nivel de confanza del $95 \%$ ).

\begin{tabular}{|l|l|c|}
\cline { 2 - 3 } \multicolumn{2}{c|}{} & II $(\boldsymbol{\mu m})$ \\
\hline \multirow{4}{*}{ Boquilla } & AI-11003VS & $1559,64 \pm 101,41 \mathrm{a}$ \\
\cline { 2 - 3 } & AI-11004VS & $1432,94 \pm 84,03 \mathrm{a}$ \\
\cline { 2 - 3 } & FL-5VS & $618,65 \pm 36,09 \mathrm{c}$ \\
\cline { 2 - 3 } & TT-11004VP & $948,03 \pm 53,46 \mathrm{~b}$ \\
\hline \multirow{4}{*}{ Presión (bar) } & 1 & $1242,65 \pm 71,47 \mathrm{a}$ \\
\cline { 2 - 3 } & 2 & $1004,15 \pm 60,30 \mathrm{~b}$ \\
\hline \multirow{4}{*}{ Altura relativa } & C2 & $839,90 \pm 94,31 \mathrm{c}$ \\
\cline { 2 - 3 } & C1 & $1010,54 \pm 92,36 \mathrm{bc}$ \\
\cline { 2 - 3 } & 0 & $1330,01 \pm 132,42 \mathrm{a}$ \\
\cline { 2 - 3 } & $-\mathrm{C} 1$ & $1432,41 \pm 125,39 \mathrm{a}$ \\
\cline { 2 - 3 } & $-\mathrm{C} 2$ & $1047,87 \pm 92,671 \mathrm{~b}$ \\
\cline { 2 - 3 } & $-\mathrm{C} 3$ & $1060,86 \pm 116,43 \mathrm{~b}$ \\
\hline
\end{tabular}

El efecto de la altura relativa del colector sobre el intervalo intercuartílico fue significativo (Tabla A. 10). Los colectores centrales presentaron significativamente mayor valor de intervalo intercuartílico que los colectores de los extremos (Tabla A. 9). El colector C2 (a mayor altura) fue el que presentó menor valor de intervalo intercuartílico.

Tabla A. 10. Resultado del ANOVA para la variable intervalo intercuartílico a un nivel de confianza del $95 \%$.

Fuente Suma de cuadrados GL Cuadrado Medio Cociente-F P-Valor

EFECTOS PRINCIPALES

$\begin{array}{lrrrrr}\text { A: Boquilia } & 1,92915 \mathrm{E} 7 & 3 & 6,43049 \mathrm{E} 6 & 51,51 & 0,0000 \\ \text { B:Colector } & 5,48068 \mathrm{E} 6 & 5 & 1,09614 \mathrm{E} 6 & 8,78 & 0,0000 \\ \text { C:Presión } & 1,92945 \mathrm{E} 6 & 1 & 1,92945 \mathrm{E} 6 & 15,46 & 0,0001 \\ \text { RESIDUOS } & 1,59797 \mathrm{E} 7 & 128 & 124842,0 & \end{array}$

TOTAL (CORREGIDO)

$4,29927 \mathrm{E} 7$

137 
Efecto de los factores sobre la variable número de impactos por $\mathrm{cm}^{2}$

La interacción entre el factor boquilla y el factor presión fue significativa para la variable número de impactos por $\mathrm{cm}^{2}$ (Tabla A. 11). El incremento de presión de 1 a 2 bar aumentó significativamente el número de impactos por $\mathrm{cm}^{2}$ en cada boquilla (Figura A. 17). Sin embargo, este incremento fue mayor para la boquilla AI-11003VS. La boquilla TT-11004VP fue la que presentó significativamente mayor número de impactos por $\mathrm{cm}^{2}$ para las dos presiones, mientras que la boquilla FL-5VS fue la que produjo significativamente menor número de impactos por $\mathrm{cm}^{2}$.

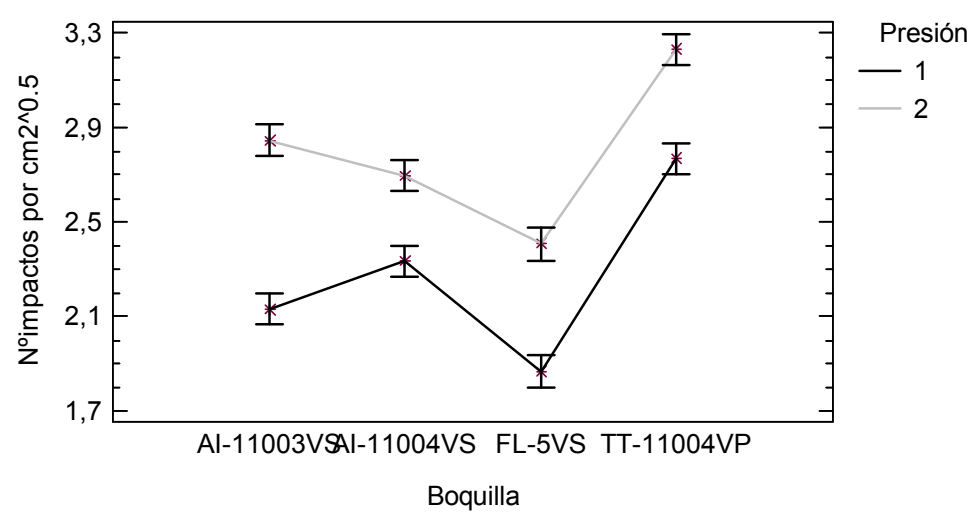

Figura A. 17. Interacción del factor presión por el factor boquilla para la variable número de impactos por $\mathrm{cm}^{2} \wedge$, 5 . Intervalos LSD a un nivel de confianza del $95 \%$.

La interacción entre la boquilla y la posición del colector fue significativa (Tabla A. 11). Los colectores centrales (0 y -C1) presentaron el máximo número de impactos por $\mathrm{cm}^{2}$ para cualquiera de las boquillas (Figura A. 18). La TT-11004VP produjo los valores mayores, mientras que la FL-5VS presentó el menor número de impactos por $\mathrm{cm}^{2}$. A medida que los colectores se situaron más alejados del centro hacia los extremos, el número de impactos por $\mathrm{cm}^{2}$ se redujo, así como las diferencias entre las boquillas. 


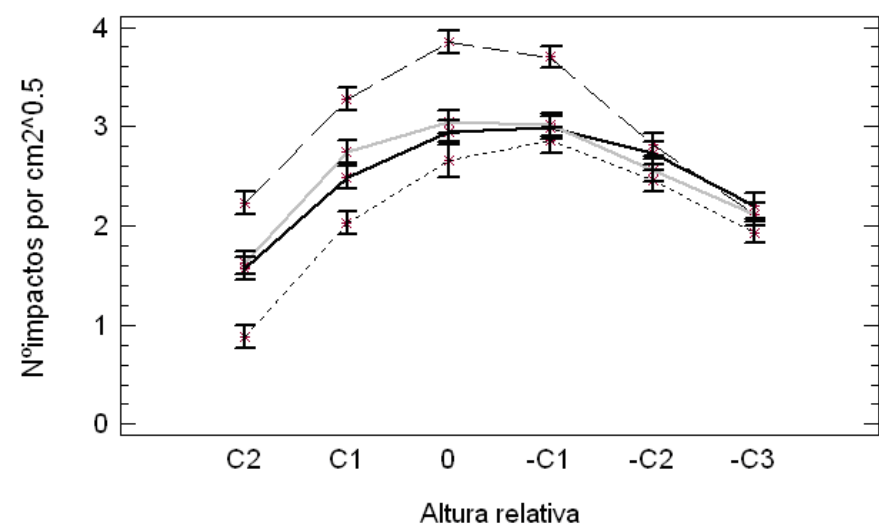

Boquilla

- Al-11003Vs

- Al-11004VS

.... FL-5VS

- - TT-11004VP

Figura A. 18. Interacción del factor boquilla por el factor altura relativa para la variable número de impactos por $\mathrm{cm}^{2} \wedge$,5. Intervalos $L S D$ a un nivel de confianza del $95 \%$.

La interacción entre la presión y la altura relativa de los colectores fue significativa (Tabla A. 11). Hubo mayor diferencia en el número de impactos por $\mathrm{cm}^{2}$ entre los colectores centrales y los extremos cuando se pulverizó a la presión de 2 bar que a 1 bar (Figura A. 19).

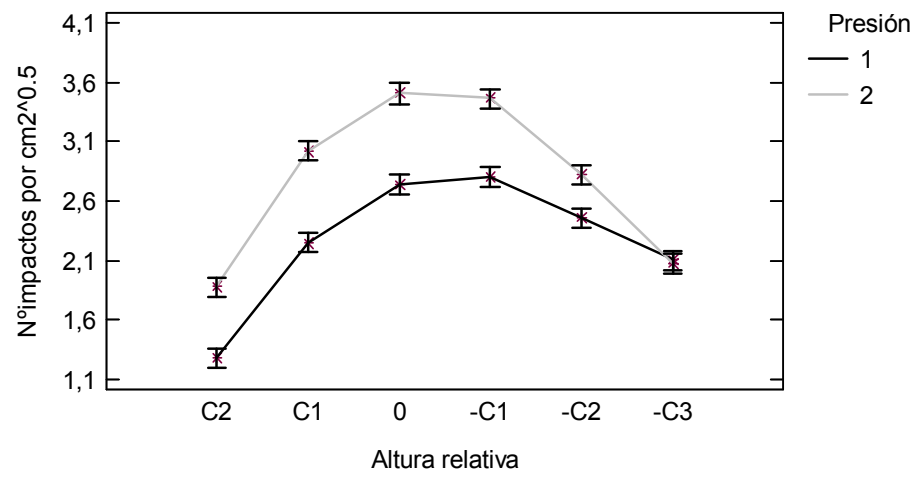

Figura A. 19. Interacción del factor presión por el factor altura relativa para la variable número de impactos por $\mathrm{cm}^{2} \wedge$, 5. Intervalos LSD a un nivel de confianza del $95 \%$. 
Tabla A. 11. Resultado del ANOVA para la variable número de impactos por $\mathrm{cm}^{2}$ a un nivel de confianza del $95 \%$.

\begin{tabular}{|c|c|c|c|c|c|}
\hline Suma de & cuadrados & GL & Cuadrado Medio & Cociente-F & P-Valor \\
\hline \multicolumn{6}{|l|}{ EFECTOS PRINCIPALES } \\
\hline A: Boquilla & 12,5055 & 3 & 4,16851 & 106,46 & 0,0000 \\
\hline B: Colector & 41,7527 & 5 & 8,35054 & 213,26 & 0,0000 \\
\hline C:Presión & 9,32243 & 1 & 9,32243 & 238,09 & 0,0000 \\
\hline \multicolumn{6}{|l|}{ INTERACCIONES } \\
\hline$A B$ & 4,64866 & 15 & 0,30991 & 7,91 & 0,0000 \\
\hline $\mathrm{AC}$ & 0,585594 & 3 & 0,195198 & 4,99 & 0,0028 \\
\hline $\mathrm{BC}$ & 2,69871 & 5 & 0,539742 & 13,78 & 0,0000 \\
\hline RESIDUOS & 4,15051 & 106 & 0,0391558 & & \\
\hline TOTAL (CORREGIDO) & 79,185 & 138 & & & \\
\hline
\end{tabular}

\section{Efecto de los factores sobre la variable recubrimiento}

La interacción entre el factor boquilla y la altura relativa fue significativa (Tabla A. 12). El recubrimiento fue mayor en los colectores centrales y disminuyó conforme aumentaba la distancia de separación de los colectores respecto a éstos (Figura A. 20). Las boquillas de inducción de aire produjeron mayor recubrimiento sobre todos los colectores y no existieron diferencias significativas entre ellas. La boquilla TT-11004VP consiguió el mismo recubrimiento que las boquillas de inducción de aire para los colectores situados por encima del colector central, sin embargo el recubrimiento disminuyó en mayor medida en los colectores situados por debajo de éste. La boquilla FL-5VS proporcionó el menor recubrimiento. 


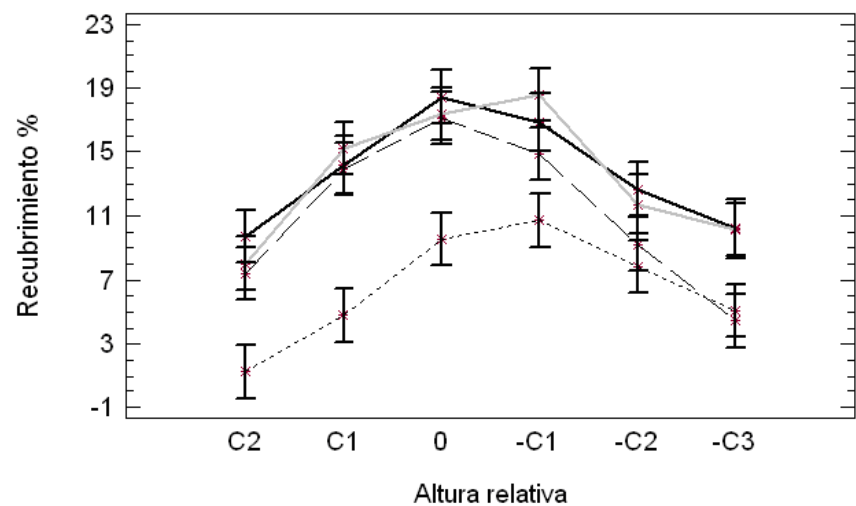

Boquilla

- Al-11003VS

Al-11004VS

FL-5VS

- - TT-11004VP

Figura A. 20. Interacción del factor boquilla por el factor altura relativa para la variable recubrimiento. Intervalos LSD a un nivel de confianza del $95 \%$.

Tabla A. 12. Resultado del ANOVA para la variable recubrimiento a un nivel de confianza del $95 \%$.

\begin{tabular}{|c|c|c|c|c|c|}
\hline Suma de & cuadrados & GL & Cuadrado Medio & Cociente-F & $\mathrm{P}-\mathrm{Val}$ or \\
\hline \multicolumn{6}{|l|}{ EFECTOS PRINCIPALES } \\
\hline A: Boquilla & 1163,26 & 3 & 387,752 & 46,91 & 0,0000 \\
\hline B: Colector & 1688,56 & 5 & 337,711 & 40,86 & 0,0000 \\
\hline C:Presión & 1,37801 & 1 & 1,37801 & 0,17 & 0,6839 \\
\hline \multicolumn{6}{|l|}{ INTERACCIONES } \\
\hline $\mathrm{AB}$ & 242,749 & 15 & 16,1833 & 1,96 & 0,0251 \\
\hline $\mathrm{AC}$ & 22,8572 & 3 & 7,61908 & 0,92 & 0,4330 \\
\hline $\mathrm{BC}$ & 91,7963 & 5 & 18,3593 & 2,22 & 0,0574 \\
\hline RESIDUOS & 884,404 & 107 & 8,26546 & & \\
\hline TOTAL (CORREGIDO) & 4120,84 & 139 & & & \\
\hline
\end{tabular}


Efecto de los factores sobre la variable volumen depositado por unidad de superficie

La interacción entre los factores presión y boquilla fue significativa para la variable volumen depositado por unidad de superficie (Tabla A. 13). Las boquillas de aire inducido son las que depositaron sobre los colectores mayor volumen de caldo por unidad de superficie, aunque la cantidad depositada varió en función de la presión: a 1 bar de presión el volumen depositado fue significativamente mayor que a 2 bar (Figura A. 21). Cuando se pulverizó con la boquilla TT-11004VP y la FL-5VS el aumento de 1 bar de presión no tuvo efecto significativo. La boquilla FL-5VS fue la que depósito significativamente menor volumen de caldo por unidad de superficie.

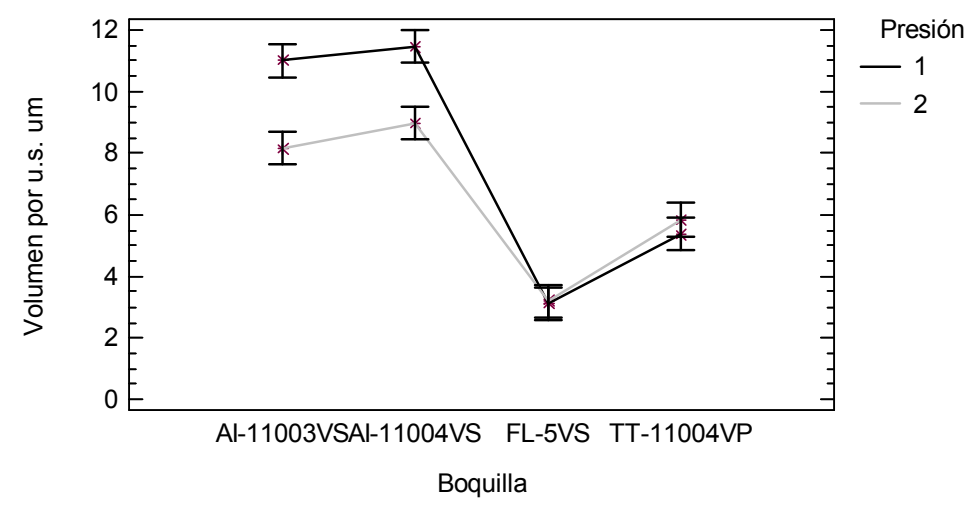

Figura A. 21. Interacción del factor presión por el factor boquilla para la variable volumen depositado por unidad de superficie. Intervalos LSD a un nivel de confianza del $95 \%$.

En la Figura A. 22 se observa la interacción entre la boquilla y la altura relativa del colector sobre el volumen depositado (Tabla A. 13). En general, todas las boquillas depositaron mayor cantidad de caldo en los colectores centrales y ésta se fue reduciendo conforme aumentaba la distancia a éstos. Sin embargo, las diferencias de volumen depositado por unidad de superficie en cada posición de los colectores variaron en función de la boquilla. Las mayores diferencias entre colectores centrales y extremos se produjeron con la boquilla 
TT-11004VS. La boquilla AI-11004VS y la FL-5VS presentaron diferencias similares. La boquilla AI-11003VS presentó una distribución del volumen en función de la altura diferente al resto de boquillas ya que el máximo volumen lo depositó a la altura $\mathrm{C} 1$.

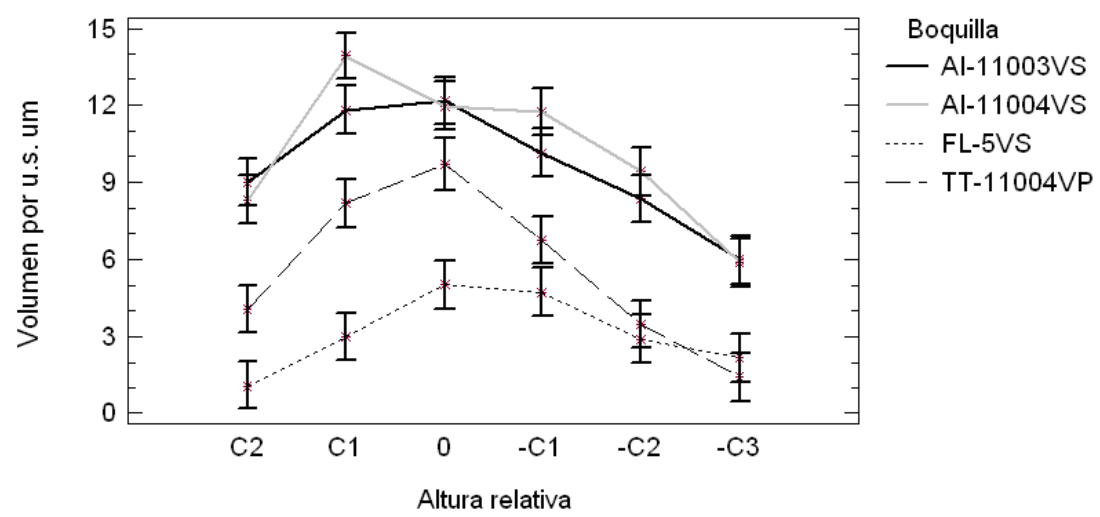

Figura A. 22. Interacción del factor boquilla por el factor altura relativa para la variable volumen depositado por unidad de superficie. Intervalos $L S D$ a un nivel de confianza del $95 \%$.

La presión no influyó significativamente sobre el volumen depositado por unidad de superficie de los colectores situados en el centro (C1, 0 y $-\mathrm{C} 1)$. Sin embargo, en los colectores de los extremos, el volumen por unidad de superficie fue significativamente mayor para la presión de 1 bar que para la de 2 bar (Figura A. 23). 


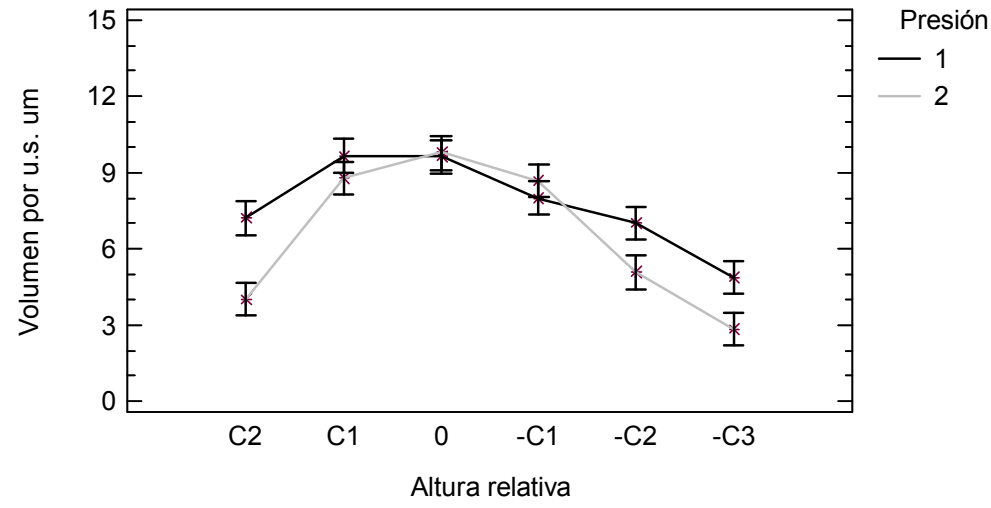

Figura A. 23. Interacción del factor presión por el factor altura relativa para la variable volumen depositado por unidad de superficie. Intervalos LSD a un nivel de confianza del $95 \%$.

Tabla A. 13. Resultado del ANOVA para la variable volumen depositado por unidad de superficie a un nivel de confianza del $95 \%$.

\begin{tabular}{|c|c|c|c|c|c|}
\hline Fuente & Suma de cuadrados & GL & Cuadrado Medio & Cociente-F & $\mathrm{P}$-Valor \\
\hline \multicolumn{6}{|c|}{ EFECTOS PRINCIPALES } \\
\hline A:Boquilla & 1206,62 & 3 & 402,207 & 153,77 & 0,0000 \\
\hline B: Colector & 629,711 & 5 & 125,942 & 48,15 & 0,0000 \\
\hline C:Presión & 51,3311 & 1 & 51,3311 & 19,62 & 0,0000 \\
\hline
\end{tabular}

INTERACCIONES

$\begin{array}{lrrrrr}\mathrm{AB} & 132,682 & 15 & 8,84544 & 3,38 & 0,0001 \\ \mathrm{AC} & 78,3913 & 3 & 26,1304 & 9,99 & 0,0000 \\ \mathrm{BC} & 63,6886 & 5 & 12,7377 & 4,87 & 0,0005 \\ \text { RESIDUOS } & 287,722 & 110 & 2,61565 & & \end{array}$

TOTAL (CORREGIDO)

2453,85 


\section{ANEJO 6. VALORES DE SSE Y R $\mathbf{R}^{2}$ EN EL ENSAYO DE DISPOSITIVOS CENTRÍFUGOS}



Anejo 6

Tabla A. 14. Valores de SSE y R2 para los colectores del ensayo de pulverización centrífuga.

\begin{tabular}{|c|c|c|c|c|c|c|c|c|}
\hline \multirow[b]{2}{*}{ Cabezal } & \multirow[b]{2}{*}{ Rep, } & \multirow[b]{2}{*}{ Vel. } & \multirow[b]{2}{*}{$\begin{array}{l}\text { Caudal } \\
\text { (1/min) }\end{array}$} & \multirow[b]{2}{*}{ Dist,rel, } & \multicolumn{2}{|c|}{$\begin{array}{ll}\begin{array}{l}\text { Ajuste } \\
\text { normal }\end{array} & \text { Log- }\end{array}$} & \multicolumn{2}{|c|}{$\begin{array}{ll}\text { Ajuste } & \text { Rosin- } \\
\text { Rammler } & \end{array}$} \\
\hline & & & & & SSE & $\mathbf{R}^{2}$ & SSE & $\mathbf{R}^{2}$ \\
\hline $\mathrm{c} 1$ & 1 & r1 & 0,416 & $-0,5$ & 0,176 & 0,9548 & 0,085 & 0,9783 \\
\hline $\mathrm{c} 1$ & 1 & r1 & 0,416 & $-0,166$ & 0,123 & 0,9707 & 0,053 & 0,9873 \\
\hline $\mathrm{c} 1$ & 1 & $\mathrm{r} 1$ & 0,416 & 0,166 & 0,080 & 0,9835 & 0,032 & 0,9934 \\
\hline $\mathrm{cl}$ & 1 & $\mathrm{r} 1$ & 0,416 & 0,5 & 0,065 & 0,9905 & 0,038 & 0,9944 \\
\hline $\mathrm{c} 1$ & 1 & r1 & 0,833 & $-0,5$ & 0,254 & 0,9764 & 0,049 & 0,9954 \\
\hline $\mathrm{c} 1$ & 1 & r1 & 0,833 & $-0,166$ & 0,362 & 0,9532 & 0,173 & 0,9777 \\
\hline c1 & 1 & r1 & 0,833 & 0,166 & 0,320 & 0,9623 & 0,095 & 0,9888 \\
\hline c1 & 1 & r1 & 0,833 & 0,5 & 0,203 & 0,9786 & 0,047 & 0,9950 \\
\hline $\mathrm{c1}$ & 1 & $\mathrm{r} 2$ & 0,416 & $-0,5$ & 0,083 & 0,9933 & 0,292 & 0,9766 \\
\hline $\mathrm{c} 1$ & 1 & $\mathrm{r} 2$ & 0,416 & $-0,166$ & 0,316 & 0,9850 & 0,045 & 0,9979 \\
\hline $\mathrm{c} 1$ & 1 & $\mathrm{r} 2$ & 0,416 & 0,166 & 0,140 & 0,9917 & 0,029 & 0,9983 \\
\hline $\mathrm{c} 1$ & 1 & $\mathrm{r} 2$ & 0,416 & 0,5 & 0,038 & 0,9969 & 0,132 & 0,9892 \\
\hline c1 & 1 & r2 & 0,833 & $-0,5$ & 0,193 & 0,9877 & 0,031 & 0,9980 \\
\hline $\mathrm{c} 1$ & 1 & r2 & 0,833 & $-0,166$ & 0,224 & 0,9790 & 0,072 & 0,9932 \\
\hline $\mathrm{c} 1$ & 1 & r2 & 0,833 & 0,166 & 0,258 & 0,9788 & 0,066 & 0,9946 \\
\hline $\mathrm{c} 1$ & 1 & $\mathrm{r} 2$ & 0,833 & 0,5 & 0,077 & 0,9945 & 0,099 & 0,9929 \\
\hline $\mathrm{c} 1$ & 1 & r3 & 0,416 & $-0,5$ & 0,249 & 0,9829 & 0,531 & 0,9634 \\
\hline $\mathrm{c} 1$ & 1 & r3 & 0,416 & $-0,166$ & 0,084 & 0,9963 & 0,358 & 0,9843 \\
\hline $\mathrm{c} 1$ & 1 & r3 & 0,416 & 0,166 & 0,081 & 0,9964 & 0,258 & 0,9886 \\
\hline $\mathrm{c} 1$ & 1 & r3 & 0,416 & 0,5 & 0,322 & 0,9832 & 0,803 & 0,9581 \\
\hline $\mathrm{c} 1$ & 1 & r3 & 0,833 & $-0,5$ & 0,230 & 0,9876 & 0,239 & 0,9871 \\
\hline $\mathrm{c} 1$ & 1 & r3 & 0,833 & $-0,166$ & 0,780 & 0,9650 & 0,286 & 0,9872 \\
\hline $\mathrm{c} 1$ & 1 & r3 & 0,833 & 0,166 & 0,493 & 0,9791 & 0,125 & 0,9947 \\
\hline $\mathrm{c} 1$ & 1 & r3 & 0,833 & 0,5 & 0,503 & 0,9779 & 0,154 & 0,9933 \\
\hline $\mathrm{c} 2$ & 1 & r1 & 0,416 & $-0,5$ & 0,047 & 0,9927 & 0,042 & 0,9935 \\
\hline $\mathrm{c} 2$ & 1 & $\mathrm{r} 1$ & 0,416 & $-0,166$ & 0,083 & 0,9846 & 0,045 & 0,9917 \\
\hline $\mathrm{c} 2$ & 1 & r1 & 0,416 & 0,166 & 0,070 & 0,9833 & 0,017 & 0,9959 \\
\hline $\mathrm{c} 2$ & 1 & r1 & 0,416 & 0,5 & 0,062 & 0,9909 & 0,191 & 0,9719 \\
\hline $\mathrm{c} 2$ & 1 & $\mathrm{r} 1$ & 0,833 & $-0,5$ & 0,206 & 0,9676 & 0,083 & 0,9869 \\
\hline $\mathrm{c} 2$ & 1 & r1 & 0,833 & $-0,166$ & 0,095 & 0,9773 & 0,038 & 0,9909 \\
\hline
\end{tabular}




\begin{tabular}{|c|c|c|c|c|c|c|c|c|}
\hline \multirow[b]{2}{*}{ Cabezal } & \multirow[b]{2}{*}{ Rep, } & \multirow[b]{2}{*}{ Vel. } & \multirow[b]{2}{*}{$\begin{array}{l}\text { Caudal } \\
(1 / \text { min })\end{array}$} & \multirow[b]{2}{*}{ Dist,rel, } & \multicolumn{2}{|c|}{$\begin{array}{l}\text { Ajuste } \\
\text { normal }\end{array}$} & \multicolumn{2}{|c|}{$\begin{array}{l}\text { Ajuste } \\
\text { Rammler }\end{array}$} \\
\hline & & & & & SSE & $\mathbf{R}^{2}$ & SSE & $\mathbf{R}^{2}$ \\
\hline c2 & 1 & r1 & 0,833 & 0,166 & 0,118 & 0,9738 & 0,038 & 0,9917 \\
\hline c2 & 1 & r1 & 0,833 & 0,5 & 0,156 & 0,9796 & 0,039 & 0,9949 \\
\hline $\mathrm{c} 2$ & 1 & r2 & 0,416 & $-0,5$ & 0,064 & 0,9912 & 0,028 & 0,9961 \\
\hline c2 & 1 & $\mathrm{r} 2$ & 0,416 & $-0,166$ & 0,053 & 0,9929 & 0,071 & 0,9905 \\
\hline c2 & 1 & r2 & 0,416 & 0,166 & 0,375 & 0,9580 & 0,169 & 0,9811 \\
\hline c2 & 1 & r2 & 0,416 & 0,5 & 0,192 & 0,9837 & 0,049 & 0,9959 \\
\hline $\mathrm{c} 2$ & 1 & $\mathrm{r} 2$ & 0,833 & $-0,5$ & 0,087 & 0,9914 & 0,041 & 0,9960 \\
\hline c2 & 1 & $\mathrm{r} 2$ & 0,833 & $-0,166$ & 0,137 & 0,9818 & 0,025 & 0,9966 \\
\hline c2 & 1 & $\mathrm{r} 2$ & 0,833 & 0,166 & 0,126 & 0,9779 & 0,053 & 0,9908 \\
\hline c2 & 1 & $\mathrm{r} 2$ & 0,833 & 0,5 & 0,071 & 0,9915 & 0,024 & 0,9972 \\
\hline $\mathrm{c} 2$ & 1 & r3 & 0,416 & $-0,5$ & 0,033 & 0,9976 & 0,089 & 0,9937 \\
\hline c2 & 1 & r3 & 0,416 & $-0,166$ & 0,053 & 0,9953 & 0,091 & 0,9918 \\
\hline c2 & 1 & r3 & 0,416 & 0,166 & 0,168 & 0,9857 & 0,036 & 0,9969 \\
\hline $\mathrm{c} 2$ & 1 & r3 & 0,416 & 0,5 & 0,115 & 0,9916 & 0,062 & 0,9955 \\
\hline $\mathrm{c} 2$ & 1 & r3 & 0,833 & $-0,5$ & 0,051 & 0,9965 & 0,080 & 0,9945 \\
\hline $\mathrm{c} 2$ & 1 & r3 & 0,833 & $-0,166$ & 0,123 & 0,9902 & 0,034 & 0,9973 \\
\hline c2 & 1 & r3 & 0,833 & 0,166 & 0,056 & 0,9944 & 0,062 & 0,9938 \\
\hline $\mathrm{c} 2$ & 1 & r3 & 0,833 & 0,5 & 0,067 & 0,9954 & 0,035 & 0,9976 \\
\hline $\mathrm{c} 1$ & 2 & r1 & 0,416 & $-0,5$ & 0,137 & 0,9617 & 0,073 & 0,9797 \\
\hline c1 & 2 & r1 & 0,416 & $-0,166$ & 0,161 & 0,9617 & 0,092 & 0,9781 \\
\hline c1 & 2 & r1 & 0,416 & 0,166 & 0,082 & 0,9610 & 0,050 & 0,9763 \\
\hline $\mathrm{cl}$ & 2 & r1 & 0,416 & 0,5 & 0,071 & 0,9810 & 0,038 & 0,9897 \\
\hline c1 & 2 & r1 & 0,833 & $-0,5$ & 0,302 & 0,9618 & 0,118 & 0,9850 \\
\hline c1 & 2 & r1 & 0,833 & $-0,166$ & 0,147 & 0,9792 & 0,042 & 0,9941 \\
\hline $\mathrm{c} 1$ & 2 & r1 & 0,833 & 0,166 & 0,305 & 0,9602 & 0,125 & 0,9837 \\
\hline c1 & 2 & r1 & 0,833 & 0,5 & 0,283 & 0,9744 & 0,085 & 0,9923 \\
\hline c1 & 2 & $\mathrm{r} 2$ & 0,416 & $-0,5$ & 0,023 & 0,9970 & 0,046 & 0,9941 \\
\hline c1 & 2 & $\mathrm{r} 2$ & 0,416 & $-0,166$ & 0,042 & 0,9970 & 0,059 & 0,9957 \\
\hline $\mathrm{c} 1$ & 2 & $\mathrm{r} 2$ & 0,416 & 0,166 & 0,162 & 0,9885 & 0,061 & 0,9957 \\
\hline c1 & 2 & $\mathrm{r} 2$ & 0,416 & 0,5 & 0,087 & 0,9881 & 0,045 & 0,9938 \\
\hline c1 & 2 & r2 & 0,833 & $-0,5$ & 0,235 & 0,9830 & 0,072 & 0,9947 \\
\hline $\mathrm{c} 1$ & 2 & r2 & 0,833 & $-0,166$ & 0,181 & 0,9843 & 0,026 & 0,9978 \\
\hline
\end{tabular}


Anejo 6

\begin{tabular}{|c|c|c|c|c|c|c|c|c|}
\hline \multirow[b]{2}{*}{ Cabezal } & \multirow[b]{2}{*}{ Rep, } & \multirow[b]{2}{*}{ Vel. } & \multirow[b]{2}{*}{$\begin{array}{l}\text { Caudal } \\
(1 / \mathrm{min})\end{array}$} & \multirow[b]{2}{*}{ Dist,rel, } & \multicolumn{2}{|c|}{$\begin{array}{l}\text { Ajuste } \\
\text { normal }\end{array}$} & \multicolumn{2}{|c|}{$\begin{array}{l}\text { Ajuste } \\
\text { Rammler }\end{array}$} \\
\hline & & & & & SSE & $\mathbf{R}^{2}$ & SSE & $\mathbf{R}^{2}$ \\
\hline $\mathrm{c} 1$ & 2 & r2 & 0,833 & 0,166 & 0,215 & 0,9817 & 0,060 & 0,9949 \\
\hline $\mathrm{c} 1$ & 2 & $\mathrm{r} 2$ & 0,833 & 0,5 & 0,118 & 0,9916 & 0,030 & 0,9978 \\
\hline $\mathrm{c} 1$ & 2 & r3 & 0,416 & $-0,5$ & 0,083 & 0,9940 & 0,323 & 0,9769 \\
\hline $\mathrm{c} 1$ & 2 & r3 & 0,416 & $-0,166$ & 0,047 & 0,9982 & 0,223 & 0,9916 \\
\hline $\mathrm{c} 1$ & 2 & r3 & 0,416 & 0,166 & 0,185 & 0,9948 & 0,053 & 0,9985 \\
\hline $\mathrm{c} 1$ & 2 & r3 & 0,416 & 0,5 & 0,250 & 0,9781 & 0,551 & 0,9516 \\
\hline $\mathrm{c} 1$ & 2 & r3 & 0,833 & $-0,5$ & 0,185 & 0,9894 & 0,219 & 0,9875 \\
\hline $\mathrm{c} 1$ & 2 & r3 & 0,833 & $-0,166$ & 0,417 & 0,9771 & 0,199 & $\begin{array}{l}0,9891 \\
\end{array}$ \\
\hline $\mathrm{c} 1$ & 2 & r3 & 0,833 & 0,166 & 0,436 & 0,9775 & 0,159 & 0,9918 \\
\hline $\mathrm{c} 1$ & 2 & r3 & 0,833 & 0,5 & 0,220 & 0,9882 & 0,326 & 0,9824 \\
\hline $\mathrm{c} 2$ & 2 & r1 & 0,416 & $-0,5$ & 0,046 & 0,9917 & 0,133 & 0,9759 \\
\hline $\mathrm{c} 2$ & 2 & r1 & 0,416 & $-0,166$ & 0,063 & 0,9865 & 0,042 & 0,9910 \\
\hline $\mathrm{c} 2$ & 2 & r1 & 0,416 & 0,166 & 0,075 & 0,9797 & 0,063 & 0,9828 \\
\hline $\mathrm{c} 2$ & 2 & $\mathrm{r} 1$ & 0,416 & 0,5 & 0,170 & 0,9755 & 0,063 & 0,9909 \\
\hline $\mathrm{c} 2$ & 2 & r1 & 0,833 & $-0,5$ & 0,100 & 0,9836 & 0,024 & 0,9960 \\
\hline $\mathrm{c} 2$ & 2 & $\mathrm{r} 1$ & 0,833 & $-0,166$ & 0,123 & 0,9780 & 0,040 & 0,9929 \\
\hline $\mathrm{c} 2$ & 2 & $\mathrm{r} 1$ & 0,833 & 0,166 & 0,167 & 0,9619 & 0,059 & 0,9865 \\
\hline $\mathrm{c} 2$ & 2 & r1 & 0,833 & 0,5 & 0,126 & 0,9759 & 0,030 & 0,9942 \\
\hline $\mathrm{c} 2$ & 2 & $\mathrm{r} 2$ & 0,416 & $-0,5$ & 0,035 & 0,9959 & 0,069 & 0,9919 \\
\hline $\mathrm{c} 2$ & 2 & $\mathrm{r} 2$ & 0,416 & $-0,166$ & 0,157 & 0,9873 & 0,078 & 0,9937 \\
\hline $\mathrm{c} 2$ & 2 & $\mathrm{r} 2$ & 0,416 & 0,166 & 0,111 & 0,9922 & 0,122 & 0,9914 \\
\hline $\mathrm{c} 2$ & 2 & $\mathrm{r} 2$ & 0,416 & 0,5 & 0,085 & 0,9911 & 0,103 & 0,9893 \\
\hline $\mathrm{c} 2$ & 2 & $\mathrm{r} 2$ & 0,833 & $-0,5$ & 0,237 & 0,9732 & 0,067 & 0,9924 \\
\hline $\mathrm{c} 2$ & 2 & $\mathrm{r} 2$ & 0,833 & $-0,166$ & 0,150 & 0,9814 & 0,035 & 0,9956 \\
\hline $\mathrm{c} 2$ & 2 & $\mathrm{r} 2$ & 0,833 & 0,166 & 0,371 & 0,9648 & 0,133 & 0,9874 \\
\hline $\mathrm{c} 2$ & 2 & $\mathrm{r} 2$ & 0,833 & 0,5 & 0,239 & 0,9747 & 0,092 & 0,9902 \\
\hline $\mathrm{c} 2$ & 2 & r3 & 0,416 & $-0,5$ & 0,111 & 0,9867 & 0,041 & 0,9951 \\
\hline $\mathrm{c} 2$ & 2 & r3 & 0,416 & $-0,166$ & 0,071 & 0,9947 & 0,077 & 0,9943 \\
\hline c2 & 2 & r3 & 0,416 & 0,166 & 0,041 & 0,9970 & 0,100 & 0,9927 \\
\hline $\mathrm{c} 2$ & 2 & r3 & 0,416 & 0,5 & 0,071 & 0,9945 & 0,021 & 0,9984 \\
\hline c2 & 2 & r3 & 0,833 & $-0,5$ & 0,084 & 0,9938 & 0,021 & 0,9985 \\
\hline $\mathrm{c} 2$ & 2 & r3 & 0,833 & $-0,166$ & 0,168 & 0,9825 & 0,046 & 0,9952 \\
\hline
\end{tabular}




\begin{tabular}{|c|c|c|c|c|c|c|c|c|}
\hline \multirow[b]{2}{*}{ Cabezal } & \multirow[b]{2}{*}{ Rep, } & \multirow[b]{2}{*}{ Vel. } & \multirow[b]{2}{*}{$\begin{array}{l}\text { Caudal } \\
\text { (l/min) }\end{array}$} & \multirow[b]{2}{*}{ Dist,rel, } & \multicolumn{2}{|c|}{$\begin{array}{l}\text { Ajuste } \\
\text { normal }\end{array}$} & \multicolumn{2}{|c|}{$\begin{array}{l}\text { Ajuste } \\
\text { Rammler }\end{array}$} \\
\hline & & & & & SSE & $\mathbf{R}^{2}$ & SSE & $\mathbf{R}^{2}$ \\
\hline c2 & 2 & r3 & 0,833 & 0,166 & 0,228 & 0,9827 & 0,050 & 0,9962 \\
\hline c2 & 2 & r3 & 0,833 & 0,5 & 0,050 & 0,9957 & 0,068 & 0,9941 \\
\hline $\mathrm{c} 1$ & 3 & r1 & 0,416 & $-0,5$ & 0,109 & 0,9716 & 0,061 & 0,9840 \\
\hline $\mathrm{c} 1$ & 3 & r1 & 0,416 & $-0,166$ & 0,168 & 0,9503 & 0,131 & 0,9611 \\
\hline c1 & 3 & r1 & 0,416 & 0,166 & 0,100 & 0,9612 & 0,058 & 0,9774 \\
\hline c1 & 3 & r1 & 0,416 & 0,5 & 0,046 & 0,9828 & 0,019 & 0,9931 \\
\hline $\mathrm{c} 1$ & 3 & r1 & 0,833 & $-0,5$ & 0,175 & 0,9682 & 0,051 & 0,9906 \\
\hline $\mathrm{c} 1$ & 3 & r1 & 0,833 & $-0,166$ & 0,144 & 0,9766 & 0,060 & 0,9903 \\
\hline c1 & 3 & r1 & 0,833 & 0,166 & 0,227 & 0,9605 & 0,126 & 0,9781 \\
\hline c1 & 3 & r1 & 0,833 & 0,5 & 0,161 & 0,9844 & 0,029 & 0,9972 \\
\hline $\mathrm{c} 1$ & 3 & r2 & 0,416 & $-0,5$ & 0,047 & 0,9906 & 0,057 & 0,9885 \\
\hline $\mathrm{c} 1$ & 3 & $\mathrm{r} 2$ & 0,416 & $-0,166$ & 0,174 & 0,9859 & 0,048 & 0,9961 \\
\hline c1 & 3 & r2 & 0,416 & 0,166 & 0,224 & 0,9829 & 0,048 & 0,9963 \\
\hline c1 & 3 & r2 & 0,416 & 0,5 & 0,042 & 0,9958 & 0,023 & 0,9977 \\
\hline $\mathrm{c1}$ & 3 & $\mathrm{r} 2$ & 0,833 & $-0,5$ & 0,065 & 0,9953 & 0,027 & 0,9980 \\
\hline c1 & 3 & $\mathrm{r} 2$ & 0,833 & $-0,166$ & 0,300 & 0,9731 & 0,102 & 0,9908 \\
\hline $\mathrm{c} 1$ & 3 & $\mathrm{r} 2$ & 0,833 & 0,166 & 0,137 & 0,9878 & 0,027 & 0,9976 \\
\hline c1 & 3 & $\mathrm{r} 2$ & 0,833 & 0,5 & 0,184 & 0,9881 & 0,036 & 0,9977 \\
\hline $\mathrm{c} 1$ & 3 & r3 & 0,416 & $-0,5$ & 0,052 & 0,9962 & 0,244 & 0,9823 \\
\hline c1 & 3 & r3 & 0,416 & $-0,166$ & 0,103 & 0,9964 & 0,472 & 0,9837 \\
\hline c1 & 3 & r3 & 0,416 & 0,166 & 0,051 & 0,9981 & 0,233 & 0,9914 \\
\hline $\mathrm{cl}$ & 3 & r3 & 0,416 & 0,5 & 0,544 & 0,9598 & 0,991 & 0,9267 \\
\hline c1 & 3 & r3 & 0,833 & $-0,5$ & 0,044 & 0,9975 & 0,185 & 0,9894 \\
\hline c1 & 3 & r3 & 0,833 & $-0,166$ & 0,420 & 0,9793 & 0,092 & 0,9955 \\
\hline $\mathrm{c} 1$ & 3 & r3 & 0,833 & 0,166 & 0,370 & 0,9817 & 0,073 & 0,9964 \\
\hline c1 & 3 & r3 & 0,833 & 0,5 & 0,155 & 0,9920 & 0,226 & 0,9883 \\
\hline $\mathrm{c} 2$ & 3 & r1 & 0,416 & $-0,5$ & 0,117 & 0,9818 & 0,059 & 0,9909 \\
\hline c2 & 3 & r1 & 0,416 & $-0,166$ & 0,181 & 0,9652 & 0,089 & 0,9829 \\
\hline c2 & 3 & r1 & 0,416 & 0,166 & 0,100 & 0,9737 & 0,041 & 0,9891 \\
\hline c2 & 3 & r1 & 0,416 & 0,5 & 0,173 & 0,9701 & 0,072 & 0,9876 \\
\hline c2 & 3 & r1 & 0,833 & $-0,5$ & 0,240 & 0,9590 & 0,089 & 0,9848 \\
\hline c2 & 3 & r1 & 0,833 & $-0,166$ & 0,231 & 0,9484 & 0,127 & 0,9716 \\
\hline
\end{tabular}


Anejo 6

\begin{tabular}{|c|c|c|c|c|c|c|c|c|}
\hline \multirow[b]{2}{*}{ Cabezal } & \multirow[b]{2}{*}{ Rep, } & \multirow[b]{2}{*}{ Vel. } & \multirow[b]{2}{*}{$\begin{array}{l}\text { Caudal } \\
\text { (1/min) }\end{array}$} & \multirow[b]{2}{*}{ Dist,rel, } & \multicolumn{2}{|c|}{$\begin{array}{ll}\text { Ajuste } & \text { Log- } \\
\text { normal } & \end{array}$} & \multicolumn{2}{|c|}{$\begin{array}{l}\text { Ajuste } \\
\text { Rammler }\end{array}$} \\
\hline & & & & & SSE & $\mathbf{R}^{2}$ & SSE & $\mathbf{R}^{2}$ \\
\hline c2 & 3 & r1 & 0,833 & 0,166 & 0,209 & 0,9594 & 0,082 & 0,9840 \\
\hline c2 & 3 & r1 & 0,833 & 0,5 & 0,201 & 0,9535 & 0,086 & 0,9801 \\
\hline c2 & 3 & r2 & 0,416 & $-0,5$ & 0,096 & 0,9820 & 0,045 & 0,9916 \\
\hline $\mathrm{c} 2$ & 3 & $\mathrm{r} 2$ & 0,416 & $-0,166$ & 0,095 & 0,9870 & 0,038 & 0,9948 \\
\hline c2 & 3 & r2 & 0,416 & 0,166 & 0,088 & 0,9903 & 0,040 & 0,9956 \\
\hline c2 & 3 & r2 & 0,416 & 0,5 & 0,131 & 0,9823 & 0,054 & 0,9927 \\
\hline c2 & 3 & r2 & 0,833 & $\begin{array}{l}-0,5 \\
\end{array}$ & 0,063 & 0,9911 & 0,076 & 0,9893 \\
\hline c2 & 3 & $\mathrm{r} 2$ & 0,833 & $-0,166$ & 0,112 & 0,9820 & 0,024 & 0,9961 \\
\hline c2 & 3 & r2 & 0,833 & 0,166 & 0,088 & 0,9847 & 0,028 & 0,9951 \\
\hline c2 & 3 & r2 & 0,833 & 0,5 & 0,300 & 0,9669 & 0,109 & 0,9880 \\
\hline $\mathrm{c} 2$ & 3 & r3 & 0,416 & $-0,5$ & 0,055 & 0,9933 & 0,135 & 0,9834 \\
\hline $\mathrm{c} 2$ & 3 & r3 & 0,416 & $-0,166$ & 0,083 & 0,9935 & 0,195 & 0,9846 \\
\hline c2 & 3 & r3 & 0,416 & 0,166 & 0,129 & 0,9925 & 0,038 & 0,9978 \\
\hline c2 & 3 & r3 & 0,416 & 0,5 & 0,086 & 0,9943 & 0,072 & 0,9953 \\
\hline c2 & 3 & r3 & 0,833 & $-0,5$ & 0,152 & 0,9889 & 0,092 & 0,9933 \\
\hline c2 & 3 & r3 & 0,833 & $-0,166$ & 0,053 & 0,9941 & 0,055 & 0,9939 \\
\hline $\mathrm{c} 2$ & 3 & r3 & 0,833 & 0,166 & 0,220 & 0,9820 & 0,050 & 0,9959 \\
\hline c2 & 3 & r3 & 0,833 & 0,5 & 0,192 & 0,9879 & 0,024 & 0,9985 \\
\hline
\end{tabular}





\section{ANEJO 7. RESULTADOS DEL EFECTO DE LOS \\ FACTORES SOBRE LAS VARIABLES EN EL ENSAYO DE DISPOSITIVOS CENTRÍFUGOS}

\section{Efecto de los factores sobre la variable mediana del diámetro}

La interacción entre el tipo de cabezal y el caudal fue significativa para la variable mediana del diámetro (Tabla A. 15). Los cabezales produjeron tamaños de diámetros de impacto con una mediana similar cuando el caudal pulverizado fue de 0,42 1/min (Figura A. 24). Sin embargo, cuando se duplicó el caudal, el valor de la mediana aumentó y fue mayor para el cabezal 2.

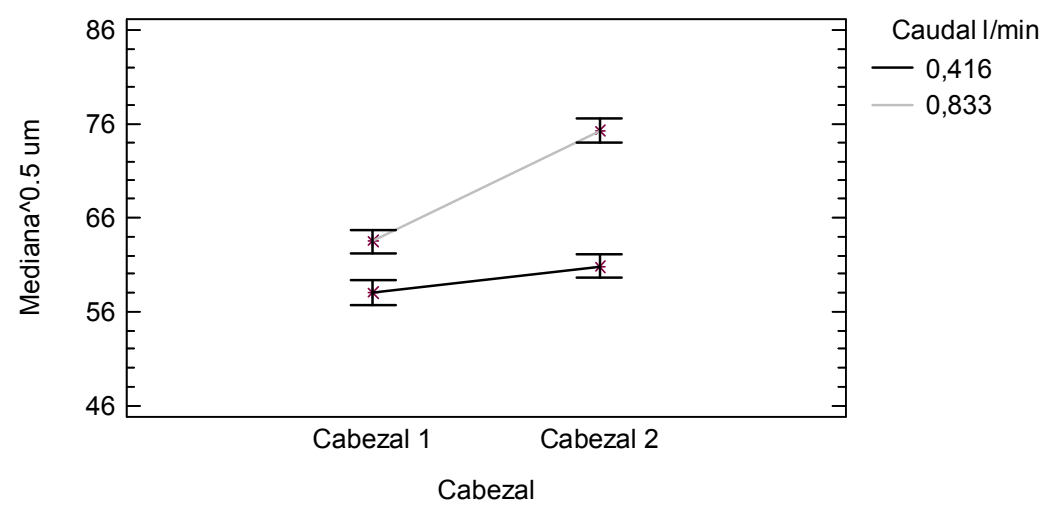

Figura A. 24. Interacción del factor cabezal por el factor caudal para la variable mediana del diámetro. Intervalos LSD a un nivel de confianza del $95 \%$.

La velocidad de giro del motor influyó significativamente sobre la mediana del diámetro de los impactos (Tabla A. 15). El aumento de r1 a r2 incrementó significativamente el valor de la mediana en la misma proporción en los 2 cabezales. El cabezal 2 produjo en cualquier caso valores significativamente mayores de mediana que el 1 . Al pasar de r2 a r3 el incremento en el valor de la mediana fue mayor en el cabezal 1 que en el cabezal 2, por lo que las medianas se igualaron hasta no alcanzar diferencias significativas entre ellas (Figura A. 25). 


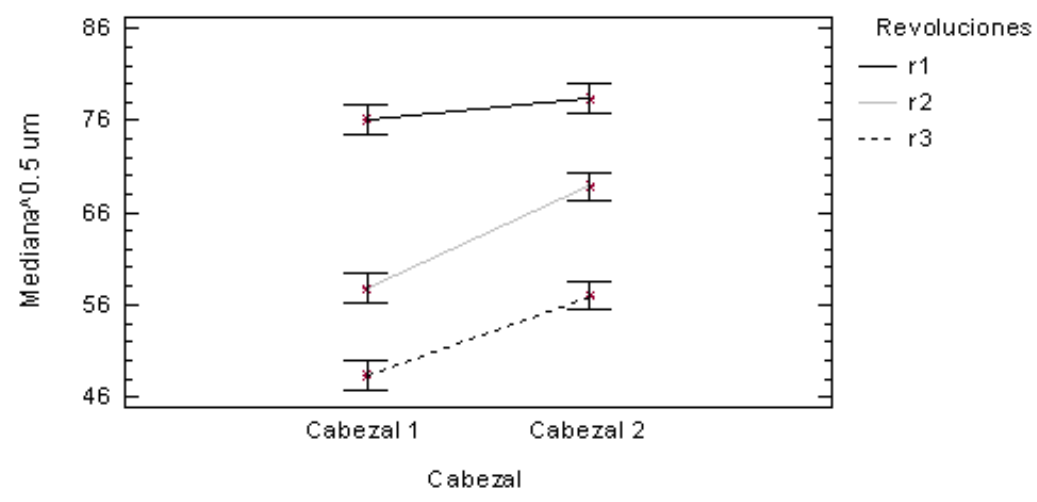

Figura A. 25. Interacción del factor cabezal por el factor velocidad de giro para la variable mediana del diámetro. Intervalos LSD a un nivel de confianza del $95 \%$.

La interacción entre la velocidad de giro del motor y la posición del colector resultó significativa para la mediana del diámetro de los impactos (Tabla A. 15). Para las velocidades de giro más altas ( $\mathrm{r} 2$ y r3) la mediana fue menor en los colectores centrales y mayor en los extremos (Figura A. 26). Sin embargo, para la velocidad de giro más baja (r1) la mediana del diámetro de los impactos fue igual en los colectores extremos que en el central C1 y algo más baja en el colector $-\mathrm{C} 1$.

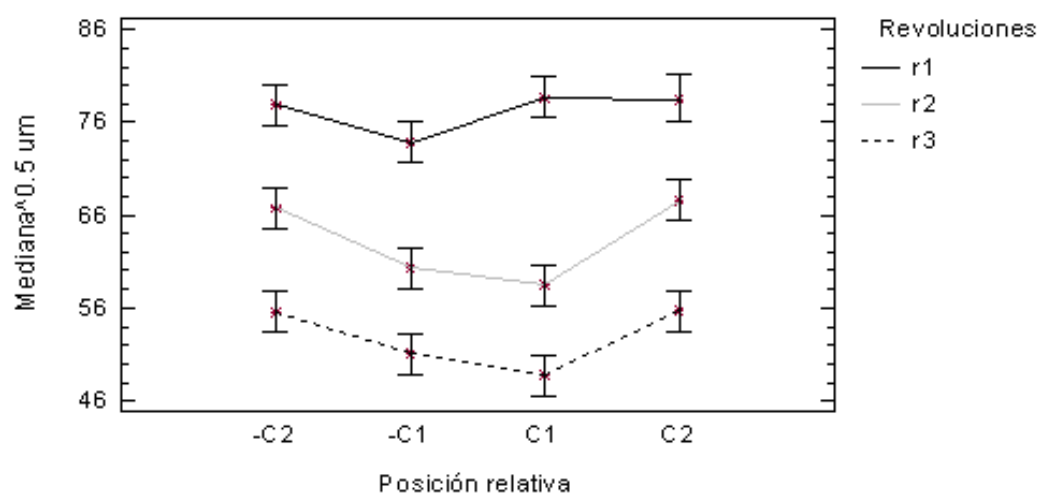

Figura A. 26. Interacción del factor posición relativa por el factor velocidad de giro para la variable mediana del diámetro. Intervalos LSD a un nivel de confianza del $95 \%$. 
Tabla A. 15. Resultado del ANOVA para la variable mediana del diámetro a un nivel de confianza del $95 \%$.

\begin{tabular}{|c|c|c|c|c|c|}
\hline Suma de & cuadrados & GL & Cuadrado Medio & Cociente-F & P-Valor \\
\hline \multicolumn{6}{|l|}{ EFECTOS PRINCIPALES } \\
\hline A:Cabezal & 1866,31 & 1 & 1866,31 & 65,05 & 0,0000 \\
\hline B:Caudal & 3463,3 & 1 & 3463,3 & 120,71 & 0,0000 \\
\hline C:colector & 922,282 & 3 & 307,427 & 10,72 & 0,0000 \\
\hline D:Revoluciones & 13675,4 & 2 & 6837,68 & 238,33 & 0,0000 \\
\hline \multicolumn{6}{|l|}{ INTERACCIONES } \\
\hline $\mathrm{AB}$ & 716,521 & 1 & 716,521 & 24,97 & 0,0000 \\
\hline $\mathrm{AC}$ & 206,012 & 3 & 68,6708 & 2,39 & 0,0720 \\
\hline $\mathrm{AD}$ & 479,741 & 2 & 239,87 & 8,36 & 0,0004 \\
\hline $\mathrm{BC}$ & 178,337 & 3 & 59,4457 & 2,07 & 0,1078 \\
\hline $\mathrm{BD}$ & 76,8453 & 2 & 38,4227 & 1,34 & 0,2661 \\
\hline $\mathrm{CD}$ & 384,101 & 6 & 64,0168 & 2,23 & 0,0450 \\
\hline RESIDUOS & 3299,41 & 115 & 28,6905 & & \\
\hline TOTAL (CORREGIDO) & 25498,2 & 139 & & & \\
\hline
\end{tabular}

Efecto de los factores sobre la variable D25 del diámetro

En el cabezal 1, el caudal no influyó sobre la variable D25 del diámetro (Figura A. 27). Además, los valores observados no se diferenciaron significativamente del cabezal 2 con el caudal de 0,42 1/min. Sin embargo, el cabezal 2 con el caudal de $0,83 \mathrm{l} / \mathrm{min}$ produjo impactos con un D25 significativamente mayor que con el de $0,42 \mathrm{l} / \mathrm{min}$. 


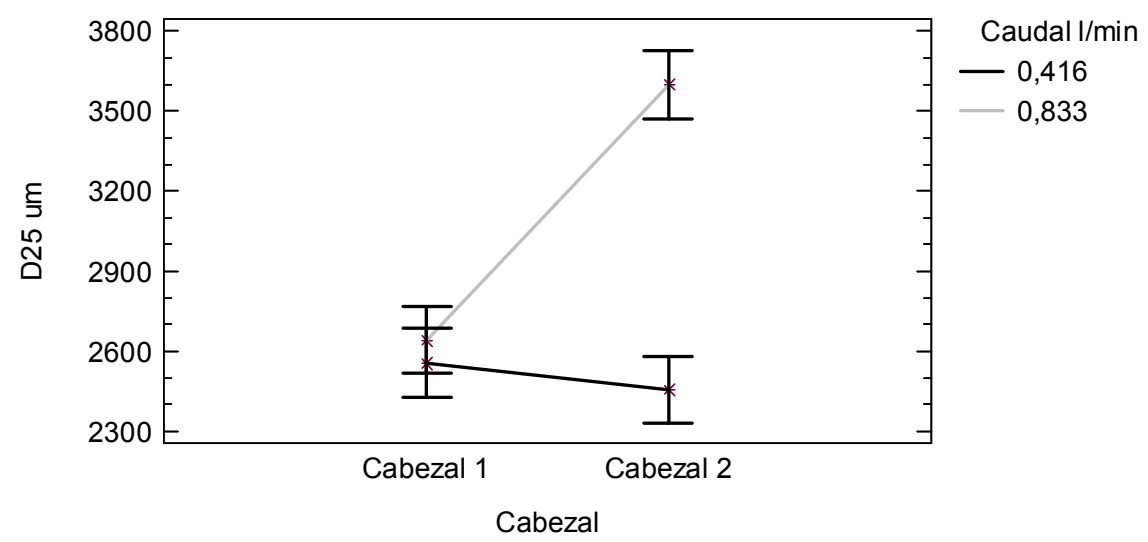

Figura A. 27. Interacción del factor cabezal por el factor caudal para la variable D25 del diámetro. Intervalos LSD a un nivel de confianza del $95 \%$.

La interacción entre el tipo de cabezal y su velocidad de giro fue significativa (Tabla A. 16), y las tendencias fueron similares a las observadas en la variable mediana del diámetro de los impactos. El descenso de la velocidad de giro del motor incrementó el D25 (Figura A. 28). La variable obtuvo valores significativamente mayor para el cabezal 2 a las velocidades r2 y r3. Sin embargo, cuando la velocidad de giro disminuyó a r1 los cabezales produjeron impactos con igual valor de D25.

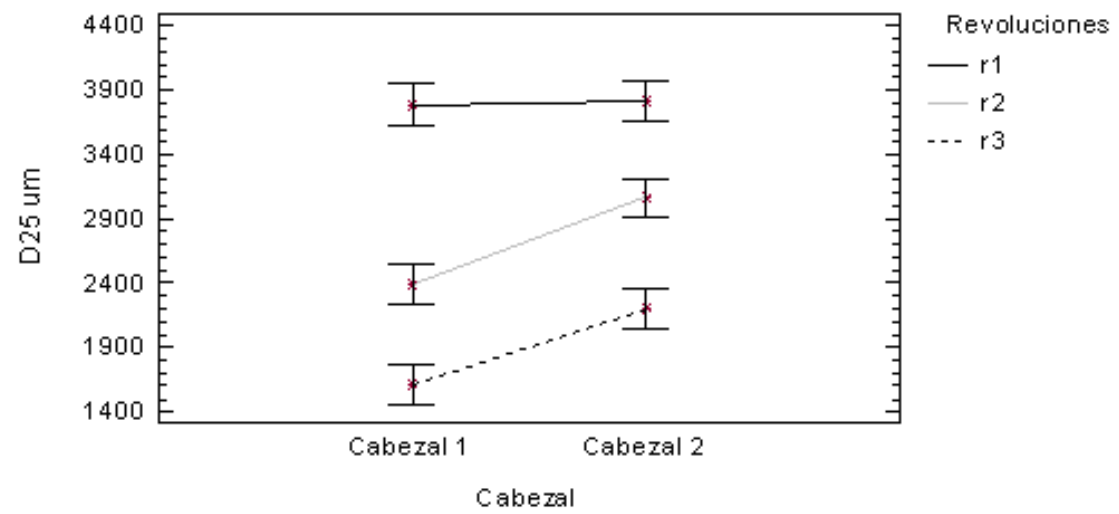

Figura A. 28. Interacción del factor cabezal por el factor velocidad de giro para la variable D25 del diámetro. Intervalos LSD a un nivel de confianza del $95 \%$. 
La interacción entre la velocidad de giro del motor y la posición relativa del colector también fue significativa (Tabla A. 16) y con tendencias muy similares a las observadas para la mediana. Las velocidades de giro $\mathrm{r} 2$ y r3 produjeron impactos menores en los colectores centrales que en los extremos (Figura A. 29). Sin embargo, a la velocidad r1 se generaron impactos con menor valor de D25 únicamente en el colector $-\mathrm{C} 1$.

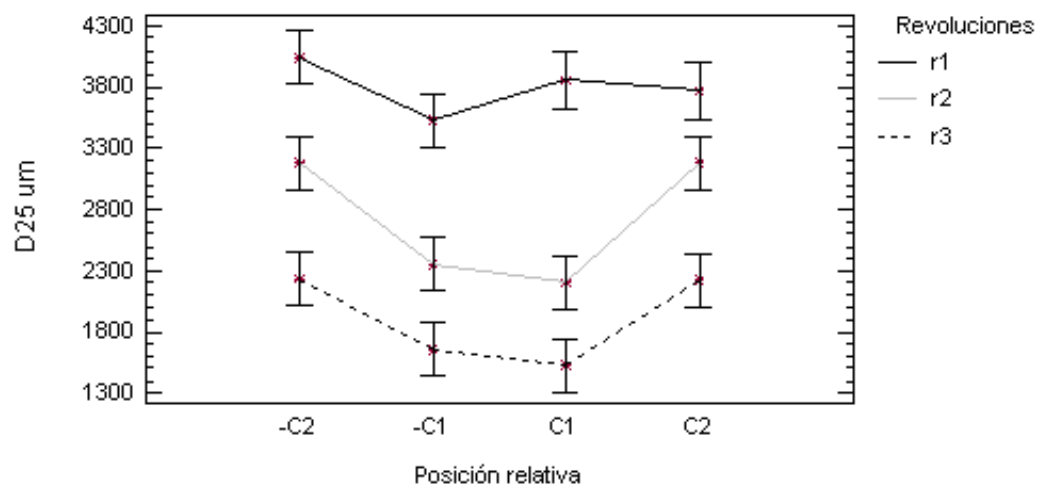

Figura A. 29. Interacción del factor posición relativa por el factor velocidad de giro para la variable D25 del diámetro. Intervalos LSD a un nivel de confianza del $95 \%$. 
Tabla A. 16. Resultado del ANOVA para la variable D25 del diámetro a un nivel de confianza del $95 \%$.

\begin{tabular}{|c|c|c|c|c|c|}
\hline Suma de & cuadrados & GL & Cuadrado Medio & Cociente-F & P-Valor \\
\hline \multicolumn{6}{|l|}{ EFECTOS PRINCIPALES } \\
\hline A:Cabezal & $6,41714 \mathrm{E} 6$ & 1 & $6,41714 \mathrm{E} 6$ & 22,25 & 0,0000 \\
\hline B:Caudal & $1,3181 \mathrm{E} 7$ & 1 & $1,3181 \mathrm{E} 7$ & 45,71 & 0,0000 \\
\hline C:colector & $1,21813 \mathrm{E} 7$ & 3 & $4,06044 \mathrm{E} 6$ & 14,08 & 0,0000 \\
\hline D: Revoluciones & $8,2683 \mathrm{E} 7$ & 2 & $4,13415 \mathrm{E} 7$ & 143,35 & 0,0000 \\
\hline \multicolumn{6}{|l|}{ INTERACCIONES } \\
\hline $\mathrm{AB}$ & $9,84589 \mathrm{E} 6$ & 1 & $9,84589 \mathrm{E} 6$ & 34,14 & 0,0000 \\
\hline $\mathrm{AC}$ & $1,23237 \mathrm{E} 6$ & 3 & 410791,0 & 1,42 & 0,2392 \\
\hline $\mathrm{AD}$ & $2,82555 \mathrm{E} 6$ & 2 & $1,41277 \mathrm{E} 6$ & 4,90 & 0,0091 \\
\hline $\mathrm{BC}$ & $1,2409 \mathrm{E} 6$ & 3 & 413635,0 & 1,43 & 0,2364 \\
\hline $\mathrm{BD}$ & 550344,0 & 2 & 275172,0 & 0,95 & 0,3881 \\
\hline $\mathrm{CD}$ & $3,7702 \mathrm{E} 6$ & 6 & 628367,0 & 2,18 & 0,0499 \\
\hline RESIDUOS & $3,3453 E 7$ & 116 & 288388,0 & & \\
\hline TOTAL (CORREGIDO) & 1, & $71 \mathrm{E} 8$ & 140 & & \\
\hline
\end{tabular}

\section{Efecto de los factores sobre la variable D75 del diámetro}

Los cabezales 1 y 2 con el caudal de 0,42 1/min no presentaron diferencias significativas en los valores de D75 del diámetro de los impactos (Figura A. 30). Al duplicar el caudal, el valor de D75 aumentó para los dos cabezales. Sin embargo, en el cabezal 2 aumentó en mayor proporción que en el cabezal 1, dando lugar a diferencias significativas de D75 entre ellos. 


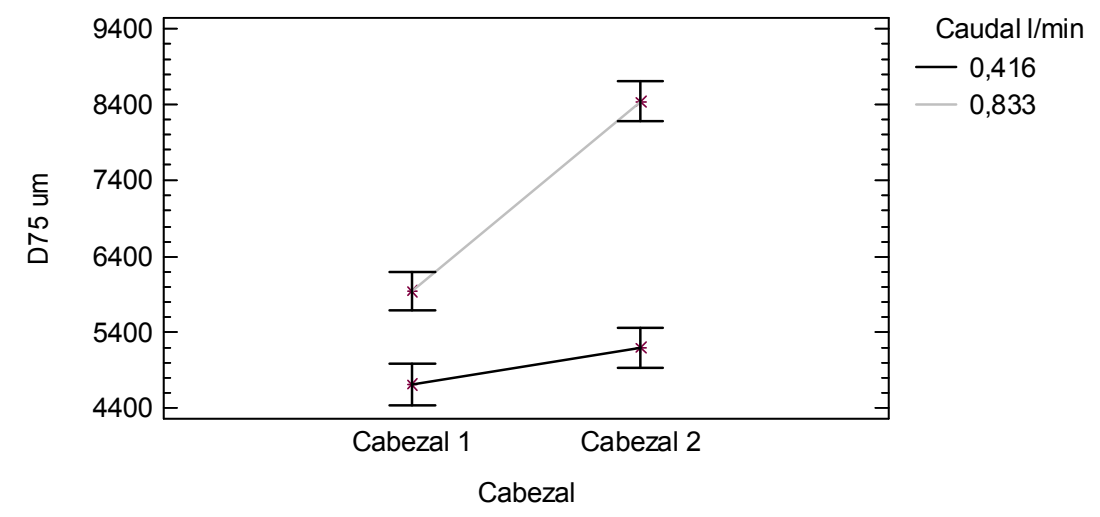

Figura A. 30. Interacción del factor cabezal por el factor caudal para la variable D75 del diámetro. Intervalos LSD a un nivel de confianza del $95 \%$.

La interacción entre los cabezales y la velocidad de giro del motor fue significativa (Tabla A. 17) y las tendencias fueron similares a las que se observaron para las variables mediana y D25 (Figura A. 31). Al reducir la velocidad de giro del motor, los valores de D75 aumentaron en ambos cabezales. Para el cabezal 2 fueron significativamente mayores a las velocidades de giro $\mathrm{r} 2$ y r3. Sin embargo, a la velocidad de giro $\mathrm{r} 1$ no se obtuvieron diferencias significativas entre los cabezales.

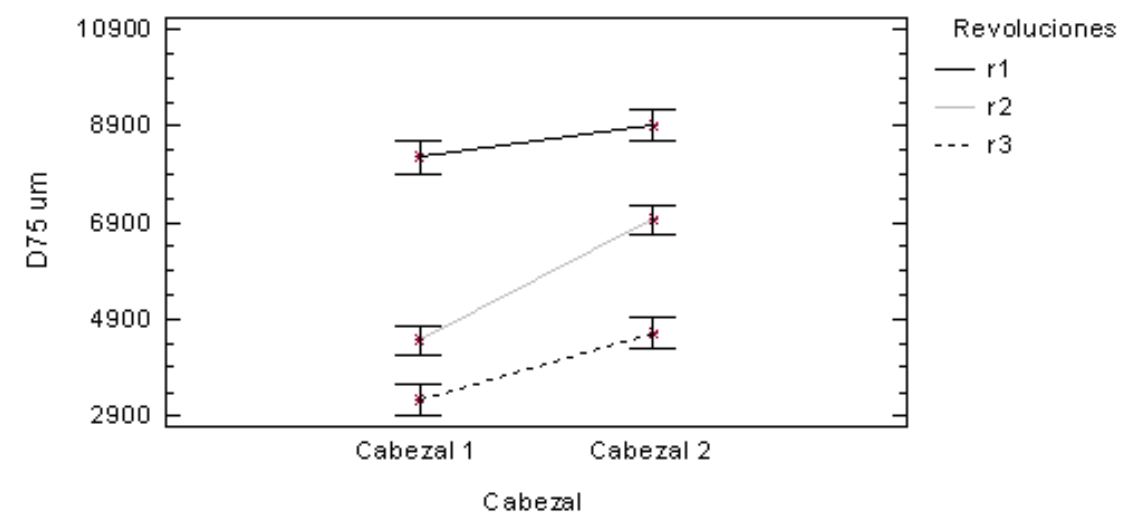

Figura A. 31. Interacción del factor cabezal por el factor velocidad de giro para la variable D75 del diámetro. Intervalos LSD a un nivel de confianza del $95 \%$. 
A las velocidades de giro $\mathrm{r} 2$ y r3 se obtuvieron valores de D75 menores en los colectores centrales que en los extremos (Figura A. 32). Sin embargo, a la velocidad $\mathrm{r} 1$ no se observa una tendencia clara.

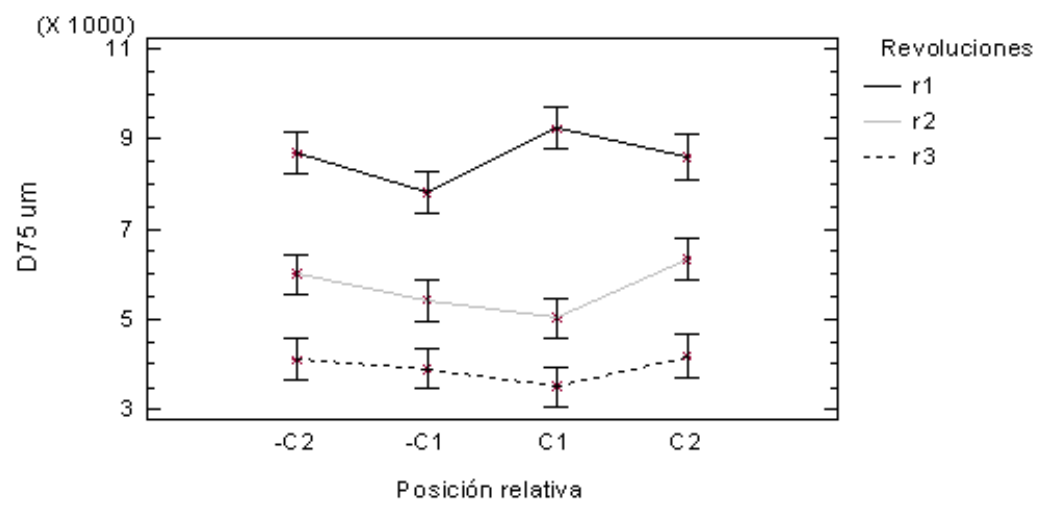

Figura A. 32. Interacción del factor posición relativa por el factor velocidad de giro para la variable D75 del diámetro. Intervalos LSD a un nivel de confianza del $95 \%$.

Tabla A. 17. Resultado del ANOVA para la variable D75 del diámetro a un nivel de confianza del $95 \%$.

\begin{tabular}{|c|c|c|c|c|c|}
\hline Suma de & cuadrados & GL & Cuadrado Medio & Cociente-F & P-Valor \\
\hline \multicolumn{6}{|l|}{ EFECTOS PRINCIPALES } \\
\hline A:Cabezal & $7,88814 \mathrm{E} 7$ & 1 & $7,88814 \mathrm{E} 7$ & 63,03 & 0,0000 \\
\hline B:Caudal & $1,77299 \mathrm{E} 8$ & 1 & $1,77299 \mathrm{E} 8$ & 141,68 & 0,0000 \\
\hline C:colector & $9,71702 \mathrm{E} 6$ & 3 & $3,23901 \mathrm{E} 6$ & 2,59 & 0,0563 \\
\hline D: Revoluciones & $5,09788 \mathrm{E} 8$ & 2 & $2,54894 \mathrm{E} 8$ & 203,68 & 0,0000 \\
\hline \multicolumn{6}{|l|}{ INTERACCIONES } \\
\hline$A B$ & $3,5748 \mathrm{E} 7$ & 1 & $3,5748 \mathrm{E} 7$ & 28,57 & 0,0000 \\
\hline $\mathrm{AC}$ & $7,41344 \mathrm{E} 6$ & 3 & $2,47115 \mathrm{E} 6$ & 1,97 & 0,1216 \\
\hline $\mathrm{AD}$ & $1,99806 \mathrm{E} 7$ & 2 & $9,99031 \mathrm{E} 6$ & 7,98 & 0,0006 \\
\hline $\mathrm{BC}$ & 831101,0 & 3 & 277034,0 & 0,22 & 0,8814 \\
\hline $\mathrm{BD}$ & $5,68356 \mathrm{E} 6$ & 2 & $2,84178 \mathrm{E} 6$ & 2,27 & 0,1078 \\
\hline $\mathrm{CD}$ & $1,71181 \mathrm{E} 7$ & 6 & $2,85301 \mathrm{E} 6$ & 2,28 & 0,0407 \\
\hline RESIDUOS & \multicolumn{2}{|c|}{$1,45165 \mathrm{E} 8$} & \multicolumn{2}{|c|}{$1,25142 \mathrm{E} 6$} & \\
\hline TOTAL (CORREGIDO) & 1,0 & $2 \mathrm{E} 9$ & 140 & & \\
\hline
\end{tabular}


Efecto de los factores sobre la variable intervalo intercuartílico del diámetro

La interacción entre el caudal y el cabezal para la variable intervalo intercuartílico fue significativa (Tabla A. 18). El cabezal 1 produjo intervalos intercuartílicos significativamente menores que el cabezal 2 para los dos caudales (Figura A. 33). El aumento de caudal de $0,421 / \mathrm{min}$ a $0,831 / \mathrm{min}$ produjo un aumento significativo del intervalo intercuartílico del los impactos producidos por los dos cabezales, sin embargo, el amento fue mayor para el cabezal 2.

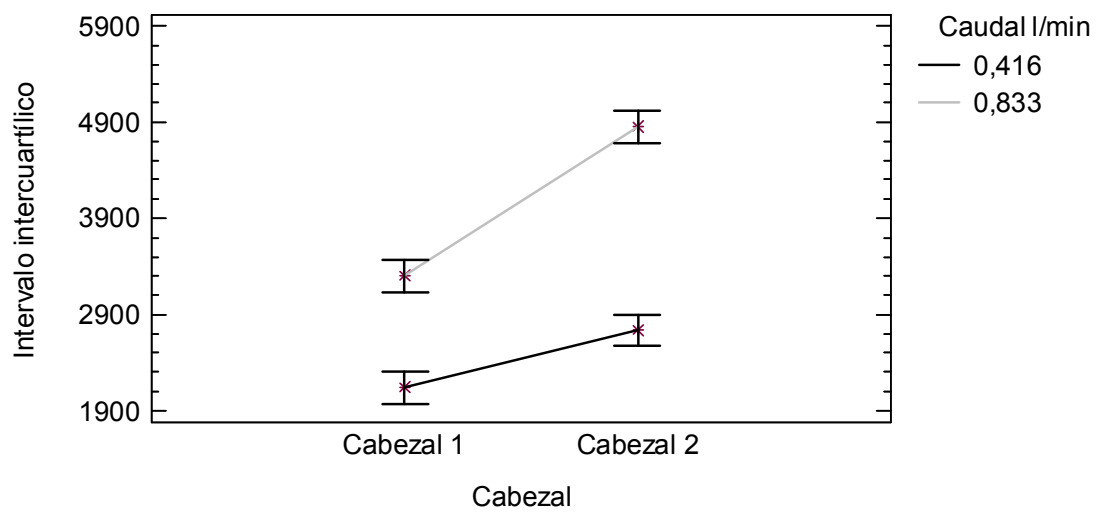

Figura A. 33. Interacción del factor cabezal por el factor caudal para la variable intervalo intercuartílico del diámetro. Intervalos LSD a un nivel de confianza del $95 \%$.

También la interacción entre el factor cabezal y el factor caudal fue significativa (Tabla A. 18). Con el cabezal 2 se obtuvieron intervalos intercuartílicos significativamente mayores para las tres velocidades de giro estudiadas (Figura A. 34). Sin embargo estas diferencias fueron mayores para r2. En los dos cabezales se observa que una disminución de la velocidad de giro del motor incrementó significativamente el intervalo intercuartílico. 


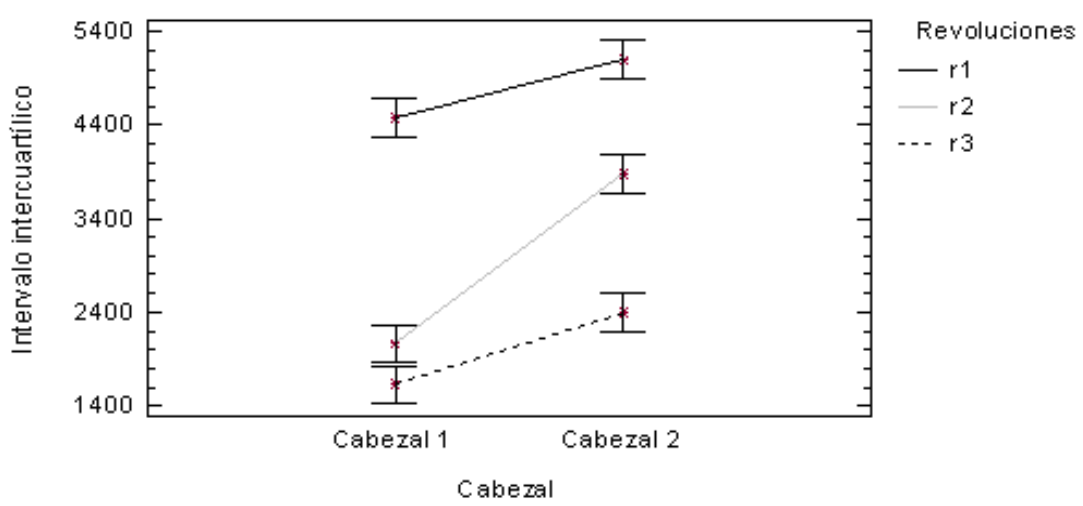

Figura A. 34. Interacción del factor cabezal por el factor velocidad de giro para la variable intervalo intercuartílico del diámetro. Intervalos $L S D$ a un nivel de confianza del $95 \%$.

Igualmente, la interacción entre la velocidad de giro y la posición relativa de los colectores fue significativa para la variable intervalo intercuartílico (Tabla A. 18). No se observaron diferencias significativas entre las diferentes posiciones de los colectores a las velocidades r2 y r3 (Figura A. 35). Sin embargo, a la velocidad $\mathrm{r} 1$, el colector $\mathrm{C} 1$ presentó valores significativamente mayores en $\mathrm{C} 1$.

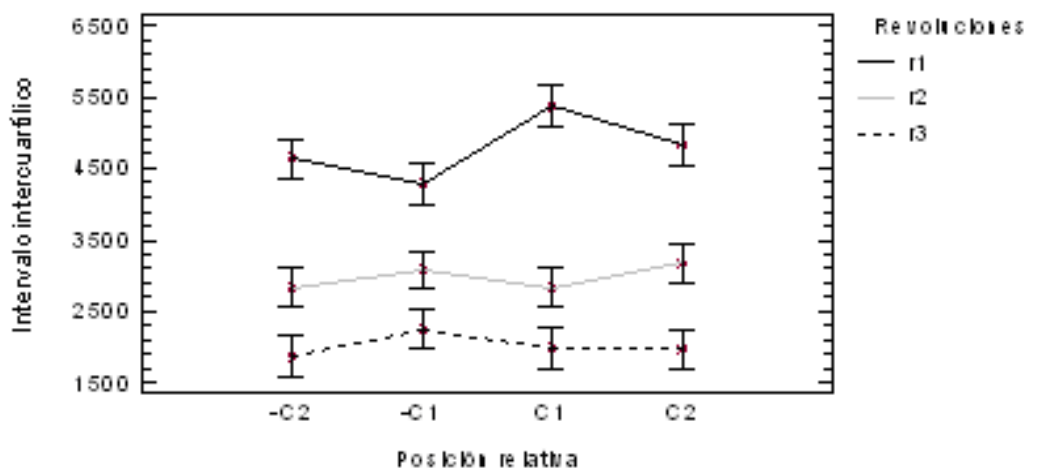

Figura A. 35. Interacción del factor posición relativa por el factor velocidad de giro para la variable intervalo intercuartílico del diámetro. Intervalos LSD a un nivel de confianza del $95 \%$. 
Tabla A. 18. Resultado del ANOVA para la variable intervalo intercuartílico del diámetro a un nivel de confianza del $95 \%$.

\begin{tabular}{|c|c|c|c|c|c|}
\hline Suma de & cuadrados & GL & Cuadrado Medio & Cociente-F & P-Valor \\
\hline \multicolumn{6}{|l|}{ EFECTOS PRINCIPALES } \\
\hline A:Cabezal & $4,03446 \mathrm{E} 7$ & 1 & $4,03446 \mathrm{E} 7$ & 84,72 & 0,0000 \\
\hline B:Caudal & $9,3798 \mathrm{E} 7$ & 1 & $9,3798 \mathrm{E} 7$ & 196,96 & 0,0000 \\
\hline C:colector & $1,65194 \mathrm{E} 6$ & 3 & 550646,0 & 1,16 & 0,3296 \\
\hline D:Revoluciones & $1,82523 \mathrm{E} 8$ & 2 & $9,12616 \mathrm{E} 7$ & 191,63 & 0,0000 \\
\hline \multicolumn{6}{|l|}{ INTERACCIONES } \\
\hline $\mathrm{AB}$ & $8,09996 \mathrm{E} 6$ & 1 & $8,09996 \mathrm{E} 6$ & 17,01 & 0,0001 \\
\hline $\mathrm{AC}$ & $2,61656 \mathrm{E} 6$ & 3 & 872187,0 & 1,83 & 0,1453 \\
\hline $\mathrm{AD}$ & $9,90435 \mathrm{E} 6$ & 2 & $4,95218 \mathrm{E} 6$ & 10,40 & 0,0001 \\
\hline $\mathrm{BC}$ & 423362,0 & 3 & 141121,0 & 0,30 & 0,8280 \\
\hline $\mathrm{BD}$ & $5,91914 \mathrm{E} 6$ & 2 & $2,95957 \mathrm{E} 6$ & 6,21 & 0,0027 \\
\hline $\mathrm{CD}$ & $7,64066 \mathrm{E} 6$ & 6 & $1,27344 \mathrm{E} 6$ & 2,67 & 0,0182 \\
\hline RESIDUOS & $5,52423 \mathrm{E} 7$ & 116 & 476227,0 & & \\
\hline TOTAL (CORREGIDO) & $4,07804 \mathrm{E} 8$ & 140 & & & \\
\hline
\end{tabular}

Efecto de los factores sobre la variable recubrimiento

La interacción entre los cabezales y los caudales para la variable recubrimiento fue significativa (Tabla A. 19). Aunque no se aprecian diferencias significativas entre los cabezales para el caudal de 0,42 1/min, cuando se duplica el caudal, los recubrimientos aumentaron significativamente, pero no en la misma proporción. El recubrimiento producido con el cabezal 2 fue entonces significativamente mayor (Figura A. 36). 


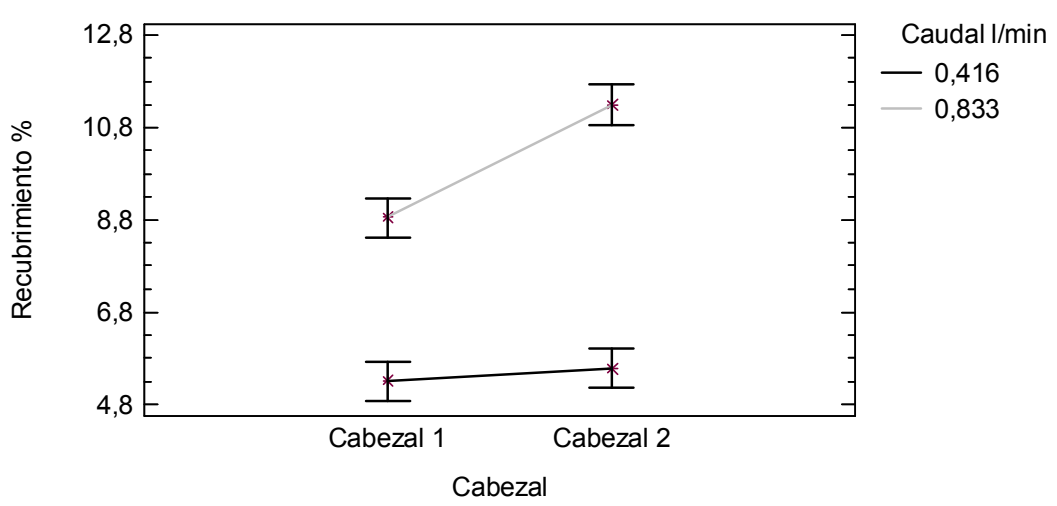

Figura A. 36. Interacción del factor cabezal por el factor caudal para la variable recubrimiento. Intervalos LSD a un nivel de confianza del $95 \%$.

También resultó significativa la interacción entre el caudal y la velocidad de giro (Tabla A. 19). No se observaron diferencias significativas entre las velocidades con el caudal de 0,42 1/min (Figura A. 37). Sin embargo, se observó un incremento del recubrimiento conforme se redujó la velocidad de giro del motor para el caudal de $0,83 \mathrm{l} / \mathrm{min}$.

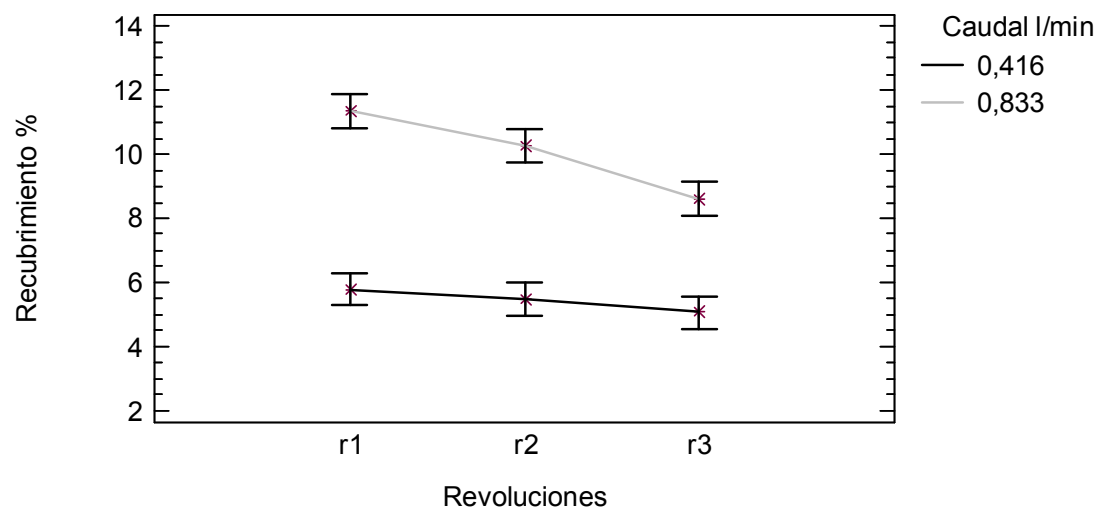

Figura A. 37. Interacción del factor velocidad de giro por el factor caudal para la variable recubrimiento. Intervalos LSD a un nivel de confianza del $95 \%$.

Igualmente la interacción entre los cabezales y la posición relativa de los colectores resultó significativa (Tabla A. 19). Los colectores centrales presentaron recubrimientos menores que los colectores de los extremos (Figura 
A. 38). Los colectores extremos presentaron significativamente mayores recubrimientos con el cabezal 2.

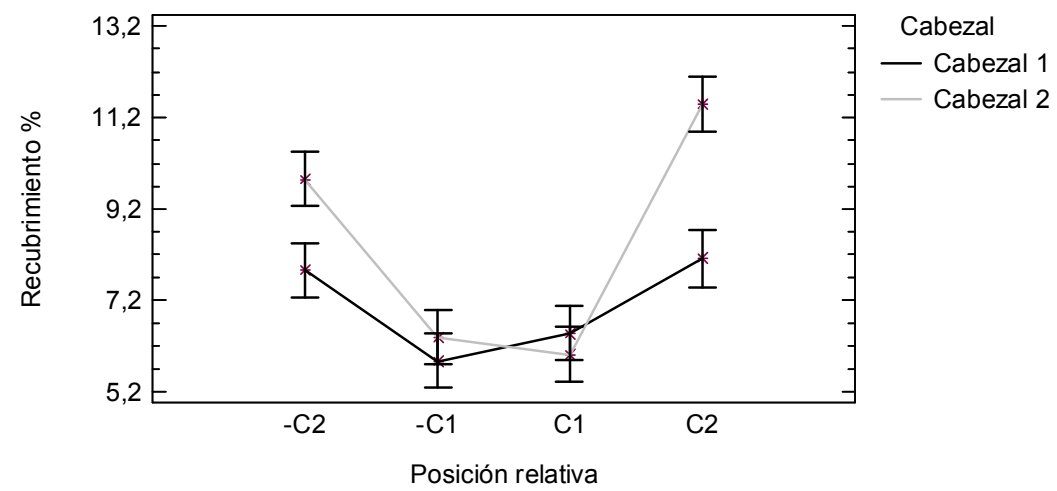

Figura A. 38. Interacción del factor cabezal por el factor posición relativa para la variable recubrimiento. Intervalos LSD a un nivel de confianza del $95 \%$.

Tabla A. 19. Resultado del ANOVA para la variable recubrimiento a un nivel de confianza del $95 \%$.

\begin{tabular}{|c|c|c|c|c|c|}
\hline Suma de & cuadrados & GL & Cuadrado Medio & Cociente-F & P-Valor \\
\hline \multicolumn{6}{|l|}{ EFECTOS PRINCIPALES } \\
\hline A:Cabezal & 65,3226 & 1 & 65,3226 & 20,20 & 0,0000 \\
\hline B:Caudal & 756,81 & 1 & 756,81 & 234,01 & 0,0000 \\
\hline C:colector & 361,66 & 3 & 120,553 & 37,28 & 0,0000 \\
\hline D:Revoluciones & 72,0508 & 2 & 36,0254 & 11,14 & 0,0000 \\
\hline \multicolumn{6}{|l|}{ INTERACCIONES } \\
\hline$A B$ & 42,0936 & 1 & 42,0936 & 13,02 & 0,0005 \\
\hline $\mathrm{AC}$ & 74,851 & 3 & 24,9503 & 7,71 & 0,0001 \\
\hline $\mathrm{AD}$ & 8,26347 & 2 & 4,13174 & 1,28 & 0,2826 \\
\hline $\mathrm{BC}$ & 43,0247 & 3 & 14,3416 & 4,43 & 0,0054 \\
\hline $\mathrm{BD}$ & 24,4714 & 2 & 12,2357 & 3,78 & 0,0256 \\
\hline $\mathrm{CD}$ & 28,9308 & 6 & 4,82179 & 1,49 & 0,1872 \\
\hline RESIDUOS & 378,388 & 117 & 3,23408 & & \\
\hline TOTAL (CORREGIDO) & 1821,36 & 141 & & & \\
\hline
\end{tabular}


Efecto de los factores sobre la variable volumen depositado por unidad de superficie

El único factor que influyó de manera significativa sobre el volumen de caldo depositado por unidad de superficie fue la posición relativa de los colectores (Tabla A. 21). En la Tabla A. 20 se observa que en los colectores centrales se recogió un volumen por unidad de superficie significativamente menor que en los colectores colocados en los extremos.

Tabla A. 20. Volumen depositado por unidad de superficie (Media \pm ES) en posición de colector. Valores de la media seguidos de diferente letra muestran diferencias significativas (Prueba LSD a un nivel de confanza del $95 \%$ ).

\begin{tabular}{|l|c|}
\hline Posición relativa & Volumen por u.s. $(\boldsymbol{\mu m})$ \\
\hline$-\mathrm{C} 2$ & $12,53 \pm 0,94 \mathrm{a}$ \\
\hline$-\mathrm{C} 1$ & $7,914 \pm 0,70 \mathrm{~b}$ \\
\hline $\mathrm{C} 1$ & $8,86 \pm 0,67 \mathrm{~b}$ \\
\hline $\mathrm{C} 2$ & $13,05 \pm 0,96 \mathrm{a}$ \\
\hline
\end{tabular}

Tabla A. 21. Resultado del ANOVA para la variable volumen depositado por unidad de superficie a un nivel de confianza del $95 \%$.

\begin{tabular}{|c|c|c|c|c|c|}
\hline Suma de & cuadrados & GL & Cuadrado Medio & Cociente-F & P-Valor \\
\hline \multicolumn{6}{|l|}{ EFECTOS PRINCIPALES } \\
\hline A:Cabezal & 2,86091 & 1 & 2,86091 & 0,12 & 0,7249 \\
\hline B:Caudal & 48,7599 & 1 & 48,7599 & 2,12 & 0,1477 \\
\hline C:colector & 703,498 & 3 & 234,499 & 10,20 & 0,0000 \\
\hline D:Revoluciones & 139,473 & 2 & 69,7366 & 3,03 & 0,0516 \\
\hline RESIDUOS & 3035,72 & 132 & 22,9979 & & \\
\hline TOTAL (CORREGIDO) & 3933,47 & 139 & & & \\
\hline
\end{tabular}


Efecto de los factores sobre la variable número de impactos por $\mathrm{cm}^{2}$

El cabezal 2 aumentó el número de impactos por $\mathrm{cm}^{2}$ conforme aumentó la velocidad de giro del motor (Figura A. 39). Con el cabezal 1 no se obtuvieron diferencias significativas entre las velocidades de giro r1 y r2. Sin embargo, el número de impactos por $\mathrm{cm}^{2}$ fue significativamente mayor a la velocidad $\mathrm{r} 3$. Los dos cabezales produjeron similares valores del número de impactos por $\mathrm{cm}^{2}$ a la velocidad r2, mientras que las otras el cabezal 1 produjo significativamente mayores valores.

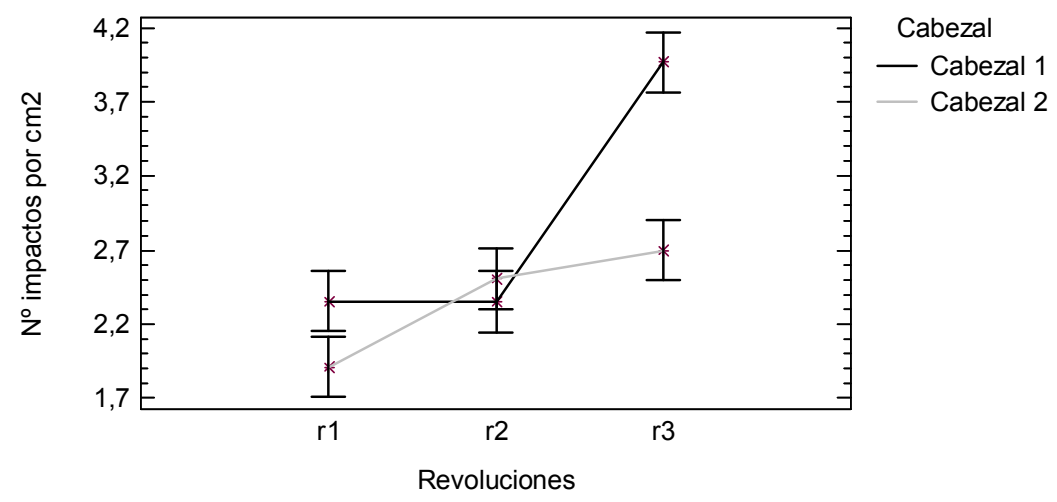

Figura A. 39. Interacción del factor velocidad de giro por el factor cabezal para la variable número de impactos por $\mathrm{cm}^{2}$. Intervalos LSD a un nivel de confianza del $95 \%$.

El número de impactos por $\mathrm{cm}^{2}$ fue significativamente mayor con el caudal de 0,83 1/min que con el de 0,42 1/min (Figura A. 40). Para el caudal de 0,42 1/min el número de impactos por $\mathrm{cm}^{2}$ se incrementó conforme se aumentó la velocidad de giro del motor, siendo las diferencias significativas entre las tres velocidades. Cuando el caudal se duplicó, no se encontraron diferencias significativas de número de impactos por $\mathrm{cm}^{2}$ a las velocidades $\mathrm{r} 1$ y r2. En cambio, cuando se trabajo a la velocidad $\mathrm{r} 3$, el número de impactos por $\mathrm{cm}^{2}$ aumentó significativamente. 


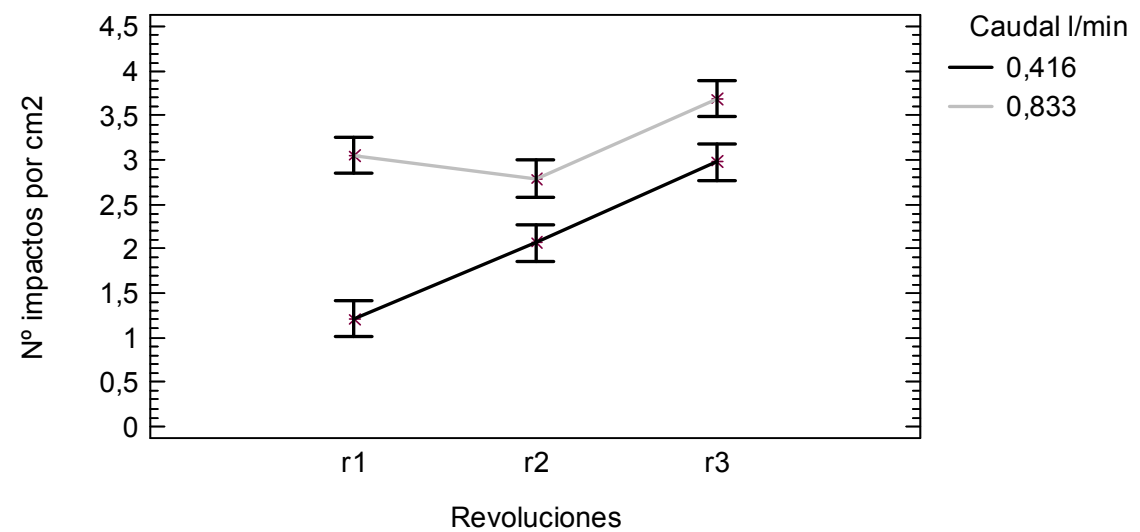

Figura A. 40. Interacción del factor velocidad de giro por el factor caudal para la variable número de impactos por $\mathrm{cm}^{2}$. Intervalos LSD a un nivel de confianza del $95 \%$.

La interacción entre el cabezal y la posición del colector fue significativa para el número de impactos por $\mathrm{cm}^{2}$ (Tabla A. 22). No se encontraron diferencias significativas entre los colectores de los extremos en ninguno de los cabezales. Sin embargo, en los colectores $\mathrm{C} 1$ y $-\mathrm{C} 1$ el cabezal 1 produjo un significativamente mayor número de impactos por $\mathrm{cm}^{2}$ que el cabezal 2 (Figura A. 41).

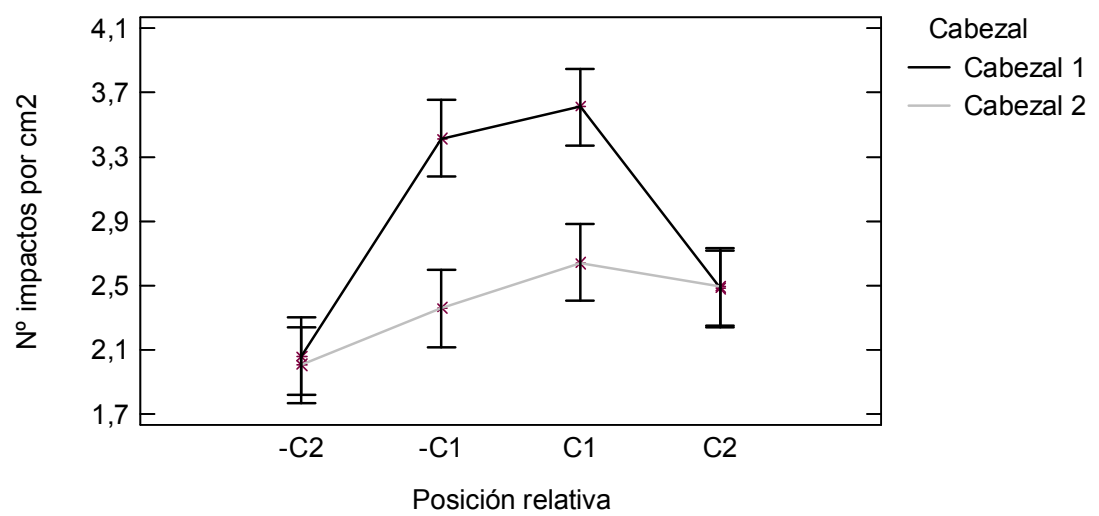

Figura A. 41. Interacción del factor cabezal por el factor posición relativa para la variable número de impactos por $\mathrm{cm}^{2}$. Intervalos LSD a un nivel de confianza del $95 \%$.

La interacción del caudal y la posición relativa para el número de impactos por $\mathrm{cm}^{2}$ también fue significativa (Tabla A. 22). El caudal de 0,83 1/min produjo similar número de impactos por $\mathrm{cm}^{2}$ en todos los colectores. Sin 238 
embargo el caudal de $0,42 \mathrm{l} / \mathrm{min}$ produjo diferencias significativas entre los colectores centrales y los extremos. Los centrales presentaron mayor número de impactos por $\mathrm{cm}^{2}$ (Figura A. 42).

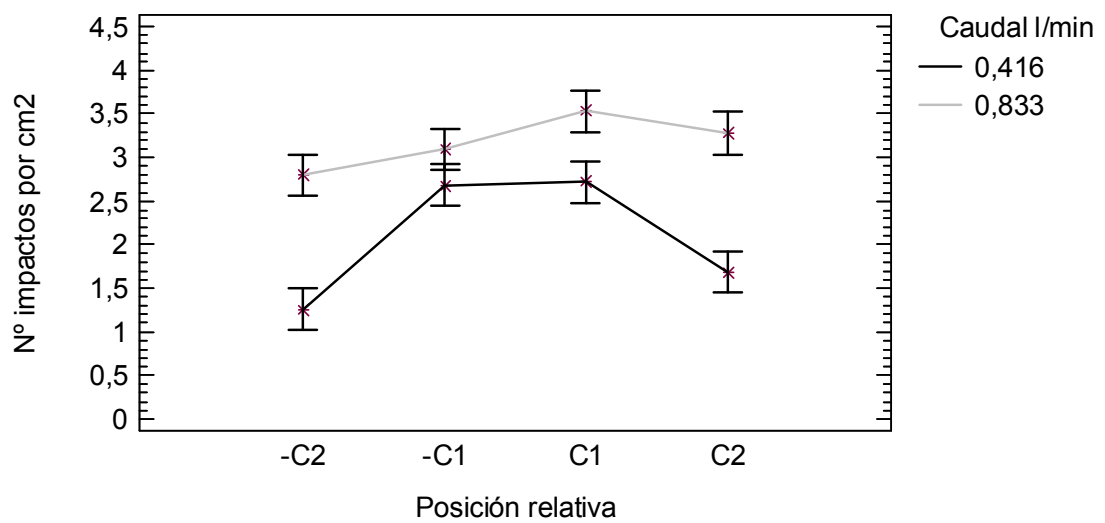

Figura A. 42. Interacción del factor caudal por el factor posición relativa para la variable número de impactos por $\mathrm{cm}^{2}$. Intervalos LSD a un nivel de confianza del $95 \%$.

El número de impactos por $\mathrm{cm}^{2}$ en los colectores extremos fue significativamente igual en los colectores situados en los extremos a todas las velocidades de giro ensayadas (Figura A. 43). Sin embargo, el número de impactos por $\mathrm{cm}^{2}$ en los colectores centrales aumentó significativamente cada vez que aumentó la velocidad de giro del motor de r1 a r2 y de r2 a r3.

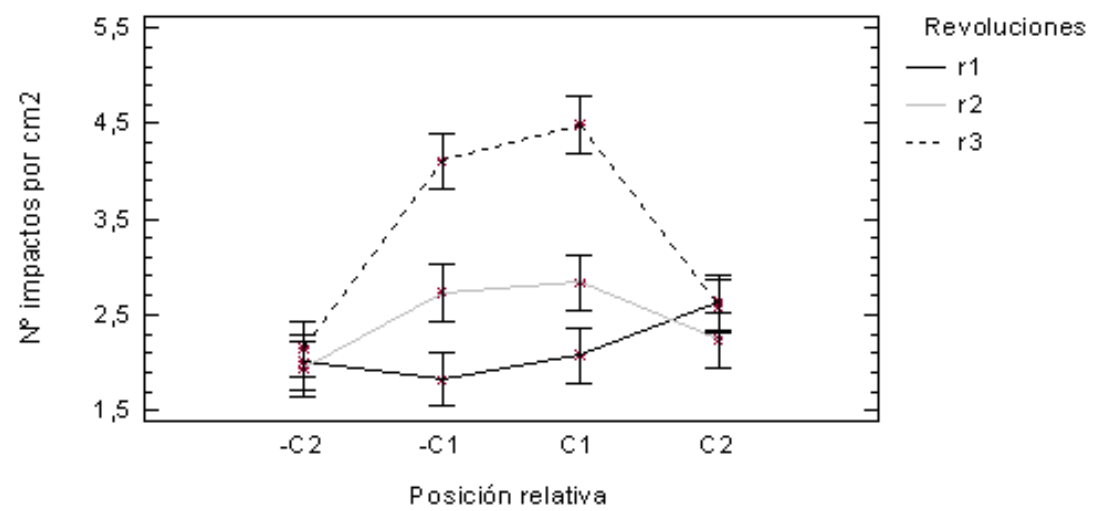

Figura A. 43. Interacción del factor velocidad de giro por el factor posición relativa para la variable número de impactos por $\mathrm{cm}^{2}$. Intervalos $L S D$ a un nivel de confianza del $95 \%$. 
Anejo 7

Tabla A. 22. Resultado del ANOVA para la variable número de impactos por $\mathrm{cm}^{2}$ a un nivel de confianza del $95 \%$.

\begin{tabular}{|c|c|c|c|c|c|}
\hline Suma de & cuadrados & GL & Cuadrado Medio & Cociente-F & P-Valor \\
\hline \multicolumn{6}{|l|}{ EFECTOS PRINCIPALES } \\
\hline A:Cabezal & 9,66836 & 1 & 9,66836 & 18,78 & 0,0000 \\
\hline B:Caudal & 42,8221 & 1 & 42,8221 & 83,18 & 0,0000 \\
\hline C:colector & 24,9541 & 3 & 8,31802 & 16,16 & 0,0000 \\
\hline D:Revoluciones & 37,6739 & 2 & 18,837 & 36,59 & 0,0000 \\
\hline \multicolumn{6}{|l|}{ INTERACCIONES } \\
\hline $\mathrm{AB}$ & 0,733995 & 1 & 0,733995 & 1,43 & 0,2348 \\
\hline $\mathrm{AC}$ & 8,75448 & 3 & 2,91816 & 5,67 & 0,0012 \\
\hline $\mathrm{AD}$ & 12,2252 & 2 & 6,11262 & 11,87 & 0,0000 \\
\hline $\mathrm{BC}$ & 8,79165 & 3 & 2,93055 & 5,69 & 0,0011 \\
\hline $\mathrm{BD}$ & 10,1296 & 2 & 5,06481 & 9,84 & 0,0001 \\
\hline$C D$ & 32,1828 & 6 & 5,3638 & 10,42 & 0,0000 \\
\hline RESIDUOS & 60,7459 & 118 & 0,514795 & & \\
\hline TOTAL (CORREGIDO) & 249,307 & 142 & & & \\
\hline
\end{tabular}




\section{ANEJO 8. DESCRIPCIÓN DE LAS PARCELAS}

\section{Parcela A y Parcela B}

La parcela A y B son dos parcelas contiguas situadas en el término de Sagunto (Valencia, España) (UTM X726240 Y4391074; Z110 m altitud). (Figura A. 44). Ambas presentan las mismas características agronómicas y tienen una superficie de 1 ha. Estaban plantadas con clementinos Citrus clementina Hort. ex Tan. var. Marisol, distribuidos al trebolillo sobre mesetas desde 1997. El marco de plantación era de 3,5 m x 4 m. Los árboles tenían una altura media de 2,5 m y un diámetro medio de $2,45 \mathrm{~m}$.

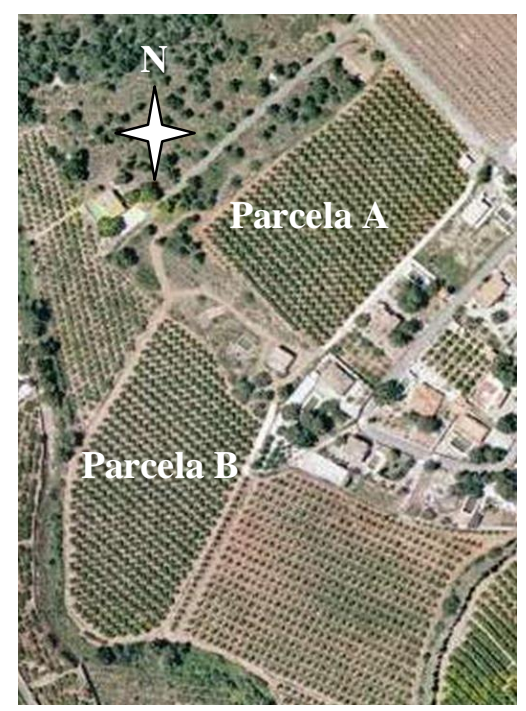

Figura A. 44. Plano de las parcelas A y B.

\section{Parcela C y Parcela D}

La parcela C y D están situadas en el término de Llíria (Valencia, España) (UTM X706741 Y4400206; Z 330 m altitud).

La parcela C estaba plantada con naranjos Citrus sinensis (L.) Osb. var. Navelina desde 1982. Los árboles eran de grandes dimensiones, entre 3-4 m de altura y 4-6 m de diámetro y no presentaban separaciones entre ellos. 
La parcela D estaba plantada con clementinos Citrus clementina Hort. ex Tan. var. Clemenules desde 1994. Sus árboles eran más pequeños, con una altura entre 2,5-3 m y un diámetro entre 3-4 m.

En ambas parcelas el marco de plantación era de 2,5 m x 6,5 m. 


\section{ANEJO 9. RESULTADOS DE LOS ANOVAS EN EL ENSAYO DE AJUSTE DE LA CONCENTRACIÓN DE SPINTOR 480 SC $^{\circledR}$}

Experiencia de residuo fresco
Día $1(\mathrm{~F}=3,95$, g.l. $=4-49, \mathrm{P}=0,008)$.
Día $2(\mathrm{~F}=30,42$, g.l. $=4-49, \mathrm{P}=0,000)$.
Día $3(F=93,06$, g.l. $=4-49, P=0,000)$.
Día $4(\mathrm{~F}=240,94$, g.l. $=4-49, \mathrm{P}=0,000)$.
Día $5(\mathrm{~F}=275,85$, g.l $=4-49, \mathrm{P}=0,000)$.
Día $6(\mathrm{~F}=108,01$, g.l. $=4-49, \mathrm{P}=0,000)$.

\section{Experiencia de residuo 3 días}

Día $1(\mathrm{~F}=11,72$, g.1. $=4-49, \mathrm{P}=0,000)$.

Día $2(\mathrm{~F}=23,25$, g.l. $=4-49, \mathrm{P}=0,000)$.

Día $3(\mathrm{~F}=42,55$, g.l. $=4-49, \mathrm{P}=0,000)$.

Día $4(\mathrm{~F}=89,98$, g.l. $=4-49, \mathrm{P}=0,000)$.

Día $5(\mathrm{~F}=53,27$, g.l. $=4-49, \mathrm{P}=0,000)$.

Día $6(\mathrm{~F}=6,93$, g.l. $=4-49, \mathrm{P}=0,000)$.

\section{Experiencia de residuo 6 días}

Día $1(\mathrm{~F}=16,10$, g.l. $=4-49, \mathrm{P}=0,000)$.

Día $2(\mathrm{~F}=49,58$, g.l. $=4-49, \mathrm{P}=0,000)$.

Día $3(\mathrm{~F}=96,52$, g.l. $=4-49, \mathrm{P}=0,000)$.

Día $4(\mathrm{~F}=182,68$, g.l. $=4-49, \mathrm{P}=0,000)$.

Día $5(\mathrm{~F}=83,50$, g.1. $=4-49, \mathrm{P}=0,000)$.

Día $6(\mathrm{~F}=9,76$, g.l. $=4-49, \mathrm{P}=0,000)$. 



\section{ANEJO 10. RESULTADOS DE LOS ANOVAS EN EL ENSAYO DE TRITURACIÓN: EFECTO DE LOS FACTORES SOBRE LA POTENCIA REQUERIDA POR EL TRACTOR}

Experiencia de trituración de naranjas

Tabla A. 23.Resultado del ANOVA para la variable potencia requerida por el tractor en el ensayo de trituración de naranjas a un nivel de confianza del $95 \%$.

\begin{tabular}{|c|c|c|c|c|c|}
\hline Suma de & cuadrados & GL & Cuadrado Medio & Cociente-F & P-Valor \\
\hline \multicolumn{6}{|l|}{ EFECTOS PRINCIPALES } \\
\hline A:Herramienta & 453,27 & 1 & 453,27 & 230,63 & 0,0000 \\
\hline B:Velocidad_avance & 14,5704 & 1 & 14,5704 & 7,41 & 0,0145 \\
\hline C:Velocidad_giro & 120,154 & 1 & 120,154 & 61,14 & 0,0000 \\
\hline \multicolumn{6}{|l|}{ INTERACCIONES } \\
\hline $\mathrm{AB}$ & 2,10042 & 1 & 2,10042 & 1,07 & 0,3157 \\
\hline $\mathrm{AC}$ & 51,9204 & 1 & 51,9204 & 26,42 & 0,0001 \\
\hline $\mathrm{BC}$ & 10,8004 & 1 & 10,8004 & 5,50 & 0,0315 \\
\hline RESIDUOS & 33,4104 & 17 & 1,96532 & & \\
\hline
\end{tabular}


Anejo 10

\section{Experiencia de trituración de mandarinas}

Tabla A. 24. Resultado del ANOVA para la variable potencia requerida por el tractoren el ensayo de trituración de mandarinas a un nivle de confianza del $95 \%$.

\begin{tabular}{|c|c|c|c|c|c|}
\hline Suma de & cuadrados & GL & Cuadrado Medio & Cociente-F & P-Valor \\
\hline \multicolumn{6}{|l|}{ EFECTOS PRINCIPALES } \\
\hline A:Herramienta & 566,927 & 1 & 566,927 & 156,02 & 0,0000 \\
\hline B:Velocidad_avance & 15,9275 & 1 & 15,9275 & 4,38 & 0,0425 \\
\hline C:Velocidad_giro & 219,525 & 1 & 219,525 & 60,41 & 0,0000 \\
\hline \multicolumn{6}{|l|}{ INTERACCIONES } \\
\hline$A B$ & 0,0240193 & 1 & 0,0240193 & 0,01 & 0,9356 \\
\hline $\mathrm{AC}$ & 49,9118 & 1 & 49,9118 & 13,74 & 0,0006 \\
\hline $\mathrm{BC}$ & 23,4294 & 1 & 23,4294 & 6,45 & 0,0150 \\
\hline RESIDUOS & 148,978 & 41 & 3,63361 & & \\
\hline TOTAL (CORREGIDO) & 1048,62 & 47 & & & \\
\hline
\end{tabular}


